THE INTERNATIONAL

REVIIEW OF RESEARCH IN

OPEN AND DISTANCE LEARNING

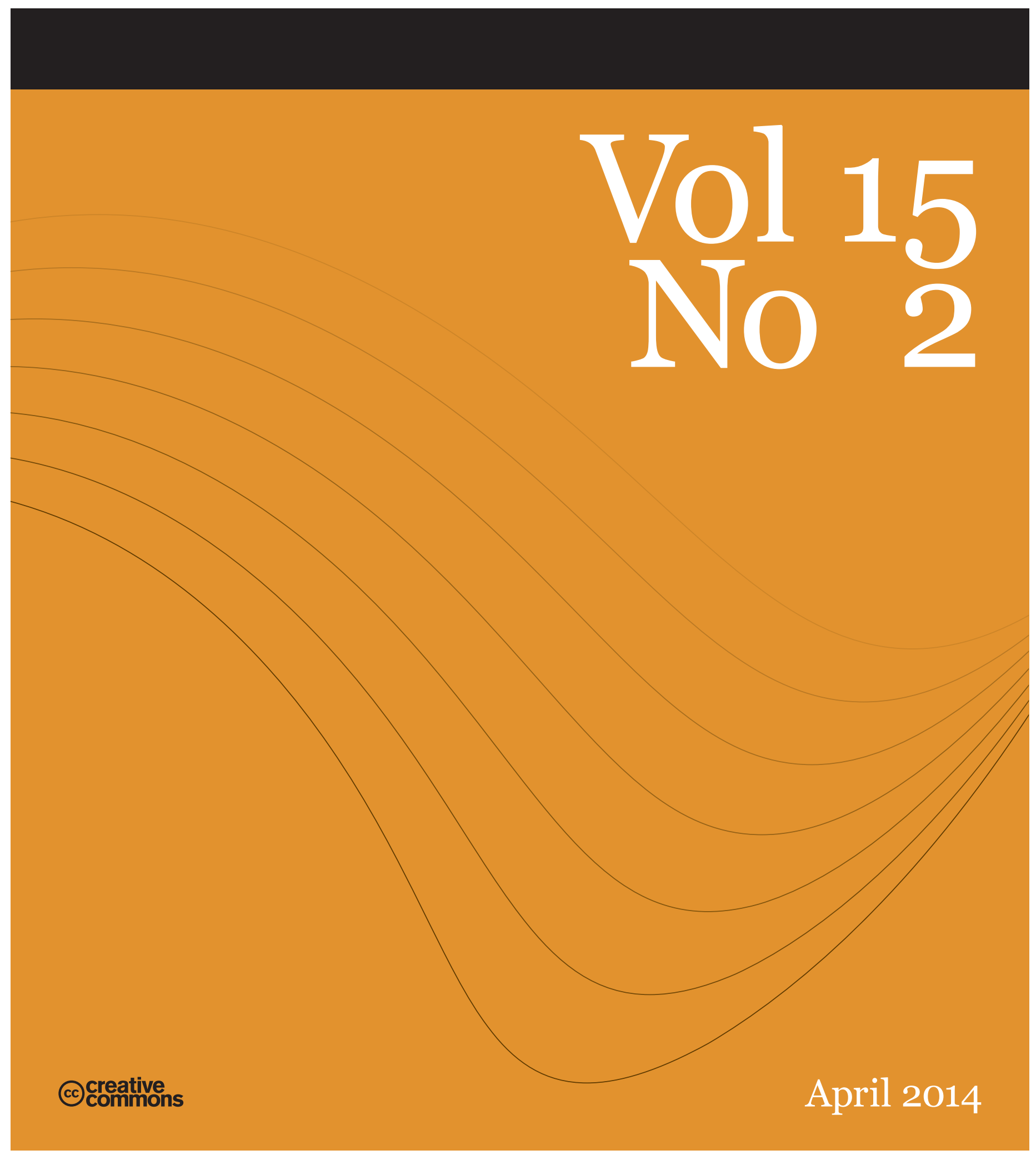




\section{Editorial - Volume 15, Issue Number 2}

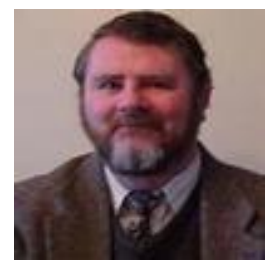

Rory McGreal

Co-Editor, IRRODL

This spring edition of IRRODL begins with several articles describing open educational resources (OER) followed by some financial considerations and a MOOC investigation. These papers will also be included in the OERKnowledgeCloud, which is supported by the UNESCO/ Commonwealth of Learning/International Council for Open and Distance Education Chairs in three countries. (I am one of them.) For those readers, who are interested in OER and MOOCs, I would recommend that they visit this repository of more than 600 research articles and reports on issues of relevance to researchers in the field. These are followed by papers on student interaction and support as well as synchronous and asynchronous learning. The later articles investigate blended learning, educational research, and the mobile cloud.

Schuwer and Kusters lead off the OER topic with an investigation into mass customization in industry and how it can help address individual learner needs in open content development. Using the concepts of "self-efficacy" and "outcome judgment", Kelly, in the next article, analyses educator perceptions of OER and makes recommendations on "easy to use" designs to improve the effectiveness of OER. Mtebe and Raisamo expose several "barriers" to implementing OER in Tanzania providing us with a new understanding of how OER initiatives might be implemented in SubSaharan Africa. Hilton et al. return to IRRODL with another analysis of how OER can reduce the cost of textbooks, reporting on open textbook initiatives in eight US colleges. MOOCs can be seen as a development emerging from the OER movement. In his blog mining analysis of MOOCs, Chen highlights some of the challenges that need to be addressed to ensure sustainability. In contrast, Marty, focuses on monetizing distance education, with fieldwork analyzing the cultural evolution of a French educational institution from a "public good" mandate to a commercial orientation.

The next topic includes the themes of interactivity and student support. Wang et al. provide us with a framework for analyzing interaction within a connectivist paradigm with four levels (operation, wayfinding, sensemaking, and innovation). Barberà et al. 
provide us with a tri-country, tri-discipline study on how faculty define competencies and how they design for competency development. Jung and Hong identify the key concerns about student support as expressed by Asian DE students in 10 jurisdictions, noting gender differences. They propose a list of supporting strategies. In a qualitative, self study, Yamagata-Lynch investigates synchronous and asynchronous approaches focusing on how best to provide support services. In a high school environment Chang et al. compare and contrast blended and traditional classroom environments. As expected, this investigation can be added to Tom Russell's list of more than 350 "no significant difference" articles.

This edition is rounded off with two articles. Teräs and Herrington, using an iterative design and rapid prototyping, show how this helps to "refine design principles" for an authentic elearning programme. Wang et al. provide us with a case study of mobile learning using cloud computing in a higher education institution.

The notes sections include a critique of MOOCs by V. Dolan followed by a book review by T. Anderson.

\section{Athabasca University $\mathbf{I}$}

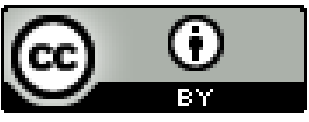




\section{Mass Customization of Education by an Institution of HE: What Can We Learn from Industry?}

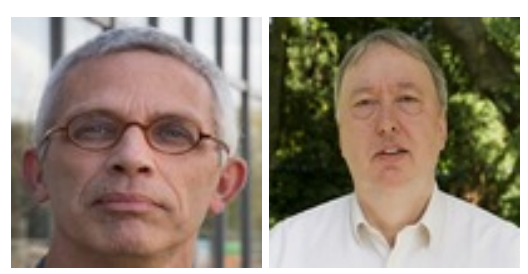

Robert Schuwer and Rob Kusters

Open Universiteit, Netherlands

\section{Abstract}

One of the claims the OER movement makes is that availability of (open) digital learning materials improves the quality of education. The promise is the ability to offer educational programs that take into account specific demands of the learner. The question is how to reach a situation where a customized demand can be met using OER with acceptable quality against acceptable costs. This situation resembles mass customization as is common in industry for several decades now. Techniques from an industry where an end product is assembled with the demands of the customer as a starting point can be translated to the field of education where courses and learning paths through a curriculum are assembled using a mixture of open and closed learning materials and learning services offered by an institution. Advanced IT support for both the modeling of the learning materials and services and a configurator to be used by a learner are necessary conditions for this approach.

Keywords: Mass customization; personalized learning; OER 


\section{Introduction}

The launch of the MIT OpenCourseware project in 2001 marked the beginning of worldwide publishing of open educational resources (OER). This development aims at achieving high availability of learning materials with the possibilities to adapt these to fit to their context of use. One of the claims the OER movement makes is that availability of (open) digital learning materials improves the quality of education (Hodgkinson-Williams, 2010; Commonwealth of Learning, 2011). The promise is the ability to offer educational programs that take into account specific demands of the learner. This promise is heard even louder since the rise of the MOOCs in 2012 (Horn \& Christensen, 2013). This trend highlights the unbundling of education, where learning, certifying of learning, and degree-awarding does not have to be offered by one single university. A consequence of this trend is the availability of more learning pathways than before, not all necessarily leading to a degree. A learner will be able to shop to fulfill his demand, thereby challenging universities to satisfy this demand. Personal circumstances (e.g., job demands, financial situation) can create a demand for alternative learning paths.

Bates (2005) noted that student diversity within the technological era has to be considered also:
Learners are not a homogenous mass, but vary considerably in terms of educational background, income, age and learning experience. This diversity of the student body is growing fast. It will become increasingly important for educational organizations to be able to deliver their teaching in a variety of technological formats, depending on the needs of the individual, the teaching context, and the target groups to be reached. (p. 211)

One can expect this demand for more individualized learning paths to grow over the coming years, because of the increasing need for people with a higher education and because of the current financial crisis. The former means that other people than youngsters are needed to fulfill the demand. The latter is the cause of budget cuts for universities and student loans, forcing more students to take a job in addition to their study activities.

OER can be considered as generic building blocks from which to create learning materials fit for a learner or a homogeneous group of learners. A more common name for those building blocks is learning objects (Neven \& Duval, 2002). Nowadays, creating these learning materials requires a lot of craftsmanship and effort, which results in different levels of quality and high associated costs. 
Publishing and reusing OER poses several challenges (Schuwer, 2013; Yuen \& Wong, 2013):

- findability of suitable OER;

- dealing with different technical formats that hinders combining the building blocks into one overall layout;

- indistinctness about underlying didactical approaches and necessary prerequisites;

- determining if the quality of the OER is sufficient;

- incompatible or even the absence of open licenses;

- fear over copyright infringement, ownership and legal barriers other than copyright;

- business models to create a sustainable ecosystem of OER;

- human factors - resistance against sharing or reuse because of lack of reward and recognition, possible negative impact on reputation, and lack of support.

Adapting OER and localizing it to the context in which it is used is an important activity for reuse (Matkin, 2009). Unfortunately, this can be a difficult and expensive process (OECD, 2007, p. 60).

So the question is how to reach a situation where a customized demand can be met using OER with acceptable quality against acceptable costs, taking into account the challenges as listed above.

In this paper we will address the applicability and added value of assemble to order (ATO) to answer this question. ATO is an approach developed in industry to combine the advantage of customization (which provides customer specific, but usually very expensive products) with mass production (which produces a standard product of acceptable quality for a low price). ATO functions by developing a limited number of components and combining these, so a large array of different products can be assembled. Such an approach will provide variety and quality for an acceptable price.

ATO is an approach to realize mass customization. In Tseng and Jiao (2001) mass customization is defined as "The technologies and systems to deliver goods and services that meet individual customers' needs with near mass production efficiency". For education, this is not equivalent to personalized learning. In Wikipedia ${ }^{1}$, personalized learning is defined as "the tailoring of pedagogy, curriculum and learning environments to meet the needs and aspirations of individual learners." According to the U.S.

\footnotetext{
${ }^{1}$ http://en.wikipedia.org/wiki/Personalized_learning, accessed January, 20, 2014
} 
Department of Education (2010, p. 12), personalization is considered as encompassing individualization and differentiation:

Individualization refers to instruction that is paced to the learning needs of different learners. Learning goals are the same for all students, but students can progress through the material at different speeds according to their learning needs. For example, students might take longer to progress through a given topic, skip topics that cover information they already know, or repeat topics they need more help on. Differentiation refers to instruction that is tailored to the learning preferences of different learners. Learning goals are the same for all students, but the method or approach of instruction varies according to the preferences of each student or what research has found works best for students like them. Personalization refers to instruction that is paced to learning needs, tailored to learning preferences, and tailored to the specific interests of different learners. In an environment that is fully personalized, the learning objectives and content as well as the method and pace may all vary (so personalization encompasses differentiation and individualization).

To describe (open) education, we use the five components open education model (5COE model) of Mulder and Janssen (2013). In this model, three components comprise education on the supply side: learning materials, learning services, and teaching efforts. Two components are on the demand side: the demand from the learner and the demand from the environment (society).

The process of mass customization in educational terms is based on a demand from a (group of) learner(s) where the combination of learning materials, learning services, and teaching efforts should fulfill certain explicit or implicit requirements and a supply of building blocks (learning materials, services, and teaching efforts) that can be combined into an offer fulfilling the demand. The resulting offer should comply with several general requirements (e.g., complying with demands at curriculum level) and potentially there is a significant number of building blocks available. To this end, the institution can meet part of the demand from a learner. Elements like determining the learning goals, adaptation of the learning process based on feedback from the learner, or assessing the level of prior knowledge are not part of this approach. We consider mass customization as an approach fitting in a continuum in approaches to tailor education to the demand of an individual learner, as depicted in Figure 1. 


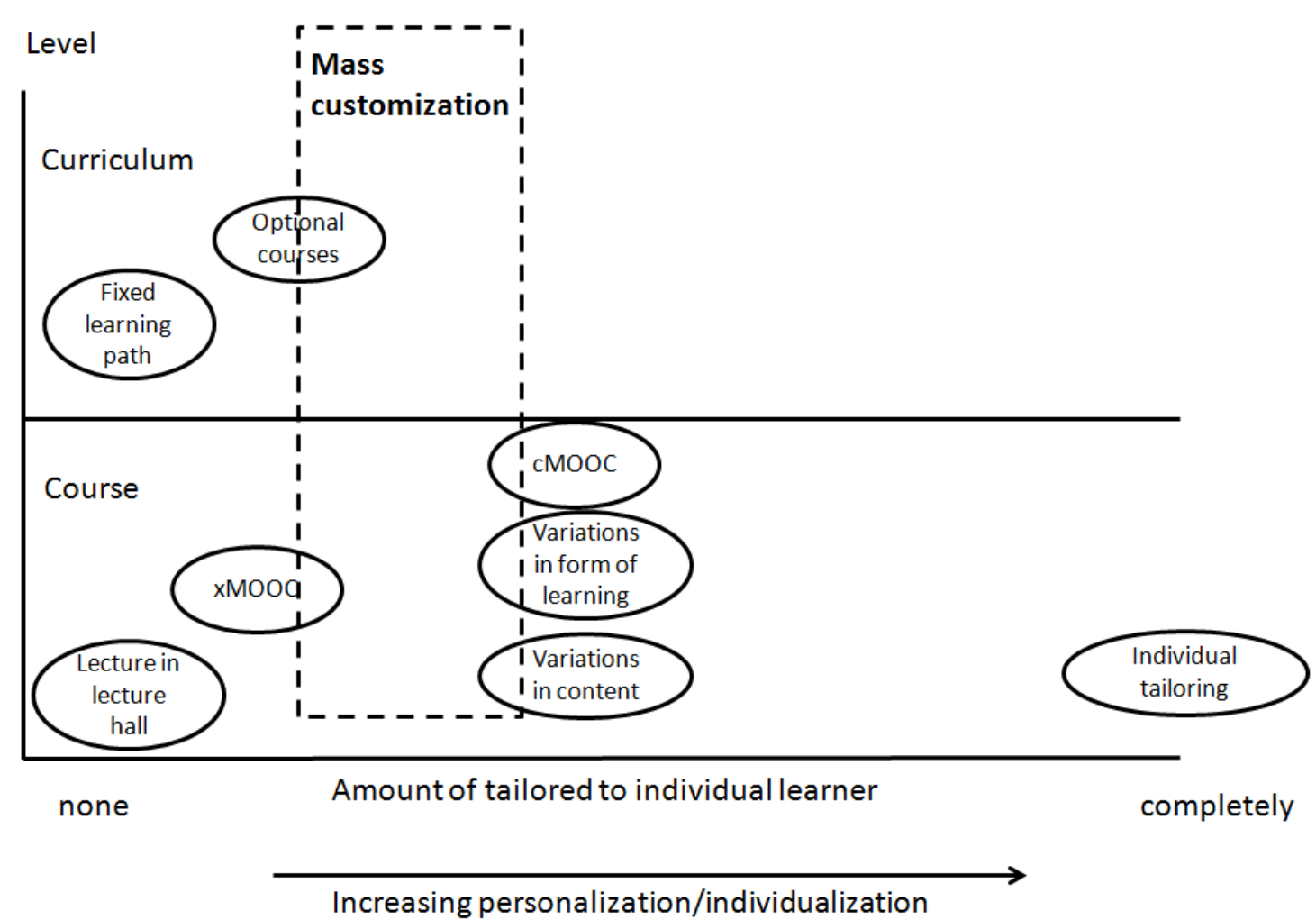

Figure 1. Continuum of tailoring education.

In Figure 1 we distinguish two levels of tailoring: course or curriculum (the vertical axis). Some examples of approaches to realize a certain amount of tailoring are added in the framework.

In this paper we will elaborate on this. We start with attempts in the educational field dating back to the 90's of the last century. Then we will introduce some terminology to use and solutions the industry has developed in both structuring products and ITsupport for the end user. We will apply these insights to the field of education. We conclude with a view on future work in this field.

\section{Current Work}

The dawn of a more demand driven approach in education is described in Kirschner and Valcke (1994). They describe that the need for a demand driven approach started at the beginning of the 20th century. They foresee development to a more demand driven approach using IT going through three stages:

- IT as a substitute for something a teacher or a student uses. An example from the past is the change from hand-written slides to PowerPoint. 
- IT as a means for innovation. An example is using a virtual lab by students for doing experiments that are either too complicated or too expensive to offer from a single institution. Examples of these can be found at http://www.vlab.co.in/index.php.

- IT as a means for transformation. Current concepts, paradigms, theories and laws of education are no longer valid and are replaced by others. We are far from this situation yet, but the concept of flipping the classroom (Barrett, 2012) is an example where IT transforms educational concepts.

In current society, where prosperity depends on a well-developed knowledge economy, the growing demand for both well-educated youngsters and a lifelong learning working staff is even more urgent. On the other hand, costs for education are under pressure both because of this growing demand and because of the current economic crisis. The cry for an efficient and effective learning process is heard (e.g., in Universities UK, 2011). To fulfill these needs, education has to become more geared to the demands of the individual learners to be as effective as possible. However, tailoring educational supply to each single demand is far from efficient. A balance between these two conflicting demands can be found in an approach where learning is tailored to the demands of the individual learner, using IT as means to realize this.

One of the early attempts to realize this situation came with the Mercator system (Valcke et al., 1997; Martens et al., 1997). This system was based on an approach where course materials were generated based on student characteristics. These characteristics could for example be determined by means of pretests. The database of materials for this system contained both domain specific content (55\%) and didactical components (45\%). The granularity of the content varied between chapters, themes, and subthemes. Students select topics from a table of contents. This table of contents can be tailor made, dependent on student characteristics. Learning materials for the selected topic and appropriate didactical elements are determined by the system.

The approach by the Mercator system turned out to be too complex to handle. Offering several different pedagogical models as a starting point resulted in offering several differing contents and learning activities. This needed a granularity of materials in the database that was too detailed to be workable ${ }^{2}$. Different versions of the same learning materials sometimes needed adjustments on the level of a paragraph. This led to a combinatorial explosion of versions of basically the same learning material that could hardly be managed. Another drawback is the level of detail with which each instance of learning material has to be described in order to make it available and usable for a specific learning demand.

${ }^{2}$ According to personal communication with Prof. dr. Rob Martens, one of the participants in the Mercator project. 
Experiences with Mercator led to the development of EML (Educational Modeling Language) (Koper \& Manderveld, 2004). EML is a semantic notation for units of learning to be used in e-learning. It enables specification of learning technology taking into account a pedagogical framework of different types of learning objects, expressing the relationships between the typed learning objects and defining the structure for the content and behavior of the different learning objects. The current standard IMS Learning Design (http://www.imsglobal.org/learningdesign/) is based on the first specifications of EML.

Several approaches use a hierarchical task network (HTN) planner to generate course materials, adapted to the competencies of the learner. Ulrich and Melis (2009) implement an HTN planner in an expert system. This approach also needs a large amount of learning materials available to be able to generate adapted courses. In Morales et al. (2009), IMS-LD is used as a basis to generate conditional learning pathways, able to adapt to run time events. This approach too requires a large amount of learning material, described in an IMS-LD vocabulary.

IMS-LD also forms the basis for an approach sketched in Hernández et al. (2009). Here a model of the user is built to be able to take into account intrinsic characteristics of the user (e.g., learning style) and the desired and achieved competencies in the learning process.

Karampiperis and Sampson (2006) describe an approach where personalization of the learning materials is limited to adaptive hypermedia systems.

Another perspective on mass customization of education is given in Asseldonk and Mulder (2004). They describe the following characteristics of mass customization.

- Batch versus flow. A batch is characterized by a programmed system, fixed rules, and users bound by these rules. Characteristics of a flow are a selfregulating system, situational rules, and autonomous users. A batch describes a closed educational system, whereas a flow describes a more open educational system.

- Atomization and navigation. Atomization is comparable with the building blocks as described before. For the user, this leads to a demand of support for navigating through the space of learning materials. The authors believe the latter to be one of the main tasks for institutions for higher education.

The growing availability of OER and other means of open education (e.g., MOOCs) provides new opportunities for creating tailor made learning pathways, eventually leading to credits or a degree. Horn and Christensen (2013) foresee a future where learning becomes a continuous, on-the-job process. The need for customization will then drive toward just-in-time mini-courses, made available in open offerings. We believe that in this situation a closed system still will have its value, with a curator's role 
in determining the quality of available learning materials and structuring the space of learning materials (e.g., by defining curricula or smaller learning pathways).

In Shoham (2012), a similar vision on future education is described, envisioning content units smaller than current courses and remixing this content to new content, customized for a learner. Neither Horn nor Shoham describes how to realize the situation.

Approaches for mass customization in engineering education are sketched in Rippel et al. (2012) and Mistree et al. (2012). These descriptions do not take into account the reuse of OER, are limited to only very specific situations, or provide no choice for the learner to create his/ her own learning path.

All approaches sketched do not provide means to realize the desirable situation where a customized demand can be met using a mixture of OER and closed materials with acceptable quality against acceptable costs. This justifies our search for an approach inspired by successful attempts in another field.

In the next section we will describe mechanisms that industry has developed to overcome the problems in mass customization for products as described. These mechanisms are the basis of IT support for a customer to match a personal demand to an individualized version of a product.

\section{Mass Customization in Industry}

Industry made the move to mass customization several decades ago. The rise of computing power and the growing abilities offered by the Internet provided the means to implement concepts of research into this subject. Products are designed as product families. Ulrich and Tung (1991) define a product family as "a large set of end products constructed from a much smaller set of components." These kinds of products are highly modularized, and use standardized interfaces to fit the modules together to a customer specific end product. Production of the end product can be characterized as assembleto-order: The end product is built to customer specifications from a stock of existing components. Assembling an end product takes into account already existing modules and the interfaces to use them.

This move enabled producers to combine the advantages of mass production, high quality and relatively cheap products, with customer specificity. This customer specificity has to be seen as bounded within the option set envisaged when engineering the product family.

One of the advanced examples is the car industry. Potential buyers for a car can use user friendly configurators that lead them through the process of assembling a car by selecting the components and features that most closely adhere to their demand. These 
configurators are indispensable because of the combinatorial explosion of different end products that arise when the different versions of the components and their features are combined.

Examples of such configurators are http://www.volkswagen.co.uk/\#/new/ passatvii/configure/ (Volkswagen Passat) and http://www.volvocars.com/uk/salesservices/sales/pages/car-configurator.aspx (Volvo).

The cornerstone of these configurators is a model of the product for which mass customization is needed. We will start by introducing the terminology to describe these models.

Some "things" in the real world are worthwhile to describe. Such a "thing" is called an object. A description of an object serves a goal and is mostly used as a means of communicating about the object. A group of similar objects is called an object type. The properties of an object type that are part of the description are called attributes or parameters. The difference is that a parameter can have several values, in most cases determined by the customer. When each attribute and parameter gets a value, we get an instance of an object type.

Which parameters a description of an object type contains is determined by the purpose of the description. Essential parameters are those attributes where different values describe essentially different instances of the object type for the purpose it is described. A specialty originates when the range of values for the essential parameters is constrained. From a specialty a variant (or configuration) is created when all parameters get a value. Constraining the range of values for parameters is called parameterizing.

\section{Example: car}

Suppose we want to describe a car for use in a configurator. Based on experience of the manufacturer, the most important parameter for this purpose is whether the car has a diesel or petrol engine. Table 1 lists the different terms we have introduced for this situation. 
Table 1

Illustration of ATO Terminology

\begin{tabular}{|c|c|}
\hline Term & Example \\
\hline Object & Car in the real world \\
\hline Object type & Cars of the same type and model \\
\hline Parameter & 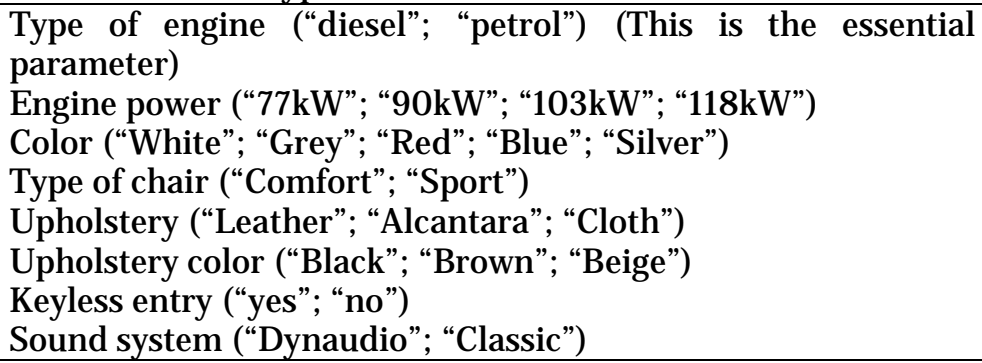 \\
\hline Specialty & $\begin{array}{l}\text { Diesel car (Type of engine="diesel") } \\
\text { Petrol car (Type of engine="petrol") }\end{array}$ \\
\hline $\begin{array}{l}\text { Variant } \\
\text { (configuration) }\end{array}$ & $\begin{array}{l}\text { Example of a variant of a diesel car: } \\
\text { Engine power: } 77 \mathrm{~kW} \\
\text { Color: Silver } \\
\text { Type of chair: Comfort } \\
\text { Upholstery: Cloth } \\
\text { Upholstery color: Black } \\
\text { Keyless entry: yes } \\
\text { Sound system: Dynaudio }\end{array}$ \\
\hline
\end{tabular}

In most cases, creating a variant by selecting values for each non-essential parameter is subject to constraints. Two special types of constraints can be distinguished:

- Inclusions: The value of parameter $\mathrm{A}$ is determined by the value of parameter $\mathrm{B}$

- Exclusions: Certain values of parameter A are not allowed when parameter B is given a certain value

For the car, an example of an inclusion could be "When the upholstery is cloth, the upholstery color is black". An example of an exclusion could be "When the type of chair is sport, the upholstery cannot be alcantara". A variant that meets all constraints is called a valid configuration.

In practice, the number of parameters to select and determine is much higher. Even more complex in reality is taking into account special offers, bundled packages (offering a discount when selected as a whole), and the numerous constraints affecting options of parameters. Even in this simplified example of a car configuration, not taking into account constraints, the total number of valid configurations is 2,880. Managing this information becomes even more difficult when new types of cars are introduced, leading to extra values for parameters or even to new parameters. For example, the parameter "keyless entry" did not exist until recently. 
A big advantage of this modeling approach is the easy maintenance when new features become available. To add new features to the model, a new parameter or new values for existing parameters are added, together with possible constraints on this.

An important prerequisite that enables products to be customized is a modular structure of the physical product with well-defined interfaces. Especially when (for reasons of efficiency) modules should be usable for different specialties or even for different types of products, this calls for a high degree of standardization of the interfaces to keep it manageable. An example are the screws used to connect two modules to each other. DIN (Deutsches Institut für Normung) maintains an extensive list of standards for these screws (DIN, 2013). A big advantage of these standards are the possibilities to outsource production of those screws to third parties where referring to the standard suffices. However, standards only have limited power. Simple things such as screws can be standardized. But if components become slightly more complex, such standardization becomes rapidly more difficult. For example, the positioning of the screw holes, which allow two components to be bolted together is not standardized. The car manufacturer will usually determine this. Only some exceptions of standardization at a higher level are known. One is the placement size for a car radio. Even something as easy to envisage as a standard for the placement of attachment positions of wheels is car and model specific. The main interfaces between components are therefore brand specific.

The configurator contains the knowledge of parameters, its values, and its constraints and guides the customer through the process to end up with a valid configuration of the car. Customization, however, is only limited to the parameters shown. So a demand for a car with an electrical engine cannot be customized in the example earlier shown. The customer will have the options to either accept this or go to another manufacturer who will give him this opportunity.

The parameters with which object types are described determine the modules made visible for a customer. The elements used for constructing the module remain invisible for the customer. A balance should be available between the number of parameters made visible to the customer and the complexity of managing this amount of information (including the constraints between the parameters). Choosing the right parameters will be market driven. For cars, types of engine and color are important parameters for a customer to determine. Rigidity of the bodywork however is for most customers not important, so this property of a car is not offered to a customer.

Summarizing, the most important lessons from industry for mass customization are:

- The basis is a model of a product where the building blocks are modeled using parameters and constraints between those parameters. 
- Strive for the right granularity of elements that builds up an end product. A balance should be found between a manageable complexity of combinations of elements and the demands the market has on customization to its needs.

- Interfaces between modules are well-defined. Where possible, interfaces are standardized, using internationally accepted standards. However, as soon as complexity and specificity of the interface increases, this will no longer be possible. In that case a more local scope (e.g., a car manufacturer) will need to be present where these interfaces are defined.

- ATO does not support full customization. For those situations, an engineer to order or small size production situation is suited. This costs (a lot) more for the customer. To formulate it another way, a customer can customize a Volkswagen Passat largely to his demands. When a special demand cannot be met however, there are two options left: Accept this (and pay a moderate amount of money) or look for another solution (that almost surely will cost a lot more; see for example the very high prices of the customer specific adaptations offered by Brabus (http:// www.brabus.de).

- To guarantee a valid configuration, configurators to guide the customer through the attributes and choices that have to be made are indispensable because of the complexity of the product model.

\section{Mass Customization in Education}

In this section we will elaborate on applying the theories and practices of mass customization from industry to education. The objectives for doing so are identical to those achieved in industry: to combine high quality and relatively low costs with customization (within limits). Our starting point is the product model for the educational field as depicted in Figure 2. 


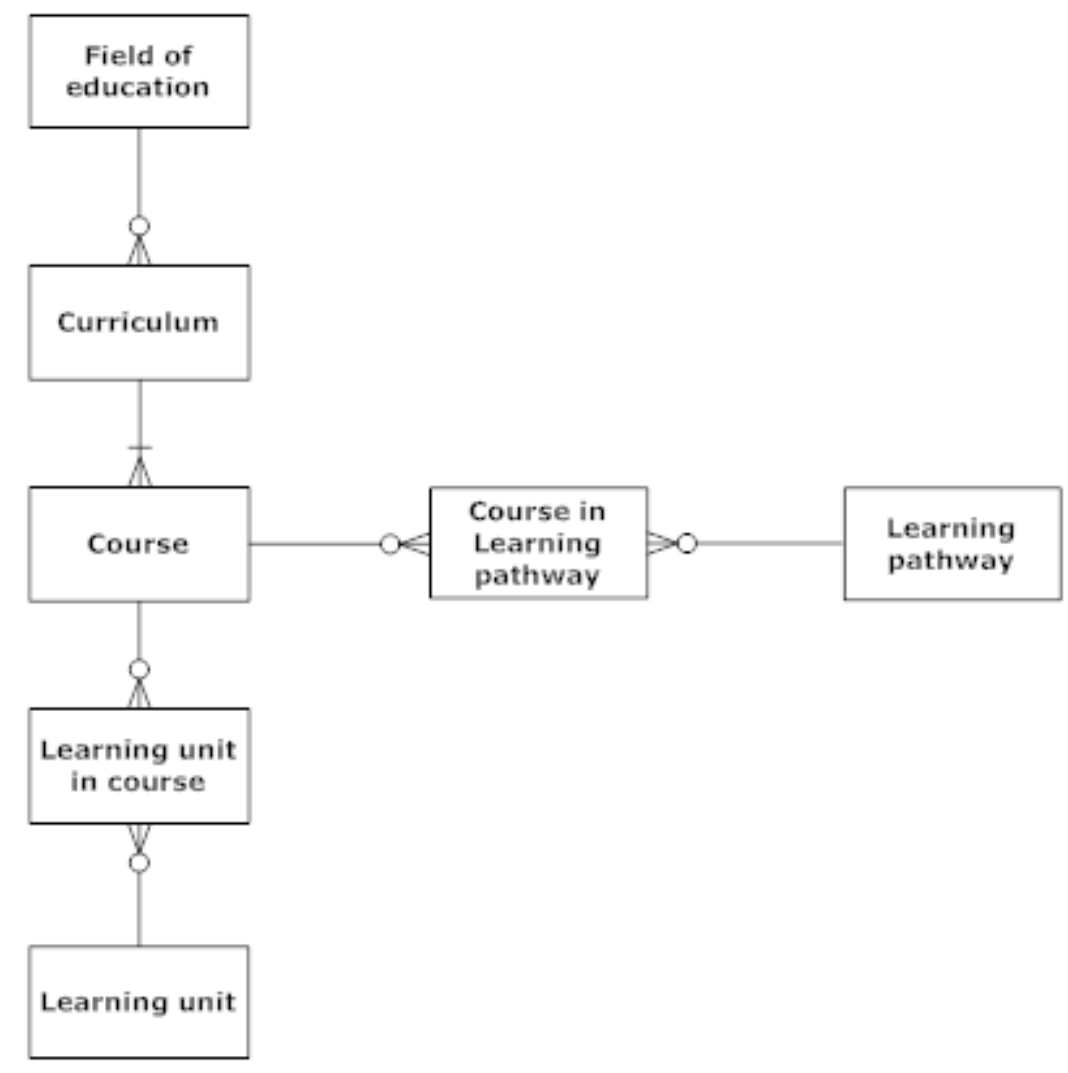

Figure 2. Product model for education.

A description of this model: For a field of education (e.g., computer science), there exist many curriculums. Each curriculum is built up of courses (e.g., a course on structured programming), each course is built up of learning units (e.g. a unit on control structures in a programming language). Courses can be organized in learning pathways. A learning pathway is the way an individual student or group of students chooses to go through a (part of a) curriculum.

In this model, variations are possible on several entities:

- course, where variations can exist in learning units (e.g., the possibility to select optional learning units or the form of a learning unit [digital or non-digital])

- curriculum, where variations can exist in the composition in courses (e.g., the possibility to select one or two courses from a list of many)

- learning pathway, where variations can exist in the way the courses are taken by a student (e.g., the order of the courses or the choice between an online or an offline variant of a specific course) 
In this vision, the learning unit is the building block where all variants are built upon. A course is an instantiation of variants of learning units, and a learning pathway is an instantiation of variants of courses in a specific sequence. Customization offered to the student can be on

- learning pathways, in variations of courses (a student can assemble an individual pathway through courses);

- courses, in variations of learning units (a student can assemble his or her own course or parts of courses out of learning units, combined with variations in learning services and teaching efforts).

A curriculum determines certain constraints on possible variations. For example, in ACM (2001) 14 knowledge areas are mentioned for a computer science curriculum. Also, high-level learning objectives are named, the knowledge and skills for a bachelor or master in computer science, and for each subject the minimum number of hours to be spent in the curriculum. A valid configuration of courses should comply to this description of a curriculum.

The starting point for a student will be configuration of his/her preferred learning pathway. To illustrate how parameterization of learning units, courses, and learning pathways could look in an educational environment, we will use the following fictitious example.

\section{Example: A Very Short Curriculum for Computer Science}

Consider courses in a curriculum for Computer Science as depicted in Table 2.

Table 2

Curriculum Computer Science

\begin{tabular}{|l|l|}
\hline Course & Remarks \\
\hline Introduction in CS & Mandatory \\
\hline Introduction in programming & Mandatory \\
\hline Advanced programming & Optional \\
\hline Databases 1 & Mandatory \\
\hline Databases 2 & Optional \\
\hline Data modeling & Optional \\
\hline Communication networks & Mandatory \\
\hline Calculus for CS & Mandatory \\
\hline Internship & Mandatory \\
\hline Constraints \\
\hline Exactly 1 optional course must be selected \\
\hline
\end{tabular}


Each course consists of several learning units. Experiences with this curriculum shows that the most important parameter for a course is the mode of delivery. To illustrate parameterization of a course, Table 3 provides one for the course Introduction in CS. This course is made up of four learning units. For the third and fourth unit, a student can select from 4 resp. 3 different options. Each learning unit is delivered in several formats. There are several modes of delivery for the course and the student can also select between several options for the final assessment and tutoring during the course. Note that the latter elements are examples of learning services and teaching efforts. There are several constraints for the parameters. There are constraints on modes of delivery in relation to start date of the course, start date and form of final assessment, and on combinations of options for learning unit 3 and 4.

Table 3

Example of Parameterization of a Course

\begin{tabular}{|c|c|}
\hline Term & Example \\
\hline Object & Course Introduction in CS \\
\hline Object type & $\begin{array}{l}\text { Course Introduction in CS for an individual student or a group of } \\
\text { similar students }\end{array}$ \\
\hline Parameter & 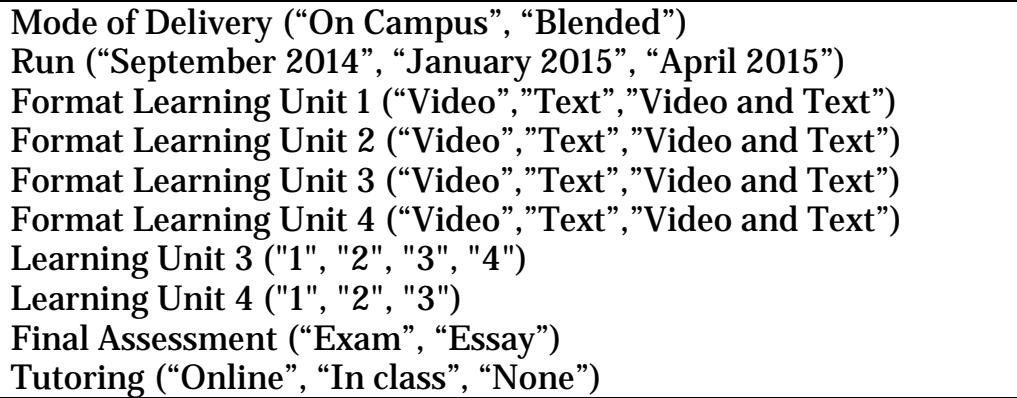 \\
\hline Specialties & $\begin{array}{l}\text { Blended course Introduction in CS (Mode of } \\
\text { delivery="Blended") } \\
\text { On Campus course Introduction in CS (Mode of delivery="On } \\
\text { Campus") }\end{array}$ \\
\hline $\begin{array}{l}\text { Variant } \\
\text { (configuration) }\end{array}$ & $\begin{array}{l}\text { Example of a variant of a blended course: } \\
\text { Run: September } 2014 \\
\text { Format Learning Unit } 1 \text { ("Video") } \\
\text { Format Learning Unit } 2 \text { ("Video and Text") } \\
\text { Format Learning Unit } 3 \text { ("Text") } \\
\text { Format Learning Unit } 4 \text { ("Video") } \\
\text { Learning Unit } 3 \text { ("2") } \\
\text { Learning Unit } 4 \text { ("1") } \\
\text { Final Assessment ("Essay") } \\
\text { Tutoring ("In class") }\end{array}$ \\
\hline Constraints & $\begin{array}{l}\text { If Mode of Delivery="On Campus" Then Startdate="September" } \\
\text { If Mode of Delivery="On Campus" Then Tutoring<>"Online" } \\
\text { If Startdate }>\text { "September" Then Final Assessment = "Essay" } \\
\text { If Learning Unit } 3=\text { "1" Then Learning Unit } 4 \diamond \text { "2" }\end{array}$ \\
\hline
\end{tabular}


Table 4 depicts a parameterization for a learning pathway. It is assumed that no more than two courses are allowed to be taken simultaneously. Furthermore, each learning path should start with Introduction with CS and end with the internship. The most important parameter for a learning pathway is which optional course is selected.

Table 4

Example of Parameterization of a Learning Pathway

\begin{tabular}{|c|c|}
\hline Term & Example \\
\hline Object & Learning pathway \\
\hline Object type & $\begin{array}{l}\text { Learning pathway for an individual student or a group of similar } \\
\text { students }\end{array}$ \\
\hline Parameter & 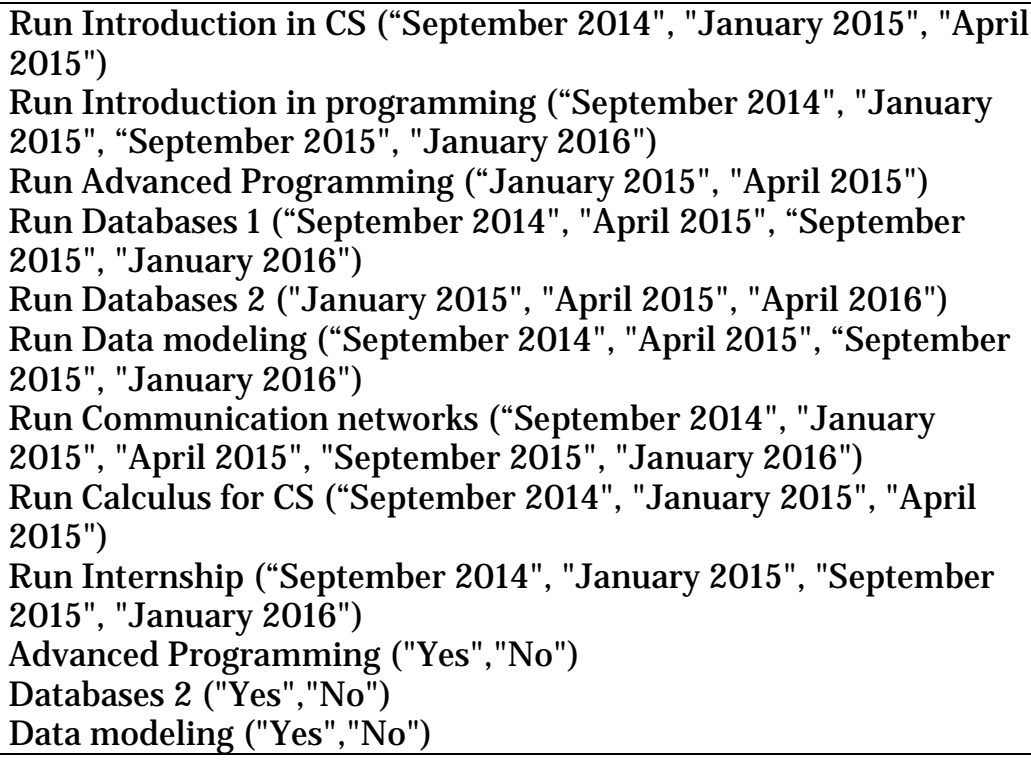 \\
\hline Specialties & $\begin{array}{l}\text { Learning pathway Programming (Advanced Programming="Yes") } \\
\text { Learning pathway Databases (Databases } 2=\text { "Yes") } \\
\text { Learning pathway Modeling (Data modeling="Yes") }\end{array}$ \\
\hline $\begin{array}{l}\text { Variant } \\
\text { (configuration) }\end{array}$ & $\begin{array}{l}\text { Example of a variant of a Learning pathway Programming: } \\
\text { Run Introduction in CS ("September 2014") } \\
\text { Run Introduction in programming ("September 2014") } \\
\text { Run Advanced Programming ("April 2015") } \\
\text { Run Databases } 1 \text { ("April 2015") } \\
\text { Run Communication networks ("J anuary 2015") } \\
\text { Run Calculus for CS ("J anuary 2015") } \\
\text { Run Internship ("September 2015") }\end{array}$ \\
\hline Constraints & $\begin{array}{l}\text { Introduction in CS in first period } \\
\text { Internship as last course } \\
\text { No more than } 2 \text { courses with same run date } \\
\text { Exactly one of the values for Advanced Programming, Databases } 2 \\
\text { or Data modeling equals "Yes" }\end{array}$ \\
\hline
\end{tabular}

Although this example describes a very simple situation, the number of possible configurations (not taking into account the constraints) is already large. Assuming the 
same parameterization for each course as the one that is described for the course Introduction in CS, the total number of learning pathways is 3 specialties * 9 courses * 4 periods (average)* 2 course specialties $* 4$ learning units $* 3$ formats $* 4$ options for learning unit $3 * 3$ options for learning unit $4 * 2$ final assessments $* 3$ tutoring modes $=$ 186,624 . The number of valid configurations is smaller, but still significant.

In reality, the number of parameters will be much larger, both for a course as for a learning pathway. Furthermore, the number of courses that make up a curriculum is much larger than the number from our example. Besides, the following requirements count for a curriculum as a whole:

1. clear, preferably unambiguous use of language;

2. no overlap (subjects handled in several places in the curriculum, whether or not consistently treated);

3. no missing parts of relevant subjects;

4. the right level (of abstraction) on the right place in the curriculum.

These requirements for a curriculum as a whole should be translated into parameters and constraints in the product model.

IMS Learning Design (IMS LD) provides us with a description of which elements together build up a course (Koper \& Manderveld, 2004). This specification dates back to 2003. The basic unit within IMS LD is the 'unit of learning'. This unit is described by the attributes depicted in Figure 3 (Koper \& Manderveld, 2004). 


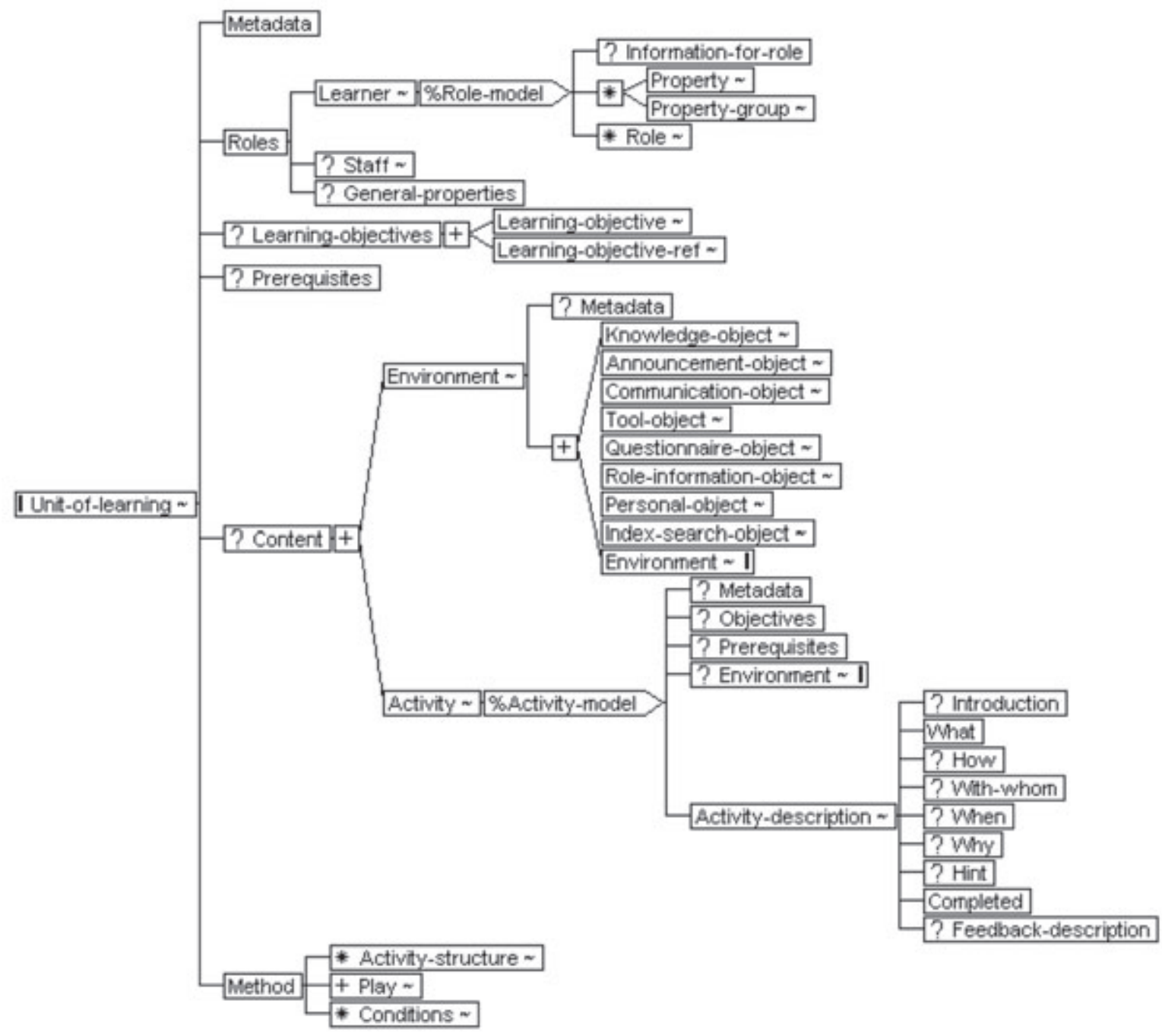

Figure 3. Basic structure of IMS LD.

The attributes given in this model can be used as parameters to create variants of learning units. In our example, we used the roles attribute as parameter for variants in tutoring. The attributes can also be used to provide the student with more information on a learning unit, so his selection will be more informed. But variants also arise due to flexibility in services as offered by the institution (e.g., the option for a blended or an online variant for a course in our example).

An important difference between the modeling of products in the industry and for education is the lack of standardized interfaces between modules in the latter situation. This complicates configuring a curriculum when (whether or not open) available sources from elsewhere should be combined into a coherent whole. In this situation, standardization can be initiated by standardizing learning objectives (for a course or course section). The description of learning materials can then be expanded by enumerating to which learning objectives the materials contribute. An attempt at such 
standardization is the Achievement Standards Network (ASN, 2013). A reasonable alternative is to standardize at the level of institution. Learning materials from outside the institution can then be added to its own structure by a careful process of selection and (limited) adjustment. The lack of standards on interfaces and the specific demands on curriculum and quality of OER leads us to the conclusion that an ATO approach is currently only viable in education when the institution orchestrates the process.

Another difference is that in industry the end product is almost completely determined by physical components. In the educational field, this is a mixture of physical components (the learning materials), learning services, and teaching efforts.

As in industry, IT support is indispensable to both the modeling of the product and assembling a valid configuration. The product data are modeled as a bill of material, in which the constraints are also defined. An important requirement of a bill of material is to manage the potential explosion in combinations of modules. A generic bill of materials (Hegge \& Wortmann, 1991) is a type of bill of materials developed specifically for these kinds of products. Also, a configurator, built upon the product model, is the tool to be used by the learner to assemble a learning pathway on demand. The challenge for the institution offering these possibilities is to organize the supply in such a way that groups of more or less homogeneous types of learners can be accommodated, where the individual user gets the feeling that his/ her unique situation is taken as a starting point.

\section{Validation}

To validate the idea as described and determine its perceived added value, eight experts where interviewed. Their expertise was in educational technology and OER. Some experts were responsible for offering a curriculum. In each interview, the idea was explained to the expert. Then $\mathrm{s} /$ he was asked to judge the added value of this approach (ranging from 1 = no added value; 2 = limited added value; 3 = reasonable added value; 4 = significant added value; $5=$ high added value) and to explain their opinion. This led to the following findings.

Seven out of eight of the experts judged the added value with 3 or higher (2 scored 3; 4 scored 4; and 1scored 5). Arguments provided were:

- This approach creates a clear view for the learner on the supply of an institution and the level of tailoring to the demands of him/ her. A learner gets more insight into expectations and individual concessions when confronted with the modeled curriculum.

- The approach can also provide insight to the institution in how tailored their supply can be. 
- Situations that occur in practice can be modeled using this approach, for example a software curriculum at the University of Utrecht with $50 \%$ free choice of courses, having to satisfy several constraints on pre-knowledge available, per period limited number of courses to select, and so on. This situation could profit from this modeling approach.

- An eye opener is the parameterization of services and not only materials.

- When different institutions use this approach, a future learner can find out which institution will have the most/ best tailored offer for him/ her.

- When supported by configurators, process data can be analyzed to find out which learning paths and/ or which course configurations will lead to the best results (learning analytics). But this should be handled carefully to not base decisions only on averages. Using a configurator will also ease adding recommender functions for certain parameters.

- This approach is especially worthwhile in a life long learning setting when the parameters make possible that the resulting configuration is closely related to the field where the learner is working, making transfer of the subject matter to practice easier (e.g., by variations in cases).

Concerns about this approach were also mentioned. A single expert (who was responsible for a curriculum) judged the added value as 2, because a necessary precondition is to make the organization adapt to this situation. This concern was mentioned by other experts. To realize a setting where this approach is possible, the learning goals and content should be described carefully and some level of standardization in building courses and curriculum should be present. Furthermore, comparing activities of a teacher with those of a car manufacturer will possibly lead to resistance of acceptance of the idea. Another consideration, mentioned by several experts, was that in many cases a mixture of this approach and individual tailoring will be necessary. Parameterization will model $80 \%$ of the demand. The remaining $20 \%$ will be created tailor-made against higher costs. Two experts questioned the business case behind this approach. When an institution embraces some form of mass customization, the costs per student will probably rise. What drivers will force an institution to start with this approach?

Several experts also made remarks on extensions of use for this approach, not limited to a regular curriculum and the possible role IMS- $L D$ could play:

- The approach is also useful for post initial education. The demand in that case is not determined by a curriculum with learning goals and demands on level and variety to have a valuable certificate or degree. But in many cases section specific demands exist for learning goals. So there exist a common set of agreements from which the parameters to vary can be derived. 
- IMS-LD provides modeling of education on a deeper, more individualized level, but it can feed modeling on the level as presented here.

This leads us to the conclusion that the idea as sketched is worthwhile to pursue further. In the next section we will sketch some possible actions.

\section{Conclusions and Future Research}

When we look at the requirements and challenges mentioned in the introduction, it can be noticed that an approach for mass customization based on ATO, if successfully transferred to the field of education, would deal with a number of the issues mentioned.

- The ability to provide variety enables adapting the educational product to requirements stemming from differences between types of students, context, and locality.

- The ability to provide acceptable development costs using this mass customization approach could give an answer to current problems with unclear business models and high costs of adaptation.

- The ability to provide acceptable quality is a serious hindrance to current acceptance of OER. The ability to handle this issue would strongly support adoption of OER.

By selecting a learning unit as granularity for the modeling of the product, available OER can be readily reused in the offerings. What is needed though to increase the findability are more detailed descriptions along with the OER on learning goals, pedagogy, required foreknowledge, and so on.

As was also mentioned in the Introduction, the demand for offering personalized learning is expected to grow in the next decade (Horn \& Christensen, 2013). In that situation, there will be a need for a supply of learning materials (both closed and open) where this supply as well as possible (but not necessarily 100\%!) fits the individual demand of a learner. When this expectation comes true, the university that succeeds in offering the best 'fit' for the potentially largest target group will gain a competitive advantage.

Creating the best 'fit' takes into account both learning technology aspects (e.g., variance in pedagogical approaches) and organizational variations (e.g., offering both f2f as online courses, paced, and not paced). Opportunities to realize such offerings can be enhanced by using techniques like learning analytics and developments like the semantic web. These techniques can be used to add to context related properties of the learning materials, thereby realizing a better findability for the OER and providing an end result better suited to the individual user with relatively low costs. 


\section{Acknowledgement}

We would like to acknowledge the following persons for their willingness to provide the validation feedback: Prof.dr. Lex Bijlsma, Dr. Pierre Gorissen, Dr. Monique J ansenVullers, Dr. Karel Kreijns, J ocelyn Manderveld MSc, Eric Slaats MSc, Fred de Vries MSc and Nicolai van der Woert MSc. 


\section{References}

ACM (2001). Computing curricula 2001 computer science. Association for Computing Machinery. Retrieved from

http:// www.acm.org/ education/ education/ education/curric_vols/ cc2001.pdf

ASN (2013). Achievement standards network. Retrieved from http:// asn.jesandco.org/

Asseldonk, T., \& Mulder, F. (2004). Massa-individualisering van hoger onderwijs (Mass individualization of higher education) (in Dutch). Redes opening van het academisch jaar. Open Universiteit: Heerlen, 19-30. Retrieved from http:// www.ou.nl/documents/ 10815/4100960e-6314-4471-8fb08dfd88d8d7dd

Barrett, D. (2012). How "flipping" the classroom can improve the traditional lecture. The Chronicle of Higher Education. Retrieved from http:// chronicle.com/article/How-Flipping-the-Classroom/130857/

Bates, A. W. (2005). Technology, e-learning and distance education (2 $2^{\text {nd }}$ ed.). New York, NY: Routledge.

Commonwealth of Learning (2011). Guidelines for open educational resources (OER) in higher education. UNESCO. Retrieved from http:// unesdoc.unesco.org/images/ 0021/ 002136/213605e.pdf

DIN. (2013). List of DIN standards. Retrieved from http://en.wikipedia.org/wiki/List_of_DIN_standards

Hegge, H. M. H., \&Wortmann, J . C. (1991). Generic bill-of-material: A new product model. International J ournal of Production Economics, 23(1-3), 117-128.

Hodgkinson-Williams, C. (2010). Benefits and challenges of OER for higher education institutions. The Commonwealth of Learning. Retrieved from http:// www.cet.uct.ac.za/ files/file/2010/HodgkinsonWilliams\%202010\%20Final-1.pdf

Horn, M., \& Christensen, C. (2013). Beyond the buzz, where are MOOCs really going? Retrieved from http:// www.wired.com/opinion/2013/02/ beyond-the-moocbuzz-where-are-they-going-really

Kirschner, P., \&Valcke, M. (1994). From supply driven to demand driven education: New conceptions and the role of information technology therein. Computers in Human Services, 10(4), 31-53. 
Koper, R., \&Manderveld, J . (2004). Educational modelling language: Modelling reusable, interoperable, rich and personalised units of learning. British J ournal of Educational technology, 35(5), 537-551.

Martens, R., Weges, H., \& Valcke, M. (1997). Elektronischeleermaterialen. Drie case studies (Digital learning materials. Three case studies) (in Dutch). Landelijke dag studievaardigheden, Heerlen. Retrieved from http:// www.open.ou.nl/lds97/ elektronische leermat.htm

Matkin, G. W. (2009). Institutional sharing of OpenCourseWare across national boundaries: A case study and historical first in higher education. Distance Education Report, 13(10), 3, 7-8.

Mistree, F., Panchal, J. H., \& Dirk Schaefer (2012). Mass-customization: From personalized products to personalized engineering education. In A. Groznik (Ed.), Pathways to supply chain excellence. InTech. Retrieved from http:// www.intechopen.com/ books/ pathways-to-supplychain-excellence/ masscustomization-from-personalized-products-to-personalized-engineeringeducation

Morales, L., Castillo, L., \& Fernández-Olivares, J . (2009). Planning for conditional learning routes. In MICAI 2009: Advances in Artificial Intelligence, 384- 396

Mulder, F., \& J anssen, B. (2013). Opening up education. In RJ acobi, H. J elgerhuis \& N. van der Woert (Eds), Trend report open educational resources 2013 (pp. 36-42). SURF SIG OER, Utrecht, Netherlands. Retrieved from http:// www.surf.nl/ en/ knowledge-and-innovation/knowledgebase/ 2013/trend-report-open-educational-resources-2013.html

Neven, F., \& Duval, E. (2002). Reusable learning objects: A survey of LOM-based repositories. Proceedings of the tenth ACM international conference on Multimedia, 291-294. Retrieved from http:// hmdb.cs.kuleuven.be/ publications/ files/Lorsurvey.pdf

OECD (2007). Giving knowledge for free. The emergence of open educational resources. Retrieved from http:// www.oecd.org/ edu/ ceri/ 38654317.pdf

Pohl, K., Böckle, G., \&van der Linden, F. (2005). Software product line engineering. Berlin Heidelberg: Springer Verlag.

Rippel, M., Panchal, J . H., Schaefer, D., \& Mistree, F. (2009). Fostering collaborative learning and educational mass customization in a graduate level engineering design course. International J ournal of Engineering Education, 25(4), 729744 . 
Schuwer, R. (2013). Kwaliteitsvraagstukken voor OER in het Nederlandse hoger onderwijs (Quality problems with OER in Dutch Higher Education) (in Dutch). SURF, Utrecht. Retrieved from http:// www.surf.nl/binaries/content/assets/surf/nl/kennisbank/2013/rapport -kwaliteit-van-open-leermaterialen-07-11-2013.pdf

Shoham, Y. (2012). Packaged online courses (POCs). Retrieved from http:// robotics.stanford.edu/ shoham/ www\%20papers/ Higher\%20Educated \%20Guesses\%20-\%20Universities.pdf

Tseng, M., \&J iao, J . (2001). Mass customization. In G. Salvendy (Ed.), Handbook of industrial engineering (pp. 684-709). New York: Wiley.

Ulrich, K.T., \& Tung K. (1991). Fundamentals of product modularity. DE-Vol. 39, Issues in Design Manufacture Integration, ASME.

Universities UK (2011). Efficiency and effectiveness in higher education. London.

U.S. Department of Education, Office of Educational Technology (2010). Transforming American education: Learning powered by technology. Washington D.C. Retrieved from http:// www2.ed.gov/about/offices/list/os/technology/ netp.pdf

Valcke, M., Martens, R., \&Weges, H. (1997). Mercator. An integral system for realizing just in time learning, tailor made courses, demand-driven education and printing on demand (Mercator. Een integraal systeem voor het realiseren van just in time learning, tailor made courses, demand-driven education en printing on demand) (in Dutch). Landelijke dag studievaardigheden, Heerlen. Retrieved from http:// www.open.ou.nl/lds97/ mercator.htm

Yuen, K., \& Wong, A.J . (2013). Open educational resources in Hong Kong. In G Dhanarajan \&D. Porter (Eds.), Open educational resources: An Asian perspective (pp. 41-51). Vancouver: Commonwealth of Learning.

\section{Athabasca University $\mathbf{Z}$}

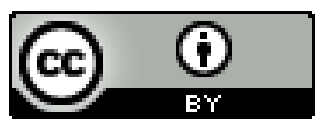




\section{A Path Analysis of Educator Perceptions of Open Educational Resources Using the Technology Acceptance Model}

Hope Kelly

University of Florida, USA

\section{Abstract}

Open educational resources (OER) are making their way into a variety of educational contexts from formal lesson planning to just in time learning. Educators and training professionals have been recognized as an important audience for these materials. The concepts of self-efficacy and outcome judgment from social cognitive learning theory serve as theoretical constructs to measure educator perceptions of OER. This study uses a path analysis, based on the technology acceptance model, to understand adoption of these resources by this audience with a particular emphasis on self-efficacy. Among the participants, three main groups were identified: K-12 educators, higher education professionals, and those involved in workplace training. A discriminant function analysis found that K-12 educators stood out as finding OER relevant to improving their practice. Recommendations are made in regards to an emphasis on easy to use designs to improve application self-efficacy of OER and instructional messaging for future K-12 educators.

Keywords: Open educational resources; technology acceptance model 


\section{Introduction}

The landscape of the Internet and World Wide Web has demonstrated an amazing rate of growth over the past 20 years. Indexed web pages are estimated to be about 8.67 billion as of December 2012 (de Kunder, 2012). That number is likely just a fraction of existing web pages, as nearly a quarter of the actual number is simply not indexed (Barabási, 2002). Amid this landscape, there are countless resources created, maintained, used, and repurposed for education. Open educational resources (OER) may be defined as educational resources that are either in the public domain or have been made freely available through their license. OER available via the Internet are making their way into the lesson plans of thousands of educators in both face to face and distance learning environments. Many resources are specifically designed for inclusion in educational settings, while other resources are re-purposed by educators to meet a specific need. This study examines educator perceptions of OER that impact their adoption and use. The participants in this study came from higher education, K-12 schools, and workplace training. Understanding how this group of users perceive the usefulness of these types of items has two potential benefits: First, creators of OER will be able to design their materials to meet the perceived needs of educators, and, second, practices for inclusion of OER in lesson planning and curriculum development may be identified which can guide teacher education and professional development instructional messages. As more educators seek out digital resources for their classes, it is useful to understand the relationships between these individuals and the resources that they seek out to support the use and re-use of OER among educators otherwise unaffiliated with the OER movement.

The open movement is guided by a determination to share resources in order to support generativity or creative intellectual growth in a generational context and with worldwide reach. Generativity in this context refers to the transformative nature of creating knowledge into the future by sharing, educating, and interacting with the next generation. Proponents from the movement have called for a shift in educational policy and practice to encourage adoption and creation of OER (Read, 2008). Many international, national, and state-level organizations have promoted or funded OER initiatives, for example, the Hewlett Foundation's Strategic Plan to Increase Access to High-Quality Educational Content (Atkins, Brown, \& Hammond, 2007) and UNESCO's Paris OER Declaration (2012). New trends in publishing and copyright have been formulated to support this growth, particularly Creative Commons licensing. Creative Commons licensing allows creators to copyright their work in a manner appropriate to how they wish to share their work. While some may wish to reserve all rights, others may adjust the license to fit their intent to make their work more open to reuse, repurposing, and remixing.

State and national governments, as well as international organizations, have determined a benefit to supporting the creation, development, and maintenance of these resources. Examples of legislation and policy promoting the development and adoption of OER are 
becoming more common (Creative Commons, 2013). It appears that modularized course content and full courses are a focus in higher education, while open textbooks are a focus in K-12 education (Florida Distance Learning Consortium, 2013). Two major forces are driving these policies and investments. First, it is believed that there will be a cost savings and, second, it is believed that providing open access to these resources empowers people all over the globe by making quality educational resources more available. While the cost savings and the dissemination of knowledge are perhaps considered as obvious goods, these resources must be useful to the audience they are directed towards if they are to be used at all.

While all these positive forces encourage the creation and acceptance of these resources, other factors hinder wide spread adoption of OER. Although there is some financial support for the creation and maintenance of OER collections, funding is limited. Further, balancing open resources and paid resources is a major concern for any educational institution (Read, 2008). Copyright and concerns for acceptance of content published outside of recognized venues has deterred many from pursuing publication in an emerging model (Schonfeld \& Houseright, 2010). Finally, systematic use of OER has not been integrated in to the curriculum for teaching professionals and many of the best-known repositories may be unknown by the majority of educational practitioners. Understanding how educators currently in the practice regard the usefulness of these resources in their own work is an area which can inform both design of OER and their access points as well as provide insight into instructional messaging targeted at OER integration.

Despite these constraints, the growth of OER is likely similar to information available digitally in general. Recently, the interest in massively open online courses (MOOCs) has flooded the blogosphere and online learning conferences alike (Mangan, 2012; Liyanagunawardena, Adams, \& Williams, 2013). As more educators turn to the Web for classroom resources, understanding why they adopt these resources will serve as a point in understanding what educators need and how they can or do implement these digital artifacts into their practice. This research focuses on attitudes about adopting these resources that is consistent with models of diffusion of innovations (Rogers, 1995) and the theory of reasoned action (Moore \& Benbasat, 1996) as exemplified in the technology acceptance model (Davis, 1989).

\section{Theoretical Foundation}

A useful theoretical framework for understanding how educators adopt OER can be constructed based on the works of Albert Bandura and Fred Davis. Bandura provides a theoretical framework and Davis provides a model. The tome Social Learning Theory (Bandura, 1977) explores ideas about how efficacy expectations and outcome expectations inform both behavior and outcomes in the chapter on antecedent determinants. Bandura presents a model regarding these concepts that is illustrated in Figure 1. Efficacy expectations may encourage or discourage an individual in attempting 
a new behavior. Typically, people are more likely to adopt something that they believe they will be able to accomplish. Outcome expectations gauge how an individual perceives the new behavior will impact outcomes, thus recognizing if there is any value or detriment in adopting the new behavior.

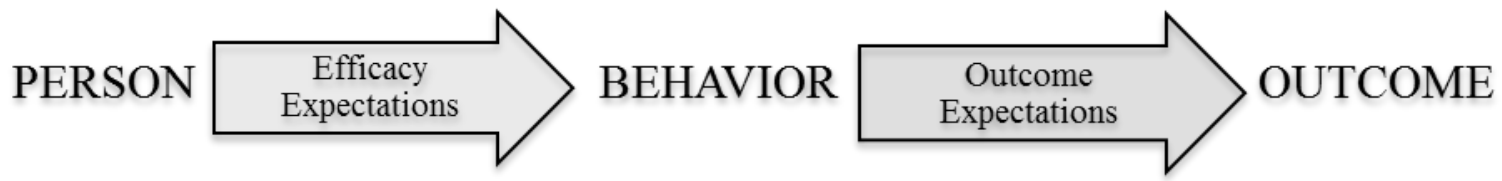

Figure 1. The difference between efficacy expectations and outcome expectations (Bandura, 1977).

Built upon the concepts of efficacy and outcome expectations, the technology acceptance model (TAM) developed by Fred Davis has been a widely used model to explore technology adoption in a variety of contexts since its development. The model seeks to explain the process of how individuals accept and use new technologies. Figure 2 illustrates an early conception of the model, which has subsequently been modified and adapted in many studies (Adams, Nelson, \& Todd, 1992; Lau \& Woods, 2009; Yi \& Hwang, 2002). The TAM postulates that external factors, often system design characteristics, contribute to an individual's perceptions of how easy to use and how useful a new technology is considered. These perceptions in turn inform the intention to use the technology, and finally determine the actual usage (variables in italics). In this study general computer system self-efficacy is tested as an external factor. All other variables of the TAM are included in the instrument and analysis. The TAM's wide use is not without its critics, however with so many replications, the model and its associated instruments have been extensively validated.

Of particular interest in this study is self-efficacy as a determining factor in TAM (Legris, Ingham, \& Collerette, 2003). This focus on self-efficacy is built upon the idea that self-beliefs affect motivation and cognition (Bandura, 1989). Self-efficacy examines attitudes toward the ability to do a given task (in this instance, to find and integrate an OER). This personal belief is closely related to the construct of perceived ease of use. Similarly, outcome expectations or judgments as identified by Bandura (1982) align well with perceived usefulness in determining if adopting the technology has value. 


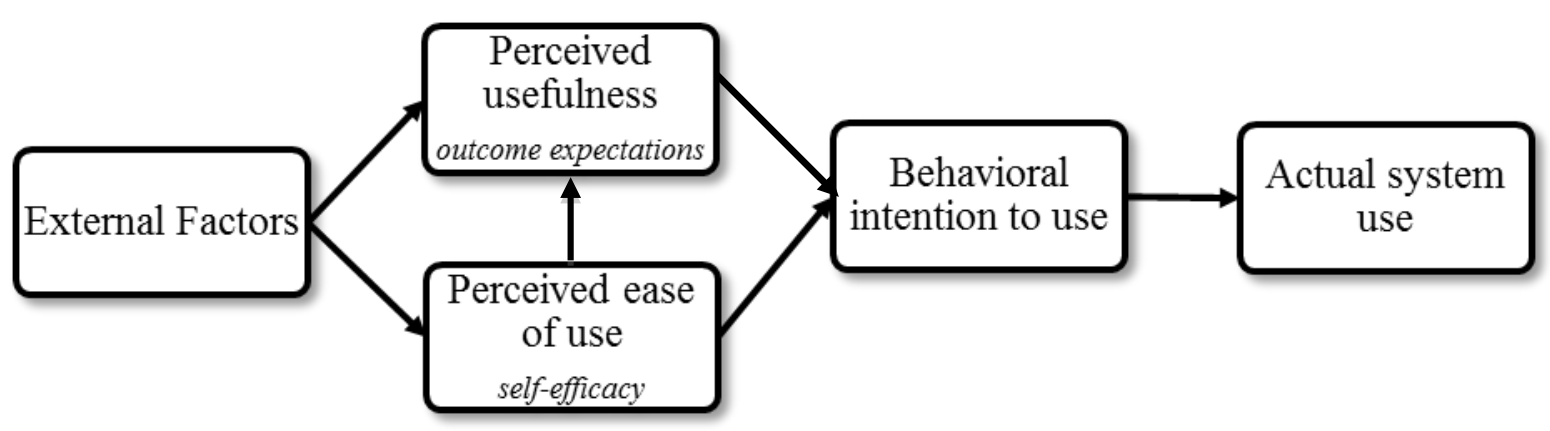

Figure 2. The technology acceptance model (Davis, 1989) with corresponding elements from Bandura (1989) in italics.

\section{OER Defined}

The TAM may provide an appropriate lens in understanding the adoption of this technology, which are defined here as web-based educational resources that are freely available via the Internet. The phrase can be further broken down into the three key words of OER, first, the open aspect of the resources, which allows for free use. The term educational separates these resources from other materials that are freely available on the Internet with an educational purpose which may come from the creator or the user of the resource. The OER phrase broadens dramatically in using the word resource, which in this context not only refers to content but a wide variety of tools to support access to the content as well as even more tools that support inquiry.

\section{Use of OER}

In the past, reuse and repurposing of digital educational resources, primarily in the form of learning objects has been viewed as onerous due to licensing and the traditional copyrights (Wiley, 2008). Now that many resources are freely available through new licensing strategies (e.g., Creative Commons), the opportunity for use is much more open. Several organizations (Connexions, DiscoverEd, MERLOT, etc.) work to aggregate these resources for improved discovery and re-use and past research has emphasized the organization of this information. With this ever widening access, attention now turns to how these materials are adopted or used. OER use can fall broadly into two categories: formal and informal learning. In formal use, a resource is typically being used as a medium for formal study or it will inform formal study. For example, a threedimensional model of a heart may be used to teach the parts of a heart in an online anatomy class. That same model may help an instructor review to prepare for a lecture on the parts of the heart. Informal use of OER can be applied to typical online behaviors of goal-directed browsing and searching for particular pieces of information. In this regard, the focus of this study is on formal learning endeavors. 


\section{Users of OER}

More than half of the sample of OER users was comprised of educators in a 2006 survey conducted by the Organisation for Economic Co-operation and Development (Hylén, 2006). They found that motivation to use these resources came from the practitioners and not from administrative guidance. "When presented with a list of proposed goals or benefits with using OER in their own teaching, the most commonly reported motive was to gain access to the best possible resources and to have more flexible materials" (Hylén, 2006, p. 54). While other studies have noted the diversity of individuals visiting different resources and repositories (Ally, Cleveland-Innes, \& Boskic, 2006; SchmidtJ ones, 2012), the professional educator's perception of OER is important to study as they are a prominent user of the resource.

\section{Methodological Rationale}

In order to study the perception of usability and usefulness of OER among educators, the technology acceptance model was adopted to provide a framework for analysis. A path analysis approach paired well to test model fitness and examine correlation between variables because the TAM is very much a path model (Wright, 1921). Path analysis is appropriate for testing model fitness and in other circumstances where common sense or existent findings point to probable relationships (Cook \& Campbell, 1979). Path analysis is an extension of multiple regression, which identifies effects between variables in a proposed model (Ritzhaupt, Dawson, \& Cavanaugh, 2012). The model used in this study focuses on examining direct effects between an exogenous variable (application self-efficacy) and four endogenous variables (perceived ease of use, perceived usefulness, and actual system use). In path analysis, direct and indirect effects can be tested; a direct effect has no intermediate variables while indirect effects can be observed through one or more additional variables. Exogenous variables are not influenced by other variables in the model, so application self-efficacy is the only variable without observed influences. The endogenous variables, in contrast, all have effects between them that are observed in the analysis. The strength of the effects was measured with the standardized regression coefficient $(\beta)$. This $\beta$ weight allowed for an interpretation of the strength of the effects between the variables. While the interpretation does not imply causality, it does have the power to predict relationships. 


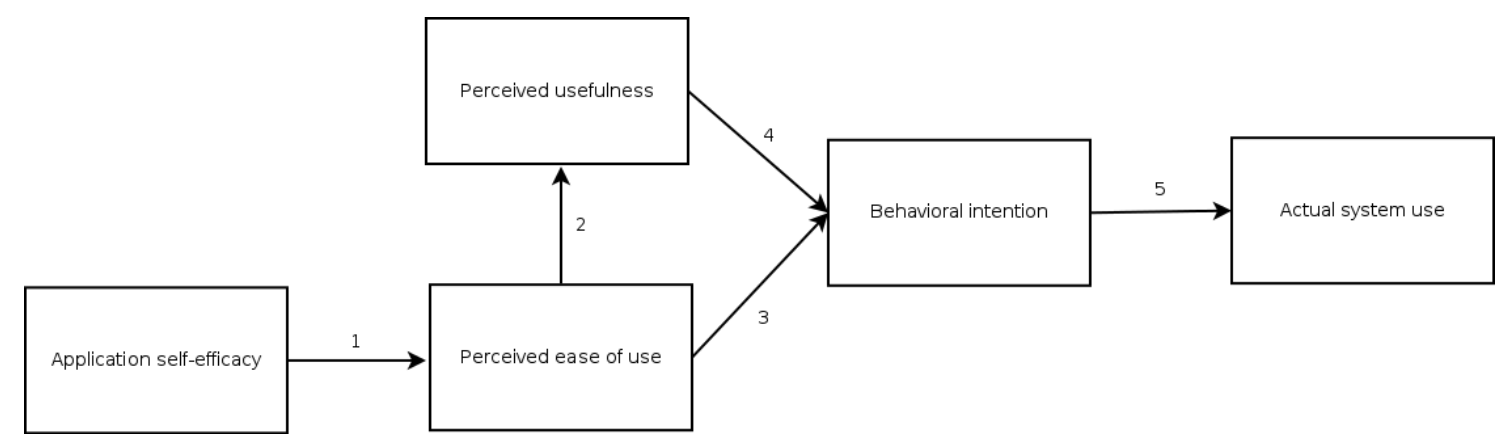

Figure 3. The technology acceptance model with application self-efficacy variable. (Developed from Davis \& Venkatesh, 1996 and Yi \& Hwang, 2003)

Based on the predictions of the TAM, the first five research questions correspond with the arrows in Figure 3:

1. Does application self-efficacy have an effect on perceived ease of use? It was predicted that application self-efficacy would positively effect perceived ease of use of OER because overall computer skill should translate to improved efficacy with a new application.

2. Does ease of use have a positive effect on perceived usefulness? This relationship was predicted to have a strong effect as indicated by the TAM since as a technology becomes more difficult to use, its perceived utility will decrease (Davis, 1989).

3. Does ease of use have a positive effect on behavioral intention to use? It was predicted that the technical quality would have a moderate effect on the intention to adopt OER (Lau \&Woods, 2009).

4. Does perceived usefulness have a positive effect on behavioral intention to use? Finding OER to be useful, particularly for improving educational practice or outcomes, was expected to have a strong effect on intention to use.

5. Does behavioral intention to use have a positive effect on actual use? It was important to consider the effect between what people intend to do and what they may actually do. This thought process bridges the gap between what an individual thinks of a technology and whether they actually adopt it. It was predicted that intention would have a moderate effect on actual use.

A final research question put forward asks if there are group differences related to the educational setting where the participant works in perceptions of OER. The goal was to 
determine if there were group differences among the educators represented in the sample (participants came from $\mathrm{K}-12$, higher education, and workplace training environments). Discriminant analysis was selected to examine which variables held the most predictive power for group membership. Discriminant analysis determines dimensions that groups may differ significantly on and also can illustrate directionality if significant variates are identified (Field, 2005). Determining group differences could help to inform instructional messages regarding OER to meet the needs of particular audiences of educators.

\section{Methodology}

\section{Participants}

A purposive sampling approach was used to collect data from a group of educators and professionals who were identified as aware of and possibly using OER in their teaching practice. Participants were solicited from educational technology listservs and working groups at the national and institutional level (e.g., International Society for Technology in Education Special Interest Group for Game and Simulation Technologies, University of North Carolina Charlotte Learning and Development group in Human Resources, etc.). From 224 responses, 128 were fully complete for analysis. A sample size of 128 responses was sufficient to meet an eight to one ratio (responses per parameter) but a sample as low as 90 would have been stable enough for analysis (Suhr, 2008). The respondents were primarily female ( $66 \%$ female to $34 \%$ male). The majority were over 40 years of age ( $40 \%$ aged over $51,29 \%$ aged 41 to $50,24 \%$ aged 31 to 40 , and $7 \%$ aged 18 to 30). The majority of the participants had graduate degrees (32\% doctoral and other terminal degrees, 56\% master's, and 12\% bachelor's). Professional in higher education (48\%), K-12 (29\%), and workplace training (23\%) were all well represented.

Participants were contacted via listserv postings and email containing a request to participate in the study with an explanation of the purpose of the research and a definition of OER. After approximately two weeks from an initial contact, a second request to complete the survey was sent to participants.

\section{Instrument}

A web-based survey, using Qualtrics ${ }^{\mathrm{TM}}$ software, was utilized to collect data from the sample of educators. All items were adapted from prior research on similar self-efficacy and use and usefulness constructs with a variety of applications (Davis, 1989; Lau \& Woods, 2009). The survey questions developed were derived from Lau and Woods (2009). Five self-efficacy items were adapted to identify personal differences in selfbeliefs about Internet use, search strategies, and typical computer usage. Items that 
measured TAM constructs constituted the rest of the survey and used the same phrasing as Lau and Woods (2009) with a change in the technology under study (from learning objects to OER). A typical question reads, "Using OER increases my teaching productivity." Respondents were then able to rate their perception of the statement on a scale going from "Strongly Agree" to "Strongly Disagree." Prior analysis used to develop the instrument proved to have high reliability, discriminant validity, and nomological validity through an extensive longitudinal study and principal factor analysis with high alpha reliabilities (Compeau, Higgins, \& Huff, 1999; Murphy, Coover, \& Owen, 1989). The survey was tested for reliability and content validity through a think-aloud protocol that used three experts in the field of educational technology. Items were revised as needed based on these analyses prior to the study. Internal consistency has met a threshold of $\alpha \geq 0.8$ for items regarding self-efficacy, perceived ease of use, and perceived usefulness.

\section{Limitations and Delimitations}

The technology acceptance model has been identified as having extremely limited biases in the instrument by Davis, the creator of TAM, and Venkatesh (1996). In the past, the TAM approach has grouped questions based upon what area of the construct they examine. Carry-over effects from this type of contextual organization have been observed in other psychometric research. Davis and Venkatesh (1996) found that the organization of questions into a grouped pattern did not affect the validity of the instrument and further noted that when the questions were mixed, respondents became frustrated with the lack of organization in the survey. The questions in the survey used in the present study have been appropriately formulated to maintain the order representative of reliable TAM instruments. In all other areas of internal validity, the TAM instrument has been observed as reliable and valid (Adams, Nelson, \& Todd, 1992; Hendrickson, Massey, \& Cronan, 1993; Segars \& Grover, 1993) and has been widely used in research concerning acceptance and use of technology.

Path analysis assumes linear relationships between variables, interval data, and the data is free from measurement error (Suhr, 2008). While path analysis can test for two or more causal hypotheses it does not identify the direction of the causality. Describing the direction of causality will be an interpretation of the data but not a finding.

The stability of the path analysis may be impacted significantly by the number of complete survey responses. With 15 parameters to measure, an ideal response would come from at least 150 individuals; however a more realistic goal that maintains the integrity of the analysis was 90. While the 128 responses met the minimum requirements for analysis, it was not optimal. 


\section{Data Analysis}

Data were normalized by recoding the Likert scale items to percentage scores (e.g., strongly agree to strongly disagree became 1.00 to .29) in order to make the items comparable across constructs (Hasson \& Arnetz, 2005). Creating composite scores for each construct of interest followed the normalization procedure. The KolmogorovSmirnov and Shapiro-Wilk tests confirmed normal distribution for self-efficacy, ease of use, usefulness, behavioral intention to use, and actual use. Outliers and way outliers existed, but were retained since they did not impact model fitness. Analysis of the correlation matrix (Table 1) demonstrated no questionable relationships among the variables. The $\beta$ weights were then calculated by conducting a series of multiple regression analysis. Model fitness was tested using AMOSTM, where the model was reconstructed (it is represented in Figure 5 and includes the $\beta$ weights).

In addition to the path analysis, a discriminant analysis was conducted to explore dimensions of group differences between higher education, K-12, and workplace training professionals. Standardized canonical discriminant function coefficients (Table 2) were used to provide analysis of group separation.

Table 1

Correlation Matrix

\begin{tabular}{llllll}
\hline & Self-efficacy & Ease of use & Usefulness & Intention & Actual use \\
Self-efficacy & 1.000 & .458 & .423 & .352 & .273 \\
Ease of use & .458 & 1.000 & .790 & .700 & .556 \\
Usefulness & .423 & .790 & 1.000 & .724 & .574 \\
Intention & .352 & .700 & .724 & 1.000 & .554 \\
Actual use & .273 & .556 & .574 & .554 & 1.000
\end{tabular}

Results

The unit of analysis for TAM hypotheses was the individual; in this instance the participating educators were the individuals. Path analysis was used to test the fitness of TAM, effect between self-efficacy and perceived ease of use, and effects between all other constructs of interest. Path analysis is appropriate for testing model fitness and in other circumstances where common sense or existent findings point to probable relationships (Cook \& Campbell, 1979). Chi-square test of model fit was 16.119, p =.007. Indices of model fit confirmed this with goodness of fit index at .954, normed fit index at .950, and comparative fit index at .965. The comparative fit index may be the most important index in this analysis as it is valid for smaller samples where .9 or higher indicates a good fit. Once model fit had been confirmed, effects between each construct 
were examined; the associated weights for each effect are found in Figure 4, where significant weights are identified in bold.

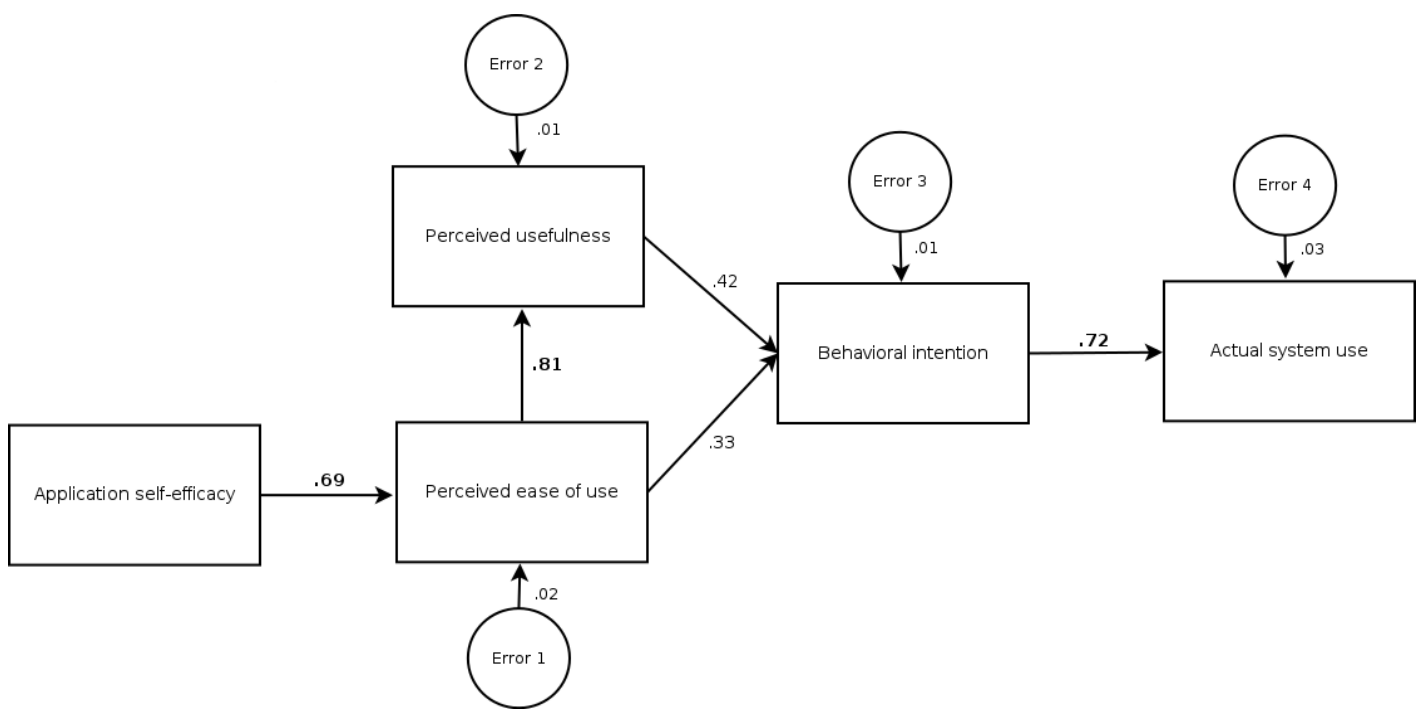

Figure 4. TAM OER Model with $\beta$ weights.

Discriminant analysis was used to conduct a multivariate analysis of variance test of the hypothesis that groups from K-12, higher education, and workplace training environments would differ significantly on a linear combination of the five variables. The overall Chi-square test was significant (Wilks $\lambda=.156, \mathrm{df}=5, \mathrm{p}<.001$ ). Function loadings are detailed in Table 2 . The first discriminant function captured $62 \%$ of the variance between groups. Perceptions of usefulness provided the largest group separation on the first discriminant function. The second discriminant function, which was heavily influenced by self-efficacy, was also considered for further interpretation as it captured $20.9 \%$ of group variance and with the first function captured $82.8 \%$ of variance. This decision to include the second function is based on the stepwise procedure set forward by Stevens (2012). Group centroids on functions one and two (Table 3) show differences between group means using the discriminant function coefficients. It can be observed that K-12 educators were distinct from higher education and workplace training participants in regards to their perceptions of usefulness of OER (Function 1). Elementary educators were quite different than all other groups in regards to self-efficacy (Function 2). 
Table 2

Standardized Canonical Discriminant Function Coefficients

\begin{tabular}{lllll}
\hline & Function & Function & Function & Function \\
& 1 & 2 & 3 & 4 \\
\hline Self-efficacy & -.181 & .959 & .511 & -.275 \\
Ease of use & .519 & -.784 & 1.190 & .765 \\
Usefulness & 1.272 & .481 & -1.057 & -.374 \\
Intention & -.997 & -.510 & .269 & -.706 \\
Actual use & -.582 & .407 & -.365 & 1.000 \\
\hline
\end{tabular}

Table 3

Functions at Group Centroids

\begin{tabular}{lll}
\hline In what type of setting do you teach? & Function 1 & Function 2 \\
\hline Elementary school & .485 & -.734 \\
\hline Middle or high school & .329 & .129 \\
\hline College or university & -.014 & -.015 \\
\hline Workplace training & -.145 & .217 \\
\hline
\end{tabular}

\section{Discussion}

\section{Path Analysis Interpretation}

Self-efficacy had a strong effect on perceived ease of use, though the two were not highly correlated. This may mean that there is some disconnect between the perceptions of the technologies asked about in the application self-efficacy portion of the survey (e.g., presentation software, email, etc.) and OER. In other words, even if someone is self confident in their use of online communication tools, this does not have a substantial impact on their level of confidence in finding and using OER. Regardless of the moderate effect, application self-efficacy positively affected attitudes about how easy OER are to use. From this, we can understand that individuals with a higher overall sense of computer application efficacy are more likely to find OER easy to use. This finding confirms the role of self-efficacy in the TAM (Davis, 1989; Lau \& Wood, 2009; \& Yi \& Hwang, 2002) as central to accepting a new technology.

Ease of use had a strong effect on perceived usefulness and was highly correlated. This indicates that OER must be considered easy to use or the perceived utility of the resource will be negatively impacted. While content may guide selection, quality in user interface design is essential in the adoption of these resources. This finding is aligned 
with the interpretation that learning object design characteristics are as important as the content they transmit; therefore technical quality should always be a consideration (Lau \& Woods, 2009). Opportunities to explore well designed and technically elegant OER in educational or training settings can improve perceptions of these resources. Further, demonstrating or embedding the application of OER in teacher education programs may improve the sense that these resources are easy to use among future teachers.

The influence of perceived ease of use and perceived usefulness to behavioral intention to use was not dramatic in either case. It may be important to analyze direct effects from these variables to actual use rather than filtering their influence through the lens of behavioral intention in the future. The concept of usefulness had a greater effect on intention to use OER. This finding is consistent with Lau and Woods' (2009) research on learning objects as well, in that perceived usefulness had a stronger effect on intention to use than perceptions on ease of use. It was anticipated that perceptions of usefulness would have a stronger effect on intention, but usefulness does come up as a major determinant in group membership in the discriminant analysis interpretation which follows.

Behavioral intention had a strong effect on whether an individual reported actual use of OER on a regular basis in their practice. This places emphasis on how an individual arrives at the intention to use these resources. This portion of the model must be observed with some caution when, as in this study, actual use is self-reported. An analysis that includes other means of collecting usage data would improve objectivity in reporting actual use. Computer log data seems like an obvious choice to meet this requirement, but may be hindered by privacy issues. While self-efficacy and outcome judgment contribute to decisions to use a resource, further exploration of how behavioral intention is influenced could provide a more complete picture of why some resources are adopted and others are not. Clements and Pawlowski examine this kind of user intent of OER in terms of types of use and trust, finding that teachers value recommendations of OER when selecting them and that trusting the integrity of an OER supports re-use (2012).

\section{Discriminant Analysis Interpretation}

The perception of usefulness of OER accounted as the strongest predictor of group separation on the first discriminant function. In general, individuals coming from K-12 environments found OER more useful than individuals working in higher education or other settings. This may mean that there are simply better resources available for this context or it may mean that there are other causes that result in a better appreciation for OER among K-12 educators. Seeking out free resources may have a relationship to the limited resources found in many school settings with out of date library collections and limited access to paid online databases. This finding connects well with Hylén's (2006) 
analysis that revealed finding quality resources to use was a major motivation to seek out OER by educators.

The second discriminant function was based on self-efficacy. Participants coming from elementary school settings had dramatically lower self-efficacy perceptions than all other groups. This could mean that OER may be more readily adopted into the curriculum of educators working with older children and adults. Educators teaching 612 grade generally reported higher application self-efficacy than their counterparts in elementary education as well as higher education. Further exploration of how to integrate OER among other computer based technologies for elementary educators in teacher education programs and professional development should be considered in order to improve the use of OER among this group.

\section{Conclusion}

The promise of easily accessible quality learning materials making their way to more educators resonates with thousands involved in formal and informal learning. While the particular educational contexts may vary widely, the quality of the design of OER is an essential component in their adoption. Users of these materials need resources that are as easy to use as they are to access. System wide design guidelines may improve the regard individuals have towards OER. This study demonstrates clearly that the perception of how easy OER are to use has a substantial influence on whether the resource is considered useful at all. Among the groups participating in this study, K-12 educators stood out as finding OER useful in their practice. This may demonstrate a need and a desire for continued growth and development of these types of resources for this particular audience. As more districts and states adopt open textbooks that are nimble enough to be remixed, there is an opportunity for educators to custom tailor their texts with OER to meet the needs of their students.

Ease of use is vital in the adoption of OER. Creators of OER will need to keep in mind their audience and usability design as they generate and index their works. If a resource is not easy to use it will not be considered useful and will likely not be used at all even if the content is excellent. Further research determining specific design aspects common to successful OER (those with high rates of use) may help authors create resources with these design criteria in mind, particularly in terms of user interface and universal design considerations.

From the preceding analysis, it appears that K-12 educators have more positive perceptions of the ease of use and usefulness of OER. Exploring group differences further will help to target instructional messages and opportunities among these educators. The findings also suggest that integrating these resources in to teacher education programs will further promote what is already considered a useful resource among this group. 


\section{References}

Adams, D., Nelson, R., \&Todd, P. (1992). Perceived usefulness, ease of use, and usage of information technology: A replication. MIS Quarterly, 16, 227- 250.

Ally, M., Cleveland-Innes, M., \& Boskic, N. (2006). Learners' use of learning objects. J ournal of Distance Education, 21(2), 44-57.

Atkins, D. E., Brown, J . S., \& Hammond, A. L. (2007). A review of the open educational resources (OER) movement: Achievements, challenges, and new opportunities. Creative common.

Bandura, A. (1977). Social learning theory. Englewood Cliffs, NJ : Prentice-Hall, Inc.

Bandura, A. (1982). Self-efficacy mechanism in human agency. American Psychologist, 37(2), 122-147.

Bandura, A. (1989). Human agency in social cognitive theory. American Psychologist, $44,1175-1184$.

Barabási, A. L. (2002). Linked: The new science of networks. Basic Books.

Compeau, D. R., Higgins, C. A., \& Huff, S. (1999). Social cognitive theory and individual reactions to computing technology: A longitudinal study. MIS Quarterly, 23(2), 145- 158.

Cook, T. D., \& Campbell, D. T. (1979). Quasi-experimentation: Design \&analysis issues for field settings. Boston: Houghton Mifflin.

Clements, K. I., \&Pawlowski, J . M. (2012). User-oriented quality for OER: understanding teachers' views on re-use, quality, and trust. J ournal of Computer Assisted Learning, 28(1), 4-14.

Creative Commons. (2013) OER policy registry. Retrieved from http:// wiki.creativecommons.org/OER_Policy_Registry

Davis, F. D. (1989). Perceived usefulness, perceived ease of use, and user acceptance of information technology. MIS Quarterly, 13(3), 318-340.

Davis, F. D., \& Venkatesh, V. (1996). A critical assessment of potential measurement biases in the technology acceptance model. International J ournal of HumanComputer Studies, 45, 19-45.

de Kunder, M. (2012). The size of the world wide web. Retrieved from http:// www.worldwidewebsize.com/. 
Florida Distance Learning Consortium. (2013). Open access textbook and OER legislation and policy. Retrieved from http://www.openaccesstextbooks.org/legislation.html

Hasson, D., \&Arnetz, B. B. (2005). Validation and findings comparing VAS vs. Likert scales for psychosocial measurements. International Electronic J ournal of Health Education, 8, 178-192.

Hendrickson, A. Massey, P., \&Cronan, T. (1993). On the test - retest reliability of perceived usefulness and perceived ease of use scales. MIS Quarterly, 17, 227230.

Hylén, J . (2006). Open educational resources: Opportunities and challenges. Proceedings of Open Education, 49-63.

Lau, S., \&Woods, P. (2009). Understanding learner acceptance of learning objects: The roles of learning object characteristics and individual differences. British J ournal of Educational Technology, 40(6), 1059-1075.

Liyanagunawardena, T. R., Adams, A. A., \&Williams, S. A. (2013). MOOCs: A systematic study of the published literature 2008-2012. International Review of Research in Open \& Distance Learning, 14(3).

Mangan, K. (2012). MOOC mania. The Chronicle of Higher Education. Retrieved from http:// chronicle.com/article/Massive-Excitement-About/ 134678/.

Moore, G. C., \& Benbasat, I. (1996). Integrating diffusion of innovations and theory of reasoned action models to predict utilization of information technology by endusers. Diffusion and adoption of information technology (pp. 132-146).

Murphy, C. A., Coover, D., \& Owen, S. V. (1989). Development and validation of the computer self-efficacy scale. Educational and Psychological Measurement, 49(4), 893- 899.

Read, M. (2008). Cultural and educational drivers of educational content. The tower and the cloud. U.S.A.: Educause.

Rogers, E. M. (1995). Diffusion of innovations. Simon and Schuster.

Segars, A., \& Grover, V. (1993). Re-examining perceived ease of use and usefulness: A confirmatory factor analysis. MIS Quarterly, 17, 517- 525.

Schmidt-J ones, C. (2012). An open educational resource supports a diversity of inquirybased learning. International Review of Research in Open \& Distance Learning, 13(1), 1-16. 
Schonfeld, R. C., \&Houseright, R. (2010). Faculty survey 2009: Key strategic insights for libraries, publishers, and societies. Creative common.

Stevens, J . P. (2012). Applied multivariate statistics for the social sciences. Routledge Academic.

Suhr, D. (2008, November). Step your way through path analysis. In Western Users of SAS Software Conference Proceedings.

United Nations Educational, Scientific and Cultural Organization. (2012). 2012 Paris OER Declaration. Retrieved from http:// www.unesco.org/ new/ fileadmin/MULTIMEDIA/HQ/CI/CI/ pdf/ Events /Paris\%20OER\%20Declaration_01.pdf

Wiley, D. (2008). Chapter 29: The learning objects literature. Handbook of research on educational communications and technology [electronic resource] (3rd ed.) New York: Lawrence Erlbaum Associates.

Wright, S. (1921). Correlation and causation. J ournal of Agricultural Research, 20(7), 557-585.

Yi, M.Y., \& Hwang, Y. (2002). Predicting the use of web-based information systems: Self-efficacy, enjoyment, learning goal orientation, and the technology acceptance model. International J ournal of Human-Computer Studies, 59, 431-449.

\section{Athabasca University $\mathbf{a}$}

(ㅇ) (1) 


\section{Investigating Perceived Barriers to the Use of Open Educational Resources in Higher Education in Tanzania}

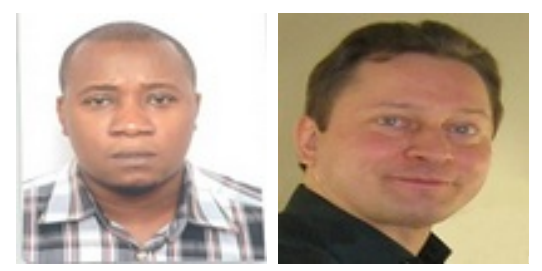

Joel S. Mtebe and Roope Raisamo

University of Tampere, Finland

\section{Abstract}

The past few years have seen increasingly rapid development and use of open educational resources (OER) in higher education institutions (HEIs) in developing countries. These resources are believed to be able to widen access, reduce the costs, and improve the quality of education. However, there exist several challenges that hinder the adoption and use of these resources. The majority of challenges mentioned in the literature do not have empirically grounded evidence and they assume Sub-Saharan countries face similar challenges. Nonetheless, despite commonalities that exist amongst these countries, there also exists considerable diversity, and they face different challenges. Accordingly, this study investigated the perceived barriers to the use of OER in 11 HEIs in Tanzania. The empirical data was generated through semi-structured interviews with a random sample of 92 instructors as well as a review of important documents. Findings revealed that lack of access to computers and the Internet, low Internet bandwidth, absence of policies, and lack of skills to create and/ or use OER are the main barriers to the use of OER in HEIs in Tanzania. Contrary to findings elsewhere in Africa, the study revealed that lack of trust in others' resources, lack of interest in creating and/or using OER, and lack of time to find suitable materials were not considered to be barriers. These findings provide a new understanding of the barriers to the use of OER in HEIs and should therefore assist those who are involved in OER implementation to find mitigating strategies that will maximize their usage.

Keywords: Open educational resources; eLearning; OER in Tanzania; OER; higher education; Sub-Saharan Africa; Tanzania 


\section{Introduction}

Tanzania like many African countries is faced with increased demand for higher education. According to O. Ezekwesili, the World Bank's VP for Africa, only 6\% of Africans participate in higher education compared to a world average of $25.5 \%$ (Kokutsi, 2011). In Tanzania, only $1.48 \%$ of Tanzanians participate in higher education (Lindow, 2011, p. 13). This percentage of student enrolment is expected to increase due to the recent expansion of secondary education under the Secondary Education Development Program (SEDP) (2004-2007). The SEDP has increased the enrolments in secondary education from 432,599 in 2000 to 1,020,510 in 2006, reaching 34\% of the school-going population in 2011 (URT, 2012). Consequently, the demand for higher education has increased massively.

Naturally, higher education institutions (HEIs) have been adopting various information and communication technologies (ICT) in a bid to meet this increased demand for higher education and to improve the quality of education. As of 2011, 80.2\% of institutions were using various educational systems mostly learning management systems (LMS) (Munguatosha, Muyinda, \& Lubega, 2011). Additionally, several institutions have been installing complex ICT infrastructure, video conferencing facilities, and other related technologies (Lwoga, 2012).

Despite these initiatives, institutions will not be able to widen access to and improve the quality of education without taking into consideration the quality of learning resources. This is because students rely on learning resources as their major source of information during the learning process (Keats, 2003). However, most institutions have continued with print-dependent educational practices where learning resources are in the form of paper textbooks and course handouts. Most of these resources are expensive, lack contextual relevance, and are difficult to share with a wider group of students (Keats, 2003; Lwoga, 2012). As the cost of textbooks and other printed resources from commercial companies continues to rise, institutions tend to use outdated books, and old or poorly designed learning resources (Keats, 2003; Ngugi, 2011).

The recent emergence of open educational resources (OER) can immensely contribute towards providing quality learning resources in HEIs in Tanzania. These are freely and openly available digitized resources that can be adapted, modified, and re-used for teaching, learning, and research (OECD, 2007). To date, thousands of resources across all disciplines have been developed and shared in the public domain through the support of the William and Flora Hewlett Foundation, the Commonwealth of Learning (COL), United Nations Educational, Scientific and Cultural Organization (UNESCO), and other international agencies. They include full courses, course modules, video of lectures, homework assignments, simulations, and electronic textbooks.

As of 2007, over 3,000 learning resources from over 300 universities were available (OECD, 2007). These include 1,900 courses from the Massachusetts Institute of Technology (MIT), 2,500 courses from over 200 universities under the OCW 
Consortium, and more than 1,500 courses under the Japanese OCW Consortium (Butcher, 2010). Other resources include 750 from China Open Resources for Education and more than 22,500 resources from Multimedia Educational Resources for Learning and Teaching Online (MERLOT) (Yuan, Mac, \& Kraan, 2008).

Moreover, there are African-based initiatives that have shared thousands of resources developed by African academics. For instance, OER Africa in partnership with the University of Michigan has shared more than 150 resources related to health education (Lesko, 2013). Similarly, COL and the William and Flora Hewlett Foundation have developed and shared 20 self-study selected subjects at the secondary-school level (Wright \& Reju, 2012). Other examples of OER African based initiatives include Teacher Education in Sub-Saharan Africa (TESSA) and University of Cape Town (UCT) Open Content.

The appropriate use of OER in higher education can widen access, reduce the costs, and improve the quality of education in Sub-Saharan countries. The quality of education is improved when instructors and learners can easily access resources that they were unable to access due to cost and/ or copyright laws (Wright \& Reju, 2012). Wright and Reju added that OER could benefit instructors who do not have teaching experience and knowledge of the subject matter that they are teaching. Additionally, instructors can use these resources to improve the quality of existing courses or develop new courses by adapting existing courses (Butcher, 2011).

The OER can also complement existing blended learning courses offered by several institutions in Tanzania. By doing so, institutions will be able to widen access to education and reduce social inequalities (Butcher, 2011; Freitas, 2012). Furthermore, HEIs can attract more students, increase institutional reputation, and attract research funding and new partnerships through participating in OER initiatives (Butcher, 2011; Hylén, 2006). For example, 35\% of new students who applied for various courses at MIT were influenced by free MIT courses they accessed previously (Caswell, Henson, J ensen, \&Wiley, 2008; MIT, 2006).

Despite the potential benefits offered by OER, the use of these resources in many HEIs in Sub-Saharan countries is very low (Freitas, 2012; Hoosen, 2012; Unwin et al., 2010). MIT OCW statistics show that only $2 \%$ of users have come from Sub-Saharan countries since 2004 (MIT, 2013). Likewise, in the past two years, almost 2 million users who accessed OER Africa resources were from South America, North America, Europe, and India (Richards, 2013).

According to Hoosen (2012), the majority of institutions in Tanzania are not active in OER initiatives. For example, in a study conducted by Samzugi and Mwinyimbegu (2013) at the Open University of Tanzania (OUT), only $21.8 \%$ of 150 respondents indicated that they had heard about OER. Likewise, none of the departments reported use of MIT resources despite the fact that the University of Dar es Salaam signed an 
agreement with MIT a few years ago. Clearly, the perceived benefits of OER cannot be realized if academics in higher education do not use them.

Therefore, it is important to investigate underlying inhibiting factors that prevent instructors from using OER in order to develop strategies that will maximize their usage. So far, however, there has been little research around OER use in Africa in general (Percy \& Belle, 2012). The majority of studies in the literature have focused on development and publication of OER repositories as well as on the integration of policies in various institutions (Andrad et al., 2011). A small number of studies have discussed barriers to the use of OER without empirically grounded evidence and they assume all Sub-Saharan countries are facing similar challenges (Hatakka, 2009; Hodgkinson-Williams, 2010).

Recently, Mtebe and Raisamo (2014) conducted a study to identify challenges that hinder instructors to adopt and use OER in higher education in Tanzania. They found that performance expectancy, facilitating conditions, and social influence did not have a statistically significant effect on instructors' intention to adopt and use OER. Only effort expectancy had a significant positive effect. The research was based on quantitative data obtained from 104 instructors in 5 HEIs and they applied the unified theory of acceptance and use of technology (UTAUT) model.

This study provides further understanding of the perceived barriers to the use of OER based on qualitative data from 11 HEIs in Tanzania. The surveyed institutions were: St J ohn University (SJ U), University of Dodoma (UDOM), Zanzibar University (ZU), State University of Zanzibar (SUZA), Dar es Salaam University College of Education (DUCE), and Tumaini University Makumira (TUM). Other institutions were: Nelson Mandela African Institution of Science and Technology (NM-AIST), Open University of Tanzania (OUT), The Institute of Accountancy Arusha (IAA), University of Dar es Salaam (UDSM), and the Institute of Finance Management (IFM).

\section{Literature Review}

A considerable amount of literature has been published to explain factors that hinder the use of OER in Sub-Saharan countries. Generally, studies have consistently described the shortage of computers and Internet and low Internet bandwidth as the main contextual barriers to the use of OER in Africa (Hatakka, 2009; Hodgkinson-Williams, 2010; Hoosen, 2012; Larson \& Murray, 2008; Wilson-Strydom, 2009). Other main barriers cited include the lack of understanding regarding copyright and intellectual property rights (IPR) issues (Hoosen, 2012; Hylén, 2006; Yuan et al., 2008), and lack of policies to encourage creation and sharing of OER (Yuan et al., 2008).

Additionally, some studies have focused on social factors (Hodgkinson-Williams, 2010; Hylén, 2006; Larson \& Murray, 2008; OECD, 2007; Yuan et al., 2008). These factors 
include lack of skills to find and use OER, lack of time to find and/ or prepare OER, and unawareness of OER existence. Other social factors include the lack of trust on the quality of OER and inability to find appropriate OER relevant to users in Africa. Table 1 summarizes some of these perceived barriers to the use of OER in Africa.

Table 1

Perceived Barriers to Use of OER in Sub-Saharan Africa

\begin{tabular}{|c|c|c|}
\hline Category & Description & Source \\
\hline Technology & $\begin{array}{ll}\text { - } & \text { Lack of access to computers and } \\
\text { the Internet } \\
\text { - } \quad \text { Low internet bandwidth } \\
\text { - } \quad \text { Uninterrupted power }\end{array}$ & $\begin{array}{l}\text { (Hatakka, 2009; } \\
\text { Hodgkinson-Williams, } \\
\text { 2010; Hoosen, 2012; } \\
\text { Larson \& Murray, 2008; } \\
\text { Wilson-Strydom, 2009; } \\
\text { Wright \& Reju, 2012) }\end{array}$ \\
\hline Legal & $\begin{array}{l}\text { - Lack of awareness amongst } \\
\text { instructors regarding copyright } \\
\text { and IPR issues }\end{array}$ & $\begin{array}{l}\text { (Hoosen, 2012; Hylén, } \\
\text { 2006; Yuan et al., 2008) }\end{array}$ \\
\hline $\begin{array}{l}\text { Institutional } \\
\text { and national } \\
\text { policies }\end{array}$ & $\begin{array}{l}\text { Lack of policies at } \\
\text { institutional/national/regional } \\
\text { level to support the creation or use } \\
\text { of OER }\end{array}$ & (Yuan et al., 2008) \\
\hline Relevance & $\begin{array}{l}\text { - Lack of resources appropriate to } \\
\text { local context }\end{array}$ & (OECD, 2007) \\
\hline Social & $\begin{array}{l}\text { - } \text { Lack of skills to select appropriate } \\
\text { OER and re-use or re-mix it } \\
\text { - } \quad \text { Unwillingness to use resources } \\
\text { produced by someone else } \\
\text { - } \quad \text { Do not trust the quality of OER } \\
\text { - } \quad \text { Lack of time devoted to produce } \\
\text { shareable materials } \\
\text { - } \quad \text { Lack of incentives or reward } \\
\text { systems for instructors } \\
\end{array}$ & $\begin{array}{l}\text { (Hodgkinson-Williams, } \\
\text { 2010; Hylén, 2006; Larson } \\
\text { \& Murray, 2008; OECD, } \\
\text { 2007; Yuan et al., 2008) }\end{array}$ \\
\hline
\end{tabular}

Most barriers to the use of OER cited in several studies (as shown in Table 1) are not based on empirically grounded evidence (Hatakka, 2009; Hodgkinson-Williams, 2010). A small number of studies with empirical evidence shows that these challenges are not uniform in all Sub-Saharan countries. For example, in a study conducted in Kenya, Uganda, and South Africa with 19 participants from TESSA found that low technology levels was not a barrier to the use of OER (Ngimwaa \& Wilsona, 2012). The real challenges were socio-economic, cultural, institutional, and national issues.

Another study conducted amongst 24 respondents from 24 countries in Africa found connectivity and IPR issues were the main obstacles to the use of OER in Africa (Hoosen, 2012). These findings were somewhat consistent with those conducted by Percy and Belle (2012) with 68 respondents across Africa. They found technology and locating relevant OER were the main barriers. Similarly, in a study conducted with 200 
respondents at OUT, Samzugi and Mwinyimbegu (2013) found that the barriers were a lack of skills to locate relevant resources and unawareness of the existence of OER.

The most recent study to identify challenges to the use of OER was conducted by Lesko (2013) in 17 HEIs in South Africa using a sample of 120 respondents. The author found that the lack of knowledge related to OER usage, lack of awareness of copyright and IPR issues, infrastructural challenges, and lack of knowledge about the existence of OER were the main barriers. The empirical findings from these few studies indicate that users from different Sub-Saharan countries face different challenges to the use of OER. This claim is supported by Bateman (2008) who pointed out that, despite commonalities that exist amongst these countries, there also exists considerable diversity, and they face different challenges.

Therefore, there is a need to empirically investigate factors that hinder instructors from using OER in HEIs in Tanzania. This will help those who are involved in OER implementation to find relevant corrective measures to promote and maximize their level of usage. This study comes at a time when HEIs have been adopting various ICT to complement existing open and distance learning (ODL) courses to widen access to needy students. The use of OER will definitely help institutions to provide quality learning resources to support these initiatives.

\section{Research Methodology}

The study used semi-structured interviews and documentary reviews as data collection methods. The interview process involved a series of open-ended questions to investigate how instructors were using Internet affordances to prepare learning resources, as well as to elicit instructors' views on the use of OER in teaching. According to Bryman (2008), semi-structured interviews enable the respondents to project their own ways of defining the world, permit a sequence of discussions, and enable the participants to raise issues that might not have been included in a pre-devised schedule.

The surveyed HEIs were selected on a convenience basis due to time and budgetary constraints. However, there was an adequate distribution of institutions across the country. Once institutions were identified, instructors were selected at random from various schools and faculties within a given institution and the selection was based on willingness to participate. Out of 163 instructors who were contacted, 98 instructors agreed to be interviewed. Due to unavailability of some instructors, we managed to interview 92 in total. During the interview process, some important institutional documents were reviewed in order to investigate the availability of enabling conditions that support the use of OER: bandwidth, policies, and use of eLearning systems.

Finally, from their personal experience instructors were asked to evaluate the relevance of 10 selected barriers to the use of OER in HEIs in Tanzania. The barriers included: 
access to computers and the Internet, Internet bandwidth, policies at institutional level to support the creation and/ or use of OER, lack of time to find suitable materials, and lack of skills to create and/or use OER. Other barriers that were selected included concerns over copyright and IPR issues, difficulties in finding suitable and relevant OER, quality of OER, lack of trust in others' resources, and lack of interest to create and/ or use OER.

Instructors were asked to rate these barriers using a 5-point Likert scale ranging from strongly agree to strongly disagree. These factors were extracted from the literature reviewed on factors that hinder the use of OER in HEIs in Africa. The study adapted factors that were relevant to the context of higher education in Tanzania. The selection of a face-to-face quantitative data collection method was based on the fact that the response rate for online data collection is normally very low and we had limited time.The research was undertaken between October 2013 and J anuary 2014.

\section{Research Findings}

\section{Demography}

Most respondents were male, 63.04\%; 36.96\% were female. There was almost an equal distribution of respondents across institutions with the exception of DUCE and UDSM which had more respondents. There were 14 respondents (15.22\%) from UDSM and 12 respondents (13.04\%) from DUCE. The number of respondents per institution is shown in Table 2.

Table 2

Respondents' Demographic Profile

\begin{tabular}{|r|r|r|r|}
\hline Respondents profile & Classification & Frequency & Percentage \\
\hline Gender & Male & 58 & 63.04 \\
\cline { 2 - 4 } & Female & 34 & 36.96 \\
\hline Institution & SJU & 8 & 8.70 \\
\cline { 2 - 4 } & UDOM & 8 & 8.70 \\
\cline { 2 - 4 } & ZU & 7 & 7.61 \\
\cline { 2 - 4 } & SUZA & 8 & 8.70 \\
\cline { 2 - 4 } & DUCE & 12 & 13.04 \\
\cline { 2 - 4 } & TUM & 7 & 7.61 \\
\cline { 2 - 4 } & NM-AIST & 7 & 7.61 \\
\cline { 2 - 4 } & OUT & 7 & 7.61 \\
\cline { 2 - 4 } & IAA & 8 & 8.70 \\
\cline { 2 - 4 } & UDSM & 14 & 15.22 \\
\hline
\end{tabular}




\section{Usage of Internet Services to Prepare Learning Resources}

The study assessed how instructors use Internet services to prepare and share learning resources.

\section{Use of the Internet to search for course notes.}

The study found that the majority of instructors use the Internet to search for course notes with $55 \%$ of respondents using it several times per week, and 33\% of respondents using it every day. Nonetheless, 33\% of respondents did not include web-based photos, audio, or videos in their courses, while $35 \%$ of respondents indicated that they did so several times per week.

\section{Use of social media networks.}

Only a small number of respondents (18\%) indicated that they never used social networks while $8 \%$ of respondents used it once per month. Clearly, the majority of instructors used social media networks frequently for social activities with $37 \%$ of respondents using them daily, while $27 \%$ of respondents used them several times per week.

\section{Awareness of OER.}

More than two-thirds of respondents (73\%) were aware of the OER movement while $27 \%$ of instructors were not aware of it. However, the majority of participants had rarely or never used OER to enhance their courses.

\section{The use of OER.}

The study found that $79 \%$ of respondents had never included OER in their courses, while $21 \%$ of respondents used OER at some stage during their preparation of learning resources. Those instructors who used OER during course preparation were asked to mention at least one OER repository they used. Some of the OER repositories mentioned are: Directory of Open Access Journals (DOAJ), MIT, Khan Academy, OpenCourseWare Consortium, and Google Scholar. They were further asked to explain why they included OER in their courses. Here are some of their responses.

Yes. It helps me to enrich my teaching materials by reading materials from different authors and publications.

I have used some of them in notes and test questions i.e. using the questions provided in the material to give to my students because they are ready made and have answers which make it easy for me to mark. 
Those who said no were asked to explain why they do not use OER in preparing their teaching resources. Some of their comments were:

No, due to lack of proper information on how to search relevant OER.

Yes! OER usage is good but most of us are not well educated on this issue and therefore I suggest those who are literate on this aspect to organize seminars and/trainings for lecturers to attend and be equipped with knowledge and skills on the use of OER.

OER is still a new jargon in HEIs in Tanzania. I believe instructors do not use it if for any other reason is because they simply don't know if they exist, and how to use them. I believe awareness training will build their capacity and they will use them, even with low bandwidth challenge.

\section{Awareness of Creative Commons licenses.}

The study found that the majority of instructors (83\%) was not aware of Creative Commons licenses. However, $17 \%$ of instructors indicated that they had heard about these licenses before.

\section{Enabling Conditions for OER Adoption and Use in Higher Education}

Through document review, the study investigated the availability of enabling conditions for the smooth adoption and use of OER in higher education. For each surveyed institution, the following factors were assessed: Internet speed, availability of ICT policies and/or eLearning policies, and use of eLearning systems for teaching and learning.

\section{Internet bandwidth.}

The study found that the Internet is generally good in most of the surveyed institutions with the exception of SJ U, IAA, and TUM. UDSM and DUCE had the highest bandwidth (155mbps) because they were connected to the SEACOM marine cable. Table 3 shows Internet bandwidth in the surveyed institutions. 
Table 3

Internet Bandwidth in Surveyed Institutions

\begin{tabular}{|l|l|}
\hline Institution & Bandwidth \\
\hline UDOM & $20 \mathrm{mbps}$ \\
\hline NM-AIST & $20 \mathrm{mbps}$ \\
\hline TUM & $7 \mathrm{mbps}$ \\
\hline IAA & $7 \mathrm{mbps}$ \\
\hline SJU & $6 \mathrm{mbps}$ \\
\hline DUCE & $155 \mathrm{mbps}$ \\
\hline UDSM & $155 \mathrm{mbps}$ \\
\hline ZU & $10 \mathrm{mbps}$ \\
\hline SUZA & $20 \mathrm{mbps}$ \\
\hline OUT & $12 \mathrm{mbps}$ \\
\hline IFM & $12 \mathrm{mbps}$ \\
\hline
\end{tabular}

\section{Availability of ICT and/ or eLearning policy.}

The study found that all of the surveyed institutions had ICT policies in place. The results showed that $54.5 \%$ of institutions had both ICT policy and eLearning policy in place, while $45.5 \%$ of institutions did not have eLearning policies. Nonetheless, interviewees pointed out that most of these policies were not operational. For example, one respondent from one institution said: "..ICT policy and eLearning policy exist only as documents (are in documentation) and they are not implemented."

\section{The use of learning management systems.}

It was revealed that almost half of the surveyed institutions (54.5\%) were using Moodle LMS while $45.5 \%$ of them were not using any LMS. With the exception of UDSM, SJ U, and SUZA, the number of active users in the systems was very low. For instance, there were 103 users at UDOM, 81 users at OUT, and 49 users at IFM.

\section{Perceived Barriers to the Use of Open Educational Resources}

\section{Lack of access to computers and the Internet.}

Sixty-eight percent of respondents indicated that lack of access to computers and the Internet was a barrier to the use of OER. Further evidence was obtained from interviews as shown below:

...lack of facilities and equipment like computers, intranet and reliable Internet connections

...not enough facilities (computer and Internet connections) to allow them use OER 
...sometimes accessibility and availability of Internet connection is problematic to many HEIs

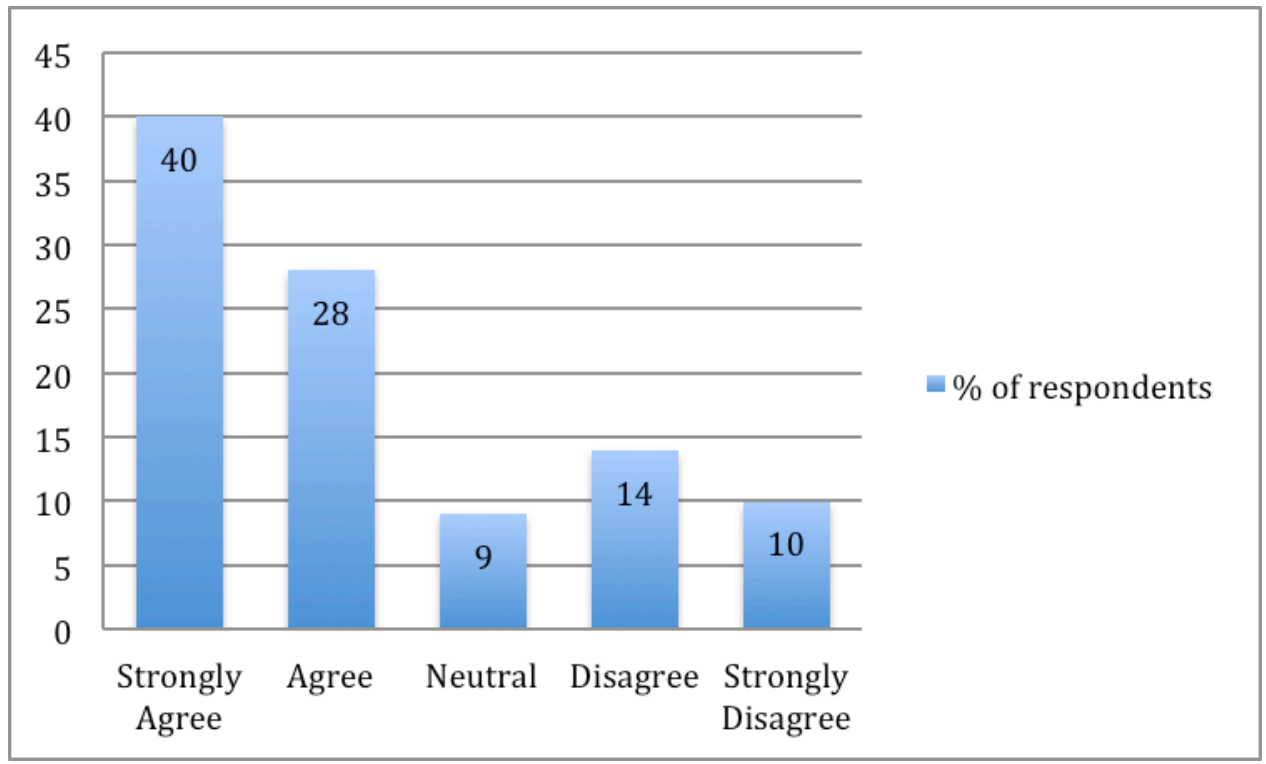

Figure 1. Lack of access to computers and the Internet.

\section{Low Internet bandwidth.}

The study found $73 \%$ of respondents rated low Internet bandwidth as a barrier to the use of OER. Fifteen percent of respondents were neutral while a small number of respondents (10\%) indicated that low Internet bandwidth was not an inhibiting factor (See Figure 2).

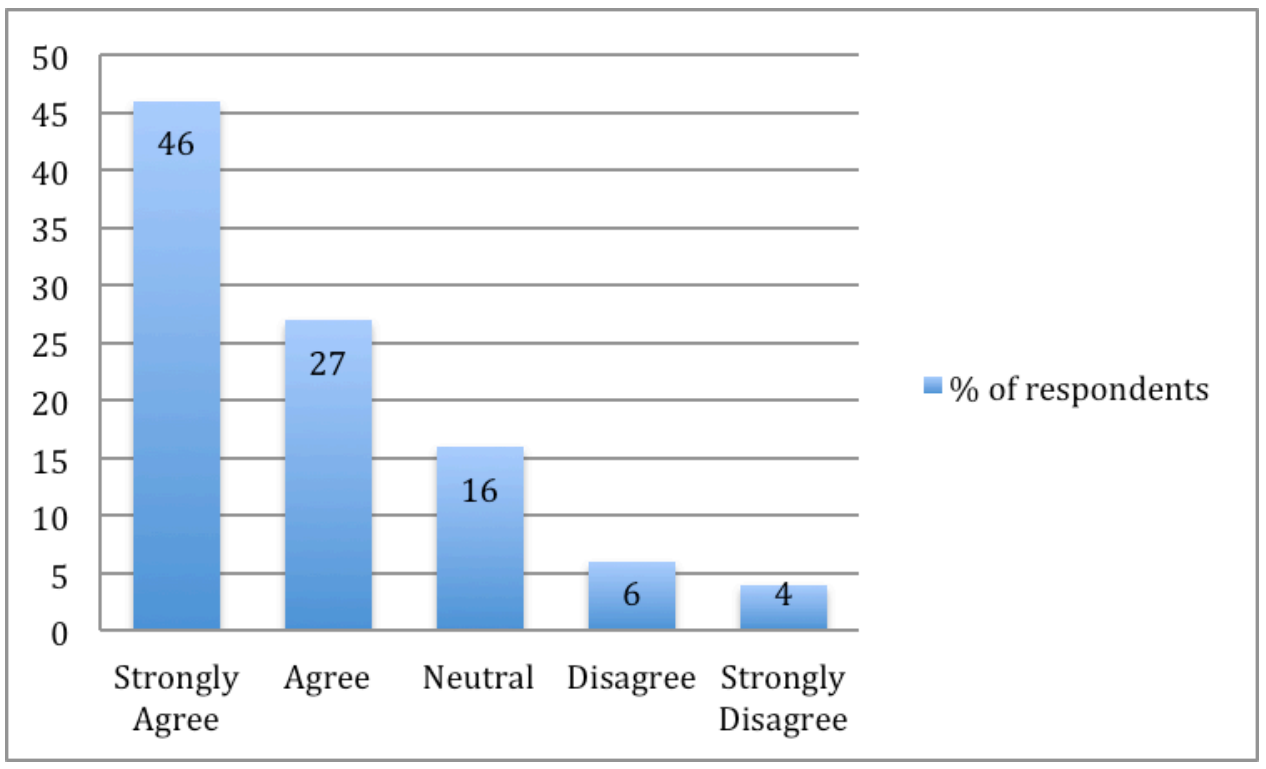

Figure 1. Low Internet bandwidth. 
In addition, the findings were supported by some comments extracted from interviews as shown below:

One of the drawbacks is reliable Internet connection and easy accessibility

...unreliable power and slow Internet connection

... but also unstable Internet connection problem contributes in preventing lecturers from using OER.

...may be due to poor Internet connection speed, and regular cut of electricity that interfere much their timetables

\section{Lack of policies at institutional level.}

A small number of instructors (19\%) said the lack of policies at institutional level was not a hindrance factor to the use of OER. However, the majority of instructors (60\%) rated lack of relevant policies as a hindrance factor (Figure 3).

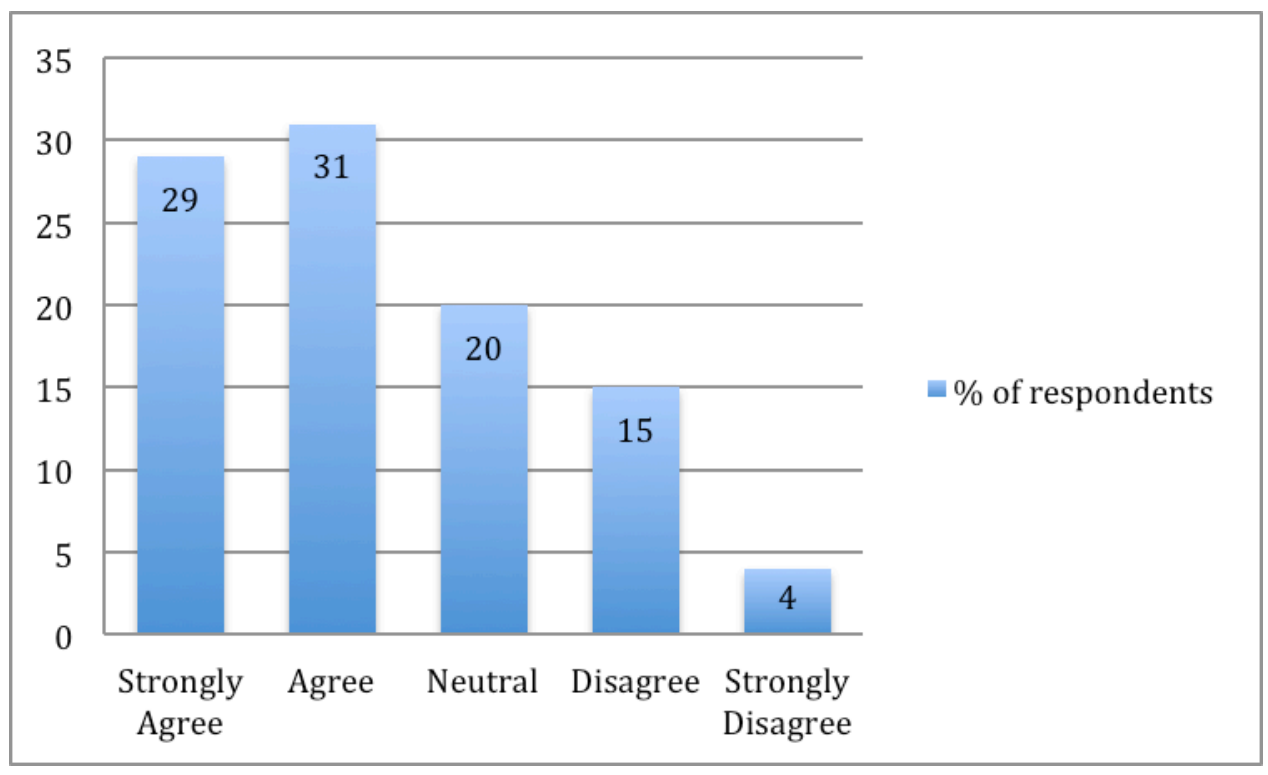

Figure 2. Lack of policies at institutional level.

\section{Lack of time to find suitable materials.}

The study revealed that the majority of respondents (55\%) felt that the lack of time to find suitable materials was not a hindrance factor. Twenty-two percent of respondents who were undecided while $23 \%$ of respondents indicated lack of time to find suitable materials was a barrier. Figure 4 indicates the distribution of responses on this factor. 


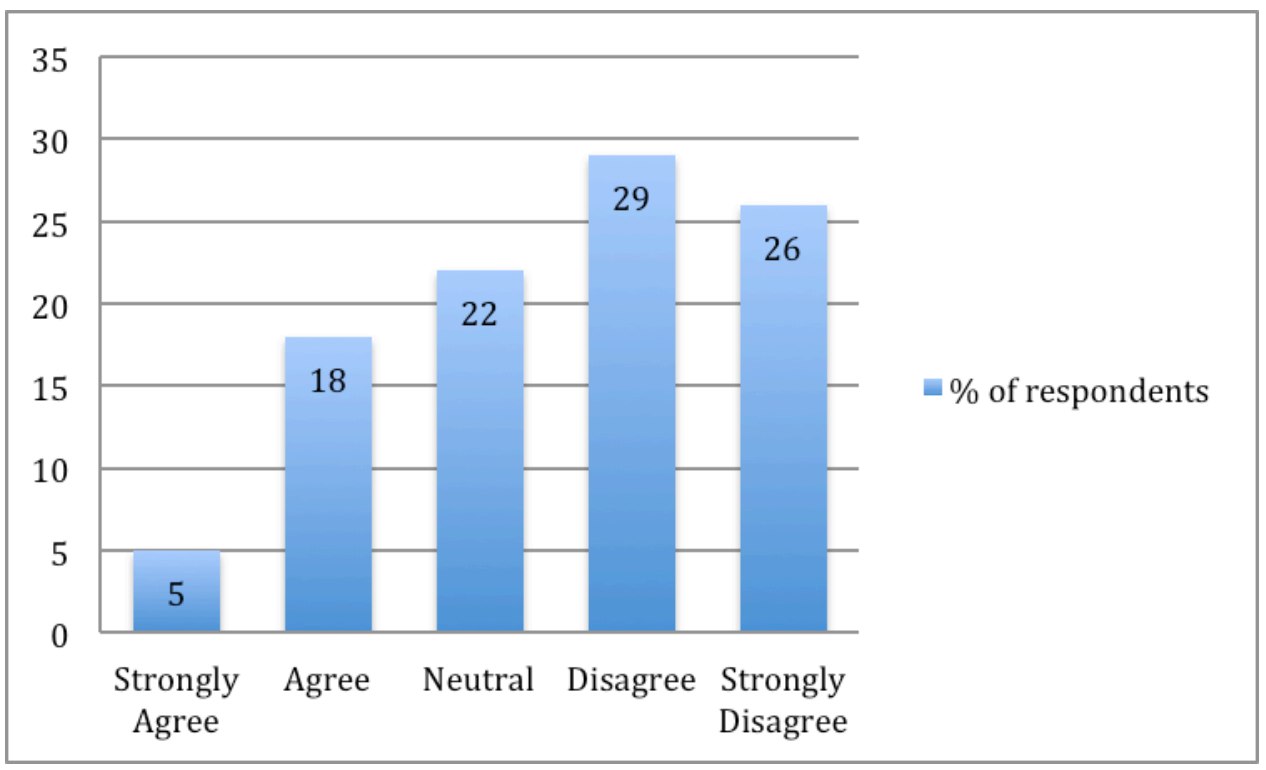

Figure 3. Lack of time to find suitable materials.

We were interested to find more on why lack of time to find learning resources via OER was a barrier. Here were some of the comments from respondents:

...the amount of time spent searching for relevant material on the Internet is a barrier, you need to spend like 4 hrs per day just to search resources and remember we have other activities as well to do.

...the truth is, for many experienced Lecturers, there is very little time to prepare teaching notes, or even lessons because they have been teaching the same thing for a long time and they feel they know everything and that their lessons are complete and are of international standard

\section{Lack of skills to create or use OER.}

The study found that $63 \%$ of respondents said the lack of skills to create and/or use OER was a barrier to the use of OER. Only a small number of respondents (20\%) indicated that lack of skills to create and/ or use OER was not a barrier. However, $16 \%$ of instructors were neutral (Figure 5). 


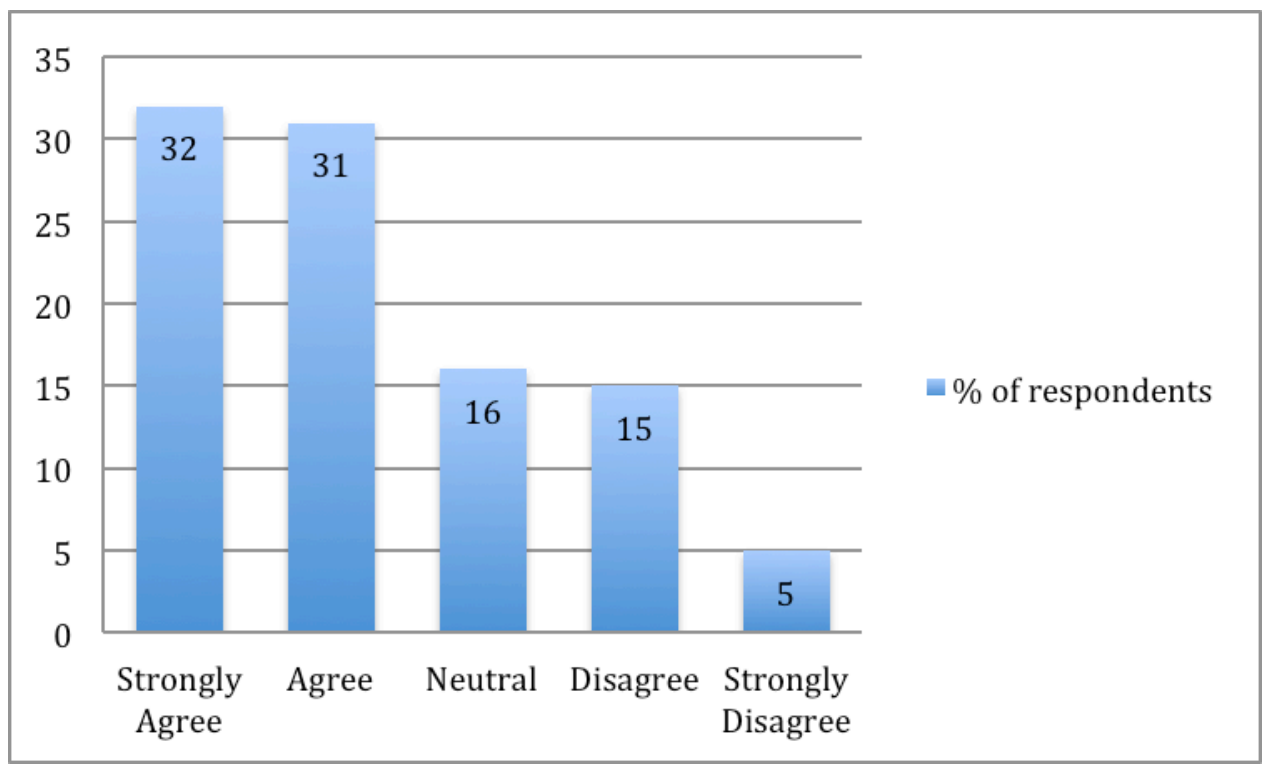

Figure 4. Lack the skills to create and/ or use OER.

From the interviews, many instructors described lack of skills to find OER as a barrier. Here are some of the comments:

...most of lecturers are unaware of OERs and even if some have glimpse of it lack knowledge on how to access them

.. lack of know-how and equipment, also steady and fast Internet connection. So they prefer to use other means, but once the former exist I am sure many will use OER

\section{Concerns over copyright and IPR issues.}

Nearly half of respondents (48\%) pointed out that concerns about copyright and IPR issues was a barrier to the use of OER. Nevertheless, $25 \%$ of respondents indicated that concerns about copyright and IPR issues was not a hindrance factor. Twenty-seven percent of respondents were undecided (See Figure 6). 


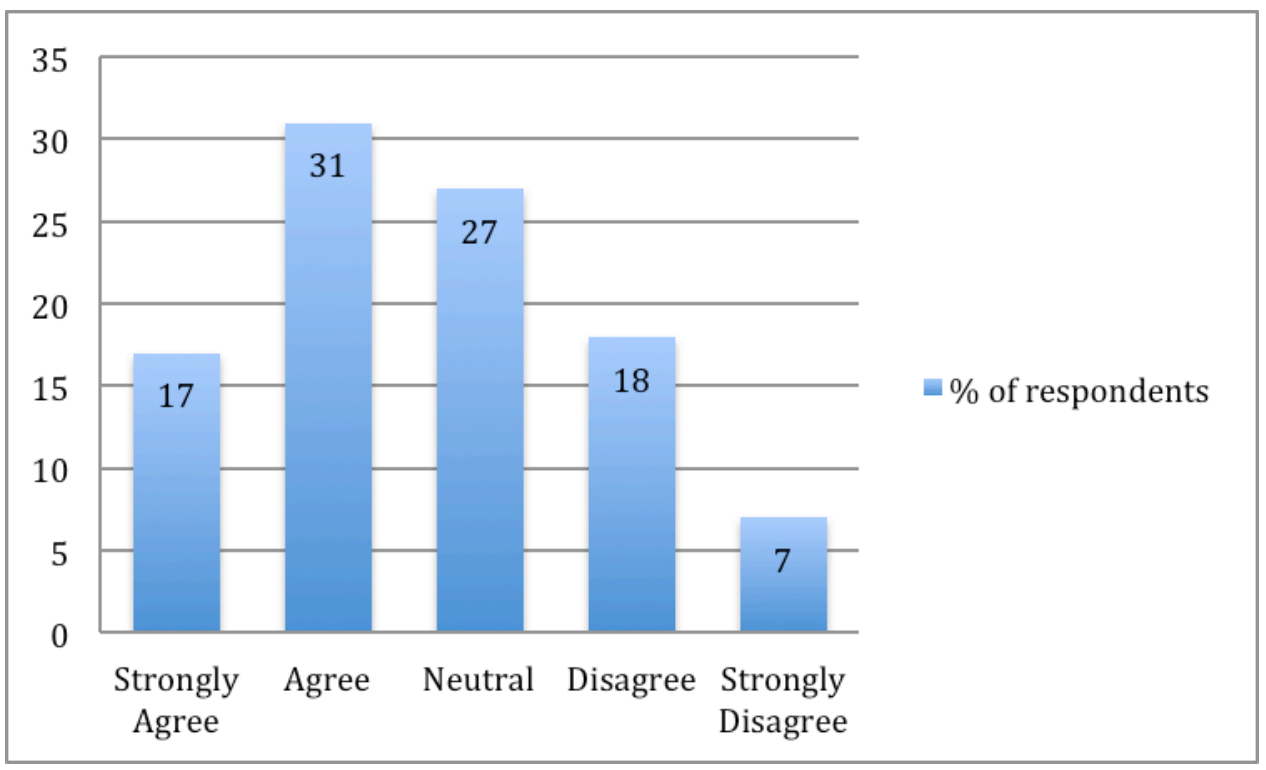

Figure 5. Concerns over copyright and IPR issues.

The comments from interviews showed that respondents were worried about sharing their resources due to unawareness of copyright issues. Here are some of the comments:

... afraid of plagiarism. Some lecturers do not understand the concept very well, most of what they write is copied from the Internet or books, therefore there is a fear that if they let the material be free, they can be sued for plagiarism

...instructors lack knowledge on the existence of OER and how to use OER but also fear to share their materials with fear of copyright issues.

\section{Challenge to find suitable and relevant OER.}

The study found that $43 \%$ said difficulties in finding relevant OER was a barrier.. However, $26 \%$ of respondents were neutral on whether the challenge of finding relevant OER was a hindrance factor or not (See Figure 7). 


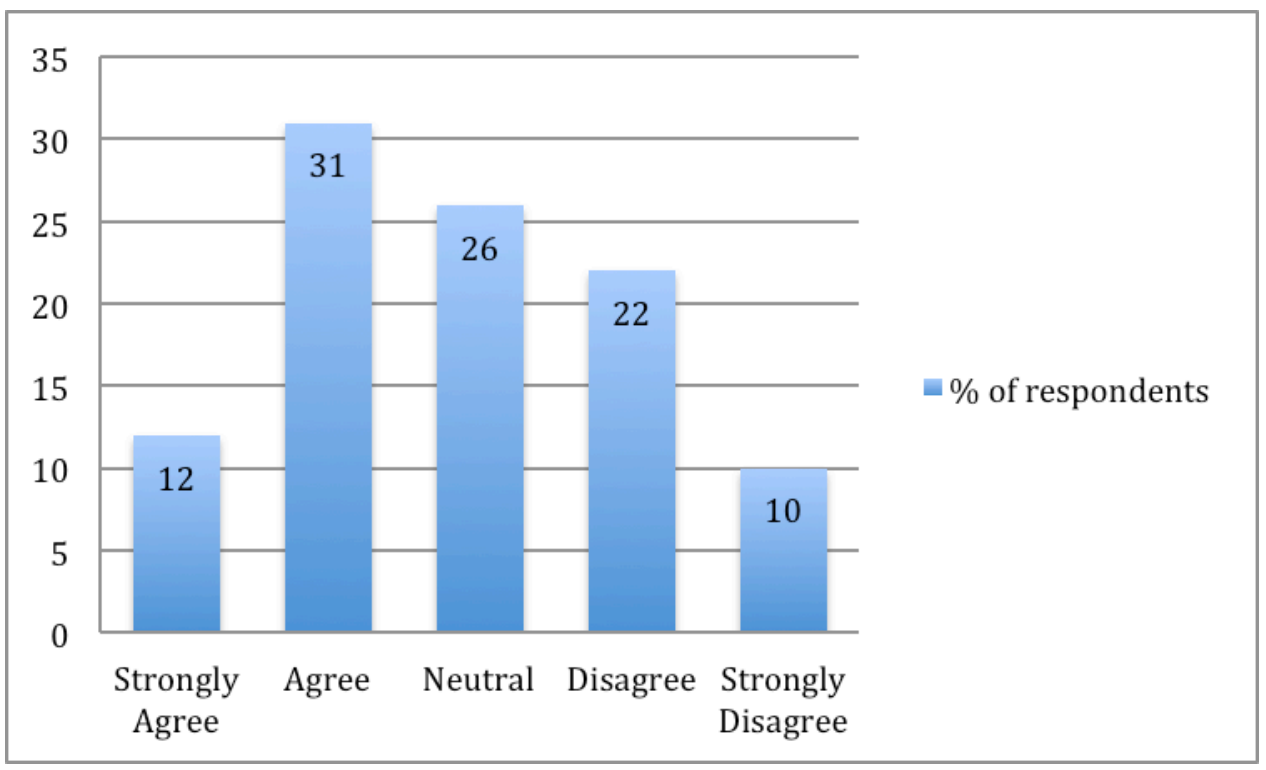

Figure 6. Suitable and relevant OER are difficult to find.

\section{Quality of OER}

Instructors were almost equally divided on whether quality of OER was a barrier to the use of OER. Thirty-five percent of respondents felt that quality of OER was a barrier, $32 \%$ of respondents were neutral, and $30 \%$ of respondents rated it as a barrier. The distribution of responses is shown in Figure 8.

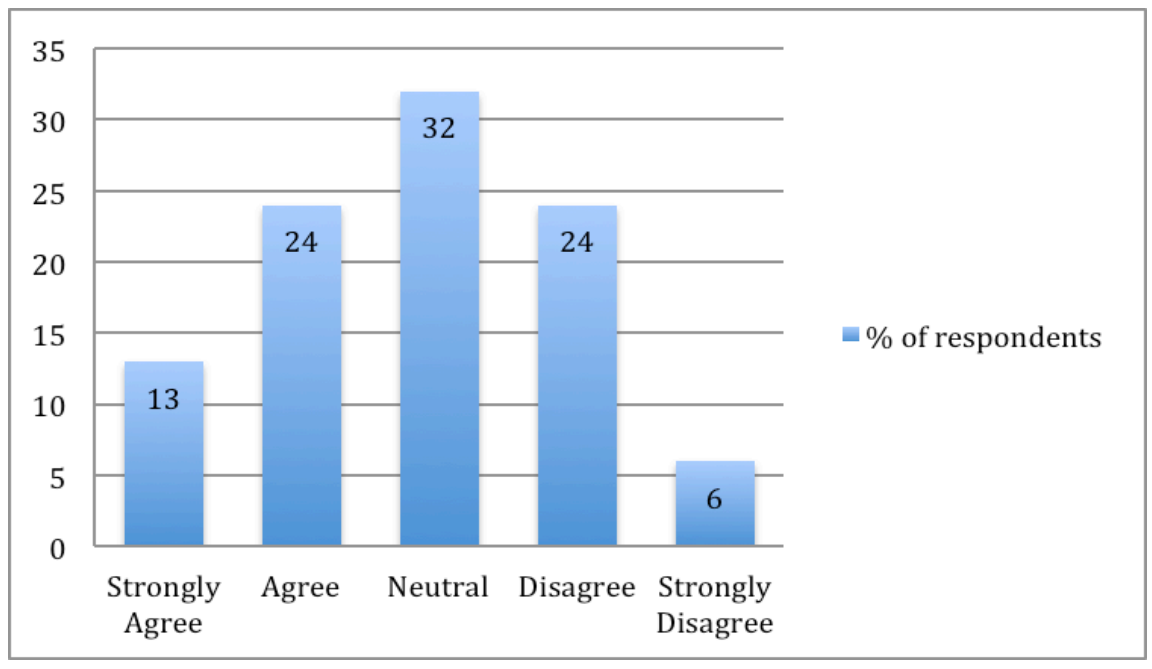

Figure 7. Quality of OER. 


\section{No trust in others' resources.}

The study revealed that many of the respondents (43\%) said the lack of trust in others' resources was not a barrier to the use of OER. Nonetheless, nearly one-third (27\%) of respondents were undecided, while $31 \%$ of respondents suggested that no trust in others' resources was a barrier (Figure 9).

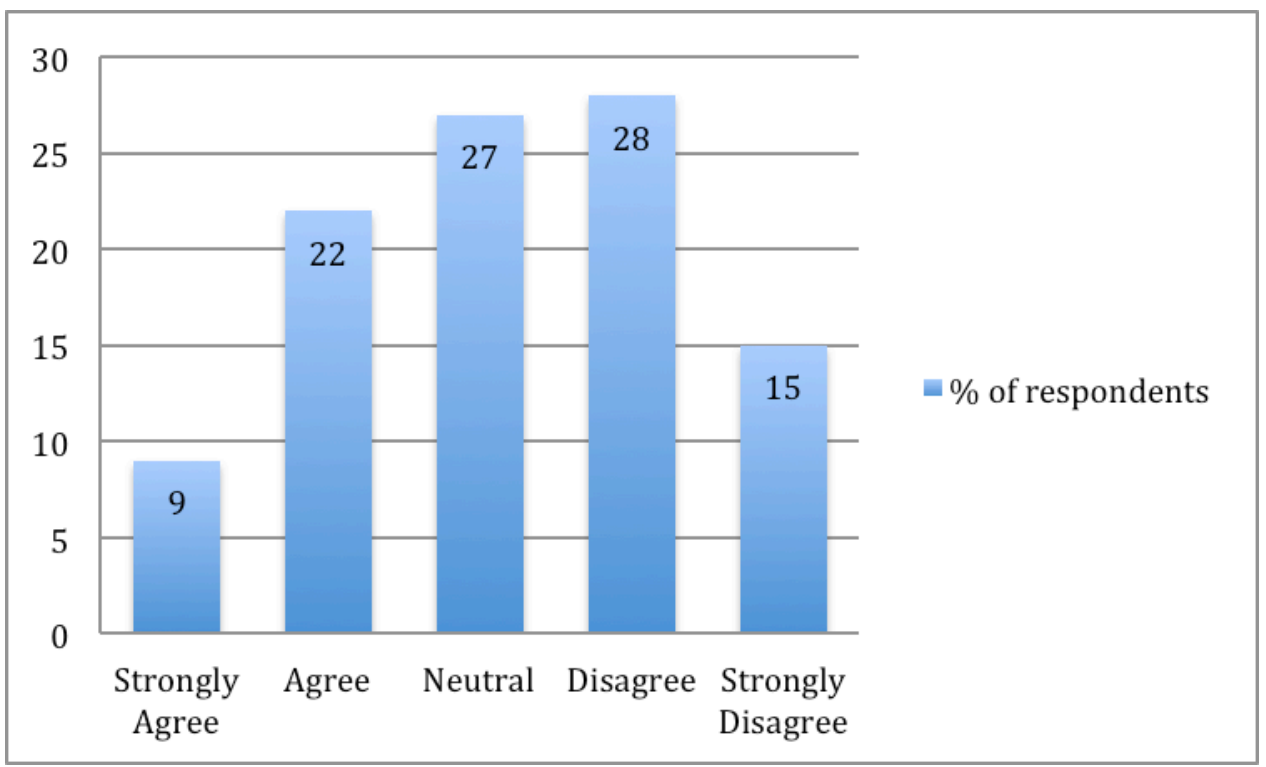

Figure 8. No trust in others' resources.

\section{Lack of interest in creating and/ or using OER.}

The study revealed that approximately half of the respondents (45\%) said the lack of interest to create and/or use OER was not a barrier to the use of OER. On the other hand, $39 \%$ of respondents rated it as a barrier, while a minority of respondents (14\%) was undecided (See Figure 10). 


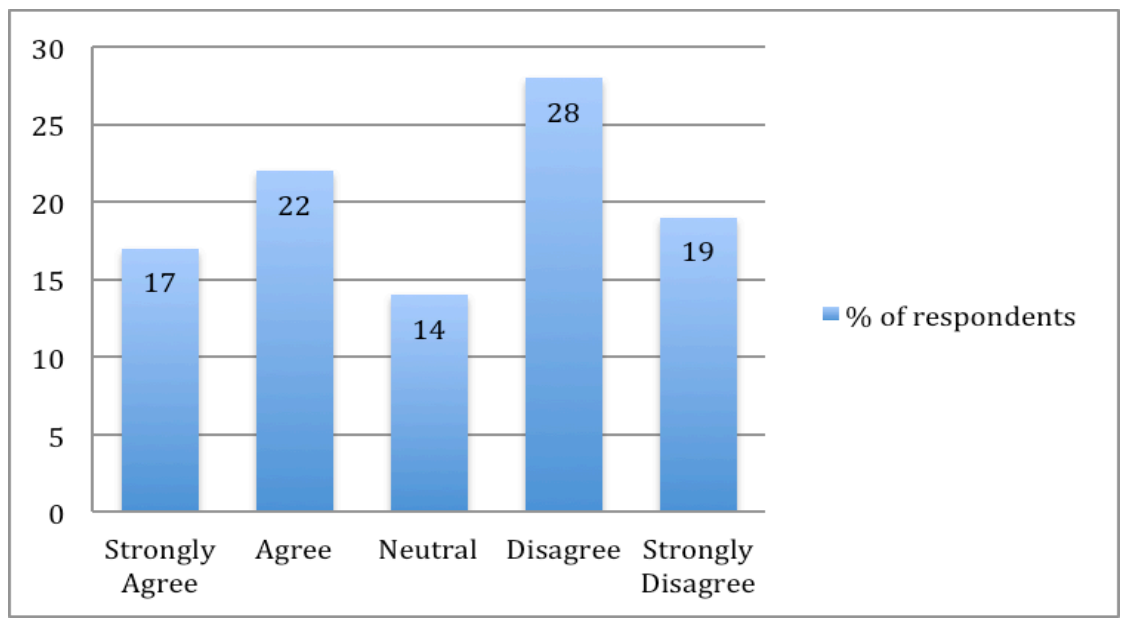

Figure 9. Lack of interest in creating and/ or using OER.

\section{Discussion}

This study aimed to investigate the barriers to the use of OER in HEIs in Tanzania. The main findings are that lack of access to computers and the Internet, low Internet bandwidth, lack of policies, and lack of skills to create and/ or use OER were considered as important inhibiting factors to use OER in HEIs in Tanzania.

The findings of the current study are consistent with those of Lwoga (2012), Samzugi and Mwinyimbegu (2013), and Tedre, Ngumbuke, and Kemppainen (2010) who found that low Internet bandwidth was a major obstacle to the use of various eLearning solutions in higher education in Tanzania. This study found that in the majority of surveyed institutions the Internet speed ranged from $7 \mathrm{mbps}$ to $20 \mathrm{mbps}$ with the exception of UDSM and DUCE. UDSM and DUCE had Internet speed of 155mbps as they are already connected to the SEACOM marine fibre cable.

Similarly, the cost of Internet connectivity in Tanzania is still high (Lwoga, 2012; Tedre et al., 2010). For example, one university surveyed by Lwoga (2012) was paying 104 million TShs per year, while another institution surveyed by Tedre et al. (2010) was paying 4 million TShs $(2140 €=3100 \$$ ) per month for a dedicated $704 \mathrm{~kb} / 128 \mathrm{~kb}$ satellite connection for 300 computers. It seems that limited Internet and its cost are barriers to the use of OER in many countries in Africa as similar findings were found in Kenya, Uganda, and South Africa (Ngimwaa \& Wilsona, 2012). According to Wright and Reju (2012), OER may not be open and free for those who do not have access to computers and the Internet. Therefore, the use of OER in higher education will depend on increased access to computers and reasonably priced Internet services.

The study also found that lack of policies at an institutional level was a major barrier to the use of OER in the surveyed institutions. This finding was consistent with the fact that nearly half of surveyed institutions (45.5\%) did not have eLearning policies in 
place. Even in institutions that had eLearning policies in place, the majority of them were not implemented. In some institutions, these policies existed but were out-dated and were developed when OER was at an early stage of implementation. For example, the UDSM ICT policy was developed in 2006, while that of OUT was developed in 2009 (Mtebe \& Raisamo, 2014). Therefore, such policies do not clarify issues that hinder the adoption of OER such as IPR and quality assurance (Bossu, Bull, \& Brown, 2012). This could be why $83 \%$ of instructors indicated that they were not aware of Creative Commons licenses.

Another main barrier to the use of OER that emerged from this study was lack of the skills to create and/ or use OER. Nearly two thirds of respondents (63\%) rated this as a hindrance factor. This finding corroborates a study conducted by Samzugi and Mwinyimbegu (2013) to investigate the accessibility of OER at OUT. They revealed that users depended on librarian assistance to find relevant OER due to lack of skills. Unless instructors are equipped with necessary skills to be able to create and/or use these resources, the use of OER in HEIs in Tanzania will be very difficult.

The most interesting finding from this study was that lack of trust in others' resources, lack of interest in creating and/ or using OER, and lack of time to find suitable materials were not considered to be the main barriers to the use of OER in the surveyed institutions. This finding was consistent with the fact that many instructors used the Internet to search for course notes to enhance their courses. This implies that instructors do trust resources from the Internet and they have the interest and time to find them. Nonetheless, they are not aware of reputable OER repositories where they could find quality resources. Therefore, in order to maximise the use of OER, there is an urgent need to raise awareness at all levels involving institutions and government entities of the value of OER in enhancing education (Ngimwaa \& Wilsona, 2012).

It is somewhat surprising that respondents were almost equally divided on two factors: lack of quality of OER and difficulties in finding suitable and relevant OER. Nearly onethird of interviewed instructors suggested that these two factors were barriers to the use of OER, while another one third indicated they were not. Similarly, almost one-third of instructors were undecided. This might be because the majority of instructors tend to search resources from unreliable sites due to unawareness of OER repositories. It seems, therefore, instructors compare the quality of the resources they find from the Internet with that of OER.

\section{Conclusions}

The adoption and use of ICT to improve the quality of education and to increase students' enrolments through blended distance learning in Tanzania is becoming common. Many HEIs are spending thousands of dollars to procure and maintain various ICT in their premises. With these efforts in place, the use of OER to complement 
these initiatives cannot be ignored. However, in order to benefit from these resources institutions have to find ways to overcome challenges revealed in this study. Moreover, institutions have to

- improve the reliability and speed of the Internet within their institutions;

- equip instructors with necessary skills to be able to create and/ or use OER;

- update relevant policies to enable smooth implementation of OER.

\section{Acknowledgement}

The authors appreciatively acknowledge the financial support from South African Institute for Distance Education (Saide), University of Dar es Salaam and the support from University of Tampere for preparing this article. The authors would also like to thank instructors from 11 institutions in Tanzania who willingly agreed to participate in the study. 


\section{References}

Andrad, A., Ehlers, U.-D., Caine, A., Carneiro, R., Conole, G., Kairamo, A.-K., ... Holmberg, C. (2011). Beyond OER: Shifting focus to open educational practices. Retrieved from http:// www.oerasia.org/ OERResources/ 8.pdf

Bateman, P. (2008). Revisiting the challenges for higher education in Sub-Saharan Africa : The role of the open educational resources movement OER Africa (pp. 1-66). Nairobi, Kenya.

Bossu, C., Bull, D., \& Brown, M. (2012). Opening up down under : The role of open educational resources in promoting social inclusion in Australia. Distance Education, 33(2), 151- 164.

Bryman, A. (2008). Social research methods. Oxford: Oxford University Press.

Butcher, N. (2010). OER dossier : Open educational resources and higher education. South Africa. Retrieved from http://www.col.org/SiteCollectionDocuments/OER_Open_Educational_Resou rces and Higher Education.pdf

Butcher, N. (2011). A basic guide to open educational resources (OER) (pp. 1- 134). Vancouver \& Paris. Retrieved from http:// www.col.org/resources/publications/Pages/detail.aspx?PID=357

Caswell, T., Henson, S., J ensen, M., \&Wiley, D. (2008). Open educational resources: Enabling universal education. International Review of Research in Open and Distance Learning, 9(1). Retrieved from http:// www.irrodl.org/ index.php/irrodl/article/view/469/1001

Freitas, D. (2012). Fostering social inclusion through open educational resources (OER). Distance Education, 33(2), 131- 134.

Hatakka, M. (2009). Build it and they will come?-Inhibiting factors for reuse of open content in developing countries. The Electronic J ournal of Information Systems in Developing Countries, 37(5), 1- 16.

Hodgkinson-Williams, C. (2010). Benefits and challenges of OER for higher education institutions. Retrieved from http:// www.col.org/SiteCollectionDocuments/OER_BenefitsChallenges_prese ntation.pdf

Hoosen, S. (2012). Survey on governments' open educational resources (OER) policies (pp. 1- 40). Retrieved from http:// www.col.org/ resources/publications/Pages/ detail.aspx?PID=408 
Hylén, J . (2006). Open educational resources : Opportunities and challenges. In Open Education. Retrieved from http://library.oum.edu.my/ oumlib/sites/default/files/file attachments/ odlresources/386010/oer-opportunities.pdf

Keats, D. (2003). Collaborative development of open content: A process model to unlock the potential for African universities. First Monday, 8(2). Retrieved from http:// firstmonday.org/ htbin/cgiwrap/ bin/ ojs/index.php/ fm/rt/ printerFriendl $\mathrm{y} / 1031 / 952$

Kokutsi, F. (2011). AFRICA: Expand university access, World Bank urges. University World News, Africa Edition Issue 198. Retrieved from http:// www.universityworldnews.com

Larson, R. C., \& Murray, M. E. (2008). Open educational resources for blended learning In high schools: Overcoming impediments In developing countries. J ournal of Asynchronous Learning Networks, 12(1), 2- 19.

Lesko, I. (2013). The use and production of OER \& OCW in teaching in South African higher education institutions. Open Praxis, 5(2), 103- 121.

Lindow, M. (2011). Weaving success: Voices of change in African higher education (p. 239). NewYork, NY 10022: Library of Congress Cataloging-in-Publication Data.

Lwoga, E. (2012). Making learning and Web 2.0 technologies work for higher learning institutions in Africa. Campus-Wide Information Systems, 29(2), 90- 107. doi:10.1108/ 10650741211212359

MIT. (2006). 2005 program evaluation findings report (pp. 1- 138).

MIT. (2013). Site statistics. Retrieved April 08, 2013, from http://ocw.mit.edu/about/ site-statistics/

Mtebe, J . S., \& Raisamo, R. (2014). Challenges and instructors' intention to adopt and use open educational resources in higher education in Tanzania. International Review of Research in Open and Distance Learning, 15(1), 250- 271.

Munguatosha, G. M., Muyinda, P. B., \&Lubega, J . T. (2011). A social networked learning adoption model for higher education institutions in developing countries. On the Horizon, 19(4), 307-320. doi:10.1108/ 10748121111179439

Ngimwaa, P., \& Wilsona, T. (2012). An empirical investigation of the emergent issues around OER adoption in Sub-Saharan Africa. Learning, Media and Technology, 37(4), 398-413. doi:10.1080/ 17439884.2012.685076 
Ngugi, C. N. (2011). OER in Africa's higher education institutions. Distance Education, 32(2), 277-287. doi:10.1080/01587919.2011.584853

OECD. (2007). Giving knowledge for free: The emergence of open educational resources. Retrieved from http:// www.oecd.org/ dataoecd/35/7/38654317.pdf

Percy, T., \& Belle, J . Van. (2012). Exploring the barriers and enablers to the use of open educational resources by university academics in Africa. In Open source systems: Long-term sustainability (pp. 112-128). Retrieved from http://link.springer.com/ chapter/ 10.1007/978-3-642-33442-9_8

Richards, G. (2013). Tracking the usage of our OER to improve their quality and impact. African Health OER Network Newsletter, 4(7). Retrieved from http:// www.oerafrica.org/ FTPFolder/ Website Materials/Health/Newsletters/ 2013/ August-2013-edition.html\#7

Samzugi, A. S., \& Mwinyimbegu, C. M. (2013). Accessibility of open educational resources for distance education learners: The case of The Open University of Tanzania. Huria J ournal of OUT, 14(76-88).

Tedre, M., Ngumbuke, F., \& Kemppainen, J . (2010). Infrastructure, human capacity, and high hopes : A decade of development of e-Learning in a Tanzanian HEI. Redefining the Digital Divide in Higher Education, 7(1).

Unwin, T., Kleessen, B., Hollow, D., Williams, J ., Oloo, L. M., Alwala, J ., ... Muianga, X. (2010). Digital learning management systems in Africa: Myths and realities. Open Learning: The J ournal of Open and Distance Learning, 25(1), 5- 23. doi:10.1080/02680510903482033

URT. (2012). Primary Education Development Programme Phase III ( 2012-2016 ). Retrieved from http:// www.ed-dpg.or.tz/pdf/PE/Primary Education Development Plan-PEDP I 2000-06.pdf

Wilson-Strydom, M. (2009). The potential of open educational resources OER Africa (pp. 1-32). Retrieved from http:// www.oerafrica.org/ understandingoer/UnderstandingOER/ ResourceDet ails/tabid/ 1424/mctl/ Details/id/36389/Default.aspx

Wright, C. R., \& Reju, S. A. (2012). Developing and deploying OERs in sub-Saharan Africa: Building on the present potential of OERs in sub-Saharan Africa. The International Review of Research in Open and Distance Learning, 13(2). Retrieved from http:// www.irrodl.org/ index.php/irrodl/article/view/ 1185/2161

Yuan, L., Mac, S., \&Kraan, W. (2008). Open educational resources - opportunities and challenges for higher education (pp. 1- 34). Retrieved from http://wiki.cetis.ac.uk/images/0/0b/OER_Briefing_Paper.pdf 


\section{Athabasca University $\mathbf{C}$}

(c) (i) 


\section{Cost-Savings Achieved in Two Semesters Through the Adoption of Open Educational Resources}
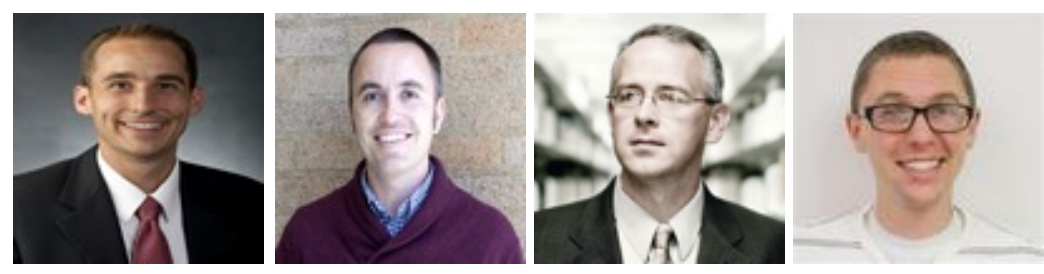

John Levi Hilton III, T. Jared Robinson, David Wiley, and J. Dale Ackerman Brigham Young University, USA

\section{Abstract}

Textbooks represent a significant portion of the overall cost of higher education in the United States. The burden of these costs is typically shouldered by students, those who support them, and the taxpayers who fund the grants and student loans which pay for textbooks. Open educational resources (OER) provide students a way to receive highquality learning materials at little or no cost to students. We report on the cost savings achieved by students at eight colleges when these colleges began utilizing OER in place of traditional commercial textbooks.

Keywords: Open educational resources; open textbooks; electronic textbooks; open access 


\section{Introduction}

For many post-secondary students and professors in the United States, it would be difficult to imagine the school experience without commercial textbooks. Textbooks are a staple of American college life even though some studies indicate that students read the textbooks less frequently than their instructors might desire (Berry et al., 2010). It is unfortunate that textbooks are underutilized, particularly when they are so costly. The continuing increases in textbook costs are symptomatic of 40-year trends of rising educational costs (Baumol, 1996; Privateer, 1999). The United States Government Accountability Office estimated that textbooks cost the average student $\$ 900$ (U.S.D.) annually (2005). A study conducted by the Student Public Interest Research Group calculated that over the past twenty years textbook costs have increased at a rate four times higher than inflation (Allen, 2010).

The rising cost of textbooks may disproportionately harm students in community colleges, where tuition is generally lower and students may face greater financial difficulties. In their longitudinal study of graduating high school seniors, Provasnik and Plenty (2008) found that individuals from lower socioeconomic statuses were more likely to postpone college enrollment, and that those who did enroll in college were more prone to choose a community college than their wealthier peers. Another study found that over half of community college students (55\%) are from the two lowest income quartiles compared with $38 \%$ of public 4 -year students (Bailey, Jenkins, \& Leinbach, 2005).

In some cases, textbooks can account for a large proportion of student educational expenditures and debt. For example, in the state of California during 2007-2008, textbooks accounted for $59 \%$ of the total cost of attending community college (Goodwin, 2011). Students with financial difficulties may choose to forgo the purchase of textbooks due to the high financial burden, particularly since textbooks are optional but tuition fees are not (Buczynski, 2007). Economists have argued that textbook costs in higher education have become nearly unavoidable in the commercial publishing model (Carbaugh \&Ghosh, 2005). But Buczynski notes,

Faculty cannot teach successfully in classroom environments, whether face to face or online, with increasing numbers of students who do not have access to required readings and other learning materials. There is a gap between the business models employed by textbook publishers and student expectations for access. (2007, p. 174)

One way that this gap can be bridged is through the utilization of open educational resources (OER). In 2002, UNESCO convened the Forum on the Impact of Open Courseware for Higher Education in Developing Countries. On this occasion, Saul Fisher from the Andrew W. Mellon Foundation recommended the group adopt the 
phrase "Open Educational Resources" to describe their proposed model of sharing educational materials. In adopting this terminology, the following definition was proffered: "The open provision of educational resources, enabled by information and communication technologies, for consultation, use and adaptation by a community of users for non-commercial purposes" (UNESCO, 2002, p. 24).

In the intervening years much has been done to bring to pass the vision stated at that 2002 UNESCO meeting. For example much OER has been created, including courses, textbooks, videos, journal articles, and other materials that are typically available online and are licensed in such a way so as to allow for reuse and revision to meet the needs of teachers and students (J ohnstone, 2006; Bissell, 2009; Hewlett, 2013; D’Antoni, 2009; Downes, 2007).

For example, Ravid et al. (2008) identified how Wiki textbooks might assist student learning both by employing digital technologies and lowering costs. Platforms such as Connexions have shown remarkable potential to harness technology and OER to reduce textbook costs for students (Baker, et al., 2009). Initiatives like Carnegie Mellon University's Open Learning Initiative (OLI) and growing numbers of departments and instructors using OER to replace traditional publisher-produced textbooks make the continued study of OER critical (J ohnstone, 2006). In some instances, governments have sponsored the development of OER. Caswell (2012) describes how Washington State community and technical colleges have created an open course library intended to help lower educational costs for students throughout the state. OER may provide substantial cost savings to students without negatively impacting student learning (Hilton \&Wiley, 2011; Allen, 2010).

Researchers and practitioners have invested significant financial, temporal, and intellectual resources into developing and distributing OER (see, for example, Fleming \& Massey, 2007; Baker, et al., 2009). While OER production and consumption still involves significant costs, the potential cost-savings benefits to students are important to continue to explore. Utilized in the classroom, OER can provide powerful tools for teaching and learning. Studies indicate that a growing number of OER are becoming available for use in the classroom (McKerlich, et al., 2013). Limited research has been done regarding the efficacy of using OER instead of traditional resources. Shepperd et al. (2008) found that students who utilized electronic textbooks performed just as well as their peers who used traditional textbooks, a finding replicated by RockinsonSzapkiw et al. (2012). Currently available studies indicate that student learning is not negatively impacted when OER are substituted for traditional learning materials (Hilton \&Laman, 2012; Wiley et Al., 2012; Hilton et al., 2013). 


\section{Context of the Study}

The context for this study is an open education initiative named Kaleidoscope Open Course Initiative (KOCI). The Kaleidoscope Open Course Initiative (KOCI) is a Next Generation Learning Challenges-funded project with three goals. KOCI was designed to (1) eliminate textbook costs as a barrier to student success, (2) improve the quality of course designs in order to increase student success, and (3) create a collaborative community to share learning and investment in the project. Eight community colleges and state colleges agreed to work together to develop new course designs and textbook replacements that exclusively use OER. Teachers from two or three schools collaborated to identify, adapt, and when necessary create OER materials for common courses that were taught at each of their schools. As part of the initiative each course was taught both by the colleges that participated in their development and also by some other KOCI colleges who had not participated in the creation of that specific course. The colleges also offered other sections using traditional textbooks. The decision of whether a particular section utilized the KOCI OER materials or traditional textbooks was determined by teacher or department preference at each college.

At the time of this study, KOCI included eight colleges or community colleges (the initiative has since grown to over 20 schools). This study focuses on seven of the original KOCI schools, as no data were available for the eighth. Our study was based on the work done at the following colleges: Cerritos College (Norwalk, CA, 22,000 students); Chadron State College (Chadron, Nebraska, 3,000 students); Mercy College (Dobbs Ferry, New York, 10,000 students across four campuses); College of the Redwoods (Eureka, California, 10,000 students); Santa Ana College (Santa Ana, California, 18,000 students); Santiago Canyon College (Orange, California, 10,000 students); and Tompkins Cortland Community College (Dryden, New York, 3,500 students).

These colleges worked together in 2010 and 2011 to replace traditional textbooks with OER across their multiple campuses. In a pilot study during the 2011-2012 academic year, KOCI schools taught the following courses that utilized OER in place of commercial textbooks: Intermediate Algebra, Developmental Reading, Developmental Writing, English Composition I, Introduction to Psychology, Business Fundamentals, Physical Geography, Chemistry Fundamentals, and Biology Fundamentals. Each school chose between one and four of these courses to implement in the fall 2011 and spring 2012 semesters. Across the seven colleges, in the fall 2011 and spring 2012 semesters there were 14,606 total enrollments in these classes. Of those, 3,867 enrollments were in sections that utilized OER, and 10,739 were for parallel sections that used commercial textbooks. Of the 256 teachers we tracked, 194 of them exclusively taught classes that did not use OER. Forty-eight of them exclusively taught classes that did. Fourteen of them taught both OER and non-OER classes. 


\section{Research Question}

As stated previously, high costs of textbooks present a barrier to learning for many students in the United States. One of the most significant benefits of using OER is that students and those who support them (including taxpayers) are able to save money that would otherwise be spent purchasing textbooks. In the present study we seek to discover precisely how much students in KOCI courses potentially saved as a result of the course materials being freely available. In addition, we examined how much money students in non-KOCI versions of the course potentially spent on their textbooks. This represents an important attempt to quantify savings that result when OER are employed. In other words, OER proponents have claimed that OER will save students money; our purpose is to examine this claim by calculating savings that occurred at seven different colleges across the United States when courses utilizing OER were implemented.

\section{Method}

In order to calculate the savings achieved by students in KOCI, and the amount spent by students in non-KOCI classes, we needed to determine how much the traditional textbooks cost in these courses, as well as calculate the number of students enrolled in each type of course. While there are a variety of approaches that could be utilized to analyze costs, we chose to use a straightforward method of calculating average costs based on actual book costs as reported by bookstores located on the campuses of the KOCI colleges. Although textbook cost data were not gathered during the 2011-2012 school year, we estimated these costs by visiting each school's bookstore website, identifying each teacher's book list for the spring 2013 semester, finding the prices of each textbook (usually directly from the bookstore website, but occasionally from Amazon or other sources), and creating a list that enumerated each teacher and the prices of their required textbooks.

For example, to identify the textbook cost for students attending Professor R's English class, we would go to the bookstore website for her school, find her booklist (see Figure 1), and sum the total costs of her books based on the prices on the bookstore website. In order to standardize costs across colleges, we always selected the price of a new book (in part because used books were not always available, see Figure 1, below), and only included required (not optional) texts. When digital books were available, we selected the digital book price. When price comparisons were available from the bookstore websites we used the cheapest price of a new text. In instances when textbooks were out of stock we obtained the cost information from www.amazon.com (again, the cheapest price of the new text). 


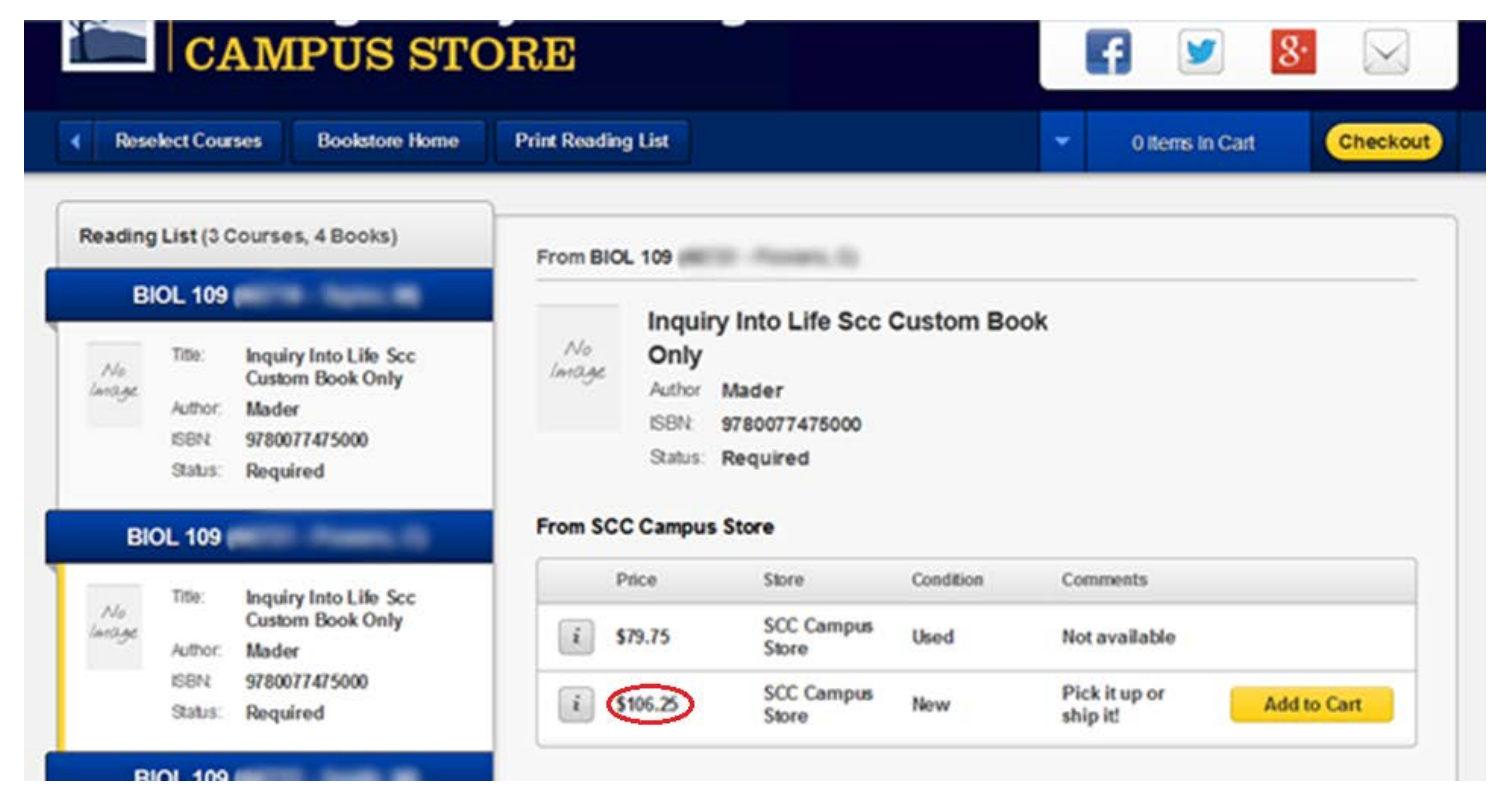

Figure 1. Example of finding textbook cost by teacher.

\section{Results}

There are many ways in which one can approach the data we obtained. We begin by examining the costs of textbooks by college. We present the costs of each course in which OER materials were available. As mentioned previously, the OER versions of the course had zero textbook costs; below, we enumerate the costs in those sections using traditional textbooks.

Table 1 shows the costs of texts at Cerritos, which had five KOCI classes: Business Fundamentals, English Composition I, Physical Geography, Developmental Reading, and Developmental Writing. The average textbook costs we calculated by summing together the costs of all required books per section and then divided by the total number of sections. These averages were weighted according to the number of students in each section (e.g., classes with high enrollment would affect cost data more than classes with low enrollments). 
Table 1

Cerritos College Costs per Course

\begin{tabular}{|l|l|l|l|l|l|}
\hline Class & $\begin{array}{l}\text { Average } \\
\text { textbook } \\
\text { cost for } \\
\text { non-KOCI } \\
\text { sections }\end{array}$ & $\begin{array}{l}\text { Students } \\
\text { enrolled in } \\
\text { KOCI } \\
\text { sections }\end{array}$ & $\begin{array}{l}\text { Students } \\
\text { enrolled in } \\
\text { non-KOCI } \\
\text { sections }\end{array}$ & $\begin{array}{l}\text { Potential } \\
\text { amount } \\
\text { saved by } \\
\text { KOCI } \\
\text { students }\end{array}$ & $\begin{array}{l}\text { Potential } \\
\text { amount } \\
\text { spent by } \\
\text { non-KOCI } \\
\text { students }\end{array}$ \\
\hline $\begin{array}{l}\text { Business } \\
\text { Fundamentals }\end{array}$ & $\$ 42.97$ & 944 & 44 & $\$ 40,563.68$ & $\$ 1,890.68$ \\
\hline $\begin{array}{l}\text { English } \\
\text { Composition I }\end{array}$ & 63.11 & 317 & 2,943 & $20,005.87$ & $185,732.73$ \\
\hline $\begin{array}{l}\text { Physical } \\
\text { Geography }\end{array}$ & 102.00 & 363 & 731 & $37,026.00$ & $74,562.00$ \\
\hline $\begin{array}{l}\text { Developmental } \\
\text { Reading }\end{array}$ & 36.54 & 49 & 589 & $1,790.46$ & $21,522.06$ \\
\hline $\begin{array}{l}\text { Developmental } \\
\text { Writing }\end{array}$ & 90.14 & 54 & 408 & $4,867.56$ & $36,777.12$ \\
\hline Total & $\begin{array}{l}\$ 65.93 \\
\text { (average) }\end{array}$ & 1,727 & 4,715 & $\$ 104,253.57$ & $\$ 320,484.59$ \\
\hline
\end{tabular}

As illustrated in Table 1, textbook costs per class ranged from $\$ 36.54$ (Reading) to $\$ 102.00$ (Geography). Across the five classes, textbooks cost on average $\$ 65.93$ per course. There were 1,727 students enrolled in KOCI classes at Cerritos. Those students potentially saved a total of $\$ 104,253.57$ over the two semesters. There were 4,683 students enrolled in classes similar to those using KOCI texts; however, these classes used traditional textbooks. Those students potentially spent a total of $\$ 320,484.59$ on textbooks during this same time period. Table 2 shows the text costs for Chadron State College, which had two KOCI classes: Introduction to Psychology and Developmental Writing. 
Table 2

Chadron State College Costs per Course

\begin{tabular}{|l|l|l|l|l|l|}
\hline Class & $\begin{array}{l}\text { Average } \\
\text { textbook cost }\end{array}$ & $\begin{array}{l}\text { Students } \\
\text { enrolled in } \\
\text { KOCI } \\
\text { sections }\end{array}$ & $\begin{array}{l}\text { Students } \\
\text { enrolled in } \\
\text { non-KOCI } \\
\text { sections }\end{array}$ & $\begin{array}{l}\text { Potential } \\
\text { amount } \\
\text { saved by } \\
\text { KOCI } \\
\text { students }\end{array}$ & $\begin{array}{l}\text { Potential } \\
\text { amount } \\
\text { spent by } \\
\text { non-KOCI } \\
\text { students }\end{array}$ \\
\hline $\begin{array}{l}\text { Intro. to } \\
\text { Psychology }\end{array}$ & $\$ 163.19$ & 27 & 55 & $\$ 4,406.13$ & $\$ 8,975.45$ \\
\hline $\begin{array}{l}\text { Developmental } \\
\text { Writing }\end{array}$ & $\$ 24.00$ & 48 & 7 & $1,152.00$ & 168.00 \\
\hline Total & $\begin{array}{l}\$ 107.31 \\
\text { (average) }\end{array}$ & 75 & 62 & $\$ 5,558.13$ & $\$ 9,143.45$ \\
\hline
\end{tabular}

As shown in Table 2, there were two averages for textbook costs: $\$ 163.19$ for Psychology and $\$ 24.00$ for Writing. The average text cost at Chadron is $\$ 107.30$, largely because of the high number of students enrolled in the non-KOCI sections of Introduction to Psychology. The 75 students enrolled in KOCI sections at Chadron potentially saved $\$ 5,558.13$. The 62 students enrolled in similar non-KOCI sections of these classes potentially spent $\$ 9,143.45$.

Mercy College offered one KOCI course: College Algebra. The average textbook cost for taking a non-KOCI College Algebra class at Mercy College was \$170.00. During the 2011-2012 school year, 50 students enrolled in KOCI sections of this class and they potentially saved $\$ 8,500.00$. Additionally, there were 136 students enrolled in nonKOCI sections of this class, who potentially spent $\$ 23,120.00$ buying their books for the class.

Table 3 illustrates the textbook costs for College of the Redwoods, which had three KOCI classes: Biology Fundamentals, Introduction to Psychology, and Developmental Reading. 
Table 3

College of the Redwoods Costs per Course

\begin{tabular}{|l|l|l|l|l|l|}
\hline Class & $\begin{array}{l}\text { Average } \\
\text { textbook } \\
\text { cost }\end{array}$ & $\begin{array}{l}\text { Students } \\
\text { enrolled in } \\
\text { KOCI } \\
\text { sections }\end{array}$ & $\begin{array}{l}\text { Students } \\
\text { enrolled in } \\
\text { non-KOCI } \\
\text { sections }\end{array}$ & $\begin{array}{l}\text { Potential } \\
\text { amount } \\
\text { saved by } \\
\text { KOCI } \\
\text { students }\end{array}$ & $\begin{array}{l}\text { Potential } \\
\text { amount } \\
\text { spent by } \\
\text { non-KOCI } \\
\text { students }\end{array}$ \\
\hline $\begin{array}{l}\text { Biology } \\
\text { Fundamentals }\end{array}$ & $\$ 148.43$ & 154 & 306 & $\$ 22,858.22$ & $\$ 45,419.58$ \\
\hline $\begin{array}{l}\text { Intro. to } \\
\text { Psychology }\end{array}$ & 174.19 & 61 & 806 & $10,625.59$ & $140,397.14$ \\
\hline $\begin{array}{l}\text { Developmental } \\
\text { Reading }\end{array}$ & 53.75 & 27 & 119 & $1,451.25$ & $6,396.25$ \\
\hline Total & $\begin{array}{l}\$ 154.21 \\
\text { (average) }\end{array}$ & 242 & 1,231 & $\$ 34,935.06$ & $\$ 192,212.97$ \\
\hline
\end{tabular}

As shown in Table 3, the textbook averages at Redwoods ranged from $\$ 53.75$ (Reading) to $\$ 174.19$ (Psychology). On average, across these three classes, textbooks cost $\$ 156.14$. There were 242 students enrolled in KOCI classes at the school, who potentially saved $\$ 34,935.06$. There were 1,231 students enrolled in similar non-KOCI classes at the school. Those students potentially spent $\$ 192,212.97$ on textbooks.

Table 4 shows the textbook costs for Santa Ana College, which had three KOCI classes: Business Fundamentals, Intermediate Algebra, and English Composition I.

Table 4

Santa Ana College Costs per Course

\begin{tabular}{|l|l|l|l|l|l|}
\hline Class & $\begin{array}{l}\text { Average } \\
\text { textbook } \\
\text { cost }\end{array}$ & $\begin{array}{l}\text { Students } \\
\text { enrolled in } \\
\text { KOCI } \\
\text { sections }\end{array}$ & $\begin{array}{l}\text { Students } \\
\text { enrolled in } \\
\text { non-KOCI } \\
\text { sections }\end{array}$ & $\begin{array}{l}\text { Potential } \\
\text { amount } \\
\text { saved by } \\
\text { KOCI } \\
\text { students }\end{array}$ & $\begin{array}{l}\text { Potential } \\
\text { amount } \\
\text { spent by } \\
\text { non-KOCI } \\
\text { students }\end{array}$ \\
\hline $\begin{array}{l}\text { Business } \\
\text { Fundamentals }\end{array}$ & $\$ 37.00$ & 124 & 126 & $\$ 4,588.00$ & $\$ 4,662.00$ \\
\hline $\begin{array}{l}\text { Intermediate } \\
\text { Algebra }\end{array}$ & 103.50 & 42 & 34 & $4,347.00$ & $3,519.00$ \\
\hline $\begin{array}{l}\text { English } \\
\text { Composition I }\end{array}$ & 64.38 & 26 & 538 & $1,673.88$ & $34,636.44$ \\
\hline Total & $\begin{array}{l}\$ 60.03 \\
\text { (average) }\end{array}$ & 192 & 698 & $\$ 10,608.88$ & $\$ 42,817.44$ \\
\hline
\end{tabular}


The textbook averages at Santa Ana College ranged from $\$ 37.00$ (Business) to $\$ 103.50$ (Algebra). The average price of textbooks in these three classes was $\$ 60.03$. The 192 students enrolled in KOCI classes at the school potentially saved $\$ 10,608.88$. There were 698 students enrolled in similar classes that used traditional textbooks. Those students potentially spent $\$ 42,817.44$.

Santiago Canyon College offered two KOCI courses: Biology Fundamentals and Intermediate Algebra. However, no data for accompanying non-KOCI classes were obtained for the Intermediate Algebra course, thus only the data for Biology Fundamentals could be used. The average textbook cost for this class was $\$ 135.17$. There were 145 students enrolled in this KOCI class. Those students potentially saved $\$ 19,464.48$ because they did not have to pay for a textbook; in contrast the 434 students who were enrolled in a similar Biology Fundamentals class potentially spent $\$ 58,663.78$ on textbooks for this class.

Table 5 shows the textbook cost data for Tompkins Cortland Community College, which has four KOCI classes: Principles of Biology II, Intermediate Algebra, Introduction to Psychology, and Academic Writing I.

Table 5

Tompkins Cortland Community College Costs per Course

\begin{tabular}{|l|l|l|l|l|l|}
\hline Class & $\begin{array}{l}\text { Average } \\
\text { textbook } \\
\text { cost }\end{array}$ & $\begin{array}{l}\text { Students } \\
\text { enrolled in } \\
\text { KOCI } \\
\text { sections }\end{array}$ & $\begin{array}{l}\text { Students } \\
\text { enrolled in } \\
\text { non-KOCI } \\
\text { sections }\end{array}$ & $\begin{array}{l}\text { Potential } \\
\text { amount } \\
\text { saved by } \\
\text { KOCI } \\
\text { students }\end{array}$ & $\begin{array}{l}\text { Potential } \\
\text { amount } \\
\text { spent by } \\
\text { non-KOCI } \\
\text { students }\end{array}$ \\
\hline $\begin{array}{l}\text { Biology } \\
\text { Fundamentals }\end{array}$ & $\$ 207.00$ & 24 & 104 & $\$ 4,968.00$ & $\$ 21,528.00$ \\
\hline $\begin{array}{l}\text { Intermediate } \\
\text { Algebra }\end{array}$ & 142.35 & 32 & 797 & $4,555.20$ & $113,452.95$ \\
\hline $\begin{array}{l}\text { Intro. to } \\
\text { Psychology }\end{array}$ & 67.36 & 135 & 988 & $9,093.60$ & $66,551.68$ \\
\hline $\begin{array}{l}\text { English } \\
\text { Composition I }\end{array}$ & 119.51 & 20 & 602 & $2,390.20$ & $71,945.02$ \\
\hline Total & $\begin{array}{l}\$ 108.99 \\
\text { (average) }\end{array}$ & 211 & 2,491 & $\$ 21,007.00$ & $\$ 273,477.65$ \\
\hline
\end{tabular}

As illustrated in Table 5, textbook costs ranged from $\$ 67.36$ (Psychology) to $\$ 207.00$ (Biology) at Tompkins Cortland. The average cost of a textbook across these four classes was $\$ 108.99$. The 211 students enrolled in KOCI classes potentially saved \$21,007.00. The 2,491 students enrolled in classes using traditional textbooks potentially spent $\$ 273,477.65$. 
Another way to approach these data is to examine how much each course cost across the several schools. Table 6 shows the average cost of textbooks by subject.

Table 6

Text Costs by Subject

\begin{tabular}{|c|c|c|c|c|c|c|}
\hline $\begin{array}{l}\text { Course } \\
\text { examined }\end{array}$ & $\begin{array}{l}\text { Colleges } \\
\text { where } \\
\text { taught }\end{array}$ & $\begin{array}{l}\text { Average } \\
\text { textbook } \\
\text { cost } \\
\text { across } \\
\text { courses }\end{array}$ & $\begin{array}{l}\text { Students } \\
\text { enrolled } \\
\text { in KOCI } \\
\text { sections }\end{array}$ & $\begin{array}{l}\text { Students } \\
\text { enrolled } \\
\text { in non- } \\
\text { KOCI } \\
\text { sections }\end{array}$ & $\begin{array}{l}\text { Potential } \\
\text { amount } \\
\text { saved by } \\
\text { KOCI } \\
\text { students }\end{array}$ & $\begin{array}{l}\text { Potential } \\
\text { amount } \\
\text { spent by } \\
\text { non-KOCI } \\
\text { students }\end{array}$ \\
\hline $\begin{array}{l}\text { Biology } \\
\text { Fundamentals }\end{array}$ & $\begin{array}{l}\text { Redwoods, } \\
\text { Santiago, } \\
\text { Tompkins } \\
\text { Cortland }\end{array}$ & $\$ 148.28$ & 323 & 844 & $\begin{array}{l}\$ 47,894 . \\
44\end{array}$ & $\begin{array}{l}\$ 125,148 . \\
32\end{array}$ \\
\hline $\begin{array}{l}\text { Business } \\
\text { Fundamentals }\end{array}$ & $\begin{array}{l}\text { Cerritos, } \\
\text { Santa Ana }\end{array}$ & 41.76 & 1,068 & 170 & $\begin{array}{l}44,599.6 \\
8\end{array}$ & $7,099.20$ \\
\hline $\begin{array}{l}\text { Developmental } \\
\text { Reading }\end{array}$ & $\begin{array}{l}\text { Cerritos, } \\
\text { Redwoods }\end{array}$ & 39.74 & 76 & 708 & $3,020.24$ & $28,135.92$ \\
\hline $\begin{array}{l}\text { Developmental } \\
\text { Writing }\end{array}$ & $\begin{array}{l}\text { Cerritos, } \\
\text { Chadron }\end{array}$ & 83.10 & 102 & 415 & $8,476.20$ & $34,486.50$ \\
\hline $\begin{array}{l}\text { English } \\
\text { Composition I }\end{array}$ & $\begin{array}{l}\text { Cerritos, } \\
\text { Santa Ana, } \\
\text { Tompkins } \\
\text { Cortland }\end{array}$ & 71.16 & 363 & 4,083 & $\begin{array}{l}25,831.0 \\
8\end{array}$ & $\begin{array}{l}290,546.2 \\
8\end{array}$ \\
\hline $\begin{array}{l}\text { Intermediate } \\
\text { Algebra }\end{array}$ & $\begin{array}{l}\text { Mercy, } \\
\text { Santa Ana, } \\
\text { Tompkins } \\
\text { Cortland }\end{array}$ & 144.36 & 124 & 967 & $\begin{array}{l}17,900.6 \\
4\end{array}$ & $139,596.12$ \\
\hline $\begin{array}{l}\text { Introduction to } \\
\text { Psychology }\end{array}$ & $\begin{array}{l}\text { Chadron, } \\
\text { Redwoods, } \\
\text { Tompkins } \\
\text { Cortland }\end{array}$ & 115.85 & 223 & 1,849 & $\begin{array}{l}25,834.5 \\
5\end{array}$ & $\begin{array}{l}214,206.6 \\
5\end{array}$ \\
\hline $\begin{array}{l}\text { Physical } \\
\text { Geography }\end{array}$ & Cerritos & 102.00 & 363 & 731 & $\begin{array}{l}37,026.0 \\
0\end{array}$ & $74,562.00$ \\
\hline Total & & $\begin{array}{l}\$ 90.61 \\
\text { (average) }\end{array}$ & 2,642 & 9,767 & $\begin{array}{l}\$ 210,582 \\
.83\end{array}$ & $\begin{array}{l}\$ 913,780 . \\
99\end{array}$ \\
\hline
\end{tabular}

As illustrated in Table 6, there were nine subjects taught using KOCI materials across the seven different schools. Per course cost averages ranged from $\$ 41.76$ (Business) to \$148.28 (Biology).

How much money did students collectively potentially save or spend across these KOCI sections? We used the data from the above tables to create a comparison of the average textbook costs in each of the seven KOCI schools that are the focus of this study, as well as the amounts potentially saved or spent by students in these colleges. The total average textbook costs averaged across all non-KOCI classes at each of these schools was $\$ 90.61$. There were 3,734 enrollments in KOCI classes. Those students potentially 
saved a total of $\$ 338,337.74$ because they did not have to buy texts for their KOCI classes. There were 10,004 enrollments in non-KOCI sections of these classes; these students potentially spent $\$ 906,462.44$ on textbooks for these classes. Note that these numbers for KOCI and non-KOCI enrollments are higher than those displayed in Table 6, for reasons discussed below.

\section{Discussion}

The results of this study were fairly straightforward. Our purpose in the present study was to quantify the amount of money students in KOCI courses potentially saved as a result of their course materials being freely available. In addition, we wanted to understand how much money students in non-KOCI versions of the course potentially spent on their textbooks. The amount saved per textbook varied per school, in part because of the different costs of textbooks utilized by each department or individual. For example, a textbook for an introductory course in psychology at College of the Redwoods cost $\$ 174.19$, while the average cost of a textbook for the same course at Tompkins Cortland Community College was $\$ 67.36$. This difference is an indicator of the variance in commercial textbook costs.

While there are limitations (discussed below) to our ability to precisely identify the amount of money potentially saved by students, we were able to calculate the average cost per textbook across these courses. The average cost per textbook that we calculated (\$90.61) is in harmony with other studies on textbook costs (such as U.S. Government Accountability Office, 2005, cited previously). Because we were able to identify students enrolled in sections utilizing open materials, we could calculate the amount of money potentially saved by these students. When the amount potentially spent by non-KOCI students is combined with the amount potentially saved by KOCI students, the resulting cost savings are greater than one million dollars for one academic school year. This significant cost savings suggests that the claim that OER can reduce costs for students is valid.

We acknowledge there are additional costs not accounted for, in that the original creation of many of the OER which were later used in KOCI was funded by grants from foundations or governments. Thus some of the costs described in this article have been shifted from students to grant-issuing organizations. However, it is also important to note that these development costs are one-time costs, as opposed to the ongoing costs faced by students semester after semester. Also, these one-time development costs must be amortized across all uses by all students over all terms, both within and without KOCI. We did not include these costs in our analyses. Additional costs that are not accounted for in our cost estimate include the training and coaching in OER implementation that was provided to KOCI faculty through the grant, and costs potentially incurred if students choose to print out the OER which are freely available online. 
One limitation in this study is that it is difficult to predict the ways in which students choose to obtain their books. We calculated prices based on the cheapest new or digital copy. However, some students would have borrowed or rented textbooks, not purchased them, or obtained a used copy. Throughout the paper we described "potential" savings in order to acknowledge that some students choose not to purchase textbooks. This nonpurchasing behavior would affect the amount of savings that occurred.

There were also some limitations to obtaining textbook cost data using the method described above. Since this aspect of the research was done ex post facto, we could not be certain that the books we found for spring 2013 always matched the books that were employed in the fall 2011/spring 2012 semesters. In some instances, textbook costs could not be determined because of a school's current use of OER. Most notably, the Math 116 class at Mercy College currently only uses OER texts; therefore we used historical reports from faculty members to arrive at the price of the Mercy Math textbooks. The Math classes at Redwoods and the Writing and Reading classes at Chadron currently only use OER texts; we were unable to find historical cost information on these texts, and excluded them from the cost average. While the costs of these textbooks was excluded from creating an average textbook price, the number of students participating in these courses was added into our overall cost-savings figure, thus explaining the difference between the numbers inTable 6 and the overall numbers reported in the paragraph belowit.

When looking for textbook costs, we did so at the teacher level. For example, if we knew that Teacher X at Santa Ana taught a non-KOCI section of Algebra, we specifically looked for her by name on the school website to determine how much textbooks in her class cost (as different teachers often require different textbooks). However, in some instances, we could not identify specific textbook costs for a specific teacher. For example, four of the schools' bookstore websites (Redwoods, Tompkins Cortland, Mercy, and Cerritos) did not identify books by teacher; rather they are identified by course section number. Because only 2013 books were available (and we had 2012 section numbers) we were not able to specifically identify which teacher used which books. In these cases, we determined the cost of each section of a specific class listed on the bookstore website for the spring 2013 semesters and averaged the costs of books required by those sections. For example, since you cannot search for textbooks by teacher at Cerritos College's bookstore website, to find the textbook cost for Professor Y's English 52 class at Cerritos, we went to Cerritos's bookstore website, found the textbook cost for each section of English 52 in the spring 2013 semester, and took an average of those textbook costs. As illustrated in Figures 2 and 3 there was sometimes a wide variety in costs per section. For example, section 20128 only required one book (The Great Gatsby) while section 20235 required two textbooks, which were much more expensive. The costs of the textbooks of these and other sections of English 52 were averaged together and non-Kaleidoscope classes were assigned the average per-section cost of the non-KOCI classes. Similarly, in instances in which a teacher was not teaching during spring 2013, we used the average textbook cost among the other sections at his 
or her school for that particular class to assign textbook costs. While these limitations exist, and we acknowledge that these data are not necessarily generalizable, these data provide a glimpse into actual textbooks faced by college students in the United States.

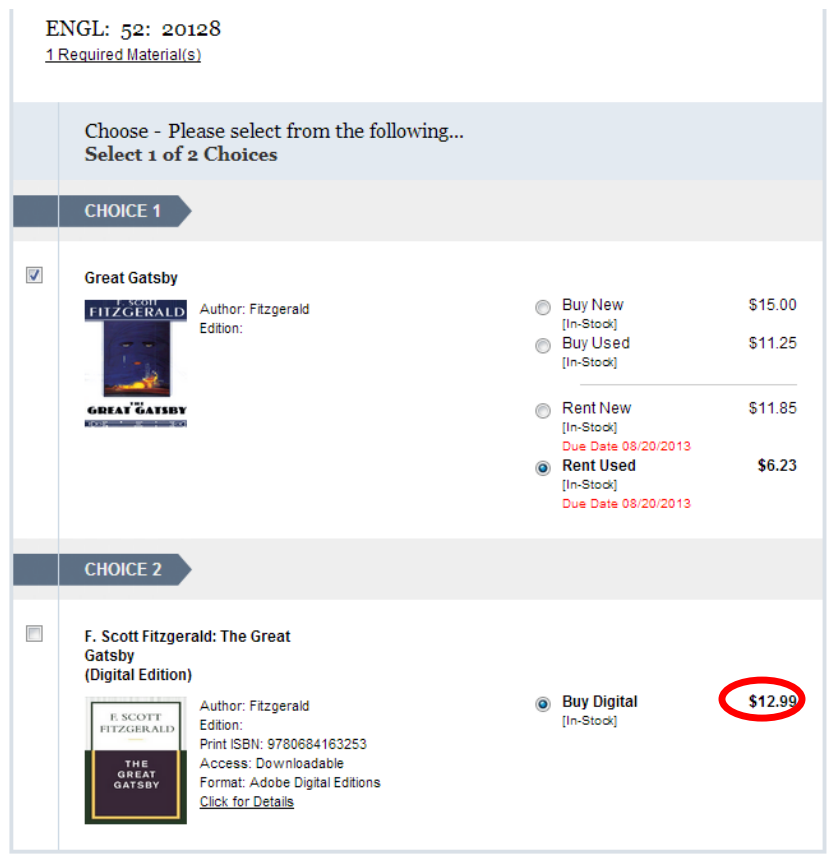

Figure 2. Example 1 for finding an average section textbook cost.

Books
Textbooks \& Course Materials
Digital Textbooks
General Books

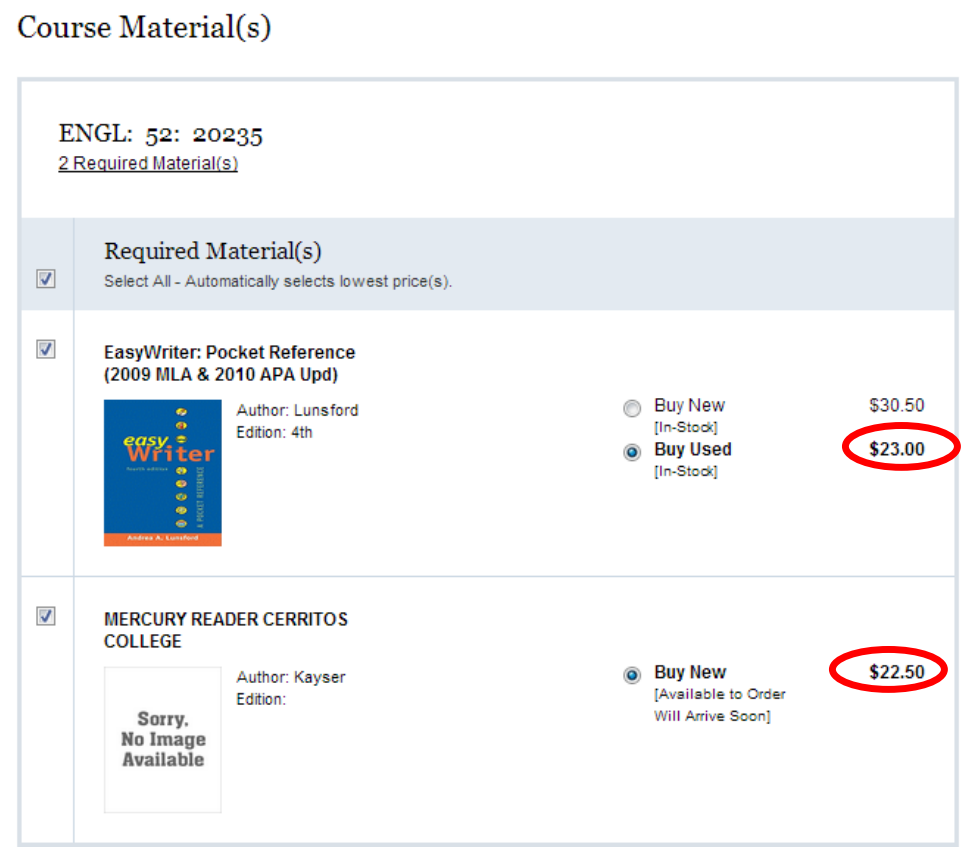

Figure 3. Example 2 for finding an average section textbook cost. 


\section{Conclusion}

Open educational resources have a large potential to save students, as well as the parents and taxpayers who support them through grants and loans, significant amounts of money. We found that the average textbook cost across all non-KOCI classes at the seven KOCI schools we studied was $\$ 90.61$, meaning that a full-time student would spend over $\$ 900$ on textbooks each year.. Broad adoption of OER makes that cost zero for every student impacted. If these savings were realized by only $5 \%$ of the $20,994,113$ students in the United States who enrolled in college during the 2011 fall semester (National Center for Education Statistics, 2013), the total savings would be approximately one billion dollars per year. 


\section{References}

Allen, N. (2010). A cover to cover solution: How open textbooks are the path to textbook affordability. The Student Public Interest Research Group. Retrieved from http:// www.studentpirgs.org/ sites/ student/files/reports/A-Cover-ToCover-Solution_4.pdf

Bailey, T., J enkins, D., \& Leinbach, T. (2005). What we know about community college low-income and minority student outcomes: Descriptive statistics from National Surveys. Community College Research Center.

Baker, J ., Thierstein, J ., Fletcher, K., Kaur, M., \&Emmons, J . (2009). Open textbook proof-of-concept via Connexions. The International Review of Research in Open and Distance Learning, 10(5).

Baumol, W. J . (1996). Children of performing arts, the economic dilemma: The climbing costs of health care and education. J ournal of Cultural Economics, 20(3), 183206.

Berry, T., Cook, L., Hill, N., \& Stevens, K. (2010). An exploratory analysis of textbook usage and study habits: Misperceptions and barriers to success. College Teaching, 59(1), 31-39.

Bissell, A. (2009). Permission granted: Open licensing for educational resources. Open Learning, The J ournal of Open and Distance Learning, 24, 97-106.

Buczynski, J . A. (2007). Faculty begin to replace textbooks with freely accessible online resources. Internet Reference Services Quarterly, 11(4), 169-179.

Carbaugh, R., \& Koushik G. (2005). Are college textbooks priced fairly? Challenge, 48(5) 95-112.

Caswell, T. (2012). The Open Course Library of the Washington State Colleges. In D. G. Oblinger (Ed.), Game changers: Education and information technologies (pp. 259-262). Retrieved from http:// www.educause.edu/Resources/GameChangersEducationandInform/Cas eStudy2TheOpenCourseLibrary/250347.

D’Antoni, S. (2009). Open educational resources: Reviewing initiatives and issues. Open Learning, The J ournal of Open and Distance Learning, 24, 3-10.

Downes, S. (2007). Models for sustainable open educational resources. Interdisciplinary J ournal of Knowledge and Learning Objects, 3, 29-44.

Fleming, C., \& Massey, M. (2007). J orum open educational resources report. Retrieved from www.jorum.ac.uk/ docs/pdf/ 0707 J orumOERreportFinal.pdf 
Goodwin, M. A. L. (2011). The Open Course Library: Using open educational resources to improve community college access (Doctoral dissertation). Washington State University.

Hewlett (2013). Open educational resources. Retrieved from http:// www.hewlett.org/ programs/ education-program/ open-educationalresources

Hilton, J ., Gaudet, D., Clark, P., Robinson, T. J., \&Wiley, D. (2013). The adoption of open educational resources by one community college math department. The International Review of Research in Open and Distance Learning, 14(4). Retrieved from http:// www.irrodl.org/ index.php/irrodl/article/view/ 1523.

Hilton, J ., \& Laman, C. (2012). One college’s use of an open psychology textbook. Open Learning, 27(3), 265-272.

Hilton, J ., \& Wiley, D. (2011). Open-access textbooks and financial sustainability: A case study on Flat World Knowledge. The International Review of Research on Open and Distance Learning, 12(5). Retrieved from http:// www.irrodl.org/index.php/irrodl/article/view/960/ 1860

J ohnstone, S. M. (2006). Open educational resources serve the world. Educause Quarterly, 28(3), 15.

McKerlich R., Ives, C., \& McGreal, R. (2013). Measuring use and creation of open educational resources in higher education. The International Review of Research on Open and Distance Learning, 14(4). Retrieved from http:// www.irrodl.org/ index.php/irrodl/ article/ view/ 1573/ 2637.

National Center for Education Statistics. (2013). http://nces.ed.gov/.

Privateer, P. M. (1999). Academic technology and the future of higher education: Strategic paths taken and not taken. J ournal of Higher Education, 60-79.

Provasnik, S., \& Planty, M. (2008). Community colleges: Special supplement to The Condition of Education 2008: Statistical anaylsis report, August 2008.

Ravid, G., Kalman, Y. M., \& Rafaeli, S. (2008). Wikibooks in higher education: Empowerment through online distributed collaboration. Computers in Human Behavior, 24(5), 1913-1928.

Rockinson-Szapkiw, A. J ., Courduff, J ., Carter, K., \&Bennett, D. (2012). Electronic versus traditional print textbooks: A comparison study on the influence of university students' learning. Computers \& Education. 
Shepperd, J . A., Grace, J . L., \& Koch, E. J . (2008). Evaluating the electronic textbook: Is it time to dispense with the paper text? Teaching of Psychology, 35(1), 2-5.

UNESCO. (2002). Forum on the impact of open courseware for higher education in developing countries: Final report. Retrieved from www.unesco.org/ iiep/ eng/ focus/ opensrc/ PDF/ OERForumFinalReport.pdf

U.S. Government Accountability Organization. (2005, J uly). College textbooks: Enhanced offerings appear to drive recent price increases (Publication No. GAO-05-806). Retrieved from http:// www.gao.gov/ new.items/d05806.pdf.

Wiley, D., Hilton, J., Ellington, S., \&Hall, T. (2012). A preliminary examination of the cost savings and learning impacts of using open textbooks in high school science classes. International Review of Research in Open and Distance Learning.

\section{Athabasca University $\mathbf{I}$}

(ㅇ) $\odot$ 


\section{Investigating MOOCs Through Blog Mining}

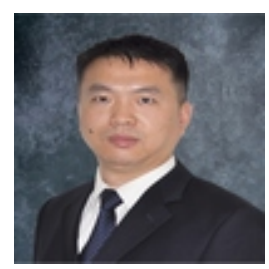

Yong Chen

Old Dominion University, USA

\section{Abstract}

MOOCs (massive open online course) is a disruptive innovation and a current buzzword in higher education. However, the discussion of MOOCs is disparate, fragmented, and distributed among different outlets. Systematic, extensively published research on MOOCs is unavailable. This paper adopts a novel method called blog mining to analyze MOOCs. The findings indicate, while MOOCs have benefitted learners, providers, and faculty who develop and teach MOOCs, challenges still exist, such as questionable course quality, high dropout rate, unavailable course credits, ineffective assessments, complex copyright, and limited hardware. Future research should explore the position of MOOCs and how it can be sustained.

Keywords: MOOC; MOOCs; online learning; blog mining 


\section{Introduction}

A MOOC (massive open online course) is "an online course with the option of free and open registration, a publicly shared curriculum, and open-ended outcomes" (McAulay, Stewart, \& Siemens, 2010). As one of the two most emerging developments in educational technology, MOOC and tablet computing (New Media Horizon, 2013), MOOCs is the buzzword of 2012 in higher education (Daniel, 2012). The fast development of MOOCs attracts many reports and debates among educators. So far, a large volume of press articles and blogs has covered MOOCs. However, discussions of MOOCs are disparate, fragmented, and distributed among different outlets. Systematic and extensive published research on MOOCs is still unavailable (Daniel, 2012; Clow, 2013).

Since blog posts are the main sources of discussion about MOOCs at this stage, this paper adopts a novel research method, called blog mining, to analyze what themes and trends about MOOCs can be found. The goal of this research is to synthesize related discussions in blogs, to provide an in-depth review of MOOCs, and to identify the challenges and future trends of MOOCs. This paper hopes to aid MOOC providers and higher education institutions that might be interested in joining MOOCs to understand what is going on in this fast-moving field. It will offer necessary insights and tips so stakeholders can become knowledgeable about what drives the rapid expansion of MOOCs and the issues they are facing.

\section{Background}

In an age of global competition, information glut and rapid technological changes require learners to become informed on how to retrieve, organize, and evaluate information, how to construct knowledge, and how to develop the ability to work in teams (Mioduser, Nachmias, \& Forkush-Baruch, 2008; Schrire \& Levy, 2012). Due to the advance of information communication technologies (ICTs), the quality of online delivery platforms has improved in recent years. Online activities closely related to social media, such as discussions, blogs, and video lectures, can be easily embedded in online learning (Skiba, 2012). As an extension of existing online learning approaches (Yuan, Powell, \& Cetis, 2013), MOOCs is a model to deliver learning content of a course online to anyone who wants to take it (Educause, 2013). By taking advantage of various web-based technologies, including video presentations, computer-based assessments, and online communication forums, MOOCs allows a large number of learners to access course content, formative and summative assessments, and supports from their fellow learners (Balfour, 2013). It is "a dynamic learning model that offers collaborative and social engagement opportunities for learners to construct knowledge" (Skiba, 2012, p. 416). MOOCs is self-organizing, connected, and open. It has embedded social media affordances, such as perpetual connectivity, asynchronous interaction, unforeseen 
collaborations, and emerging learning opportunities (deWaard, Abajian, Gallagher, Hogue, Keskin, Koutropoulos, \&Rodriguez, 2011).

In 2008, Siemens and Downes offered the first MOOC - " Connectivism and Connective Knowledge" (Yuan, Powell, \& Cetis, 2013). This is a type of asynchronous online learning, which can involve a large number of learners and flexibility for different levels of learners. What makes it unique is that it is free and open to anyone who has Internet access. The creators believed a free course could bring the best education in the world to the most remote corners of the planet, help people in their careers, and expand intellectual and personal networks (Pappano, 2012). This belief seems to be proven by a MOOC called "artificial-intelligence", launched by a Stanford professor, Sebastian Thrun, in 2011, which attracted 160,000 learners in 190 countries (Lewin, 2012). Since MOOCs has been booming in recent years, it plays an increasingly important role in higher education around the world (Meyer \& Zhu, 2013).

MOOCs represents an emerging methodology of online teaching and an important development in open education. Its structure was inspired by the philosophy of connectivism and implementation requires conceptual changes in perspectives from both facilitators (tutors) and learners (Rodriguez, 2013). It is "based on the explicit principles of connectivism (autonomy, diversity, openness, and interactivity) and on the activities of aggregation, remixing, repurposing and feeding forward the resources and learning" (Rodriguez, 2013, p. 1). MOOCs has two distinct branches: (1) connectivist MOOCs (cMOOCs) and (2) a more formal MOOCs (xMOOCs) (Hill, 2012). The pedagogies behind these two branches are different. cMOOCs is built on connectivism (Kop \& Hill, 2008; Siemens \& Downes, 2008), which is a sophisticated and innovative reconceptualization of what it means to know and to learn. In contrast, xMOOCs is based on behaviorist pedagogy that relies on information transmission (Bates, 2012). Siemens (2012) notes, "CMOOCs focus on knowledge creation and generation whereas xMOOCs focus on knowledge duplication" (p. 1). According to Rodriguez (2013), learners and their knowledge are the focuses of cMOOCs. He points out that successful cMOOCs examples in recent years include Connectivism and Connective Knowledge (CCK08), Personal Learning Environments, Networks, and Knowledge (PLENK2010), MobiMOOC (2010), EduMOOC (2011), Change11 (2011/2012), Digital Story Telling (DS106) (2011/2012), and LAK12 (2012). However, compared with cMOOCs, xMOOCs attracts more attention. It focuses on the course content or the instructor. The main players in xMOOCs are Coursera, Udacity, EdX, MITx, and Udemy. Table 1 provides brief descriptions of them. 
Table 1

Main xMOOCs

\begin{tabular}{|l|l|l|l|l|}
\hline Initiatives & Introduction & For profit & $\begin{array}{l}\text { Certification } \\
\text { fee }\end{array}$ & $\begin{array}{l}\text { Institution } \\
\text { credits }\end{array}$ \\
\hline Coursera & $\begin{array}{l}\text { An educational company } \\
\text { founded by two Stanford } \\
\text { professors in April 2012. }\end{array}$ & Yes & Yes & Partially \\
\hline Udacity & $\begin{array}{l}\text { A start-up founded by Stanford } \\
\text { professors offering free courses } \\
\text { in partnership with colleges } \\
\text { and professors. }\end{array}$ & Yes & Yes & Partially \\
\hline edX & $\begin{array}{l}\text { A joint partnership between } \\
\text { Massachusetts Institute of } \\
\text { Technology (MIT) and Harvard } \\
\text { in December 2011. }\end{array}$ & No & Yes & No \\
\hline Udemy & $\begin{array}{l}\text { A learning platform founded by } \\
\text { investors. }\end{array}$ & Yes & Yes & Partially \\
\hline
\end{tabular}

(Source: Yuan, Powell, \& Cetis, 2013)

MOOCs is the current buzzword in higher education. Because it is a disruptive innovation (Skiba, 2012), it initiates many discussions about higher education. Although its future is not clear yet, a number of MOOC platforms have been developed and offer courses independent of or in collaboration with universities (Yuan, Powell, \& Cetis, 2013). In 2012, some elite universities lined up to join forces with MOOC providers (Lewin, 2012). For example, Coursera began with Princeton, the University of Pennsylvania, Stanford, and the University of Michigan. The University of California, Berkeley, and the University of Texas joined edX (Lewin, 2012). Despite the fast development of MOOCs, limited research or evidence is available to support either the positive or the negative opinions about them (Skiba, 2012).

\section{Method}

MOOCs is an innovative way of teaching and learning (Meyer \& Zhu, 2013). As a new type of asynchronous online learning, it provides unique benefits for learners and providers, namely higher education institutions, commercial organizations, and faculty. Because MOOCs is based on the Internet and blog posts are the main sources of discussions about it at this stage, a novel research method, blog mining, was employed in this study to synthesize the related discussions in blogs, to provide an in-depth review of MOOCs, and to identify the future trends and challenges of MOOCs. Blogs allow selfmotivated bloggers to freely and easily post ideas, individual experiences, and opinions (Furukawa, Ishizuka, Matsuo, Ohmukai, \& Uchiyama, 2007; Rubin, Burkel, \& QuanHaase, 2011). Since blogs have a "high degree of exophoricity, quotation, brevity, and rapid of content update" (Ulicny, Baclawski, \& Magnus, 2007, p. 1), running a blog 
mining analysis can improve the timeliness and relevance of this study (Chau \& $\mathrm{Xu}$, 2012). Figure 1 shows the steps of a blog mining process.

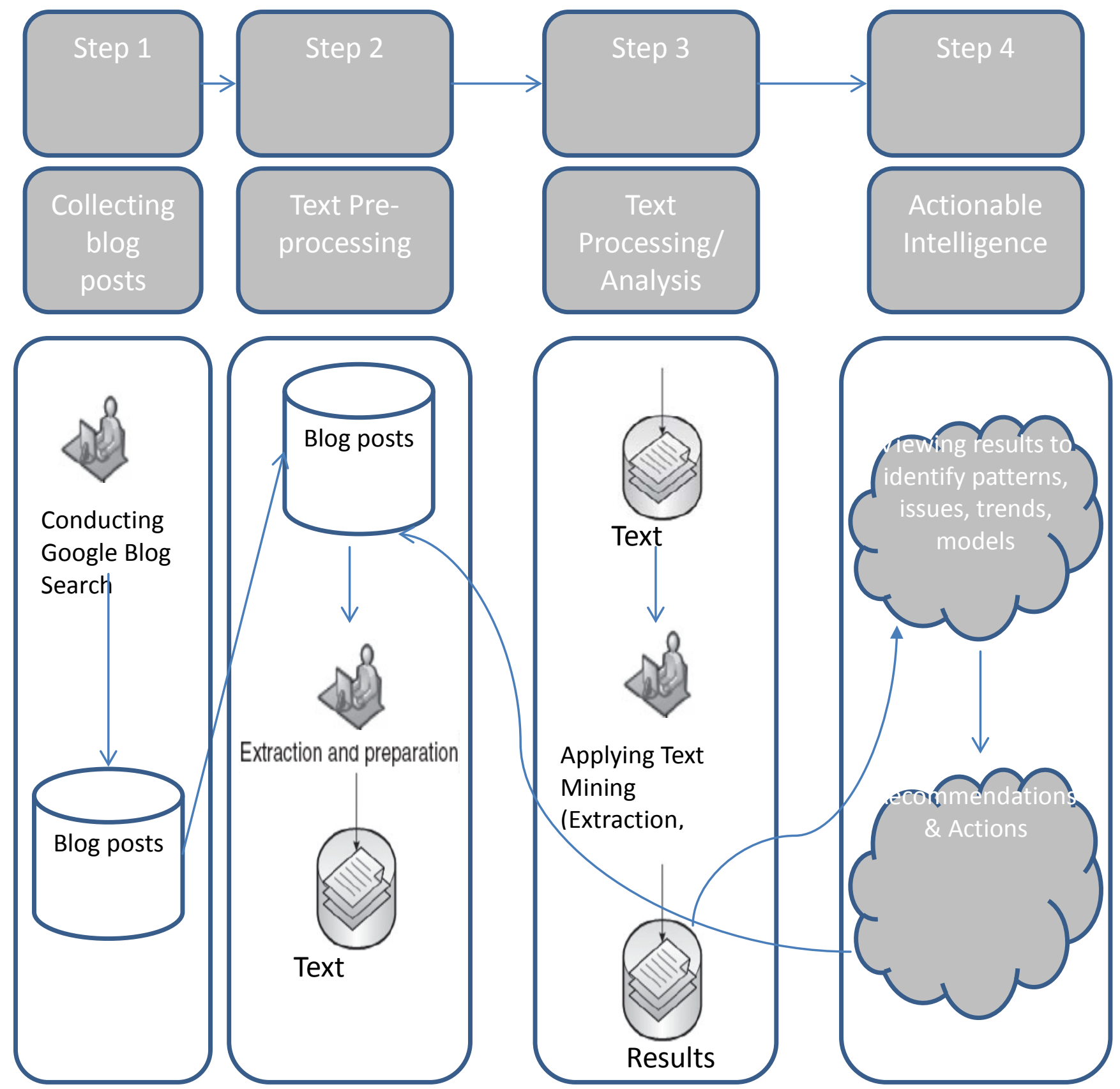

Figure 1. Blog mining process (Source: Abdous \& He, 2011).

Google Blog Search (http://www.google.com/blogsearch) is specially designed to retrieve content from blogs that are freely and publicly available on the Internet. In this study, a query search was conducted first by applying the advanced search option of Google Blog Search with the keyword "MOOC". To identify the latest blog content discussing MOOCs, the query time period was set from January 1, 2010 to J une 31, 
2013. After the query was performed, Google returned the results of the query search with a large number of blog posts created by numerous Internet bloggers. A further step-by-step examination of the resulting pages determined Google actually displayed 306 relevant blog posts and automatically filtered other blog posts considered very similar to the first 306 blog posts.

The blog posts were manually copied and saved as a text file for further analysis. Data pre-processing was conducted next via manually going through all the blog posts. This process determined five irrelevant or redundant blog posts for removal. The remaining posts were utilized as a finalized sample data set that provided a glimpse into the ongoing concerns and discussions associated with MOOCs. In the next step, a concept analysis and mapping (CAAM) technique was adopted to analyze the content of the remaining blog posts, because CAAM has been proven an effective research technique for studying textual written statements (Jackson \& Trochim, 2002). In particular, CAAM software called Leximancer (www.leximancer.com) was utilized to load the blog content, to extract and classify the key concepts and themes, and to identify the patterns and relationships between concepts and themes. Leximancer is

text mining software that can be used to analyze the content of collections of textual documents and to visually display the extracted information in a browser. The information is displayed by means of a conceptual map that provides an overview of the material, representing the main concepts contained within the text and how they are related. (Leximancer, 2010, p. 1)

Leximancer is based on Bayesian theory, which argues fragmented information can be used to predict what occurs in a system (Watson, Smith, \& Watter, 2005). In recent years, various studies have adopted Leximancer as their research tool (e.g., Watson, Smith, \& Watter, 2005; Smith \& Humphreys, 2006; Cretchley, Rooney, \& Gallois, 2010).

Leximancer looked for words that appeared most frequently in the loaded data and then generated a list of concepts. These concept terms were further clustered into themes, based on their relationship to each other. Next, clusters of concepts were grouped by themes named after the most prominent concept in that group. The themes were displayed as large circles on a concept map, which represented the strength of association between concepts and provided a conceptual overview of the semantic structure of the data (Cretchley, Rooney, \&Gallois, 2010; Martin \& Rice, 2011). Concept terms were displayed as spots in the large circles. The large theme circles were heatmapped to indicate their importance. For example, the most important theme appeared in red and the second hottest in orange and so on, according to the color wheel (Leximancer Manual, 2011). 


\section{Results}

Leximancer produced several types of concept maps that indicated the extracted concepts from the sample data set and their interrelationships. An example of concept maps generated by Leximancer from the sample data is shown in Figure 2. Leximancer generated a report that listed the themes and concept terms using its text analytics algorithms. Several closely linked concepts form a cluster and are displayed as dots inside circles. The closer the distance between concepts, the stronger they are semantically linked. Themes (clusters of concepts) are represented as circles. Their importance levels are indicated by the size and the heat degree color of the circles (Leximancer, 2010; Campbell, Pitt, Parent, \& Berthon, 2011; Martin \& Rice, 2011).

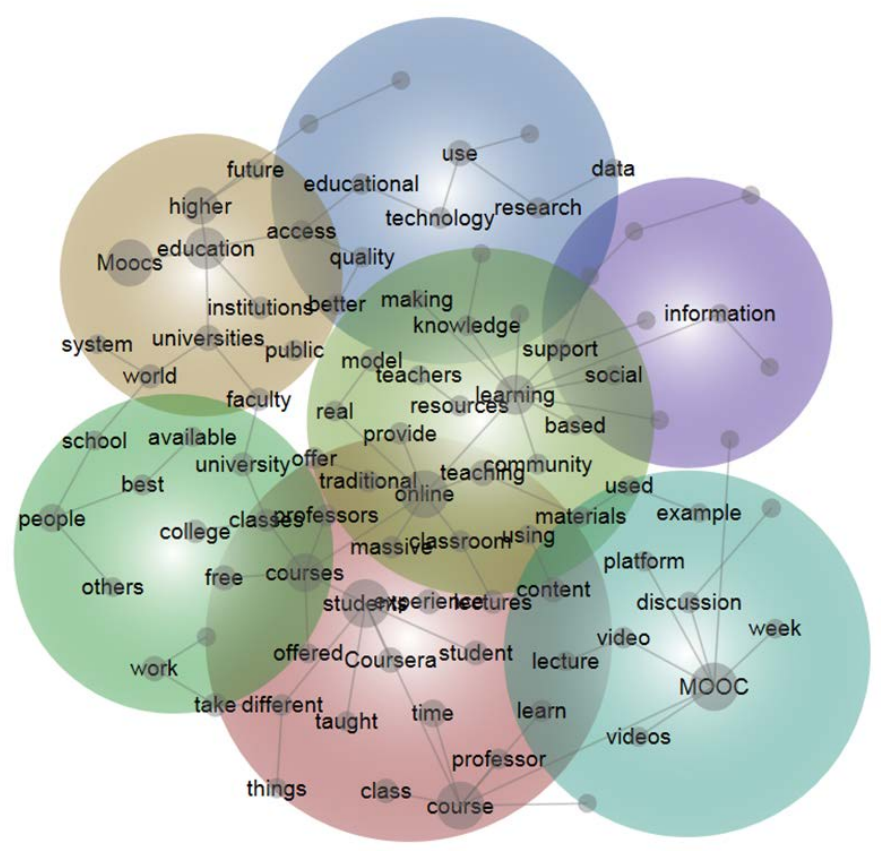

Figure 2. A concept map example generated by Leximancer from the sample data.

To better explain Figure 2, Table 2 lists each theme and the details of its concept terms. Themes are related with circles in Figure 2, while concept terms are related with the dots. 
Table 2

Cluster of Concepts Associated with MOOCs in Blog Posts

\begin{tabular}{|c|c|}
\hline $\begin{array}{c}\text { Cluster of concepts } \\
\text { (themes) }\end{array}$ & Concept terms \\
\hline Students & $\begin{array}{c}\text { Students, course, online, courses, time, Coursera, } \\
\text { content, experience, student, class, lectures, } \\
\text { professors, massive, learn, classroom, different, } \\
\text { professor, things, taught, offered }\end{array}$ \\
\hline MOOCs & $\begin{array}{c}\text { MOOCs, education, higher, universities, world, } \\
\text { faculty, institutions, access, public, better, future, } \\
\text { system }\end{array}$ \\
\hline Learning & $\begin{array}{c}\text { Learning, teaching, model, traditional, provide, offer, } \\
\text { community, resources, support, using, real, } \\
\text { materials, knowledge, used, social, based, } \\
\text { teachers }\end{array}$ \\
\hline People & $\begin{array}{c}\text { People, work, free, university, take, college, classes, } \\
\text { best, available, school, others }\end{array}$ \\
\hline MOOC & MOOC, video, discussion, platform, videos, lecture, \\
week, example
\end{tabular}

Surprisingly, MOOC and MOOCs are both themes. The differences between the concept terms in the two themes are shown in Table 2. Literally speaking, MOOC means a single mass open online course, while MOOCs are several such courses. However, according to the concept list generated by Leximancer in this study, MOOC refers to the structure and components of a mass open online course; whereas, MOOCs represent a new mode of higher education. The difference indicates bloggers have assigned specific meanings to MOOC and MOOCs in their posts.

\section{Discussion}

Compared with traditional classroom-based learning, MOOCs is an innovative way of teaching and learning (Meyer \& Zhu, 2013). This blog mining shows a number of elite higher education institutions around the world have provided MOOCs. Although the trend is unclear, MOOCs has brought big impacts to higher education. A detailed discussion is presented next. 


\section{Benefits for Learners}

Table 2 shows students and people are both themes in the blog mining results. As a disruptive innovation, MOOCs provides learners with a lot of benefits. MOOCs is open to any person who has access to the Internet. It provides free online courses and makes higher education accessible to a global audience (Meyer \& Zhu, 2013). Learners around the world can enroll in MOOCs without any cost. They can even take courses from top universities, as more elite higher education institutions provide MOOCs (Lewin, 2012). They do not need to go to campus or pay expensive tuition for taking courses from top ranking universities. This is a great benefit for learners in developing countries, where high quality, higher education resources are limited. Even in developed countries, MOOCs allows middle class families to offset their high college tuition rates (Thrift, 2013).

MOOCs is a great mechanism for lifelong learning (Skiba, 2012), and users range from teenagers to retirees (Pappano, 2012). According to Belanger and Thornton (2013), learners take MOOCs for the purpose of gaining an understanding of the subject matter, increasing social experience and intellectual stimulation, taking advantage of the convenience,overcoming barriers to traditional education options, and exploring online education. MOOCs is the right learning mode for people looking for extra learning by maximizing their time. This allows self-motivated learners to craft their own educational path by accessing the knowledge, lectures, quizzes, homework, exams, and personalities of the best professors at the top universities in the world (Raza, 2013).

Even in-class students can benefit from the online materials in MOOCs. In some MOOCs, in-class students and MOOC students take classes together. Some professors rearrange their courses to allow their students to complete the online lessons first and come to class later for interactive projects (Lewin, 2013). Such an arrangement allows in-class students and MOOC students to interact with each other. The interaction is very helpful for improving learning effects.

\section{Benefits for Providers}

MOOCs makes it possible for everyone to access higher education, so it has generated significant interest from policy-makers, higher education institutions, and commercial organizations (Yuan, Powell, \& Cetis, 2013). Carey (2013) argues that MOOCs helps higher education policy-makers to address budget constraint problems and to lower the cost of degree courses by experimenting with inexpensive, low-risk, higher education forms. Institutions have been involved in engaging and experimenting with MOOCs to expand access to higher education, achieve marketing and branding, and develop potential new revenue streams (Yuan, Powell, \& Cetis, 2013). Commercial organizations provide a platform based on MOOCs and develop partnerships with institutions to enter the higher education market and to explore new delivery modes in higher education (Yuan, Powell, \& Cetis, 2013). 
Other than the above stakeholders, faculty who teach MOOCs should not be neglected. MOOCs may be prompting some faculty to pay more attention to their teaching styles. It provides faculty an opportunity to learn from dedicated and successful teachers and re-examine their own pedagogical practices so that they can maintain or improve high quality interactions between themselves and students, in face-to-face courses and online courses. As Bali (2013) points out, faculty should dip into MOOCs for professional development, because MOOCs allows them to "observe how others teach online, join community conversations about topics that interest them, taste students' online learning experiences, learn something new in a structured way, and find well-chosen resources on a topic or sub-topic". Moreover, according to Kolowich (2013), MOOCs could increase faculty's visibility among their colleagues and with the general public, increase their earning power, and help them obtain tenure.

\section{Challenges}

In online learning, three characteristics are the most important: (1) quality of material covered, (2) engagement of the teacher, and (3) interactions among students (Pappano, 2012). Because MOOCs is an extension of existing online learning approaches (Yuan, Powell, \& Cetis, 2013), these three characteristics are highly important for MOOCs as well. Although a number of prestigious universities and commercial organizations have been involved in MOOCs and a large number of learners are taking MOOCs currently, MOOCs is confronted with a series of challenges regarding these three characteristics, such as questionable course quality, high dropout rate, unavailable course credits, limited learning assessment methods, puzzling copyright, and limited hardware.

\section{Questionable course quality.}

As mentioned above, the elite universities are rushing into MOOCs for the purpose of expanding access to higher education, marketing and branding, and developing new revenue streams. Are the MOOC courses they provide of good quality? Maybe some are not. As Daniel (2012) argues, even though the elite universities actively involved in MOOCs gained their reputations in research, they may or may not be talented in teaching, especially teaching online. In other words, research is different from teaching. That these elite universities make great achievements in research does not mean that they are capable of offering high quality online learning courses.

Another concern comes from the resources used to support the quality of MOOCs. High quality MOOC courses need huge investments. However, according to Yuan, Powell, and Cetis (2013), it is unclear how MOOCs will make money now and in the near future. For now, learners do not need to pay any fee for taking MOOC courses. But they must pay some fees for providers if they need certificates. Are these charges enough for providers to develop and maintain the academic rigor of MOOC courses the same as that of traditional classes, if not higher? Probably not. Without necessary investments, how can MOOCs with acceptable quality be produced continuously? 
Moreover, the huge number of learners in MOOCs causes big troubles for the interaction between instructors and learners. Usually social media is used widely by MOOCs for learner discussions. Since the number of learners in one single MOOC course is large, it is very difficult, maybe impossible, for the instructor to monitor all course discussions, interact with each learner, and provide feedback (Pappano, 2012; Clow, 2013). The lack of interaction between MOOC instructors and learners will definitely damage the course quality. In addition, the diversity of learners in a MOOC causes the lack of a common knowledge base and educational background among them (Pappano, 2012). As such, when learners post discussions about the course content or other related topics, these discussions might not be very fruitful. Because fruitful discussions are important components in the learning process, learners will not benefit much from such discussions. As a result, the course quality will be damaged by the lack of a common knowledge base and educational background among MOOClearners.

\section{High dropout rate.}

MOOCs has substantially higher dropout rates than traditional education (Clow, 2013). Only about $10 \%$ of the learners who enroll in the largest MOOCs actually complete the course (Daniel, 2012; Sandeen, 2013). Scholars have tried to determine the reasons. For example, Clow (2013) adopts the funnel of participation to explain the high dropout rates in MOOCs. He borrows the idea of "purchase funnel" from the field of marketing and sales, and separates learners' experiences in MOOCs into four steps: (1) awareness, (2) registration, (3) activity, and (4) progress. The number of learners in these steps becomes smaller and smaller from a MOOC's beginning to its end. Clow (2013) argues the high rate is difficult to mitigate because of a lack of existing support resources for learners. McAulay, Stewart, and Siemens (2010) note the high dropout rate is an almost-inevitable consequence of any open, online activity, because initial commitment is missing.

The high dropout rate in MOOCs might be caused by the low cost from the learners' side. Unlike traditional education, MOOCs does not require learners to pay tuition. Any learner can register for a MOOC without considering the cost. Thus, it is no wonder big registration numbers of many MOOCs are shown. In contrast, traditional education has limited space. Students must pay tuition to enroll in a course. They must think about the cost of dropping a course, because they will lose their money and probably need to pay the tuition again if they want to retake this course to obtain credit in the future. However, the cost for MOOCs learners to drop a course can be neglected. The dropping cost is so low that few learners will think about it seriously.

Another reason for the high dropout rate in MOOCs might be the lack of an admission process. No admission process makes MOOCs open to anyone. Learners can register a MOOC regardless of their educational background. Without the admission process, it is difficult to determine whether a learner's education background meets the requirements of a course and whether a course is right for a learner. Because the selection process is missing at the beginning, a big number of learners can register for a MOOC. Once the 
course begins, it is very likely some learners find the course is not what they want or their background does not allow them to catch up with the course.

\section{Unavailable course credits.}

Few colleges or universities offer full course credit to students who complete a MOOC (Meyer \& Zhu, 2013). Many professors teaching MOOCs think students do not deserve course credit for completing a MOOC (Kolowich, 2013). The concerns for course credit are mainly about course quality and the assessment of learning (Meyer \& Zhu, 2013). According to Lederman (2013), only five of Coursera's courses are approved for course credit by the American Council on Education. However, the acceptance of MOOCs for credit hours is growing. Currently, some MOOC providers charge fees for certificates and some have begun to offer credits. For example, the University of Washington offers students college credits for some of its courses, if they take them through Coursera, pay a fee, and complete the additional assessments (Long, 2012). The Colorado State University's Global Campus gives three credits for students who complete a free course offered by Udacity and pass a proctored test (Lewin, 2012; Skiba, 2012). Companies that offer MOOC platforms, such as Coursera, EdX, and Udacity, are growing (Skiba, 2012).

However, Porter (2013) argues that MOOCs is more like "learning tutorials" or "online interactive workshops" than "college courses." Does MOOCs have to be connected with credits? The answer remains unclear. Yuan, Powell, and Cetis (2013) argue that since most learners using MOOCs are people who already have a degree, it is not important whether a MOOC carries credit. This argument raises the debate about MOOCs and degrees. Daniel (2012) indicates what decides whether or not a student can obtain a degree is determined not by their mastery of the course, but by the admissions process to the university. So, he argues that the completion of a MOOC should not be connected with credits, which are towards a degree qualification.

\section{Ineffective assessments.}

Conducting effective assessments in a MOOC is a big challenge so far. On one hand, as a type of asynchronous online learning, MOOCs inheres security risks on the Internet. On the other hand, the number of available effective assessment methods is limited. The development of technology makes diverse cheating methods available for online assessments. According to a study completed by King, Guyette, and Piotrowski (2009), $73.6 \%$ of the students think it is easier to cheat in an online environment than in a conventional one. Methods of cheating with online assessments include using online communication and telecommunications, Internet surfing (Rogers, 2006), copying and pasting from online sources (Underwood \& Szabo, 2003), obtaining answer keys in an illegitimate way, taking the same assessment several times, and getting unauthorized assistance (Rowe, 2004). Other means of cheating on online tests include someone other than the actual student taking the online test and copying answers from elsewhere (Sasikumar, 2013). 
Therefore, MOOCs needs effective assessment methods that can perform user validation and prevent plagiarism (Cooper \& Sahami, 2013). For now, how to ensure the right person is taking a test with the correct materials remains a challenge. To mitigate this risk, some MOOCs providers offer proctored exams. Most of them are making plans to charge fees for such service (Lewin, 2013). For example, to validate students who are taking proctored exams, Coursera, edX, and Udacity tries to set-up partnerships with Pearson so MOOCs learners can take in-person examinations in Pearson testing centers (Parry, 2012; Udacity, 2012; Yuan, Powell, \& Cetis, 2013). Other than proctored exams, biometric authentication seems to be a solution for validating learners (Wang, Ge, Zhang, Chen, Xin, \&Li, 2013).

Because MOOCs relies heavily on computers, assessment methods that can be easily implemented by computers are used widely in MOOCs, including multiple choice questions, formulaic problems with correct answers, logical proofs, computer codes, and vocabulary activities (Cooper \& Sahami, 2013). However, none of these methods is good for assessing written work. So far two mechanisms have been adopted to evaluate essay assignments: (1) machine-based automated essay scoring (AES) and (2) calibrated peer review (CPR) (Balfour, 2013). But due to the limited capabilities of these two mechanisms, assessment methods implemented by computers are adopted widely in MOOCs.

\section{Complex copyright.}

Who is the owner that holds the copyrights for a MOOC course? The answer remains unclear because copyrights for a MOOC course are multifaceted. On one hand, copyrights for a MOOC course involve faculty, learners, universities, and MOOCs providers (Porter, 2013). Thus, MOOCs presents complex copyright issues that could challenge the relationships between a higher education institution, its faculty and learners, and MOOCs providers (Educause, 2013b). On the other hand, materials adopted in MOOCs are in diverse formats and they can be generated by either faculty or learners, or both. To date, a university can first offer a MOOC course with the best of intentions and then offer it via a MOOC provider. It is very likely that the MOOC provider makes profits by selling the MOOC course to other universities. Such a transaction raises the question: Should the university creating the MOOC course get rewards (Creelman, 2013)? In addition, MOOCs providers could violate the common institutional policy approach by establishing a proprietary claim on materials in its courses, licensing to the users the terms of access and use of those materials, and establishing its ownership claim of user-generated content (Educause, 2013b). Most materials in MOOCs, such as syllabuses, course policies, lecture videos, assignments, quizzes, class activities, and schedules, are developed by faculty (Porter, 2013). Therefore, according to the common institutional policy, copyrights for a MOOC course should belong to faculty who develop it, not MOOC providers. As such, Porter (2013) argues that faculty should be careful to understand the laws, policies, and contracts regarding copyrights when they develop MOOCs. However, learners who generate content for MOOCs should not be neglected. Some MOOCs require learners to submit 
assignments, evaluations, discussions, and projects. Once these materials are submitted, who owns them? Can MOOC providers use materials generated by learners in one MOOC course on other MOOC courses? These questions make it necessary to consider who owns materials in MOOC courses and who owns MOOC courses.

Besides the unclear ownership, MOOCs lacks its own copyright protection mode. Traditional copyright protection allows faculty and universities to reach copyright agreements regarding faculty's rights to their materials by following Creative Commons licenses, which regulate materials reuse and adaptation. The agreements work well for campus courses, in which faculty and universities are the main players of copyright protection. Compared with campus courses, MOOCs brings more stakeholders under copyright protection, such as learners and MOOCs providers. Obviously, the aforementioned agreements are not fit for MOOCs. Furthermore, Educause (2013b) indicates that fair-use exceptions to traditional copyright protection face challenges as well because MOOCs is open to learners around the world. As such, MOOCs needs its own copyright protection mode that involves faculty, universities, learners, and MOOCs providers.

\section{Limited hardware.}

In terms of hardware, MOOCs requires computers, headsets/speakers, microphones, and an Internet connection. Among the course contents, video lectures are the main components in MOOCs. Many course contents of MOOCs are delivered in video format via the Internet. To watch a high quality video, learners need broadband connections. However, not every learner has access to a fast Internet connection. A survey conducted by the Pew Internet \& American Life Project in 2012 shows that even in the U.S. only about $66 \%$ of adults have broadband access at home (Cooper \& Sahami, 2013), not to mention that many MOOCs learners are in developing countries and have limited access to the Internet. This hardware limitation needs to be overcome to make MOOCs accessible to more learners.

\section{Trends}

As a disruptive innovation, MOOCs transform higher education (Shirky, 2012). Cooper and Sahami (2013) note that MOOCs has the potential for making education accessible at a global level. Yuan, Powell, and Cetis (2013) argue that MOOCs will provide a powerful tool to make fundamental changes in the organization and delivery of higher education over the next decade. Daniel (2012) points out MOOCs will have an important impact in two ways: (1) improving teaching and (2) encouraging institutions to develop distinctive missions. MOOCs makes it possible for learners to obtain a complete college education from an elite institution online-free or at relatively low cost. This trend brings pressure for higher education institutions. Some colleges, especially the expensive, private schools that are not elite, will find it more difficult to attract students (Perez-Pena, 2012). Meanwhile, lower-tier colleges may have trouble convincing students their courses are worth the price (Lewin, 2012). 


\section{MOOCs and traditional higher education.}

Different from traditional higher education, MOOCs offers free, flexible courses to anyone who has Internet access. Will MOOCs replace traditional higher education? The answer is not clear yet. Many institutions choose to experiment with MOOCs as a way to improve their traditional model. For example, MIT and Harvard are conducting experiments with edX to learn how to educate their on-campus students more effectively (Bates, 2013). San J ose State University embeds MOOCs in traditional classes so students take MOOCs as homework and engage in deep problem-solving in the classroom (J arrett, 2012).

So far, traditional higher education is providing more and more online courses to meet learners' needs. Learners have the option to take online courses and obtain their degrees. Compared with MOOCs, these online courses are not free and learners will receive credits once they finish these online courses. The challenges MOOCs bring to traditional higher education begin from learners' choice between MOOCs and these online courses. When course qualities are the same, why do learners pay for taking online courses instead of taking free MOOCs? However, Clow (2013) argues that MOOCs alone cannot replace degrees or most other formal qualifications and the longterm value for universities is from things that cannot be cheaply duplicated through a MOOC. Therefore, instead of replacing traditional higher education, MOOCs is more likely to coexist with traditional higher education for a while. How long will the coexistence last? Will MOOCs replace traditional higher education ultimately? These questions provide a direction for future research.

\section{How can MOOCs be sustained?}

Although MOOCs are free for learners, developing MOOCs is not free. Belanger and Thornton (2013) indicate that Duke University's first MOOC on Bioelectricity cost over 600 hours to build and deliver. According to Stiehm (2013), an anthropology professor in Duke University estimated that he made 20 times more effort to complete the lessons for his MOOC than for his face-to-face course. However, the current business mode does not enable MOOCs to make money. How can MOOCs be sustained? Kolowich (2012) argues MOOCs will not be open for long and that many MOOCs will be developed as revenue-generating ventures. As such, will MOOCs be available for everyone? If not free, how can they compete with traditional higher education? A recent Insidetrack and ACE survey shows that faculty who have participated in teaching MOOCs and higher education administrators see MOOCs as a way to enhance the on-campus experience, not replace it (Inside Track, 2013). Therefore, the business mode that can sustain MOOCs is a topic for future research as well. 


\section{Limitations of this Study}

Blog mining is a novel method to synthesize related discussions in blogs to provide an in-depth review of MOOCs, and to identify future trends and challenges of MOOCs. It is well suited to MOOCs research, where existing academic studies are not adequate. However, blog posts can have an inherent bias. For example, the information on blogs is not peer-reviewed; authorship of some blog pages is either unclear or unknown; and some blog information might be posted for commercial purposes (He, 2013). Furthermore, the process of analyzing clusters and themes is subjective. To mitigate these limitations and improve research validity, blog mining should be combined with other research methods. Thus, the findings in this research should be validated by additional research with other methods.

\section{Conclusions}

MOOCs is a disruptive innovation and the current buzzword in higher education, but the discussions of MOOCs are disparate, fragmented, and distributed among different outlets. Systematic, extensively published research on MOOCs is not available. This paper adopts a novel method called blog mining to analyze MOOCs. Specifically, Google Blog Search and concept analysis and mapping software called Leximancer are applied in this study for data mining and result analysis.

The result of blog mining indicates that MOOCs benefits stakeholders, namely learners, faculty, universities, and providers. As more and more higher education institutions begin to provide MOOC courses, MOOCs seems to be a new direction for higher education. However, MOOCs face a lot of challenges, such as questionable course quality, high dropout rate, unavailable course credits, ineffective assessments, complex copyright, and limited hardware. These findings aid MOOCs providers and higher education institutions that might be interested in joining MOOCs to understand what is going on in this fast-moving field. MOOCs expanded fast recently because of the benefits it brings to stakeholders. But the aforementioned challenges hinder its further development. Future research needs to explore ways to overcome these challenges. In addition, this paper offers insights and tips for stakeholders so they can become knowledgeable about what drives the rapid expansion of MOOCs and the issues they might face if they choose to join MOOCs. Although MOOCs expanded fast recently, the position of MOOCs remains unclear. Will it coexist with traditional higher education or be a replacement? The answer is not available. A more urgent issue is how MOOCs can be sustained. Future research needs to explore the answers. 


\section{References}

Abdous, M., \&He, W. (2011), Using text mining to uncover students' technology-related problems in live video streaming. British J ournal of Educational Technology, 40(5), 40-49.

Balfour, S. P. (2013). Assessing writing in MOOCs: Automated essay scoring and calibrated peer review. Research \& Practice in Assessment, 8, 40-48.

Bali, M. (2013). 5 reasons teachers should dip into MOOCs for professional development. Retrieved from $\underline{\mathrm{htt}} \mathrm{p} / /$ moocnewsandreviews.com/5-reasonsteachers-should-dip-into-moocs-for-professional-development2/\#ixzz2ngE9J 9hC

Bates, T. (2012). What's right and what's wrong about coursera-style MOOCs. Retrieved from http:// www.tonybates.ca/ 2012/ 08/ 05/ whats-right-and-whats-wrongabout-coursera-style-moocs/

Belanger, V., \& Thornton, J . (2013). Bioelectricity: A quantitative approach-Duke University' first MOOC (Technical Report). Duke University, NC, USA.

Campbell, C., Pitt, L., Parent, M., \& Berthon, P. (2011). Understanding consumer conversations around ads in a Web 2.0 world. J ournal of Advertising, 40(1), 87-102.

Carey, K. (2013). Obama, Rubio agree on one thing: Technology could fix the higher ed mess. Retrieved from http:// tinyurl.com/ cogw2kh.s

Chau, M., \&Xu, J . (2012). Business intelligence in blogs: Understanding consumer interactions and communities. MIS Quarterly, 36(4), 1189-1216.

Clow, D. (2013). MOOCs and the funnel of participation. In Proceedings of the Third International Conference on Learning Analytics and Knowledge (pp. 185-189). ACM, New York.

Cooper, S., \&Sahami, M. (2013). Education reflections on Stanford's MOOCs: New possibilities in online education create new challenges. Communications of the ACM, 56(2), 28-30.

Creelman, A. (2013). MOOCs-copyright confusion. Retrived from http://acreelman.blogspot.com/2013/10/moocs-copyright-confusion.html

Cretchley, J ., Rooney, D., \& Gallois, C. (2010). Mapping a 40-year history with Leximancer: Themes and concepts in the J ournal of Cross-Cultural Psychology. J ournal of Cross-Cultural Psychology, 41(3), 318-328. 
Daniel, J . (2012). Making sense of MOOCs: Musing in a maze of myth, paradox and possibility. J ournal of Interactive Media in Education, 3.

deWaard, I., Abajian, S., Gallagher M.S., Hogue, R., Keskin, N., Koutropoulos, A., \& Rodriguez, O. (2011). Using mLearning and MOOCs to understand chaos, emergence, and complexity in education. The International Review of Research in Open and Distance Learning, 12(7), 95-115.

DiSalvio, P. (2012). Pardon the disruption: Innovation changes how we think about higher education. New England J ournal of Higher Education, 9/4/2012, 1.

Educause (2013). What is a MOOC? Retrieved from http:// www.educause.edu/library/massive-open-online-course-mooc

Educause (2013b). Copyright challenges in a MOOC environment. Retrieved from https:// net.educause.edu/ir/ library/pdf/ PUB9014.pdf

Furukawa, T., Ishizuka, M., Matsuo, Y., Ohmukai, I., \& Uchiyama, K. (2007). Analyzing reading behavior by blog mining. In Proceedings of the National Conference on Artificial Intelligence (Vol. 22, No. 2, pp. 1353). Menlo Park, CA; Cambridge, MA; London; AAAI Press; MIT Press; 1999.

Gardner, L., \&Young, J . (2013). California's move toward MOOCs sends shock waves, but key questions remain unanswered. The Chronicle of Higher Education.

He, W. (2013). A survey of security risks of mobile social media through blog mining and an extensive literature search. Information Management \& Computer Security, 21(5), 381-400.

Hill, P. (2012). Four barriers that MOOCs must overcome to build a sustainable model.

Retrieved from http:// mfeldstein.com/four-barriers-that-moocs-mustovercome-to-become-sustainable-model

Inside Track (2013). To MOOC or not to MOOC: Strategic lessons from the pioneers. Retrieved from http:// www.insidetrack.com/mooc-mooc-strategic-lessonspioneers/

J ackson, K., \& Trochim, W.K.M. (2002), Concept mapping as an alternative approach for the analysis of open-ended survey responses. Organizational Research Methods, 5(4), 307-336.

J arrett, J . (2012). What are MOOCs and why are education leaders interested in them? Retrieved from http:/ / www.huffingtonpost.com/ impatient-optimists/ what-aremoocs-and-why-ar_b_2123399.html 
King, C. G., Guyette, R. W., \& Piotrowski, C. (2009). Online exams and cheating: An empirical analysis of business students' views. The J ournal of Educators Online, 6(1), 1-11.

Kolowich, S. (2012). MOOCs for credit. Inside Higher Education. Retrieved from http:// www.insidehighered.com/news/2012/10/29/ coursera-strikes-mooclicensing-deal-antioch-university

Kolowich, S. (2013). The professors who make the MOOCs. Chronicle of Higher Education. Retrieved from http:// chronicle.com/article/The-ProfessorsBehind-the-MOOC/ 137905/ \#id=overview

Kop, R., \&Hill, A. (2008). Connectivism: Learning theory of the future or vestige of the past? The International Review of Research in Open and Distance Learning, $9(3)$.

Lederman, D. (2013). Expanding pathways to MOOC credit. Inside Higher Education. Retrieved from http:/ / www.insidehighered.com/news/ 2013/ 02/ 07/ ace-deems5-massive-open-courses-worthy-credit

Leximancer (2010). Leximancer white paper. Brisbane, Australia: Leximancer. Retrieved from https:// www.leximancer.com/lmedia/Leximancer_White_Paper_2010.pdf

Leximancer (2011). Leximancer manual: Version 4. Brisbane, Australia: Leximancer. Retrieved from https:// www.leximancer.com/lp/ 4.00.20L1173952/m/doc/LeximancerManual. pdf

Lewin, T. (2012, November 19). College of future could become one, come all. The New York Times.

Lewin, T. (2013, February 20). Universities abroad join partnerships on the Web. The New York Times.

Long, K. (2012, J uly 18). UW to offer fee-based courses through Coursesea. The Seattle Times.

Martin, N., \& Rice, J . (2011). Cybercrime: Understanding and addressing the concerns of stakeholders. Computers \& Security, 30(8), 803-814.

McAulay, A., Stewart, B., \& Siemens, G. (2010). The MOOC model for digital practice. University of Prince Edward Island. Retrieved from http:// www.elearnspace.org/Articles/MOOC_Final.pdf 
Meyer, J .P., \&Zhu, S. (2013). Fair and equitable measurement of student learning in MOOCs: An introduction to item response theory, scale linking, and score equating. Research \& Practice in Assessment, 8(1), 26-39.

Mioduser, D., Nachmias, R., \& Forkush-Baruch, A. (2008). New literacies for the knowledge society. In J . Voogt \& G. A. Knezek (Eds.), International handbook of information technology in primacy and secondary education (pp.23-42). New York; London: Springer.

New Media Horizon and EDUCAUSE (2013). NMC Horizon report: 2013 higher education edition. New Media Consortium.

Pappano, L. (2012, November 2). The year of the MOOC. The New York Times, 2(12).

Parry, M. (2012, September 6). EdX offfres proctored exams for open online course. The Chronicle of Higher Education.

Perez-Pena, R. (2012, J uly 17). Top universities test the online appeal of free. The New York Times.

Perez-Pena, R. (2012). Top universities test the online appeal of free. The New York Times. Retrieved from http:// www. nytimes. com/2012/ 07/ 18/ education/topuniversities-test-theonline-appeal-of-free

Porter, J . E. (2013). MOOCS, “Courses”, and the question for faculty and student copyrights. The CCCC-IP Annual: Top Intellectual Property Developments of 2012.

Raza, K. (2013). What's a mooc and why you should know and care! Retrieved from http:// socialmediatoday.com/khalidraza9/1413716/ what-mooc

Reich, J . (2012). Summzrizing all MOOCs in one slide: Market, open and dewey. Retrieved from http://blogs.edweek.org/edweek/ edtechresearcher/2012/05/all_moocs_explai ned_market_open_and_dewey.html

Rodriguez. C. O. (2013). MOOCs and the Al-Standard like courses: Two successful and distinct course formats for massive open online courses. The European J ournal of Open, Distance and E-Learning. Retrieved from http:// www.eurodl.org/ ?article $=516$

Rogers, C. F. (2006). Faculty perceptions about e-cheating during online testing, J ournal of Computing Sciences in Colleges, 22(2), 206-212.

Rowe, N. C. (2004). Cheating in online student assessment: Beyond plagiarism. Online J ournal of Distance Learning Administration, 7(2). 
Rubin, V. L., Burkel, J ., \& Quan-Haase, A. (2011). Facets of serendipity in everyday chance encounters: A grounded theory approach to blog analysis. Information Research: an International Electronic J ournal, 6(3).

Sandeen, C. (2013). Assessment's place in the new MOOC world. Research \& Practice in Assessment, 8(1), 5-12.

Schrire, S., \& Levy, D. (2012). Troubleshooting MOOCs: The case of massive open online course at a college of education. In Proceedings of the World Conference on Educational Multimedia, Hypermedia and Telecommunications (pp. 761766).

Sasikumar, M. (2013). E-learning: Opportunity and challenges. Retrieved from http:// www.cdacmumbai.in/design/ corporate_site/ override/ pdf-doc/elearning.pdf

Shirky, C. (2012). Napster, Udacity and the academy [Web log post].

Siemens, G. (2012). MOOCs are really a platform. Elearnspace. Retrieved from http:// elearnspace.org/ blog/2012/07/25/ moocs-are-really-a-platform/

Siemens, G., \&Downes, S. (2008). Connectivism \& connected knowledge: CCK08, CCK09. Retrieved from http:// ltc.umanitoba.ca/connectivism/

Skiba, D. (2012). Disruption in higher education: massively open online courses (MOOCs). Nursing Education Perspectives, 33(6), 416-417.

Smith, A. E., \& Humphreys, M.S. (2006). Evaluation of unsupervised semantic mapping of natural language with Leximancer concept mapping. Behavior Research Methods, 38(2), 262-279.

Stiehm, C. (2013). Faculty members share experiences with MOOCs. Retrieved from http:// www.dukechronicle.com/ articles/2013/ 09/27/ faculty-members-shareexperiences-moocs

Thrift, N. (2013). To MOOC or not to MOOC. Chronicle of Higher Education. Retrieved from http:// chronicle.come/ blogs/ worldwise/ to-mooc-or-not-to-mooc/31721

Udacity blog (2012). Udacity in partnership with Pearson VUE announces testing centers. Retrieved from http:// blog.udacity.com/2012/ 06/ udacity-inpartnership-with-pearson-vue.html

Ulicny, B., Baclawski, K., \& Magnus, A. (2007). New metrics for blog mining. In Defense and Security Symposium (pp. 657001-657001). International Society for Optics and Photonics. 
Underwood, J ., \& Szabo, A. (2003). Academic offences and e-learning: Individual propensities in cheating. British J ournal of Educational Technology, 34(4), 467-477.

Voss, B. D. (2013). Massive open online courses (MOOCs): A primer for university and college board members. Retrived from http://agb.org/sites/agb.org/files/report_2013_MOOCs.pdf

Wang, F., Ge, B., Zhang, L., Chen, Y., Xin, Y., \& Li, X. (2013). A system framework of security management in enterprise systems. Systems Research and Behavioral Science.

Watson, M., Smith, A., \&Watter, S. (2005). Leximancer concept mapping of patient case studies. In Knowledge-based intelligent information and engineering systems (pp. 1232-1238). Springer Berlin Heidelberg.

Yuan, L., Powell, S., \& Cetis, J . (2013). MOOCs and open education: Implications for higher education. Retrieved from http:// www.smarthighered.com/ wpcontent/uploads/2013/03/MOOCs-and-Open-Education.pdf

\section{Athabasca University $\mathbf{a}$}

(ㄷ) $(1)$ 


\section{Monetizing French Distance Education: A Field Enquiry on Higher Education Value(s)}

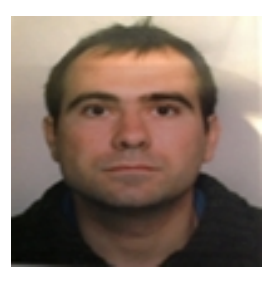

Olivier Marty

Cnam, France

\section{Abstract}

A field enquiry in French distance education allows us to analyze the evolution of a specific institution towards new public management: Parallel to a trend of free courseware and open education, there is a paradoxical reality of distance education monetization. Whereas history shows how traditional French education is a state controlled public good, a new policy is changing the organization's culture towards a commercial and industrial activity. From inside the institution, we describe the cultural changes, with its human resources, accounting, and marketing dimensions. We relate debates about the institution's business model within the economy of knowledge selling either services or contents, focusing on the learner's experience. Lastly, we analyze the notion of value underlying this monetization of a distance education institution: both the computing of a specific training's value and the shared values of the workers binding up their collective identity.

Keywords: Money; distance education; France; marketing; value 


\section{Introduction: From Participatory Observation to Education Sciences Analysis}

\section{Collection of Data}

Since 2011 I have been conducting a participatory observation within a French national distance education institution, occupying training engineering and management functions within the organization. My main focus of analysis is education management, since it is the research axis of the education sciences laboratory I belong to (Cnam, CRF, Axis 4).

Attending to the organization's daily life, with a declared research goal, I have collected empirical raw material, archived online ${ }^{1}$. I want now to take some distance to rethink my ethnographical data in order to place it within the long run evolution of French national distance education.

During this ethnographic study, which could become an exploratory work for a larger quantitative enquiry, I have observed a deep change in the organization's culture: recruiting private sector executives to replace civil servants and precisely accounting for every single resource and investment in order to be profitable on the e-learning market. I want to describe and analyze precisely this monetization of a public institution, conducted in an atmosphere of possible privatization. I will try to show that this mutation is deeply changing education's value: both the estimated value of a particular training course (how much is it worth on the market?) and the workers' values within the institution (what do they value in their educational work?).

\section{Review of Literature}

My article is framed by fundamental research on distance education (Moore, 2012) as well as by French distance education history. I will, for example, discuss the dilemma between selling either method or pedagogy, which has a correspondence with Moore's transactional model: Pedagogy is related to communication whereas method is in relation to course structure. Moore, in his recently reedited handbook, collaborates with Otto Peters, who is fundamental to understanding the process of industrialization of education and mega universities. These works had a French reception by J acques Perriault - former researcher within the institution studied - and nowadays Pierre Moeglin and the scientific review Distances and Mediations of Knowledge.

At the Conservatory, where I conduct my research, I am indebted to J ean-Marie Barbier's (2009) work on education activities. I use social sciences methods as taught at École Normale Supérieure where I have been trained by Florence Weber (2008), influenced by the North American author Erwin Goffman. Methods of specialized

\footnotetext{
${ }^{1}$ http://educations.voila.net
} 
ethnography within higher education organizations are detailed by Mercer (2007) and Trowler (2012).

The history of the French education system is a field of research covered by Prost (2007) and Lescure (2010) for the part concerning adult education. The international question of commodification of education has been analyzed and criticized by Shumar (1997, 2008).

Finally, the measure of value within an organization has been discussed by Vatin (2008), with an influence from John Dewey (1997). The question of the values of a community, personified by leaders, is the central question of my $\mathrm{PhD}$, defended at the University of Western Paris in 2011 (author's online publication).

\section{Distance Education History within the French State System of} Education

\section{Education as a Public Good, Provided by the French Central State}

Since the $18^{\text {th }}$ century, French education has been state controlled: First engineering schools like Ecole des Ponts et Chaussées (1747) or Ecoles des Mines (1783) were created by government in order to provide trained workers for key functions of the administration, such as construction of bridges, roads, and organization of mines. Therefore, medieval universities (La Sorbonne university, Toulouse University, etc.), still partly supervised by Catholic Church powers, were in competition with these public state schools. A new system of production of the elites was created, reinforced by the French Revolution (1789-1799) and Napoleonian Imperial University.

Since then, higher education has been organized by the French state, giving the right to universities and public schools to deliver diplomas. In France, higher education has been and still is a state concern. In 1838 was created the Ministère de l'instruction publique, rebaptised in 1932 Ministère de l'éducation nationale and currently named the Ministère de l'enseignement supérieur et de la recherche, dedicated to higher education.

Private organizations entered this field of higher education in the 19th century: École supérieure de commerce de Paris, the first private business school, was created in 1819 and other provincial initiatives followed. Today these schools are under state control since their diplomas are evaluated by the Ministry of higher education and research. 
As a result of this 250 year history, education has been considered a public good of general interest, provided by state institutions and controlled by the French government. Money is not the main value: Knowledge is the central item and it relies on meritocracy, that is to say the best position given to the best learner. State grants are provided to students coming from low income families and access to training is free. The main selection is not money-based but made through competition: The difficulty of a “Grande École's “concours d'entrée” is what makes it and its students valuable.

An ideology of equity between all French young students is well spread in the education system: The most prestigious curricula are based on mathematics, where performances are said to be less sensitive to family background than for French language subjects. Politically, most teachers are on the left wing and French sociologists (like Bourdieu, 1990) are known for their criticism of the system's imperfection (i.e., elites' social reproduction).

However, with the development of lifelong learning (a European policy), adult training and the influence of the Anglo-American model of private education in Europe, France may have to change this state tradition. Indeed, many student exchanges (like the Erasmus program in Europe) confront the public service with private curricula from other countries. Research activity necessitates fund raising and this is part of a process of privatization of science (Feyerabend, 2010) and education. In France, a 1971 law for permanent education fostered company training of workers. A new market for adult training was born, where universities, schools, and specialized organisms (independent or "université d'entreprise") are now competing. This competition soared with a technological evolution during the 2000s due to the Internet and e-learning development.

This is the educational environment of distance education, state public service created in 1939 to provide instruction to French young learners in parts of France occupied by Germans at the beginning of World War 2. I will try to show that, since its creation, this public service has been a rather innovative institution and how it is now anticipating a possible shift towards a privatization of education.

\section{Distance Education: From a Public Service to a Profitable Institution}

In France distance education is represented by a public institution created in 1939, by the occupied State of France. It has grown after the war into a public service, reaching the status of an academy (education administrative subdivision of the French territory) in 1986. First positioned in Paris, it moved to Futuroscope (central region) in the 1990's and counts eight sites all over French territory. It is a public administration under the control of both the Ministère de l'éducation nationale and the Ministère de l'enseignement supérieur et de la recherche. It provides learners with a complete curriculum, from primary school to master degrees. 
All along its development, the institution has grown into an industrial producer of knowledge, sending lectures and education material to hundreds of thousands of learners (200,000 in 2011). This industrialization, characteristic of a massive education institution, was associated with the experimentation of all new pedagogy technologies: Lectures sent by post were soon accompanied by telephone contact, television, Minitel and finally the Internet with web sites, email, forum, chat, virtual classes, and so on. The institution was a tool to experiment with the massive use in French education of new technologies.

However, whereas primary and secondary education (which is compulsory in France, until the age of 16) are considered as a public service, with a legitimacy to be state funded and free for all citizens, higher education is reconsidering its position. Indeed, the French ministry for higher education and research asks the institution to be selfsufficient as to what concerns higher education and adult learning.

Therefore, the institution has to rethink its business model: The value of each training course has to be reconsidered to measure whether it is profitable or not. Every training course is now competing in a distance learning market where there are many universities and schools, as well as private companies, investing in e-learning tools like learning management systems. It is in this context that we conducted our ethnographical study: The organization is under pressure and has to reinvent its business model. I will now describe this evolution from inside, with the change of habits, traditions, and new values imposed on workers.

\section{Institution's Transformation: Towards an Industrial Culture}

\section{Changing Human Resources}

Traditionally, the distance learning institution's higher education service recruits state teachers in order to manage its training courses and programs. They come from high schools or universities and are recruited for a job that is slightly different from what they are used to: They focus on the administrative part and don't have to teach any longer. The job is about recruiting and making contracts for authors and tutors, conceiving new curricula and elaborating partnership with publishers or universities. It is both an activity of management and training engineering. The workers we studied have to harmonize different departments: a production department in charge of printing and sending lectures, or preparing learning websites; an administration department in charge of admission, collecting and having tests corrected, sending the final training certification (signed by the manager/ engineer).

However the mode of recruitment changed when we conducted our participatory observation: With the rise of new public management (NPM), a new direction was 
established to give priority to workers coming from the private sector (having worked with a publisher, an adult training company, etc.) or trained in private business schools. Being a "pedagogue" with strong in-classroom experience was no longer the main criteria to be selected. Civil-servants are nowadays in competition with private workers and everyday life has changed.

At a higher level, I had informal interviews with directors who were recruited in order to determine and conduct the organization's strategy. Their very title says a lot about the new public management they represent: They are called "business unit directors", and their services are defined by the market segment they target. Most of them are outsiders, having professional experience in private organizations not necessarily linked with education. They represent the new generation, wearing suits and ties, talking about clients and money.

\section{Changing Workers' Habits}

I first observed confusion in the vocabulary used to designate the audience targeted by the institution. Whereas former employees use the word "usager" (which is the French word for any user of a public service), the new generation more often talks about "clients". The ideology of public service and common good is therefore replaced by the notion of private interest and the transaction of money opening rights to the consumer. However a compromise is found around the notion of "learner" ("apprenant"), designating neither a student nor a pupil but an adult engaged in specific training. This term refers to the institution's sector of activity and not its mode of operating (public/ private activity).

Another difference appears in the way people are dressed: Whereas the old generation of teachers have a casual style, the newcomers more easily come to work with a formal costume and a tie. The notion of time tends to be stricter: Employees' schedules are controlled by a time-machine (they have to badge in and out of the institution) in order to measure how much time they spend within this industry of knowledge.

And here comes the most important change: This focus on work measure is stressed by the top management. A few management controllers were hired in order to set up a tool to measure the activity. After having audited all sites and departments, they built up an Excel spreadsheet computing all the costs of specific training. Whereas the most experienced employees had the habit of creating new training courses without knowing in detail how much it would cost or whether it would be profitable, they now have to estimate precisely the amount of money they invest and the expected return on investment.

The employees have to fill in many costs within the Excel document: how many days spent conceiving and then coordinating the pedagogical device; how many pages of lectures brought to authors; how many pages to design and to publish a website by the production department; how much time spent animating the forum and website; how 
many hand-ins to be corrected by the tutors; how many days of presence in a classroom for hybrid training combining distance and presence. All these costs are summed up and compared to the prevision of learners and the estimated price of the training (fixed by a specific worker in charge of analyzing all of the institution's prices). Then the Excel tool gives a financial analysis, with margin, benefits, and cash flows. Thus, all workers are fostered to discover this accounting dimension and see reality through this economic focus.

This is a major cultural change since none of them had this habit of accounting - and a few among the eldest had difficulties with the Excel computer tool. This reform led to a great deal of trouble among the workers (at least the ones of the older generation, judging the tool as impossible to handle given the complexity of their training projects). It took a few months to accept the use of this tool and it is still not well considered by all.

Another tool recently implemented by top management is a validation of all new projects through a process entitled "product's life cycle". Like in the industrial sector, all the training courses are considered as products, which are born, developed, and finally suppressed whenever they are no longer profitable enough. Training engineers therefore have to fill in this document, including many business considerations they had no habit of: market, commercial target (quantitative data and qualitative comments about this target), general description of the pedagogical dimension of the product (is it innovative? what are the services included?), planning of implementation, income hypothesis, and so on. Here again this marketing process, illustrating new public management, had a cold reception by former teachers. They saw an invasion of economics into their craft of pedagogy.

The cultural change just described is summed up by a current controversy within the institution. It is indeed an administrative public institution but rumors say that it may be turned into an industrial and commercial public institution. This change of legal status would be a turning point indicating a clear change in the organization's culture: Private sector habits and monetization would be the official nature of the institution. Unions and old employees are criticizing this possible change of status, arguing it would betray the spirit of French public education.

After this glimpse of everyday life micro evolution, let's consider how the institution is rethinking its business model. If it is now widely admitted that training involves money, there is not yet a consensus on what is to be sold. 


\section{Selling What to Whom? About Commodification of Education}

\section{Method versus Pedagogy}

Commodification of education in America has been described by Shumar $(1997,2008)$. In our European case we saw that it implied a few business tools to estimate the economic value of a specific training course in order to be profitable on the market. For both there is common evidence: Education is a product that can be sold.

At the institution I studied, however, there is still a debate about what is to be sold. In an interview, the general director of training declared that content was no longer the core of the institution's business model. Delivering a document (either paper or online), mere reading material or a video, is not the main added value of the training. It is the job of publishers to edit such content and sell it in the market. What I would call "method"2, that is to say courses' content, is what is traditionally seen by the consumer as the materialization of knowledge. Method is the result of the learning process, what has been learnt. However, the general director of training puts forward another item as more important: pedagogy.

Pedagogy 3 is a set of services provided by teachers to the learner. They orientate before any engagement in a curriculum (by phone), they help in case of difficulties in the course (through an online forum), they correct mistakes (on the hand-ins), they recognize the learning process (through marks and a certificate delivered by the institution), they give pieces of advice about future orientation (for any other training).

This economy of service that would replace the industrial production of content, according to the training general director, is however not clearly defined. There are debates about how it should be sold: free content and extra services bought one by one by the learner? Content plus services to be paid all at once? There is, in both cases, a challenge to think of economy of knowledge independently from these two dimensions of a teacher's craft: economy of service (pedagogy) and economy of production (method).

This strategic uncertainty may be due to contenders such as $\mathrm{MOOC}^{4}$ who are giving away much of their content and services, both method and pedagogy. Business models in distance education are therefore contested by universities and private institutions distributing their knowledge on the Internet. Decades old institutions have to reinvent what they sell and how they sell it to be competitive on the Internet market.

\footnotetext{
${ }^{2}$ From Ancien Greek mathein (to learn) and hodos (path): the mental path that will follow the learner, the sum of all that he will have conceived at the end of his training.

${ }^{3}$ From Ancient Greek paideia (child) and gogein (to lead): it refers to a notion of accompaniment.

${ }^{4}$ Massive online open courses
} 


\section{Learner's Experience}

Another controversy is about the learner's experience. Influenced by experiential marketing, attention is paid to what the learner will feel and live during his/ her training. A training course (or formation) is different from a mere piece of information since it is bigger (it is a complex set of information pieces) and goes deeper in the learner's mind. Learning a piece of information is an everyday process in order to solve common problems. But learning a complex set of information devices (going through a formation) is a much more important mental activity: It takes time, the learner tends to identify himself/ herself with the knowledge acquired, and he/ she will remember it for a longer period of time.

Therefore attention is paid to this learning experience. To amplify identification, a service of socialization has been set up. Since the experience of learning is stronger within a community, the institution set up a network tool supervised by a community manager. Learners can exchange tips and tricks about the course. They feel part of a learning team and there is both cooperation and competition. They help each other and they compete to outwit each other. There is solidarity in case of difficulty and honor amplifies the results of each and every individual learner. This service is provided for free up to now and the institution is thinking about an independent price from the training: Here again the business model is under construction.

Last, an alumni community is strengthened by a marketing tool. The institution invested in a specific website collecting learners' success stories. Testimonials from students having a double career as athlete or artist are highlighted with many images and positive comments. For example, a French surfing champion is interviewed since he did all his high school with the distance education institution, having therefore the possibility to study at hot surfing spots. Another example is a family who decided to sail all around the world, the children attending distant classes with the institution. A community manager deals with the website's forum, answering questions and orientating debates about the institution. Such marketing of training makes the learner's community more united around a few 'stars', leaders to follow. But it also allows the institution to convert prospects into clients. Indeed, the institution's online catalogue is directly linked to this website. The institution is therefore selling dreams, associating itself with rather innovative ways of life and learning experiences.

\section{The Professional Education Market}

Selling training courses, whether it is a combination of method and pedagogy or a new learning experience, is not natural in France. I showed earlier that French national history led to thinking that education was a public good by nature. However, with adult training development and lifelong learning, France's legislation changed. The 1971 law about permanent education created a new market: professional training financed by a company's human resources department (HR). 
This new market has been targeted by specific training organisms, but also by universities and public schools, adding new training programs to their portfolio. The institution we studied created a specific department dedicated to this professional market. This department, linked both with the commercial department and the training department, is highly representative of the commodification of education. Indeed, its main activity is to sell training to professional organizations. It is placed near the headquarters and represents modernity within the institution. Whereas most activities are scattered across eight different sites in France, this one is at the heart of the institution.

I therefore observed an institution moving from an administrative culture delivering a public good to an industrial culture selling profitable training on the market. Even if what is to be sold is not yet clearly defined, a tendency of monetization appears. Let's see what the consequences of this new strategy are. We will focus on the very notion of value and its estimation, underlying the question of money.

\section{A Question of Value(s)}

\section{Value of Training}

I showed how selling specific training implied its evaluation. Within the institution, this is made with particular software that sums up all costs and benefits and makes automatically a financial analysis (margin, profitability, etc.). It is a financial approach to value: All future costs and benefits are summed up and actualized at the present moment, in order to take a decision about whether to invest or not. Monetization implies that all training programs' value can be computed with numbers, quantified and estimated throughout time. This was hard to admit for most teachers but the shift in the organization's culture and employee turnover makes it a common reality for any new worker.

I want now to add a field-based complement to this financial analysis of value. Indeed, discounting coming gains and losses to estimate present value is future-oriented and does not take into account past experience. French teachers within this institution regularly say that school and training courses are here for values transmission. That is to say that a learner going through specific training will be changed deeply, so deeply that what he or she will consider as valuable will be different.

When a client buys training, he/ she discounts future gains (value of this training on the labor market for example) and losses (how much it costs, including opportunity cost, that is to say what he/ she could do instead of this training) in order to determine if the

price of the training is in tune with his/her personal estimation of its value. And when 
the distance education institution proposes a price for the training, it takes into account what the client would be ready to pay.

But what is missed in this value estimation is the learner's change of values throughout the training. For example, having done a training program in management, he/ she will be even more attracted by management than before and value therefore everything that deals with management. $\mathrm{He} /$ she will probably become a manager and will therefore retrospectively over-value his/her training in management. Generalizing this idea, training retrospectively increases its own value by itself: Since it implies a new valuation in the trainee's mind, it tends to legitimate itself.

The distance education institution I studied had the intuition of this estimation of value taking into account past experiences, and especially previous training courses. Indeed, a business unit manager wanted to implement a client hooking system: giving free training would hook a learner. Indeed, free training is a way to softly discover the institution and reduce the cost of uncertainty. But it is also a way to get addicted since a first training course leads to self-valuation of other training in the same field. It is an experience that values itself since it changes the learner's vision of the world.

However, if there is a quantification of future value of any training through the accounting tool, past-oriented valuation of a training device is still a qualitative approach within the institution I studied. There is monetization of the first one, not yet of the second one.

Let's move back to a broader analysis of the question of value within the institution. We saw how French distance education was embedded within a national history of state education. In the same way, the question of a specific training course's value and its monetization is embedded within the institution's values, that is to say the values of the educators' community.

\section{Values of an Educative Community}

I tried to show throughout this study how the worker's habits changed: new public management, money-based evaluation of training, new way of dressing and talking about learners, performance-driven organization through marketing tools and computer work, and so on. From one generation of training engineers to another, the values of the educators' community changed as I described it.

This quick evolution of the distance education institution (in about 3 years) draws a specific trajectory. It started as a public service of distance education, knowledge oriented, and moved to an almost private organization, money-driven. This quick evolution bound the group together: team-building based on a common trajectory had effects that appeared strongly when talking to the different workers. A solid collective identity around a mix of old and new values appeared, so much that there is even a 
specific word designating a member of this institution. This word is based on the name of the institution and makes any worker feel part of a well-integrated group.

How to describe this identity based on an institution's trajectory? When the new general director was appointed, he distributed a strategic document planning the institution's future. A new top management team was recruited and they spread this strategic plan. Middle management represented by training engineers had therefore common dreams about the future: where to go together. It was about money-based institutional and professional work. They then shared hard times together: difficult reforms of an administrative structure, repetitive changing of colleagues and managers, and so on. These strong experiences bound the group together in the difficulties endured. And finally, when looking back over one's shoulder, all of the workers have these shared experiences as common references supporting the collective identity. They value the times they shared together and their common history separating them from most of the traditional French education institutions.

Moreover I observed a process of hero-making. Indeed, in hard times, a few workers personifying the institution's values appeared: either top managers recruited to sell goods were admired for their revolutionary vision in tune with the general director's strategic orientation; or old generation training managers, representing traditional education values, were praised for their efforts to adapt to the new situation. The group under pressure built a common imagination with heroes personifying values and accomplishing acts relevant to the new strategy.

As a result, most of the workers agree on a good atmosphere within the institution. Even leavers talk about their attachment to the institution. It is a sign that a fast trajectory leads to a highly integrated community with strong shared values.

\section{Conclusion: Retrospective and Prospective}

To sum up, the fieldwork in a major French distance education institution led to an education sciences analysis. I tried to show how state controlled education in France gave birth to a specific distance education organization about 70 years ago. This institution recently moved towards new public management, with a high turnover and many mutations in daily work in order to optimize production. Among these changes, I focused on monetization of training. This led to a description of training marketing, training accounting, and current debates about the institution's business model. If there is still hesitation about whether to sell courses' content or pedagogy services, it is agreed that the learner's experience of the training is central.

Last, I tried to analyze the notion of value underlying this monetization process: both the computation of any training program's value (future or past oriented) and the 
change in the institution's values. Indeed, this rapid evolution of the institution bound the group together around a few important experiences and valued corporate heroes.

A prospective could be the institution's stabilization now that it has been so rapidly and deeply moved. Such a possible stabilization in its new identity (selling training defined as private goods to be monetized on the market) could lead to a slower development in the same direction, supported by collective memory of this unique trajectory I described.

More generally and from a long term perspective, we can situate this monetization of French distance education within two contradictory trends of, on the one hand, free open online education and, on the other hand, privatization of teaching - implying commodification by a common measure of knowledge's value. By focusing on a microscopic case, we can describe precisely a macroscopic shift in education, shaping tomorrow's learning landscape. 


\section{References}

Babier, J . M., Bourgeois, E., Chapelle, G., \&Ruano Borbalan, J . C. (2009). Encyclopédie de la formation. PUF-Demos.

Dewey, J . (1997). Experience and education. Kindle Edition.

Feyerabend, P. (2010). Against method. Verso.

Lescure, E. (2010). Les métiers dela formation: Approches sociologiques. PUR.

Mercer, J . (2007). The challenges of insider research in educational institutions: Wielding a double-edged sword and resolving delicate dilemmas. Oxford Review of Education, 33, 1-17.

Moore, M. G. (2012). Handbook of distance education ( $2^{\text {nd }}$ ed.). Mahwah, NewJ ersey, London: Lawrence Erlabum Associates.

Prost, A. (2007). Regards historiques sur l'éducation en France, XIX-XXèmes siècles. Belin, Histoire de l'éducation.

Shumar, W. (1997). College for sale: A critique of the commodification of higher education. Falmer Press.

Shumar, W., \& Canaan, J . (2008). Structure and agency in the neoliberal university. Routledge/ Falmer.

Trowler, P. (2012). Doing insider research in universities. Amazon Kindle edition.

Vatin, F. (2008). Letravail et ses valeurs. Albin Michel.

Weber, F. (2008). Manuel de l'ethnographe. PUF.

\section{Athabasca University $\mathbf{Z}$}

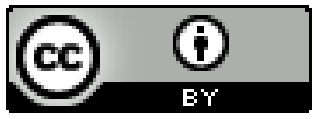




\section{A Framework for Interaction and Cognitive Engagement in Connectivist Learning Contexts $^{1}$}
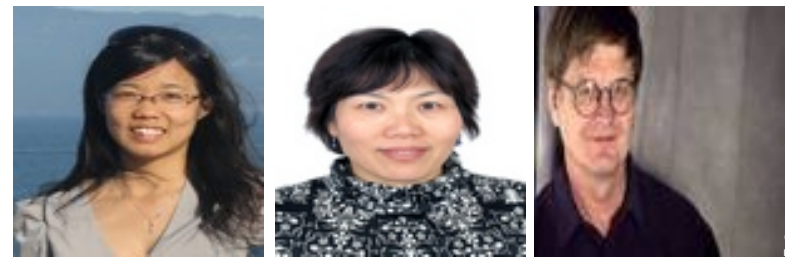

Zhijun Wang ${ }^{1}$, Li Chen ${ }^{1}$, and Terry Anderson ${ }^{2}$

1Beijing Normal University, China, ${ }^{2}$ Athabasca University, Canada

\section{Abstract}

Interaction has always been highly valued in education, especially in distance education (Moore, 1989; Anderson, 2003; Chen, 2004a; Woo \& Reeves, 2007; Wang, 2013; Conrad, in press). It has been associated with motivation (Mahle, 2011; Wen-chi, et al., 2011), persistence (Tello, 2007; J oo, Lim, \& Kim, 2011), deep learning (Offir, et al., 2008) and other components of effective learning. With the development of interactive technologies, and related connectivism learning theories (Siemens, 2005a; Downes, 2005), interaction theory has expanded to include interactions not only with human actors, but also with machines and digital artifacts. This paper explores the characteristics and principles of connectivist learning in an increasingly open and connected age. A theory building methodology is used to create a new theoretical model which we hope can be used by researchers and practitioners to examine and support multiple types of effective educational interactions. Inspired by the hierarchical model for instructional interaction (HMI) (Chen, 2004b) in distance learning, a framework for interaction and cognitive engagement in connectivist learning contexts has been constructed. Based on cognitive engagement theories, the interaction of connectivist learning is divided into four levels: operation interaction, wayfinding interaction, sensemaking interaction, and innovation interaction. Connectivist learning is thus a networking and recursive process of these four levels of interaction.

Keywords: Connectivist learning; interaction; connectivism; cognitive engagement

${ }^{1}$ The study reported in this paper is supported by the China Scholarship Council (CSC). ${ }^{*}$ Corresponding author, Research Center for Distance Education Beijing NormalUniversity 


\section{Introduction}

A new network-based pedagogy termed "connectivism" and the associated term "connected knowledge" was first developed by Siemens (2005a, 2005b, 2006) and Downes (2006) as a means to understand and explore learning in a networked digital age. With the continuing development of interactive technologies and connectivism learning theory, e-learning has been extended from early forms of print content delivered by email, to social constructivist learning, and, most recently, to connectivist learning. Connectivist learning is similar to ideas described as connected learning (Anderson \& Dron, 2011), social networked learning (Siemens \& Conole, 2011; Fonseca, 2011), and network connected teaching (Fadell et al., 2013).

The most widely discussed application of connectivist learning has been developed within some of the earliest MOOCs. These first MOOCs, known as cMOOCs or connectivist MOOCs, were developed and used to validate the ideas of connectivism developed by George Siemens and Stephen Downes. The aim of this particular model of MOOCs was to explore new ways of teaching and learning relevant to and afforded by a social and network enhanced digital age. In particular, these early MOOCs stressed the importance of learners developing their individual, personal learning networks and of creating, sharing, and enhancing net-based learning artifacts. They are quite different from the later MOOCs, referred to as XMOOCs (Malliga, 2013) which focus more on the distribution of content and ignore the aforementioned key features of cMOOCs, in that they inherently involve interaction and network construction and, especially, learnerlearner interaction focused on content creation and sharing.

Interaction has long been valued in distance education. Connectivist pedagogies stress that learning is a type of interaction centred on the learners' networked knowledge creation and growth (Downes, 2012, p. 63; Siemens, 2011, p. 85). Interaction both with other humans and with network resources is critical for connection building and network formulation. Siemens (2011) observed that "social interactions are vital to how participants made sense of course content and how they orient themselves spatially" ( $p$. 157). Downes (2012) also argued that "interaction not only promotes human contact, it provides human content... it creates a deep layer of learning content that no developer could ever hope to create" (p. 48). The same conclusion can be made from the 'model of learner-technology relationship in MOOCs' created by Siemens (2011, p. 85), which displays that interaction is as important as creation in connectivist learning.

\section{Research Questions}

Interaction is thus claimed to be a critical component and activity in connectivist learning, but little research has attempted to clarify its role in learning from a theoretical viewpoint. The research question that drives this theoretical research is, what are the characteristics and principles of interaction in a complex connectivist learning process? Can they be clearly revealed when viewed from a systematic view focused on interaction? This article provides a systematic interaction framework for 
connectivist learning, which reveals the characteristics and principles of learners' interactions so as to guide interaction design and evaluation in connectivist learning designs and implementations. This theoretical and model-building research is designed to bridge the gap between connectivist pedagogical ideas and learning practice, and to provide more specific solutions and guidance to connectivist learning designers, facilitators, and participants.

\section{Literature Review}

\section{Connectivism and its Practice Forms}

Connectivism is a relatively recent pedagogical theory, but it has proven to be both timely and useful. The seminal 2005 article by George Siemens was mentioned 669 times in scholarly publications indexed by Google Scholar in 2012, and by 2013 it had been referenced 1,603 times. The central tenets of connectivism are defined in eight principles (refer to Siemens, 2005a). These principles have shaped the development of connectivism learning designs, activities, and courses. The ideas of connectivism have been developed and contested in a series of articles, special journal issues, blog posts, presentations, workshops, and cMOOCs, including CCK08, CCK09, and CCK11. Although acclaimed by some, connectivism has also been criticized by many others (notably, Verhagen, 2006; Kop, Hill, 2008; Clarà \& Barberà, 2013). Verhagen argued that Siemens' ideas are, at best, pedagogical views, and certainly do not stand up to proper notions of the necessity for theory refutation. For a more detailed discussion of connectivism as a theory and the use of models to develop theoretical ideas, please see the overview by Kop and Hill (2008). Clarà and Barberà (2013) also pointed out three problems of connectivism as a learning theory. One of them is underconceptualization of interaction, which, on the other hand, helps us highlight the importance of interaction in connectivist learning.

Though both social constructivism and connectivism describe learning as a social process where learning occurs through social interaction, connnectivist learning occurs not just through social interaction, but also through interaction with and between networked nodes (people, media, places), because knowledge is distributed across a network of connections (Downes, 2007). Thus, in social constructivism, a network is social media for interaction, while in connectivism a network is an extension of mind. Connectivist learning therefore consists of the ability to construct and traverse those networks (Downes, 2007). Siemens' (2009) chart comparing connectivism with other theories is useful in distinguishing connectivism from other prominent learning theories.

Connectivist theory has inspired activities in different practice forms and designs based upon different purposes and understanding of connectivism by both practitioners and researchers. This study divided these activities into three forms. The first practice form 
is simple connectivist learning; the purpose of this kind of learning is to find ways to access information so as to achieve a particular answer or solution, such as pupils finding the solution to a complex mathematical problem using a search engine on a mobile phone. This focus on the process of learning is consistent with the famous claim of connectivism that "the pipe is more important than the content within the pipe" (Siemens, 2005a). The second practice form is social networked learning. The main purpose of this kind of learning is to gather people with some common interest to build a network for knowledge sharing and connection, such as Cloudworks (Conole, Galley, \& Culver, 2010) at the Open University, the Landing (Anderson, et al., 2013) at Athabasca University, and the Learning Cell (Cheng, Yu, \& Yang, 2009) at Beijing Normal University. The third practice form is complex connectivist learning in which students use and develop their own resources to prompt connection building and network formulation that is distributed in complex learning environments through knowledge creation, decision making related to complex problems, and the development of technological and pedagogical innovations, such as cMOOCs. Each of these forms is built and sustained upon interaction, to which we turn next.

\section{Research Related to Interaction in Distance Education}

"Interactions are reciprocal events that require at least two objects and two actions" (Wagner, 1994, p. 8). This definition of interaction includes the possibility of "reciprocal events" between humans and machines, which is an important construct in connectivist learning, thus it is used in this paper. The interaction discussed in this paper is one with pedagogical or educational intent and value.

Interaction has been a key concept and highly valued by most distance education theorists since the earliest correspondence generations of distance education (Taylor, 2001). The guided didactic conversation (Holmburge, 1981) and continuity of concern for students (Sewart et al., 1983) placed interaction between students and teachers at the core of distance education practice and theory. Moore's three types of interaction (1989) formed the first systematic and main theoretical framework for most research related to interaction. With the development and use of two-way communication technologies, interaction became the main research topic in distance education, and a number of theories related to interaction were created over the next two decades. These included Moore's theory of transactional distance (1993), the reintegration of the teaching acts (Keegan, 1993), modes of interaction in distance education (Anderson \& Garrison, 1998), and interaction-based models of elearning (Anderson, 2003). A great deal of research looked at how to design interaction more efficiently (Hirumi, 2002; Anderson, 2003; Ally, 2004; Chen, 2004b). From the beginning of the 21st century, with the rapid development of social media and Web 2.0 technology, social interaction has become a much discussed topic in online, campus, and blended learning research. Most research focused on interaction design, analysis, evaluation, enhanced strategies and their influence on learners' satisfaction, and learning performances in different social interaction contexts. Among these studies of interaction design, researchers were focused on interactive functions of course management systems (Chou, 2010) and interaction design of courses (Hirumi, 2006; Dunlap et al., 2007; Nandi, 2013). 
Different interaction design methods have been proposed with various perspectives, but So (2010) commented that the research on interaction should involve "tight coupling the pedagogical methods and technological affordance" (p. 256) to ensure rigor in the research on interaction. Although numerous studies have been published on the role of interaction in cognitive behaviour and social constructivist pedagogy, no analytic attention has been paid to the interaction in connectivist learning from a systematic or structured viewpoint.

\section{Types of Interaction in Connectivist Learning}

Distance education developed from cognitive behavioural pedagogical roots and later to social constructivist pedagogy and connectivism pedagogy (Anderson \& Dron, 2011), which coincided with developments of interactive affordances of networked, digital technologies. Using cognitive behavioural pedagogy, Moore (1989) first proposed three types of interaction (student-teacher, student-student, student-content) in distance education, followed by the addition of student-interface interaction as a fourth interaction (Hillman, et al., 1994). As intelligent technology developed, three other possible forms of interaction (teacher-teacher, teacher-content, and content-content) were added to the framework (Anderson \& Garrison, 1998). In social constructivist pedagogy the interaction capacity of Web 2.0 and social technologies increased the capacity and varieties while decreasing the costs of interaction for social learning. Dron (2007) added four types of interaction to the framework of interactions (group-content, group-group, learner-group, and teacher-group). Connectivist pedagogy stresses the development and nurturing of networks to be a major component of learning. The interaction affordances of a strong social network environment have extended the interaction possibilities (Ostashewski \& Reid, 2010). Networks, sets, and collectives are "emerging catalytic components" (Anderson \& Dron, 2007, p. 197) of learner interactions with others as they develop their personal networks. Finally, interactions with and learning from sets of people or objects form yet another mode of interaction (Dron \&Anderson, in press).

As discussed above, the types of interaction are extended with the development of technology in different distance learning pedagogies. Interaction is opened (beyond the class) and extended (to objects and people aggregated in groups, networks, and sets) in connectivist learning, including almost all of these types of interaction, so interaction in connectivist learning is the most complicated type, and deserves extra attention. The participants have increased choice and opportunity to interact with others according to their network literacy (Belshaw, 2013), the networks they belong to, and the sets they curate and with which they interact. Interactions extend from individuals to groups and networks, from closed to open, from small group to massive possibilities. This affords opportunities for network development, potential to develop both strong and weak links (Granovetter, 1973), and opportunity to jump across or cross boundaries. Perhaps even more important, if emergent, is the increase in the "adjacent possible" (Kauffman, 2000; Dron, 2013), whereby new and often unanticipated connections arise and can be exploited for learning potential. At the same time, such an expansion of interaction possibilities creates the need for more sophisticated conceptual models for both 
understanding and exploitation of the learning potential. However, the principles of interaction and the technologies and pedagogies with which they are most closely matched should be explored first. But it is challenging to have a sufficiently in-depth understanding of interaction merely from the classification of different interactions based on their actors within Moore's framework. So, other research perspectives are sought to reveal the principles of interaction in connectivist learning.

\section{The Strategy of Dividing Interaction into Different Levels}

Besides analysing interaction based on key actors, another strategy that researchers have adopted is to segment interaction into different levels depending on actors or activities involved. Hirumi (2002) divided the interaction of online learning into three levels, learner-self, learner-resource (human and non-human), and a meta level learnerinstruction interaction which guides the previous two types. Chen (2004b) divided interaction into operation interaction, information interaction, and concept interaction, from simple to complex and concrete to abstract. Ally (2004) divided interaction in online learning into five levels (from learner-content to learner-interface; learnersupport, learner-learner, and learner-context). The common purpose of these three studies was to explain how learning occurs from various interaction perspectives by dividing the interaction into different levels and constructing corresponding frameworks to guide interaction activity design. Compared with other studies focusing on one type of interaction, these three studies paid more attention to the relationship of interaction and learning, which is useful in providing an in-depth and systematic understanding of interaction and to build theories of interaction. Thus, the strategy of dividing interaction into different levels or taxonomies is adapted and extended in this study. We also attempted to build a framework to guide interaction activity designs. Among these three frameworks, Chen's, which is based on the relationship of interaction with meaningful and deep learning, rather than those based on the actors, has proven to be the most useful as a launching framework for this research, which will be discussed later.

\section{Research Method: Theory Building}

The methodology used in this study is theory building in applied disciplines (Lynham, 2002). This has been described as "the purposeful process or recurring cycle by which coherent descriptions, explanations, and representations of observed or experienced phenomena are generated, verified, and refined" (Lynham, 2000, p. 161). Although different researchers have advocated different theory-building processes, Lynham (2002) proposed a five-phase method of theory-building. These are theory building, conceptual development, operationalization, confirmation or disconfirmation, application, and continuous refinement and development (of the theory) as a recursive system (Lynham, 2002). This method consists of two components, described as theorizing-to-practice and practice-to-theorizing. Theorizing-to-practice is a qualitative method, while practice-to-theorizing is quantitative. Each produces a distinct in-process 
output and results in a rigorous, trustworthy, and relevant model and theory for improved action (Lynham, 2002). This research focused on a theoretical framework which, hopefully, provides an explanation of the issue, problem, or phenomenon of focus.

This study analyzes interaction in connectivist learning as a system, building a framework to explain the characteristics and principles of interaction in connectivist learning. The theorizing-to-practice component was chosen as the research strategy, because it is well suited to the applied nature of the behavioural and human sciences (Lynham, 2002) including education. We note that, similar to earlier conceptual models such as the community of inquiry model (Garrison \& Anderson, 2003), Laurillard's conversational framework (Laurillard, 2000) or Salmon's five stage e-learning model (Salmon, 2000), the early construction of a guiding graphical model has stimulated both research and practice and led to later enhancements. We hope our work stimulates similar extension, revision, and validation.

\section{Conceptual Framework for Interaction in Connectivist Learning}

\section{Hierarchical Model for Instructional Interaction}

Chen (2004a) proposed the concept of instructional interaction, which explains how distance learning occurs from an interaction perspective and delineates the role of different kinds of interaction in distance education. Chen (2004b) built a hierarchical model for instructional interaction (HMI) (Figure 1) in a distance learning context, based on Laurillard's conversation framework. According to HMI, interaction in distance learning contexts can be divided into three levels, from concrete to abstract and from low to high levels. The most concrete level is operation interaction, in which the learner operates different media and is interacting with the media interface. Due to the extensive use of technology in distance education, the operation interaction is more complicated and is both the foundation and condition of online learning. The second level is information interaction, which includes learner-teacher, learner-learner, and learner-content interactions. The third level is the most abstract one, referred to as concept interaction, which is the interaction of learners' old concepts with new ones. These three levels of interaction can occur simultaneously and recursively. The operation interaction is the foundation of information interaction, while information interaction is the foundation of concept interaction (Chen, 2004b). The higher the level, the more critical it is to the achievement of learning objectives. Chen argued that only concept interaction leads to meaningful learning. HMI, however, formulated in a constructivism context, reveals the basic interaction principles of distance and online learning (Wang, 2013), so it continues to serve as a base for our current understanding of interaction. HMII provided a guide or heuristic that was used to analyse interaction 
in constructivist learning, thus the HMI was used to build an additional theoretical framework of interaction in this study.

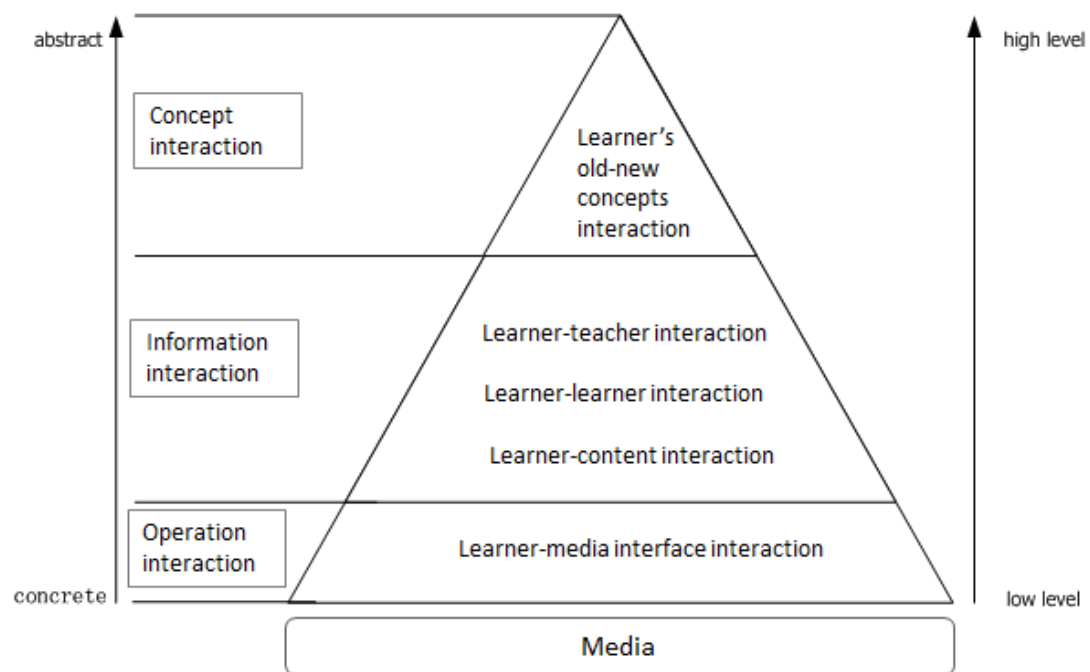

Figure 1. Hierarchical model for instructional interaction (HMII) (Chen, 2004b).

\section{Conceptual Development Process}

Connectivist pedagogy is based on creating and sustaining networks linking humans to other humans and to non-human resources because knowledge resides in networks of humans and non-human appliances (Siemens, 2005; Bell, 2011). Learners create their interaction spaces in a type of personal learning environment (PLE) (Martindale \& Dowdy, 2010) by using different media (especially social media) to create, access, and build networks with each individual at the centre of their own network. The mastery of the operation of different media and technologies, such as blogs, wikis, micro-blogging, and social media websites, enables learners to participate in connectivist learning. So operation interaction, including human-computer interaction and human-interface interaction, still serves as a basis and precondition for other interactions (Chen, 2004b) and indeed becomes even more complex in connectivist learning contexts.

The information interaction level of HMI is complicated in connectivist learning. Compared to traditional education (delivered on campus or at a distance) with wellstructured content and defined learning resources, activities, and fixed technological platforms, connectivist learning takes place in complex, information-loaded environments and stresses emergence (Kay, 2006). In this environment, content is distributed on networks amongst individuals surrounded by fragmented information which encourages rather than suppresses the emergence of creativity and deep learning in the distributed and complex environments that embrace unplanned interactions. It is important for participants to learn how to orientate themselves in such complex information contexts so as to make the information coherent and understandable (Siemens, 2011). Siemens (2011) proposed two means of orientation in complex online learning environments - wayfinding and sensemaking; he acknowledged that 
"wayfinding detail shows that people orient themselves spatially through the use of symbols, landmarks, and environmental cues" (p. 48) and "sensemaking is an activity that individuals engage in daily in response to uncertainty, complex topics, or in changing settings (p. 39)". Learners interact constantly with networks to navigate in complex environments and to filter, integrate, and extract information to develop their understanding of that information. Thus, this level consists of both kinds of interaction, wayfinding and sensemaking interaction.

The third level of HMII is concept interaction. It requires and stimulates the deepest cognitive engagement. In connectivist learning, the deepest cognitive engagement is creation. The deepest level of interaction in connectivist learning is innovation interaction, which is related to, but deeper and more applied than, concept interaction. Moreover, the concept interaction of HMI is included in both the information (wayfinding and sensemaking) and the final "innovation interaction". Innovation interaction is a process of knowledge creation and growth (Downes, 2012). It includes the presentation and expression of new ideas, solutions, theories, and models through creation of new learning artifacts individually or collaboratively for further connection building. It is mainly combined with learner-content interaction, but in collaborative and formal learning environments, learner-learner and learner-teacher interactions are also important.

Figure 2 demonstrates the above deductive process of dividing interactions in connectivist learning into four different levels: operation interaction, wayfinding interaction, sensemaking interaction, and innovation interaction.

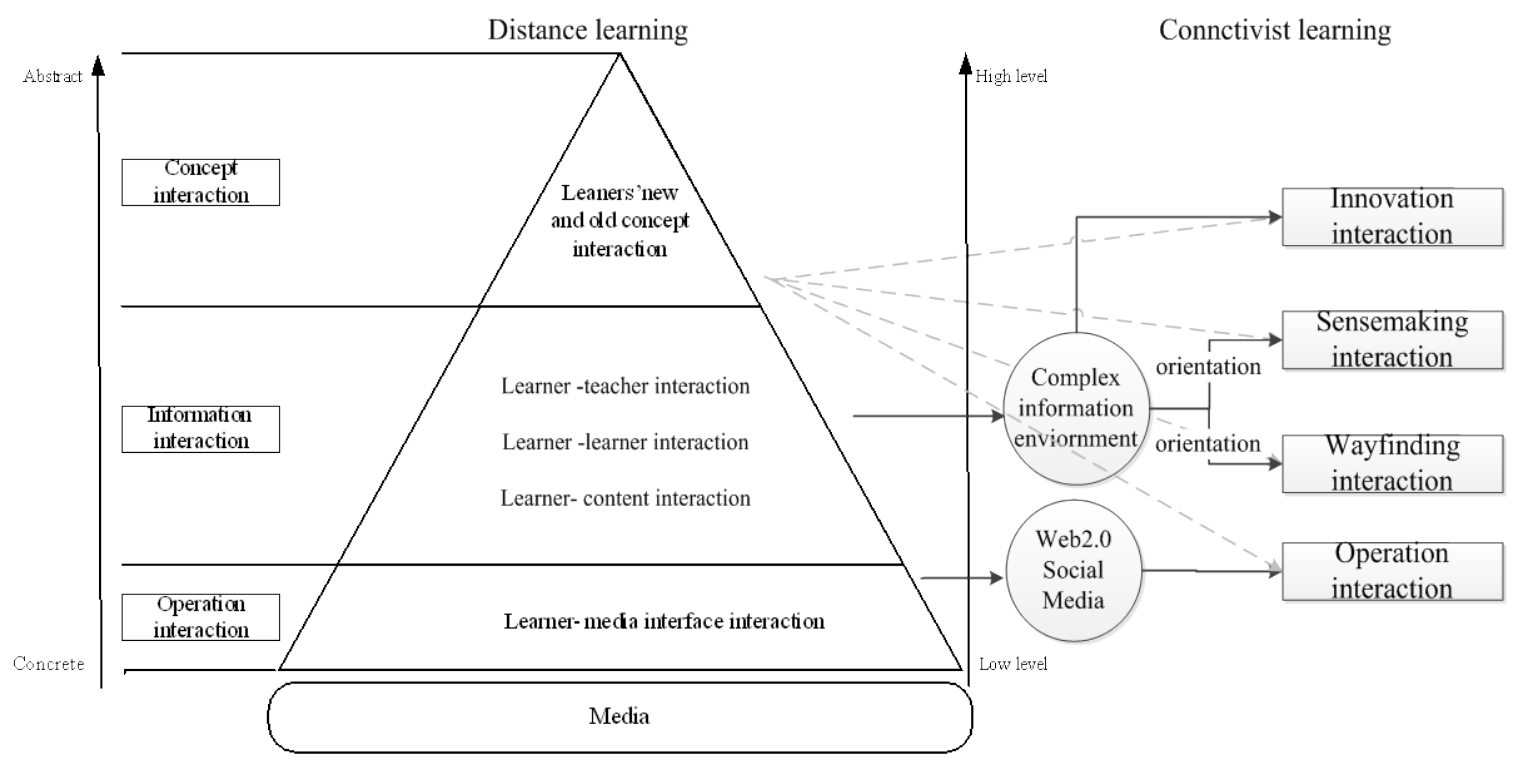

Figure 2. Conceptual development of interaction in connectivist learning.

To help us to understand the cognitive engagement at these four levels of interaction, the conceptual framework for connectivist learning is analysed and compared using 
Bloom's revised taxonomy. Bloom's cognitive taxonomy (1956) was revised and updated in 2000 by changing the nouns to verbs and elevating creation to the highest level (Anderson, et al., 2000). The revised taxonomy moves from remembering to understanding, applying, analysing, evaluating, and creating as cognitive processes (Anderson, et al., 2000). During operation interaction the learners merely practice and remember how to operate various media to build their own learning spaces. In wayfinding interaction, learners have to master the ways to navigate in a complex information environment and connect with different human and non-human resources, so they have to reach higher levels of understanding, applying, and evaluating information and connection formed in this process. Sensemaking is a patternrecognition process, so the top five categories of the cognitive taxonomy are each involved in it, especially applying, analysing, and evaluating. Innovation interaction focuses on the expression of ideas, models, or theory by artifact creation and innovation to enhance and build new social, technological, and informational connections. It thus engages learners at the deepest, creation level of Bloom's revised taxonomy.

These four levels of interaction are not independent. Changes in one influence the process of another. Only when innovation interaction happens have the learners reached the deepest level of connectivist learning. Figure 3 shows the final conceptual framework constructed in this research.

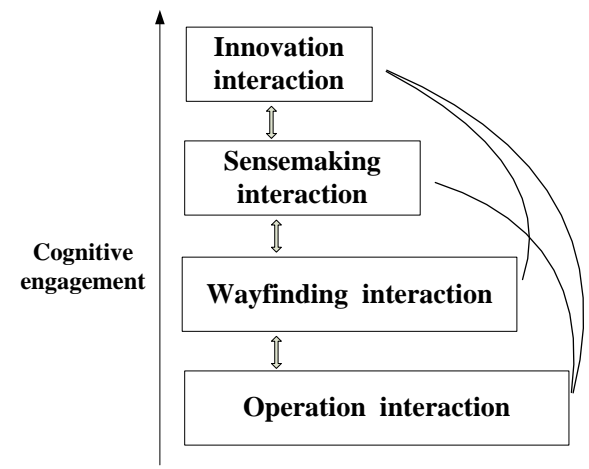

Figure 3. Conceptual framework of interaction for connectivist learning and cognitive engagement.

\section{Operationalization of the Conceptual Framework}

Lynham (2002) stated that "one of the challenges of theory-building research in applied disciplines is making the logic used to build the theory explicit and accessible to the user of the developed theory" (p. 221). Based on a literature review of connectivism, personal reflections on wayfinding, sensemaking, and artifact creation experienced in $\mathrm{CMOOC}$ learning experiences, and discussions with connectivist learning researchers, the resulting operationalized conceptual framework can be visualized as Figure 4. It is called a framework for interaction and cognitive engagement in connectivist learning. 


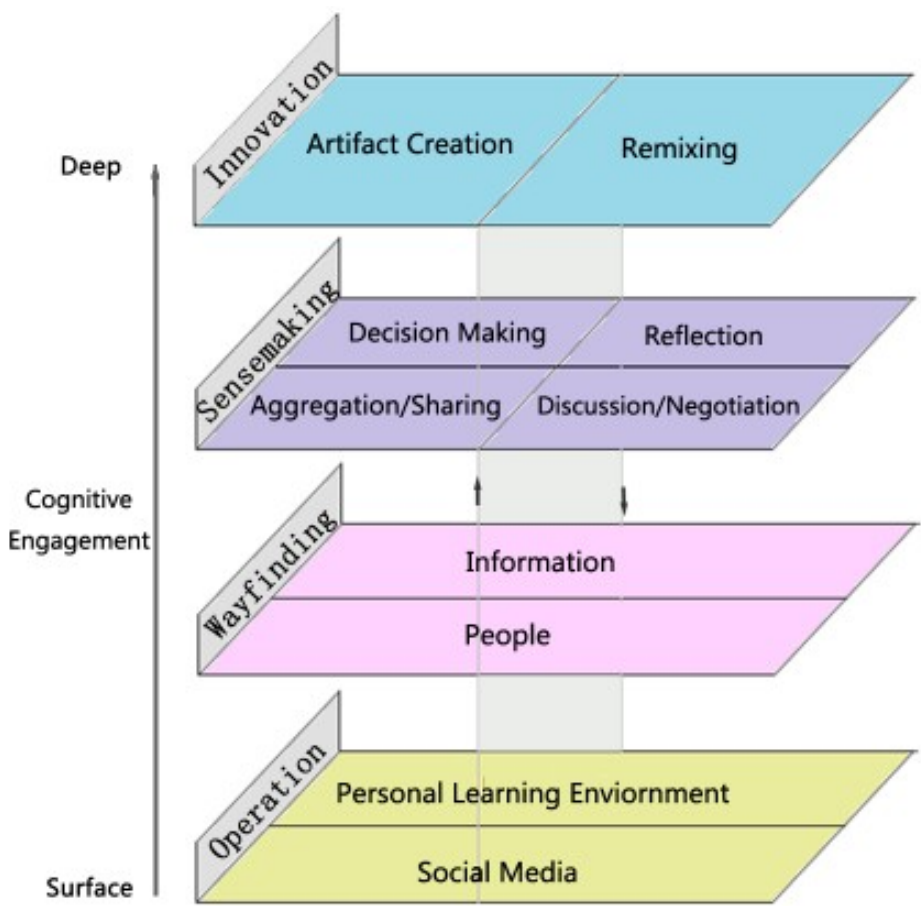

Figure 4. Framework for interaction and cognitive engagement in connectivist learning.

\section{Operation Interaction}

"Technology is an enabler of new opportunities" (Siemens, 2009, p. 2). The purpose of operation interaction is to build interaction spaces or a PLE with different technologies for connecting with different knowledge and opportunities. Compared to traditional online learning in learning management systems, PLE construction is much more open, interactive, controlled by individual learners, and has widespread social and networking connection capabilities. These characteristics are essential for the diversity and expandability of PLE and the ability for learners to bridge learning across multiple learning and living contexts. So learners strive to integrate other social and networkbased media into their PLEs. Different technologies have different affordance in supporting information aggregation, social connection, content generation, and cocreation (Sun, 2013). Learners reside in different technology spaces based on their habits and experiences of operating these media. While learners connect with different technologies in operation interaction, it also provides the possibility to connect with different groups of people and information, and to change their sensemaking behaviours. This can explain why learners are usually asked to register in a variety of social networks and they learn how to follow, aggregate, and filter content from these social network technologies at the beginning of a connectivist learning experience (Downes, 2011). Operational interaction is a process of learners connecting with different technologies through learner-interface interaction to support their further learning. A collective distributed technological network is formed in this process. 


\section{Wayfinding Interaction}

"Learning is a process of connecting specialized nodes or information sources" (Siemens, 2005). Wayfinding interaction is used to connect the pipeline for knowledge flow (Siemens, 2006, p. 79), including the connection of information and people (in groups, sets, or networks). The learning environment of connectivist learning is more complex than any other kind of learning, so it is important for the learners to judge which information is important and valuable for them so as to navigate in this environment. "The capacity for connection forming, becoming aware (of others and knowledge), and sustaining exchanges lies at the heart of knowledge exchange today" (Siemens, 2006, p. 52). The easiest and main way to maintain this learning connection is to find the right information directly, or find the right people. Learner-content interaction and learnergroup (set and network) interaction are involved in this process. This is the beginning of social network and informational network building in the interaction space created by operation interaction. Learners can not only be involved in this process actively by creating and participating in groups and networks, but also they can take advantage of recommending technologies (such as tag cloud, likes, or recommendations). A weak and looser network is formed which makes it possible to form tighter networks and groups in sensemaking interaction. The simple connectivist learning happens at this level.

\section{Sensemaking Interaction}

Sensemaking interaction is an important stage of network formulation and connection building. Downes (2006) argued that both the knowledge of individual and knowledge of social have characteristics of networks. Sensemaking interaction is a pattern recognition, information (knowledge) seeking, and a collaborative process that includes information aggregation/sharing, discussion/negotiation, reflection, and decision making. During this process, participants bring together concepts from different domains in a novel way (Siemens, 2009), and they achieve a coherent comprehension of information and make decisions quickly. Sensemaking interaction connects nodes in a technological, social, and concept (neural) network tightly together. Learners' network identities and social presence are formed gradually by participants in these sensemaking interaction activities. This is the main process of identity forming, developing, and sharing. The learner-learner (including group, set, and network) interaction and learner-content interaction in sensemaking interaction is deeper than that of wayfinding interaction. It also sets a solid foundation for innovation interaction by using the power of the social network in information connection, sharing, filtering, and aggregation, and the advantage of collective knowledge.

\section{Innovation Interaction}

Connectivist learning relies on the active participant and artifact creation of selfdirected learners (Anderson, 2009; Downes, 2012). Innovation interaction is the most challenging and the most important interaction for learners. It is a knowledge growth process by further reflection and presentation of sensemaking results. Through innovation interaction, the scope of the other three types of interaction is also extended. 
Anderson (2012) proposed open artifact persistence and networking opportunity as the primary affordances of connectivist pedagogy. Learning artifact creation requires the deepest cognitive engagement for learners, but it brings more networking opportunities for the learners through constructing and sharing artifacts on the open network where they are both accessible and persistent. Learners gain more opportunity to communicate deeply with others and get more support from the network by sharing their artifacts. Open education resources (OER) are the most important and main learning resources used in connectivist learning, as they embody these connectivist ideals of networking, sharing, and persistence. Remixing, which means using OER to create something new or modified from an existing OER (Belshaw, 2013), is increasingly important for learners in connectivist learning. Innovation interaction is the deepest learner content interaction and deepest cognitive engagement of all four of these interaction levels.

\section{The Interrelationship of Four Levels of Interaction}

Interaction, in connectivist learning contexts, is a networked process rather than a linear one - with significant recursion. It is a circulating and transactional process (as the arrowed ring shows in Figure 4). The lower levels of interaction are the foundations of the higher ones, and each level influences the next. The lower levels support the development of higher levels, while the development of higher levels extends the need for learning at lower levels, such as in innovation interaction learners may need to further connect with different technologies, information, and people to support the remixing and learning artifact creation process. The higher the levels of interaction learners are involved in, the more cognitive engagement is required of them, which creates greater challenges for them. At the same time, the higher the levels of interaction the learners engage in, the more cognitive presence, network identity, and social presence evolves in an ever increasing network that they develop in their learning. In connectivist learning, keeping knowledge circulating and growing is the purpose of all learning activities (Siemens, 2006. p. 32) and interactions. Compared with social constructivism, innovation interaction is not the end of connectivist learning, but a new beginning of further networking and connection building with different nodes (technology, social, and concept) through sharing innovation interaction artifacts in an open and persistent network.

Connectivist learning is a process of networking and connection (Siemens, 2005b). Siemens argued that learning is the process of forming three basic networks: neural networks, concept networks, and external/social networks (Siemens, 2005b). During this interaction process, not only are these three networks created, but also the technological network that supports these interactions is created. In this article we argue that the personal learning network (PLN) (Couros, 2010) in connectivist learning is created by the simultaneous construction of a concept network, a social network, and a technology network. All interactions in connectivist learning play significant roles in different connection building and networking formulation processes. Operation interaction helps learners to build their PLE and to connect with different technologies. In this PLE, learners begin to build social and concept networks from wayfinding 
interaction while sensemaking interaction enhances and optimizes their PLN. A PLN also affords the deepest level of innovation interaction. Innovation interaction further promotes and sustains new knowledge creation and connection building, thus optimizing the PLN. So connectivist learning is a spiral knowledge creation with network creation and optimization with four levels of interaction. Learners not only build their PLN by these interactions, but also enrich the entire network as a part of a larger network of all participants.

\section{Discussion}

We divided the practice of connectivist learning into three forms (simple, social, and complex). Each of these can be explained by four levels of interaction. Simple connectivist learning is supported mainly by operational interaction and wayfinding interaction, while social networked learning is supported mainly by operation interaction, wayfinding interaction, and sensemaking interaction. Complex connectivist learning combines these four levels of interaction and is enhanced by innovation interaction. All of these interactions have different characteristics and principles which need more exploration and, indeed, the whole model currently lacks empirical validation; nonetheless, we believe that this conceptual model reduces the confusion and the multiple aims and claims associated with connectivist learning.

Even initially, connectivist learning demands basic ability and network literacy to learn in complex information environments. Learners should have a good level of digital literacy and learning literacy (Littlejohn, 2013). As they learn they develop their capacity of self-regulation, orientation, and pattern recognition and to use a variety of technologies to enhance their learning. However, many of them lack these skills and even low levels of operational interaction can be a challenge for them. Each level requires increased levels of network literacy to advance to a deeper level. The participant numbers decrease as the interaction levels become higher. Most learners are involved in the wayfinding and sensemaking levels, while fewer reach the innovation level. This explains why many people register in cMOOC courses but relatively few are actively involved in creating learning artifacts (Siemens, 2011). It also helps us to understand why interaction design in connectivist learning is important. Research and, more important, learning design are needed to design interaction and scaffolding to help learners to participate in higher level interactions in connectivist learning.

Theory building is a systematic project with five phases, and continues with refinement and development. This paper has only addressed the first and second phases. Although the framework is inspired by two pioneers of connectivism (George Siemens and Stephen Downes) and other connnectivist learning researchers, the interaction in real connectivist learning contexts, such as cMOOCs, may tell us more. Thus, research to analyse the interaction process of Change $11 \mathrm{MOOC}$ is currently in progress with the aim of validating this framework and finding the characteristics and principles of each level of interaction in this framework. 


\section{Conclusion}

This paper addresses the importance of the characteristics and principles of interaction in connectivist learning and especially those associated with the development of connectivism and cMOOCs. After a brief literature review of connectivism and its practical (simple, social, and complex) forms, the study focused on complex connectivist learning. By summarizing the types of interaction in connectivist learning, it is argued that interaction in connectivist pedagogies is complicated, thus it is challenging to gain a deep understanding of analysis interaction from the perspective of actors previously identified in the literature. However by combining the HMII model and Bloom's revised taxonomy with Siemens' elements of wayfinding and sensemaking, a framework for interaction and cognitive engagement in connectivist learning is constructed using a theory-building methodology. Interaction in connectivist learning is thus divided into four levels: operation interaction, wayfinding interaction, sensemaking interaction, and innovation interaction. From the lower to the higher levels, deeper cognitive engagement is required from the learners. All of these layers influence each other. Lower-level interactions are the foundations of the higher ones, and the higher level learners engage in deeper learning with more connection and networking opportunities.

\section{Acknowledgements}

Thanks to the Centre for Distance Education at Athabasca University for providing the environment for this research.

The paper has been updated from one presented at the 25th ICDE World Conference in Tianjin, China: A Conceptual Framework on Cognitive Engagement for Connectivist Learning: Interaction Principle based Connectivism. 


\section{References}

Anderson, L. W., Krathwohl, D. R., Airasian, P. W., Cruikshank, K. A., Mayer, R. E., Pintrich, P. R., Raths, J ., \&Wittrock, M. C. (2000). A taxonomy for learning, teaching, and assessing: A revision of Bloom's taxonomy of educational objectives. New York: Pearson, Allyn \& Bacon.

Anderson, T. (2003). Getting the mix right again: An updated and theoretical rationale for interaction. The International Review of Research in Open and Distance Learning, 4(2). Retrieved from http:// www.irrodl.org/index.php/irrodl/article/view/ 149/230.

Anderson, T. (2009, J une). The dance of technology and pedagogy in self-paced distance education. Paper presented at the 17th ICDE World Congress, Maastricht.

Anderson, T. (2012)."Connectivying" your course. Retrieved from http:/ / terrya.edublogs.org/ 2012/ 12/ 18/ connectivy-your-course/

Anderson, T., \& Dron, J . (2007). Groups, networks and collectives in social software for e-learning. Paper presented at 2007 European Conference on E-Learning, Copenhagen, Denmark.

Anderson, T., \& Dron, J . (2011). Three generations of distance education pedagogy. The International Review of Research in Open and Distance Learning, 12(3). Retrieved from http:/ / www.irrodl.org/ index.php/irrodl/ article/ view/ 890/ 1663

Anderson, T., Dron J ., Poellhuber, B., \&Upton, L. (2013, October). Beyond the learning management system to support networked distance education. Paper presentated at The $25^{\text {th }}$ ICDE World Conference, Tianjin, China.

Anderson, T., \& Garrison, D. R. (1998). Learning in a networked world: New roles and responsibilities. In C. Gibson (Ed.), Distance learners in higher education (pp. 97-112). Madison, WI.: Atwood Publishing.

Ally, M. (2004). Foundations of educational theory for online learning. In T. Anderson (Ed.), Theory and practice of online learning (1st ed., pp. 3-31). Edmonton : Athabasca University Press.

Bell, F. (2011). Connectivism: Its place in theory-informed research and innovation in technology-enabled learning. The International Review of Research in Open and Distance Learning, 12(3), 98-118.

Belshaw, D. (2013). First draft of Mozilla's web literacy standard now available. Retrieved from http:/ / dougbelshaw.com/ blog/2013/ 04/26/ first-draft-ofmozillas-web-literacy-standard-now-available/. 
Bloom, B. S. (1956). Taxonomy of educational objectives, Handbook I: The cognitive domain. New York: David McKay Co Inc.

Cheng, G., Yu, S. Q., \& Yang. X. M.(2009). Design and implementation of runtime environment for learning cells. Open Education Research, 15(2), 27-36.

Chen, L. (2004a). An investigation into 'interactivity' and the related concepts. Distance Education in China, (03), 12-16+78-79.

Chen, L. (2004b). A hierarchical model for student and teacher interaction in distance learning. Distance Education in China, (05), 24-28+78.

Chou, C., Peng, H., \& Chang, C.-Y. (2010). The technical framework of interactive functions for course-management systems: Students' perceptions, uses, and evaluations. Computers \&Education, 55(3), 1004-1017.

Clarà, M., \& Barberà, E. (2013). Three problems with the connectivist conception of learning. J ournal of Computer Assisted Learning, n/a-n/a. doi: 10.1111/jcal.12040.

Conole, G., Galley, R., \& Culver, J . (2010). Frameworks for understanding the nature of interactions, networking, and community in a social networking site for academic practice. The International Review of Research in Open and Distance Learning, 12(3). Retrieved from http:// www.irrodl.org/index.php/irrodl/article/view/ 914/ 1666.

Conrad, D. (in press). Interaction and communication in online learning communities: Toward an engaged and flexible future. In O. Zawacki-Richter \& T. Anderson (Eds.), Online distance education: Towards a research agenda. Edmonton, AB: Athabasca University Press.

Couros, A. (2010). Developing personal learning networks for open and social learning. Emerging Technologies in Distance Education, 109-128.

Downes, S. (2005). Connective knowledge. Retrieved from http:// www.downes.ca/ cgi$\underline{\text { bin/page.cgi?post }=33034}$

Downes, S. (2006). Learning networks and connective knowledge. Discussion paper \#92 (online document). Instructional Technology Forum. Retrieved from http://it.coe.uga.edu/itforum/ paper92/ paper92.html.

Downes, S. (2007). What connectivism is. Retrieved from http:/ / halfanhour.blogspot.com/ 2007/ 02/ what-connectivism-is.html 
Downes, S. (2011). How to participate in MOOC. Retrieved from http:/ / halfanhour.blogspot.com/ 2011/ 09/ how-to-participate-inmooc.html

Downes, S. (2012). Connectivism and connective knowledge: Essays on meaning and learning networks. National Research Council Canada. Retrieved from http:// www. downes. ca/files/books/Connective_Knowledge-19May2012. pdf

Dron, J . (2007). Control and constraint in e-learning: Choosing when to choose. Hershey, PA.: Information Science Pub.

Dron, J . (2013). Soft is hard and hard is easy: Learning technologies and social media. Form@ re-Open J ournal per la formazione in rete, 13(1), 32-43.

Dron, J ., \&Anderson,T., (in press). Teaching crowds: Learning and social media. Edmonton : Athabasca University Press.

Dunlap, J . C., Sobel, D., \& Sands, D. I. (2007). Designing for deep and meaningful student-to-content interactions. Tech Trends, 51(4), 20-31.

Fonseca, D. E. L. (2011). EduCamp Colombia: Social networked learning for teacher training. The International Review of Research in Open and Distance Learning, 12(3), Retrieved from http:// www.irrodl.org/index.php/irrodl/article/view/ 884/ 1677

Fadell, A. M., Rogers, M. L., Satterthwaite Jr, E. H., Smith, I. C., Warren, D. A., Palmer, J. E., . . . Fiennes, H. (2013). User-friendly network connected learning thermostat and related systems and methods. US Patent.

Garrison, D. R., \&Anderson, T. (2003). E-learning in the 21st century: A framework for research and practice. London: Routledge/ Falmer.

Granovetter, M. S. (1973). The strength of weak ties. American J ournal of Sociology, 1360-1380.

Hillman, D. C. A., Willis, D. J ., \& Gunawardena, C. N. (1994). Learner-interface interaction in distance education: An extension of contemporary models and strategies for practitioners. American J ournal of Distance Education, 8(2), 3042 .

Hirumi, A. (2002). A framework for analyzing, designing, and sequencing planned elearning interactions. Quarterly Review of Distance Education, 3(2), 141-60.

Hirumi, A. (2006). Analysing and designing e-learning interactions. In C. J uwah (Ed.), Interactions in online education: Implications for theory and practice (pp. 4671). New York: Routledge. 
Holmberg, B. (1981). Status and trends of distance education. London: Kogan-Page.

J oo, Y. J ., Lim, K. Y., \& Kim, E. K. (2011). Online university students' satisfaction and persistence: Examining perceived level of presence, usefulness and ease of use as predictors in a structural model. Computers \& Education, 57(2), 1654-1664. doi: http:// dx.doi.org/ 10.1016/j.compedu.2011.02.008.

Kauffman, S. (2000). Investigations. New York, USA: Oxford University Press.

Kay, A. (2006). The dynamics of public policy: Theory and evidence. Edward Elgar Publishing.

Keegan, D. (1993). Reintegration of the teaching acts. Theoretical Principles of Distance Education, 113-134.

Kop, R., \& Hill, A. (2008). Connectivism: Learning theory of the future or vestige of the past? The International Review of Research in Open and Distance Learning, 9(3). Retrieved from http:// www.irrodl.org/index.php/irrodl/article/ view/ 523/1103.

Laurillard, D. (2000). A conversational framework for individual learning applied to the learning organization' and the learning society'. Systems Research and Behavioral Science, 16(2), 113-122.

Littlejohn, A.(2013). Understanding massive open online course. Caledonian Academy Glasgow Caledonian University, UK.

Lynham, S. A. (2000). The development of a theory of responsibleleadership for performance (Tech. Rep.). St. Paul: University of Minnesota, Human Resource Development Research Center.

Lynham, S. A. (2002). The general method of theory-building research in applied disciplines. Advances in Developing Human Resources, 4(3), 221-241.

Mahle, M. (2011). Effects of interaction on student achievement and motivation in distance education. Quarterly Review of Distance Education, 12(3), 207215,222 .

Malliga, P. (2013). A survey on MOOC providers for higher education. International J ournal of Management \& Information Technology, 7(1), 962-967.

Martindale, T., \&Dowdy, M. (2010). Personal learning environments. Emerging Technologies in Distance Education, 177-193.

Moore, M. (1989). Three types of interaction. American J ournal of Distance Education, $3(2), 1-6$. 
Moore, M. G. (1993). Theory of transactional distance. In Theoretical principles of distance education (pp. 22- 38). London: Rutledge.

Nandi, D. (2013). A comprehensive framework with design principles for supporting interaction in fully online courses (Doctoral dissertation). Royal Melbourne Institute of Technology University .

Offir, B., Lev, Y., \& Bezalel, R. (2008). Surface and deep learning processes in distance education: Synchronous versus asynchronous systems. Computers \& Education, 51(3), 1172-1183.

Ostashewski, N., \& Reid, D. (2010). Networked teacher professional development: Applying the networked learning framework to online teacher professional development. Proceedings EDGE, 12-15.

Salmon, G. (2000). E-moderating : The key to teaching and learning online. London: Clays Ltd.

Siemens, G. (2005a). Connectivism: A learning theory for the digital age. International J ournal of Instructional Technology and Distance Learning, 2(1), 3-10.

Siemens, G. (2005b). Connectivism: Learning as network-creation. Retrieved from http:// www.elearnspace.org/ Articles/networks.htm.

Siemens, G. (2006). Knowing knowledge. Lulu. com.

Siemens, G. (2009). What is connectivism? Retrieved from https:// docs.google.com/ document/d/ 14pKVP0_ILdPty6MGMJ W8eQVE Y1zibZ0RpQ2C0cePIgc/ preview

Siemens, G. (2011). Orientation: Sensemaking and wayfinding in complex distributed online information environments (Doctoral dissertation). University of Aberdeen.

Siemens, G., \& Conole, G. (2011). Special issue-Connectivism: Design and delivery of social networked learning. International Review of Research in Open and Distance Learning, 12(3). Retrieved from http:// www.irrodl.org/index.php/ irrodl/issue/view/ 44

Sewart, D., Keegan, D., \& Holmberg, B. (Eds.) (1983). Distance education: International perspectives. London: Croom Helm.

So, H. (2010). Towards rigor of online interaction research: Implication for future distance learning research. The Turkish Online J ournal of Educational Technology, 9(2), 256-263. 
Sun, H. T.(2013). Social affordance of typical Web 2.0 tools in distance education (Doctoral dissertation). Beijing Normal University.

Taylor, J . C. (2001). Fifth generation distance education. Retrieved from http:// www.usq.edu.au/ users/taylorj/ conferences.htm

Tello, S. F. (2007). An analysis of student persistence in online education. International J ournal of Information and Communication Technology Education, 3(3), 4762.

Verhagen, P. (2006). Connectivism: A new learning theory? Surf e-learning themasite. Retrieved from http:// elearning.surf.nl/e-learning/english/3793

Wagner, E. D. (1994). In support of a functional definition of interaction. The American J ournal of Distance Education, 8(2), 6-26.

Wang, Z.J .(2013). A new perspective of instructional interaction research in distance education: Structuralism. Morden Distance Education Research, 5, 28-33.

Wen-chi, V. W., Yen, L. L., \& Marek, M. (2011). Using online EFL interaction to increase confidence, motivation, and ability. J ournal of Educational Technology \& Society, 14(3), 118-n/a.

Woo, Y., \& Reeves, T. C. (2007). Meaningful interaction in web-based learning: A social constructivist interpretation. The Internet and Higher Education, 10(1), 15-25.

\section{Athabasca University $\mathbf{Z}$}

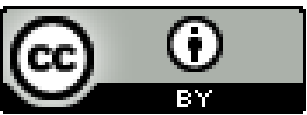




\section{Designing Online Interaction to Address Disciplinary Competencies: A Cross-Country Comparison of Faculty Perspectives}
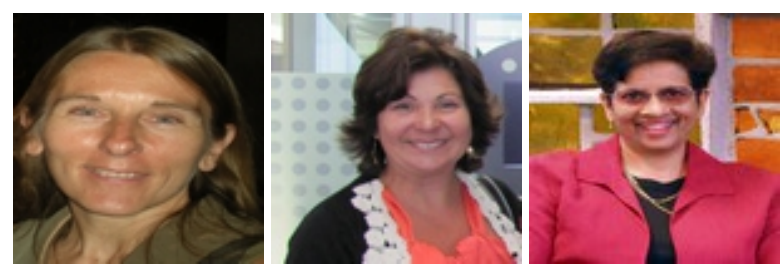

Elena Barberà' ${ }^{1}$, Ludmila Layne ${ }^{2}$, and Charlotte N. Gunawardena ${ }^{2}$

1 Universitat Oberta de Catalunya, Spain, 2University of New Mexico, USA

\section{Abstract}

This study was conducted at colleges in three countries (United States, Venezuela, and Spain) and across three academic disciplines (engineering, education, and business), to examine how experienced faculty define competencies for their discipline, and design instructional interaction for online courses. A qualitative research design employing indepth interviews was selected. Results show that disciplinary knowledge takes precedence when faculty members select competencies to be developed in online courses for their respective professions. In all three disciplines, the design of interaction to correspond with disciplinary competencies was often influenced by contextual factors that modify faculty intention. Therefore, instructional design will vary across countries in the same discipline to address the local context, such as the needs and expectations of the learners, faculty perspectives, beliefs and values, and the needs of the institution, the community, and country. The three disciplines from the three countries agreed on the importance of the following competencies: knowledge of the field, higher order cognitive processes such as critical thinking, analysis, problem solving, transfer of knowledge, oral and written communication skills, team work, decision making, leadership and management skills, indicating far more similarities in competencies than differences between the three different applied disciplines. We found a lack of correspondence between faculty's intent to develop collaborative learning skills and the actual development of them. Contextual factors such as faculty prior experience in design, student reluctance to engage in collaborative learning, and institutional assessment systems that focus on individual performance were some of these reasons.

Keywords: Instructor competencies; interaction; higher education; online learning 


\section{Introduction}

With the global expansion of eLearning, and the ability to share academic courses between countries, one question that is in the minds of many distance educators is whether a course designed in a specific discipline to address specific competencies in one country will be relevant for students of the same discipline in another country. If we are able to address this question adequately, academic courses can be designed, adapted, and exchanged internationally. Therefore, it is important to examine how academic disciplines define and communicate the culture of their discipline in online course designs, and how a discipline stipulates the competencies that need to be developed.

While many definitions of disciplinary competency exist, it is generally accepted that competencies are more than knowledge and skills; "It involves the ability to meet complex demands, by drawing on and mobilising psychosocial resources (including skills and attitudes) in a particular context" (Pisa report, p. 4). This definition is clarified by this Pisa report using the example of the competency to communicate effectively, which may draw on an individual's knowledge of language, practical IT skills and attitudes towards those with whom he or she is communicating. The OECD's Definition and Selection of Competencies Project (Rychen \& Salganik, 2001) emphasizes the key role that "context" plays in defining competencies as no frame of reference is neutral; theoretical approaches and analytical tools impact the way in which a topic is understood or problem is approached; individual characteristics such as gender, social status, culture and national context influence the form the competencies take in a specific context; and the interdependence of scientific findings and requirements of educational policy makers factor into the debate of defining a competency.

Stark (2000) notes that his empirical research confirmed previous studies which asserted that course design is closely related to enduring assumptions embedded in the disciplines and educational beliefs to which faculty members have been socialized. He further elaborates that faculty are also influenced, but less strongly, by contextual factors that depend on the local situation. In addition, the notions of interaction and competency are core concepts for understanding the interpersonal (interaction) and the intrapersonal (competency) dimensions of education. Both constructs are influenced, if not determined, socioculturally (Monaghan, Goodman, \& Meta Robinson, 2012). However, there has been very little research on how both these constructs, interaction and competency function within a discipline in a specific context, for example for a specific group of learners, in a specific academic setting, in a specific country. Such an understanding is necessary if the same course in a specific discipline is to be shared by people in different contexts.

"Most empirical research supports the view that there are important cultural differences between disciplinary groupings" (Nesi \& Gardner, 2006, p. 99). Teaching and learning Mathematics is different from teaching and learning Philosophy, for example, and effective ways to teach and learn Mathematics will differ from instructor to instructor 
and context to context. As Cameron (2008) noted, even within a discipline, there may be a need to approach the same subject in different ways to meet the learning needs of diverse students. Therefore, the design of the learning process, and a significant aspect of this learning process, that of interaction between the instructor and learners, and between learners will be designed differently. The question then is, how do these disciplinary differences and contextual differences impact online interaction and the way instructors design the instructional process? This research aims to examine this question from the perspectives of experienced online instructors in three disciplines in three countries, the United States, Venezuela, and Spain. This investigation will contribute to our understanding of how interaction is currently being designed to support the development of disciplinary competencies. We want to explore how knowledge is framed by each discipline, and what kinds of strategies promote developing competencies online.

\section{Purpose of the Study}

The aim of this paper is to report on a study conducted in higher education institutions in three countries (United States, Venezuela, and Spain) and across three disciplines (engineering, education, and business) to determine how experienced faculty identify competencies for their disciplines and design instructional activities to develop these competencies in online courses. The study also seeks to explore if disciplinary or local contextual factors take precedence when competencies are identified as important by experienced online faculty.

\section{Research Questions}

The research questions that guided this study were:

1. What academic competencies are important to experienced online instructors in their respective disciplines and what are the similarities and differences in their use of disciplinary competencies?

2. How do experienced online instructors design online interaction to develop the necessary knowledge and skills and what are the similarities and the differences found in the three countries?

Based on the identified competencies and corresponding types of interaction designed to facilitate the learning process to support the development of these competencies, implications for online instructional design will be presented along with a discussion of whether it would be possible to share the same course globally in the disciplines studied.

\section{Review of Literature}

Disciplinary knowledge and variations between disciplinary cultures (that have certain norms, beliefs, expectations, and conventions) have been defined using the seminal work of Biglan (1973), who described disciplines along three dimensions: hard/soft, 
pure/ applied, life/non-life. Subsequently, Squires (2005) made a distinction between the pure disciplines and the applied 'professional' disciplines such as Education and Medicine, observing that while the main concern in the pure disciplines is to interpret or understand the world, the professional disciplines are more focused on acting. The three disciplines selected for study in this paper can be classified as professional disciplines that are focused on application of knowledge.

Previous research in distance education has addressed the subject of disciplinary competencies (e.g., Bigatel et al., 2012; Kelly, Luke, \& Green, 2008; Hunter, 2008). Although there are exceptions (e.g., Silius et al., 2012), most of this research has focused on defining general or basic competencies for large populations (citizens of a country, a continent, and world-wide learners). In general we can distinguish between a set of studies conducted intra-nationally (e.g., Hong \& Jung, 2012) and a set of studies conducted cross-nationally (e.g., Pfeffer, 2012). Although this body of literature considers context in relation to the notion of competency, it does so at such a general level by reflecting what is common in one nation or a region of the world. These results are not very helpful in designing specific online instructional activities (Gorsky, Caspi, Antonovsky, Blau, \& Mansur, 2010) that might translate across countries. There have been a few attempts (notably Boon and van der Klink, 2002 in the USA; Eraut, 1994 in the UK) to situate competencies in terms of contextual practices (Jeris \& Johnson, 2004). This line of research examining contextual factors that influence faculty in designing the learning process is important and needs to be extended further. The current study proposes to do this by examining if contextual factors influence one of the most important aspects of the learning process: the design of interaction in online courses.

A significant body of research (J uwah, 2006) has examined the concept of interaction in distance education since Moore (1989) defined three types of interaction in an editorial published in The American J ournal of Distance Education: learner-content, learnerlearner, learner-instructor. Learner-technology interaction was added later as it has significant importance in distance and online education. This paper uses Moore's definition of interaction in distance education with a focus on learner-instructor and learner-learner interaction. Research on interaction has focused mainly on six important aspects: a) the types of interaction (Bernard et al., 2009; Gilbert \& Moore, 1998); b) the levels of interaction (Erdogan \& Campbell, 2008; Kale, 2008); c) the taxonomies of interaction (Fulford \& Sakaguchi, 2002; Nandi, Hamilton, \& Harland, 2012); d) the patterns of interaction (Loewen \& Reissner, 2009; Manca, Delfino, \& Mazzoni, 2009; Abedin, Daneshgar, \& D'Ambram, 2012); e) the design of interaction (Hurumi, 2006; Juwah, 2006; Tsai \& Lee, 2012); and f) the evaluation of interaction (Guan, Tregonning, \& Keenan, 2008; Snášel et al., 2012). It is generally accepted that interaction is a critical ingredient of a quality online course (Masoumi \& Lindström, 2012; Keengwe \& Schnellert, 2012, Quality Matters, 2011). Nevertheless, interaction is not commonly part of the design of an online course as maintaining quality interaction in an online course requires faculty time and resources. A large proportion of online courses are designed to be self-instructional learning experiences with a minimal amount of learner engagement and interaction with the course professor. Although 
instructional design itself has made great efforts to include decisions about interaction in its framework, it seems there is a need in online education to move beyond the delivery of content that is currently being reinforced by some massive open courses around the globe. Therefore, a richer conception of interaction can help to design more balanced and effective online teaching and learning based on authentic knowledge building.

Interaction in an online course is a critical factor as it reflects student engagement (Roblyer \& Wiencke, 2004). Interaction is influenced and shaped by many factors. One important factor is context, as it shapes the way faculty will design a course to meet the needs and expectations of a certain group of learners, a program, institution, or country. Stark, Lowther, Bentley, and Martens (1990) studied several disciplines and identified through factor analysis eight contextual influences on faculty course planning. The level of importance of these factors in order of rank are: 1 Student characteristics, 2 Student goals, 3 Pragmatic issues, 4 Influences external to the college or university, 5 (tie) Program and college goals, 5 (tie) Advice available on campus, 5 (tie) Literature on teaching and learning, and 6 Facilities, resources, opportunities, assistance. These eight factors and others, such as "teaching presence," "cognitive presence," and "social presence" that showed a significant relationship between academic discipline and dialogic behavior in Gorsky et al.'s (2010) study should be considered as we look at the relationship between disciplinary competencies and interaction.

\section{Method}

A qualitative research design based on in-depth interviews with online faculty was selected as the method for this study. The study was designed by the three authors of this paper in 2007, and Institutional Review Board (IRB) approval granted for this international study by the U.S. institution the same year. The study was completed in higher education institutions in Spain, the United States, and Venezuela. These institutions included one that was a wholly online institution from Spain (hereafter referred to as 'Spain'), one that was a dual-mode (traditional and distance) higher education institution from the Southwestern United States (hereafter referred to as 'US'); and four higher education institutions from Venezuela (referred to collectively as 'Venezuela,' and treated as a single unit of analysis.)

\section{Participants}

A purposeful sample of 19 experienced online faculty members was selected for interviews. The faculty were from the three countries (six from Spain, six from US, and seven from Venezuela) teaching in three diverse disciplines. These faculty members had extensive teaching experience ranging from 10 to 25 years in their respective fields. All had taught at least three courses online in their discipline. Eight faculty interviewees were from education, six from engineering, and five from business. Of the eight interviewees from the education discipline, two were from the US, four from Venezuela, and two were from Spain. The engineering sample consisted of two faculty members 
from each country. The business school sample consisted of two faculty members from the US, two from Spain, and one from Venezuela.

\section{Instruments and Procedure}

An initial set of interview questions that corresponded to the research questions was developed collaboratively by the researchers from the three countries and translated into three languages: English, Catalan, and Spanish. The interview questions were then pilot tested by doctoral students from the US university and the researchers from each university in Spain and Venezuela. Based on the pilot instrument feedback, several questions were refined and modified. The final interview guide had 26 questions, out of which three main questions and associated sub-questions were selected for analysis in this study. The main questions were: (a) In your discipline, what kinds of knowledge and skills should students have when they graduate? (b) Relative to the previous questions, which competencies do you focus on when designing interactive learning activities? (c) Are these competencies focused on individual or collaborative group work? Data collection procedures entailed the use of open-ended questions in face-toface interviews. All interviews were tape recorded and the recordings were transcribed for analysis.

Faculty interviews in the U.S. institution were conducted by one of the authors of this paper and her doctoral students, and the data analyzed for this institution by the end of 2007. Interviews were conducted in the Venezuelan institutions in 2008 by one of the authors of this paper and data analyzed for the Venezuelan institution during 20082009. The procedure for the institution in Spain was similar to the Venezuelan institution. Interviews were conducted by the primary author of this study in 2008, and subsequently, the codes verified by a graduate assistant and data analyzed for this institution in 2009. The interviews from Spain and the United States were analyzed and coded with Atlas.ti 5.0 qualitative software, while the interviews from Venezuela were analyzed manually. During 2010, the three institutions shared the findings, collaborated to analyze data and began to determine the codes and themes that emerged across institutions.

\section{Data Analysis}

An interpretative, narrative approach to data analysis was employed to examine the relationships between multiple disciplines and countries. The data analysis procedure included several steps. First, data was coded in each of the three countries and a coding list developed. Then, the coding lists were shared among the three countries, and a master coding list developed for the study. Concept mapping was used as a data analysis technique to facilitate the comparison of data across the countries and multiple disciplines. The analysis was discussed via face-to-face meetings, audio and desktop conferencing, and electronic messaging. Triangulation occurred in three ways: (a) data triangulation was achieved by gathering data from three different contexts, (b) investigator triangulation was achieved by employing several researchers to analyze the data, and (c) theory triangulation was achieved by employing three different conceptual 
frameworks (disciplinary, contextual, online interaction) to interpret the data (J anesick, 2003). These three types of triangulation helped to account for the trustworthiness and credibility of findings for similar contexts.

\section{Findings and Discussion}

The results are organized by disciplines: engineering, education and business. The results for the first research question that show how academic competencies were defined by faculty for each discipline can be seen in Table 1 . We then discuss the unique perspectives that emerged for each discipline by each country and context. Next, we discuss the competencies shared by the three disciplines (see Table 2). To address the second research question, we provide a detailed analysis of the design of interaction by discipline and by country (see Tables 3-5). We conclude by making comparisons of the salient similarities and differences across disciplines and countries, and discuss the role of disciplinary influences and contextual influences on the design of online interaction. We conclude with implications for the design of online interaction.

\section{Engineering}

\section{Q1. Academic Competencies and Engineering Profile}

From the six interviews of engineering faculty, we identified several important academic competencies. Based on faculty opinion from all three countries, these competencies involve both knowledge and experience, and the need for students to be able to function like professional engineers in the field. Students should be able to identify, and solve problems and communicate their knowledge to others. They need to be able to manage, lead, and work in teams. Therefore, engineers must possess more than content knowledge, and must have the ability to function as an engineer in the workplace. One US faculty member described it as "learning through the school of hard knocks." Therefore, when a faculty member says "knowledge of the field," it is not merely knowledge of content, but also the integration of process skills (see Table 1 for a detailed list of competencies).

These are the main competencies that define an engineer's profile: Analytical, critical thinking, problem solving, decision making, managing, evaluating, working in teams, leading, and communicating orally and in writing. Comparing our results to a previous study conducted by Davis, Beyerlein, and Davis (2005), we found several similarities in our identified profile for engineers. This study identified the main competencies for an engineer as follows: analyst, problem solver, designer, researcher, communicator, collaborator, leader, self-grower, achiever and practitioner.

We observed that the US civil engineering and the electrical and computer engineering faculty members defined knowledge of the field as constituting both knowledge and experience, which includes: 1) Understanding how industry works, for example, identifying roles and responsibilities of each player in the construction industry, 2) Experience in the field, 3) Connecting previous knowledge to new situations, 4) 
Applying critical thinking to solving problems, and 5) Conducting research. One faculty member observed: "If they don't have this knowledge and experience, it leads to confusion and litigation."

The two faculty members from Venezuela (one from civil and one from computer engineering) also emphasized the importance of both knowledge and experience, and noted that decision making in the real world context and transferring knowledge into new situations were equally important. This includes mastery of knowledge and acquiring knowledge and skills to evaluate "material strength and resistance and appropriateness in construction projects." Therefore, laboratory skills are necessary from the outset. For these two faculty knowledge of the field also included the ability to apply new knowledge into new situations, where students also have to develop skills such as analysis, critical thinking, reflection, planning strategies, decision making and be able to share and work in a team.

The two engineering faculty members from Spain, both from information technology (IT) and networking, thought of knowledge of the field more in terms of systems thinking. They stated that students must have a clear understanding of how IT systems "function," "how to trouble shoot" and "how to construct them." They should know how to assimilate this knowledge and communicate it to others. They mentioned that communication skills, both oral and written, are important for professionals in IT engineering. In addition, they emphasized the development of team and group work: "Everything is done in group projects and not individually; they must be able to work with other people to share and get used to dealing with one part of a project." Another skill that was considered important was the ability to lead teams within the company.

In summary, when comparing engineering academic competencies it can be noted that both knowledge and experience were mentioned as key factors for engineering students in all the countries. Other competencies that were emphasized are: systems thinking, communication, leadership, and team/group work skills. Online designs therefore need to focus on developing these skills to enable a student to function like an engineer while engaging them in "content" knowledge. We note that when defining engineering competencies across the three countries, disciplinary perspectives took precedence over contextual perspectives (or how a competency would differ in the context of a specific country). 
Table 1

\section{Summary of Competencies for the Three Disciplines by the Three Countries}

\begin{tabular}{|c|c|}
\hline Discipline & Competencies \\
\hline Engineering & $\begin{array}{l}\text { 1. Engage in systems thinking - understanding how an engineering system works, } \\
\text { how to trouble shoot it, and construct it. } \\
\text { 2. Connect previous knowledge to new situations } \\
\text { 3. Apply critical thinking to solving problems } \\
\text { 4. Analyze a problem, synthesize knowledge and come up with a solution } \\
\text { 5. Transfer knowledge } \\
\text { 6. Reflect } \\
\text { 7. Plan } \\
\text { 8. Make decisions } \\
\text { 9. Conduct research } \\
\text { 10. Evaluate "material strength and resistance and appropriateness in construction } \\
\text { 11. Work in groups and teams } \\
\text { 12. Lead teams } \\
\text { 13. Manage } \\
\text { 14. Communicate orally and in writing }\end{array}$ \\
\hline Education & $\begin{array}{l}\text { 1. Demonstrate knowledge domain in their specific area. } \\
\text { 2. Act ethically } \\
\text { 3. Integrate, understand and apply pedagogical and psychological theories, in } \\
\text { their practice } \\
\text { 4. Develop a capacity to integrate theories to analyze educational problems } \\
\text { 5. Apply principles of Andragogy and management. } \\
\text { 6. Design instruction applying instructional design theories and principles, using } \\
\text { appropriate technologies to enhance interaction in online environments. } \\
\text { 7. Develop self-confidence in exploring and applying instructional technologies } \\
\text { and visioning new trends in their application } \\
\text { 8. Apply declarative, procedural and contextual knowledge about } \\
\text { using/applying instructional technologies. } \\
\text { 9. Develop capacity to innovate by applying new knowledge and technologies in } \\
\text { their practice. } \\
\text { 10. Develop leadership skills. } \\
\text { 11. Work in teams and collaborate both face-to-face and online. } \\
\text { 12. Know how to help, and help people to self-regulate and acquire autonomy. } \\
\text { 13. Develop capacity for self-reflective learning, self-evaluation. } \\
\text { 14. Conduct educational research. }\end{array}$ \\
\hline Business & $\begin{array}{l}\text { 1. Solve problems. } \\
\text { 2. Problem solve in groups. } \\
\text { 3. Develop analytical skills. } \\
\text { 4. Engage in critical thinking. } \\
\text { 5. Work in teams. } \\
\text { 6. Develop communication skills (oral and writing). } \\
\text { 7. Develop leadership skills. } \\
\text { 8. Act ethically. } \\
\text { 9. Develop capacity to ask questions and listen to answers. } \\
\text { 10. Formulate and evaluate projects. } \\
\text { 11. Contextualize course topics and content. }\end{array}$ \\
\hline
\end{tabular}


Table 2

Competencies Shared by Disciplines

\begin{tabular}{|l|c|c|c|}
\hline $\begin{array}{l}\text { Disciplines } \\
\text { Competencies }\end{array}$ & Engineering & Education & Business \\
\hline $\begin{array}{l}\text { Knowledge of } \\
\text { the field }\end{array}$ & $\mathrm{X}$ & $\mathrm{X}$ & $\mathrm{X}$ \\
\hline $\begin{array}{l}\text { Apply critical } \\
\text { thinking }\end{array}$ & $\mathrm{X}$ & $\mathrm{X}$ & $\mathrm{X}$ \\
\hline $\begin{array}{l}\text { Solving } \\
\text { problem skills }\end{array}$ & $\mathrm{X}$ & $\mathrm{X}$ & $\mathrm{X}$ \\
\hline Analytical skills & $\mathrm{X}$ & $\mathrm{X}$ & $\mathrm{X}$ \\
\hline $\begin{array}{l}\text { Communication } \\
\text { skills }\end{array}$ & $\mathrm{X}$ & $\mathrm{X}$ & $\mathrm{X}$ \\
\hline $\begin{array}{l}\text { Leadership } \\
\text { skills }\end{array}$ & $\mathrm{X}$ & $\mathrm{X}$ & $\mathrm{X}$ \\
\hline $\begin{array}{l}\text { Collaboration } \\
\text { skills }\end{array}$ & $\mathrm{X}$ & $\mathrm{X}$ & \\
\hline Act ethically & $\mathrm{X}$ & $\mathrm{X}$ & \\
\hline Research skills & $\mathrm{X}$ & & \\
\hline $\begin{array}{l}\text { Application \& } \\
\text { Transfer of } \\
\text { knowledge }\end{array}$ & & & \\
\hline
\end{tabular}

\section{Q2. Design of online instructional interaction in Engineering}

As Table 3 indicates, faculty in all three countries are designing a variety of activities for engineering students to develop individual and group competencies. The faculty member who teaches civil engineering in the US stated that she designs both individual and group activities in order to help students develop the competencies they need as civil engineers. She designs online activities where students start with examples of real world problems and have the opportunity to critically think through solutions. Students have to apply skills such as analysis and synthesis in the problem solving process. Also students develop research skills while solving their assigned problems. The electrical/computer engineering faculty member also affirmed that problem solving activities were the main focus in his class. However, this faculty member centered his class on developing individual competencies, instead of designing online activities to develop group work skills. 
Table 3

Competencies and Design of Interaction for Engineering Across Three Countries.

\begin{tabular}{|c|c|c|c|}
\hline \multirow{12}{*}{ 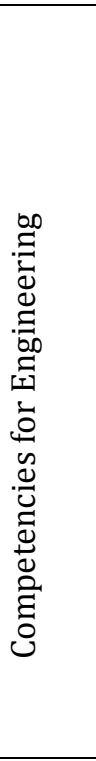 } & U.S.A. & Venezuela & Spain \\
\hline & $\begin{array}{l}\text { Understand } \\
\text { systems }\end{array}$ & & $\begin{array}{l}\text { Understand } \\
\text { systems }\end{array}$ \\
\hline & Critical thinking & Critical thinking & Critical thinking \\
\hline & Problem solving & & Problem solving \\
\hline & $\begin{array}{l}\text { Transfer of } \\
\text { knowledge }\end{array}$ & $\begin{array}{l}\text { Transfer of } \\
\text { knowledge }\end{array}$ & \\
\hline & Research skills & & \\
\hline & & $\begin{array}{l}\text { Analysis \& } \\
\text { evaluation skills }\end{array}$ & \\
\hline & & $\begin{array}{l}\text { Decision making } \\
\text { skills }\end{array}$ & \\
\hline & & Lab skills & \\
\hline & & & $\begin{array}{l}\text { Management \& } \\
\text { leadership skills }\end{array}$ \\
\hline & & & $\begin{array}{l}\text { Communication } \\
\text { skills }\end{array}$ \\
\hline & & & Build a system \\
\hline \multirow{3}{*}{ 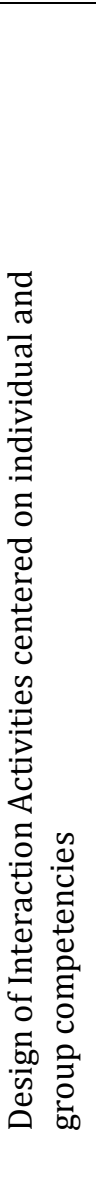 } & $\begin{array}{l}\text { Design both } \\
\text { individual and } \\
\text { group activities. }\end{array}$ & $\begin{array}{l}\text { Design learning } \\
\text { activities to } \\
\text { develop } \\
\text { competencies } \\
\text { such as: } \\
\text { Team work } \\
\text { Analysis } \\
\text { Reflection, } \\
\text { Planning action } \\
\text { strategies and } \\
\text { Decision making }\end{array}$ & $\begin{array}{l}\text { Designing group } \\
\text { project, students } \\
\text { need to show } \\
\text { leadership, } \\
\text { communication } \\
\text { and team work } \\
\text { skills used as a way } \\
\text { to the problem } \\
\text { solutions. }\end{array}$ \\
\hline & $\begin{array}{l}\text { Developing } \\
\text { individual papers } \\
\text { and presentations } \\
\text { starting with a } \\
\text { problem } \\
\text { statement, } \\
\text { students need to } \\
\text { show analysis, } \\
\text { and critical } \\
\text { thinking } \\
\text { strategies used as } \\
\text { a way to the } \\
\text { solutions. }\end{array}$ & $\begin{array}{l}\text { Designing } \\
\text { individual } \\
\text { activities where } \\
\text { student } \\
\text { demonstrate their } \\
\text { analytical } \\
\text { thinking and } \\
\text { problem solving } \\
\text { skills. }\end{array}$ & $\begin{array}{l}\text { Practical exercises } \\
\text { to be solved in } \\
\text { pairs }\end{array}$ \\
\hline & $\begin{array}{l}\text { Using example of } \\
\text { real world } \\
\text { problem that the } \\
\text { students } \\
\text { investigate. }\end{array}$ & & \\
\hline
\end{tabular}


In Venezuela, the civil engineering faculty member focuses the design of learning activities on developing individual analytical thinking, and problem solving, while the computer engineering faculty member focuses his learning activities on developing team competencies, such as team work, analysis, reflection, planning, action strategies, and decision making.

In Spain, both faculty members noted that they design more individual activities than collaborative activities. While they recognize the importance of developing teamwork skills, they take a different approach. One of them designs practical exercises to be solved in pairs, so that students can interact with each other and solve each other's problems. As he explains,

I try to make it possible for the practical exercises to be done in pairs, because by working in pairs students really help each other and if one of them gets stuck on one point and has somebody around who is working towards the same objective as him/ her and is involved in the same process, that person is able to help the student resolve the problem better than the teacher could. This is true above all when implementing a computer system, as it is possible to get stuck and the teacher does not have enough time to look at the programs that aren't working from 40 students. However, with a course colleague it is different, as you have someone with the same problem and the same desire to resolve that problem as you, which makes it much easier for him or her to give you a hand. I believe that it is very important to encourage this type of interaction, I don't intervene directly, except in the practical exercises in which the solution to the problem is complicated, I try to offer the option of working in pairs. It is important to encourage more interaction between students than with the teacher.

The second engineering/ IT faculty member designs more individual activities in the course, because

I do not feel that working in groups necessarily adds value. Group work is done more on a programmer level. The students complain because they do not want to work in groups, and although we want group working competencies to be part of the programmer, we do not want to force students.

In summary, an analysis of engineering faculty methods in all three countries indicates that they are designing instructional activities online that require students to think through problems, engage in critical thinking, and develop solutions. However, perspectives on the importance of individual and collaborative learning activities to 
meet the requirements of engineering competencies differed. Two of six faculty members are designing these activities as group work projects that require students to collaborate with each other to create solutions. While the other four faculty members acknowledge the importance of working in teams to develop leadership, management, and communication skills, they prefer to focus on developing individual problem solving and critical thinking skills. This may be related to contextual factors such as faculty experience with designing and assessing online collaborative learning, and the reluctance of students to engage in collaborative learning. It echoes Tseng and Yeh's (2013) finding that online instructors need to comprehend students' expectations on learning collaboratively. This finding may indicate the need to develop and offer faculty development programs that demonstrate how collaborative learning and evaluation strategies can be designed to correspond with student abilities and required competencies. For example, team skills can be developed in an online program by having students work in small groups to solve real world problems in a real or simulated work setting. By building online Communities of Practice that work toward a common goal, it is possible to develop team skills, leadership skills, and collaborative problem solving skills. For engineering, it can be concluded that disciplinary perspectives take precedence when faculty discuss the importance of competencies for the field, while contextual considerations impact the design of interaction, such as faculty prior experience in designing collaborative learning, to meet the needs of these competencies.

\section{Education}

\section{Q1. Academic Competencies and Education Profile}

Table 1 summarizes the competencies that emerged for education. From the eight interviews with education faculty, the competencies that emerged include application of knowledge in educational contexts, solving educational problems applying theories and new technologies, developing leadership skills, collaborating, applying instructional design principles, keeping oneself updated in new theoretical and technology trends, and developing a capacity to self-reflect and self-evaluate. Compared to the other two professions, educators stressed the importance of communication and collaboration skills, and the utilization of new technologies in instructional design. For example one of the US faculty stated:

In the program that I'm teaching they should know a lot of technologies. They should have awareness about what's coming and then a confidence that they can go out and explore new technologies and figure it out how to use them well, and how to design collaborative learning scenarios with them.

Education faculty emphasized competencies depending on their area of expertise. Of the two education faculty members interviewed in the US, one had an instructional technology background and emphasized the importance of instructional design and instructional technology competencies. The other faculty was from educational leadership and emphasized the competencies that school principals needed to develop: 
"I work in a program that primarily is committed to preparing future school leaders. Our graduates should possess the knowledge, skills and dispositions to be able to move into a beginning administrator assistant principal role in a school setting”.

Two faculty from Venezuela focused on competencies related to self-development, stressing that all educators should be conscious of their self-development which is "the ability to monitor their learning, self-reflective learning, capacity to improve their teaching skills." One of them summarized the competencies in three fundamental areas:

a) Theoretical and philosophical foundations in educational sciences, b) Use and application of methodological strategies, classroom planning, program design, and c) Instructional Design. A third respondent stated that all educators should have the capacity to integrate theories to analyze educational problems, as well as the ability to apply new knowledge in their practice. In addition, they should be able to work in groups and communities. This respondent also agreed with the previous two respondents that all educators should have the capacity to self-evaluate their practice. The fourth respondent was from educational research and therefore pointed out that all educators should be methodologically informed to investigate and apply the principles of andragogy and management.

The main competencies that emerged from the two interviews conducted in Spain were: a) knowledge of the field, b) theory application, c) ethics, d) capacity to work in teams and collaborate, e) capacity to self-reflect on their own practice, and f) capacity to selfdevelop and innovate in the field.

In summary, it was evident that the competencies considered most important depended on the specific areas of specialization within the education field the faculty came from. In all three countries, education faculty showed a common interest in the development of educators, mentioning knowledge and application of instructional technologies, capacity to work in teams and collaborate, capacity to self-reflect on their own practice, capacity to self-develop and innovate in their field, apply theories, and act ethically. Faculty from US and Venezuela noted instructional design theories and principles and the design of interaction in online environments, and research skills as important competencies.

When analyzing salient similarities and differences, three kinds of educator competencies could be distinguished. US faculty were focused on competencies that take into account specific education content, such as instructional design skills, and applying theories of learning to solve specific design problems. Faculty from Spain were driven by more general competencies such as analysis skills, research skills, and faculty from Venezuela employed a hybrid of the previous two.

\section{Q2. Design of online instructional interaction on Education}

As indicated in Table 4, both US faculty members focus on designing individual as well as interactive and collaborative learning activities, because they stated that students should develop a set of specific individual skills and autonomy in their fields, and should 
have a set of competencies that allow them to function in groups, teams, and communities. In this respect, one of them discussed the following:

(...) in educational leadership there are sets of administrative competencies that we have to align our course work with at the national and state levels. So those competencies tend to be more content focused rather than process focused. And so, with your example here, competencies that may address reflection analysis; those processes I have students write reflective papers, they do analysis, critical review, and oral and written reports. I focus on both individual as well as group competencies. 
Table 4

Competencies and Design of Interaction for Education Across Three Countries

\begin{tabular}{|c|c|c|c|}
\hline \multirow{18}{*}{ 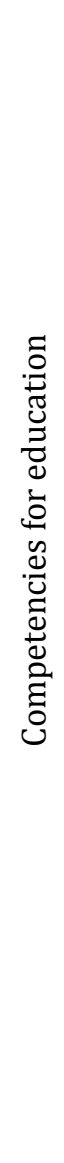 } & U.S.A. & Venezuela & Spain \\
\hline & $\begin{array}{l}\text { Instructional } \\
\text { design skills }\end{array}$ & $\begin{array}{l}\text { Instructional } \\
\text { design skills }\end{array}$ & \\
\hline & $\begin{array}{l}\text { Facilitate online } \\
\text { interaction }\end{array}$ & & \\
\hline & Critical thinker & Critical thinker & \\
\hline & Analysis skills & Analysis skills & Analysis skills \\
\hline & $\begin{array}{l}\text { Apply theories of } \\
\text { learning }\end{array}$ & $\begin{array}{l}\text { Apply theories of } \\
\text { learning }\end{array}$ & \\
\hline & Leadership skills & Leadership skills & \\
\hline & Manager skills & Manager skills & \\
\hline & & Team work & Team work \\
\hline & Technology skills & $\begin{array}{l}\text { Apply pedagogical } \\
\text { principles and } \\
\text { didactic in the } \\
\text { curriculum }\end{array}$ & \\
\hline & & $\begin{array}{l}\text { Transfer of } \\
\text { knowledge }\end{array}$ & \\
\hline & & Problem solving & \\
\hline & & $\begin{array}{l}\text { Collaborative } \\
\text { skills }\end{array}$ & $\begin{array}{l}\text { Collaborative } \\
\text { skills }\end{array}$ \\
\hline & & Research skills & Research skills \\
\hline & & $\begin{array}{l}\text { Self-reflective } \\
\text { learning }\end{array}$ & $\begin{array}{l}\text { Self-reflective } \\
\text { practice }\end{array}$ \\
\hline & & $\begin{array}{l}\text { Self-evaluation } \\
\text { skills }\end{array}$ & $\begin{array}{l}\text { Self-regulate } \\
\text { autonomy }\end{array}$ \\
\hline & & & Understand help \\
\hline & & & Act ethically \\
\hline \multirow{6}{*}{ 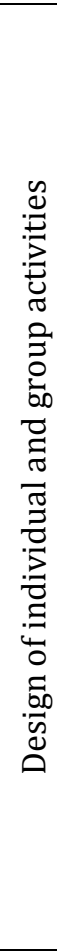 } & $\begin{array}{l}\text { Design both } \\
\text { individual and } \\
\text { group activities. }\end{array}$ & $\begin{array}{l}\text { Design both } \\
\text { individual and } \\
\text { group activities. }\end{array}$ & $\begin{array}{l}\text { Design both } \\
\text { individual and } \\
\text { group activities. }\end{array}$ \\
\hline & Videoconferences & & \\
\hline & $\begin{array}{l}\text { Design interactive } \\
\text { and collaborative } \\
\text { learning activities }\end{array}$ & $\begin{array}{l}\text { Design learning } \\
\text { activities } \\
\text { enhancing } \\
\text { collaborative } \\
\text { skills }\end{array}$ & \\
\hline & $\begin{array}{l}\text { Case-based } \\
\text { problem: } \\
\text { Solve real } \\
\text { problems in their } \\
\text { field, in group and } \\
\text { collaboratively }\end{array}$ & $\begin{array}{l}\text { Case-based } \\
\text { problems in their } \\
\text { field }\end{array}$ & $\begin{array}{l}\text { Problem solving } \\
\text { cases arguing } \\
\text { decision making } \\
\text { process }\end{array}$ \\
\hline & $\begin{array}{l}\text { Write reflective } \\
\text { papers, they do } \\
\text { analysis, critical } \\
\text { review, and oral } \\
\text { and writing } \\
\text { language query }\end{array}$ & $\begin{array}{l}\text { Write individual } \\
\text { research reports }\end{array}$ & \\
\hline & $\begin{array}{l}\text { Online discussions } \\
\text { to encourage }\end{array}$ & $\begin{array}{l}\text { Online discussions } \\
\text { to encourage }\end{array}$ & $\begin{array}{l}\text { Online } \\
\text { discussions to }\end{array}$ \\
\hline
\end{tabular}




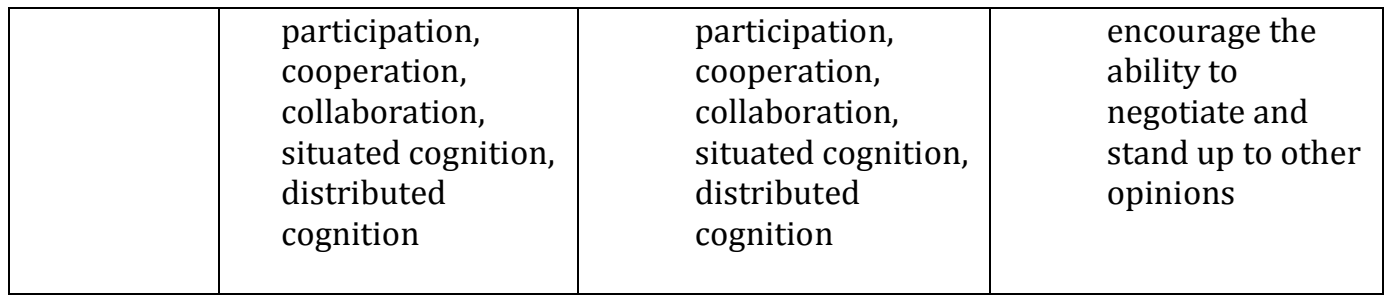

Likewise, education faculty in Venezuela, focus on developing individual as well as collaborative skills. One of them noted:

I emphasize both individual as well as collaborative skills. I design learning activities to encourage competencies such as: participation, cooperation, collaboration, situated cognition, distributed cognition, all of these in order to solve real problems in their field... Students are encouraged to write individual research reports, analyzing data into categories, then, they collaborate with each other asking questions and providing suggestions to improve their research project.

As in the cases of both US and Venezuelan education faculty, those from Spain are also designing instruction based on both individual and group competencies. One of them noted:

...reflection, decision-making and presenting arguments, and the justification for why a certain decision was made. The ability to negotiate and stand up to other opinions. All these processes are focused on group work, although I believe the students' previous individual work is also important.

This approach is corroborated by the use of online discussions which demand individual work to maintain success at the collaborative level.

Table 4 indicates that education faculty in the US, Venezuela and Spain share the common goal of designing online programs that promote collaborative and group competencies. Faculty from all three countries noted the design of case-based problem solving activities related to higher order cognitive skills such as critical, analytical thinking, problem solving, and application and transfer of knowledge. Another salient similarity between countries is the fact that they design group activities based on student-student interaction using online discussions to encourage participation, cooperation, collaboration, and communication skills.

Analysis of educator faculty perspectives on the design of interaction indicates that all faculty are designing instructional activities that help students to integrate diverse 
knowledge and skills while they are solving specific tasks and problems. Similar to other disciplines, educators are focusing on developing individual abilities such as critical thinking, applying and transferring knowledge, oral and written communication skills, and decision making. These skills have to be used in team and group activities where students demonstrate collaboration, communication, respect for the other's opinion, argumentation, group decision making, group problem solving, and critical thinking. Overall, there are trends indicating that education faculty are designing and planning more collaborative activities, and they are trying to implement collaborative tools for promoting and encouraging skilled community work, such as making decisions as a group, group communication, and strategy formation for common troubleshooting.

We conclude from this analysis that the definition of competencies by education faculty is influenced by the type of education discipline they profess. Education faculty members are more likely to take contextual factors into account as they define competencies for their profession. Compared with engineering faculty, educators are more likely to design collaborative learning activities to enhance the development of competencies related to collaboration, communication, consensus building and decision making in a group. While engineering faculty focused on content and process knowledge and developing competencies to function like an engineer, education faculty focused on developing individual and group competencies.

\section{Business}

\section{Q1. Academic Competencies and Business Profile}

Analysis for business shows three different approaches in each country: The US faculty were more concerned with developing inquiry skills such as critical thinking complemented by other skills such as leadership and conflict management. Faculty from Venezuela focused on learning techniques: "To learn a technique that allows him - the future professional - to formulate and evaluate projects". Faculty from Spain tended to be more oriented towards developing analytical skills (comprehensive reading, problem interpretation, summarizing, amongst others) to solve identified problems. Nevertheless, there is a general shared profile that comprises problem solving, analytical and critical thinking skills.

Both US business faculty members defined knowledge and competencies from a very practical and skill based perspective. While one faculty member focused more on process skills, "Being proactive, critical thinker, good writing skills, a bit of a risk taker, not afraid to ask questions.. listening to answers, acting ethically,... accountancy skills will come no matter what," the second faculty member stressed the body of knowledge covered by the course syllabus, which included organizational culture, motivation, leadership, conflict management and socialization, leadership, insights about oneself through interaction with others, ethical behavior, and analytical skills in formal organizations.

In Venezuela, the faculty members from business administration stressed the need to learn techniques that allow one to formulate and evaluate projects. Each project is 
presented as a problem to be solved and each problem requires the application of specific techniques. Faculty also focused on developing reading and analytical skills in graduate students.

Both faculty from Spain, one from economics and the other from administration focused on the development of competencies. One emphasized more interpretational and analytical skills, while the other focused on solving identified problems in groups.

In summary, business faculty in the three countries agreed on the following skills: Communication and leadership; critical thinking; and problem solving. While faculty from US and Spain agreed that team work is an important competency for the profession, faculty from Venezuela stressed analytical skills. Some notable differences in the competencies mentioned were risk taker as stated by US faculty, formulating/ evaluating projects as noted by Venezuelan faculty, and problem solving in groups as stated by faculty from Spain.

\section{Q2. Design of online instructional interaction on Business}

When asked about how faculty design interaction to develop academic competencies, the two business faculty from the US, distinguished between graduate and undergraduate competencies. They both stated that in the graduate class they design more activities involving group projects, while at the undergraduate level they design more individual learning experiences. The faculty member who focused on individual competencies said that in undergraduate classes, he assigns cases, which are not discussion based and require individual writing assignments, and the consideration of ethical behavior. In graduate classes, he assigns group projects. The other faculty member who teaches at the graduate level, focused on both developing individual skills and group skills: "I use film scenes to develop analytical skills, I show scenes and ask them to analyze it. They will sort out feelings," and "what insights they get about themselves and interaction with other people. Especially, for graduate students this is important." Currently, they both design interaction to develop individual academic competencies, yet noted the need to design more group activities in the future.

In Venezuela, the faculty member from business pointed out that he mainly focuses on enhancing individual competencies related to the capacity to be open to change, stating, "I compare how the students responses change over time during the semester". He assigned weekly quizzes to his students to evaluate their reading and analytical skills. He also mentioned that undergraduate students need much more content structure and need to learn basic skills such as the ability to analyze what they read, and to understand beyond what they read. However, he noted that his graduate students need to apply what they learn to new situations. He said that he designs his course based on the solution of problems and new techniques to solve these problems. He noted that this teaching approach is not focused on developing group competencies, but on developing individual skills and applying what they learn to new learning scenarios. "T'm interested in forming good analytical professionals capable of solving any problem that comes their way". He said that in his classes, it is optional for each student to work and study in a group. 
Faculty representing Spain who teach business and administration, affirmed that they design learning activities to be carried out individually: "The activities to achieve the competencies are more individual". While one never utilized group activity, the other acknowledged that he hardly ever plans group activities because students are reluctant to work in groups, and also because group activities are problematic in the sense that the activities need to correspond with the final exam which is an individual assignment. He explained, "If the exam disappears people will collaborate more, because now individual resolution is the thing that counts the more." This shows the constraints on team work, as students do not see much sense in doing group work if in the end they are individually assessed. These facts clearly point to a need to change grading practices and policies in higher education institutions so that collaborative team work can be rewarded.

An analysis of business faculty perspectives on the design of interaction (Table 5) indicates that they are predominantly individually oriented. All five faculty members prepare individual learning activities and only one seemed open to group work in the future because he is changing his methodology based on film scenes. Some of the arguments that made them focus on individual activities in online classes are students' reluctance to engage in group work and the individual nature of university grading practices and policies. However, this individual approach to designing learning activities contrasts with the group oriented competencies that faculty want to promote in their online classes.

We conclude that for business, competencies are designed from a predominantly disciplinary perspective with all three countries agreeing on the importance of developing analytical skills (Table 5). There were contextual variations between countries in the identification of other business skills. For example, U.S. faculty talked about the importance of leadership skills, conflict management and acting ethically, while Venezuela stressed the capacity to formulate and evaluate projects and Spain discussed the importance of team work skills. We can therefore infer that when disciplinary knowledge is put into practice, there will be variations across countries based on context. In relation to the design of interaction, all three countries focused on individual learning activities, with some hoping to develop collaborative learning activities in the future. 
Table 5

Competencies and Design of Interaction for Business Across Three Countries

\begin{tabular}{|c|c|c|c|}
\hline \multirow{16}{*}{ 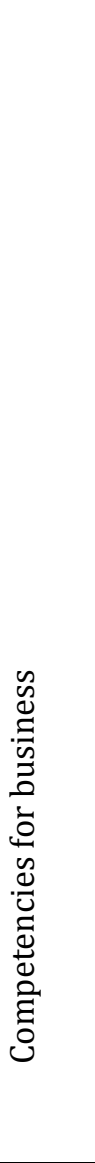 } & U.S.A. & Venezuela & Spain \\
\hline & Accountancy skills & & $\begin{array}{l}\text { Contextualize } \\
\text { course content. }\end{array}$ \\
\hline & & Problem solving & Problem solving \\
\hline & & & Team work skills \\
\hline & & & $\begin{array}{l}\text { Problem solving in } \\
\text { team }\end{array}$ \\
\hline & & $\begin{array}{l}\text { Capacity to } \\
\text { formulate and } \\
\text { evaluate projects }\end{array}$ & \\
\hline & Leadership skills & & \\
\hline & $\begin{array}{l}\text { Conflict } \\
\text { management }\end{array}$ & & \\
\hline & Act ethically & & \\
\hline & Analytical skills & Analytical skills. & $\begin{array}{l}\text { Interpretation and } \\
\text { analytical skills }\end{array}$ \\
\hline & Proactive & & \\
\hline & Critical thinker & & Critical thinker \\
\hline & $\begin{array}{l}\text { Communication } \\
\text { skills (oral and } \\
\text { writing) }\end{array}$ & Reading skills & \\
\hline & $\begin{array}{l}\text { Capacity to ask } \\
\text { question and listen } \\
\text { to the answer }\end{array}$ & & \\
\hline & Risk taker & & \\
\hline & & $\begin{array}{l}\text { Decision making } \\
\text { skills }\end{array}$ & \\
\hline \multirow{6}{*}{ 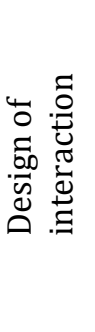 } & Individual projects & $\begin{array}{l}\text { Individual } \\
\text { projects }\end{array}$ & Individual projects \\
\hline & Group projects & & \\
\hline & $\begin{array}{l}\text { Case-based } \\
\text { problems }\end{array}$ & $\begin{array}{l}\text { Case-based } \\
\text { problems }\end{array}$ & \\
\hline & Film scenes & & \\
\hline & & Weekly quizzes & \\
\hline & & & Final Exam \\
\hline
\end{tabular}

\section{Conclusions, Implications for Design, and Future Research}

Based on our results analyzing three disciplines across three countries, we conclude that disciplinary knowledge takes precedence when faculty members select competencies to be developed in online courses for their respective professions. This finding supports Stark's (2000) empirical studies that showed that the faculty member's academic discipline exerted the strongest influence on course planning in higher education, and that to a lesser extent, the context in which they work shapes how the courses are planned and taught. 
In some cases such as the discipline of business in our study, contextual factors related to what is considered important for the profession, such as ethics, play a role in the development of additional competencies that are necessary in a particular local context. In all three disciplines, the design of interaction to correspond with disciplinary competencies was often influenced by contextual factors that modify faculty intention. What this means is that instructional design will vary across countries in the same discipline to address the local context such as the needs and expectations of the learners, faculty perspectives, beliefs and values, and the needs of the institution, the community, and country. We can therefore conclude that it is possible to design a course that will be relevant across countries from a disciplinary perspective, but it must be adapted to the local context in the design of instructional interaction and the learning process for it to be relevant to learners in that local context. Ball, Zaugg, Davies, Tateishi, Parkinson, Jensen, and Magleby (2012) identified and validated a comprehensive set of global competencies for engineering students. They found that to increasingly use collaborative engineering processes and global teams to operate on a global scale, it is necessary to think about the globalization of the traditional university's engineering curriculum. Some of the competencies identified in this study were similar to those identified in our study. However, the design of interaction to address these global competencies will differ based on the local context.

Table 2 showed a comparison of the competencies across the three disciplines selected for this study. This is of interest as it shows the type of competencies that the three disciplines from three countries agree on: knowledge of the field, higher order cognitive processes such as critical thinking, analysis, problem solving, transfer of knowledge, oral and written communication skills, team work, decision making, leadership and management skills. This indicates far more similarities in competencies than differences between the three different disciplines. Since these competencies were common to all three of the applied disciplines we studied, online course design should pay special attention to the development of these competencies. It is important to note that the interactive activities designed to develop these competencies will vary across the countries. We found a lack of correspondence between faculty's intent and desire to develop collaborative learning skills and the actual development of collaborative skills and the assessment of them.

Contextual factors such as faculty prior experience in designing collaborative learning, student reluctance to engage in collaborative learning, as well as institutional assessment systems that focus on individual performance were some of the reasons why faculty found it difficult to design collaboration even though they thought it was an important skill to develop in their learners. Ke (2013) showed that designing online interactions for deep learning does not happen naturally. In order to create more indepth, reflective and collaborative learning environments, it is necessary to observe the relationship between design and interaction. She suggests that design has a significant impact on the nature of the interaction, and whether students approach learning in a deep and meaningful manner. Tseng and Yeh (2013) conducted a qualitative study to identify important factors that were crucial for building teamwork trust. Implications for online instructors derived from this study suggest that it is important to comprehend 
students' expectations about learning collaboratively, and also understand that online collaborative learning is a more learner centered approach.

Regarding student reluctance to engage in collaborative learning as a factor influencing the design of individual activities instead of collaborative activities, similar results were found with graduate students in online environments, who were more negative about group work, and were less satisfied with group work than those who were in face-to-face sections (Gordon, Sorensen, Gump, Heindel, Caris, \& Martinez, 2011). However, these researchers suggested that given the norm of individual asynchronous work in online learning environments, online instructors should provide explicit, succinct written recommendations for how to operate in an online group environment. Alden (2011) noted the importance of faculty assessment of team efforts and suggested that grading ought to represent both (1) the quality of the product developed jointly by the team, as well as (2) the degree of participation and quality of contribution by each individual student involved in the group process. Unless students clearly see the value of group work, they are not motivated to put the extra effort to engage in collaborative learning if in the end they are individually assessed. These issues clearly point to a need to change grading practices and policies in higher education institutions to use authentic assessment (Tseng \& Yeh, 2013) so that collaborative team work in online environments can be designed appropriately and rewarded.

Our findings indicated a low correspondence between the academic competencies faculty want to develop in their students and the type of interaction and instructional activities they are currently designing in their online programs. Faculty do realize that complex skills such as problem solving and critical thinking must be developed so students can function effectively in the workplace. However, they are still not designing appropriate interactive learning activities that would enable students to engage in inquiry-based learning online to develop these complex competencies. This points to the need for faculty development in both designing interactive activities online and facilitating them. There is a need to develop a more holistic concept of interaction especially if one relies on an interaction equivalence theorem that states that meaningful and deep learning is supported as long as one of the three genuine forms of interaction is at a high level. The other two may be offered at minimal levels, or even eliminated, without degrading the educational experience. High levels of more than one of these three modes of interaction will likely provide a more satisfying educational experience, though these experiences may not be as cost or time effective as less interactive learning sequences (Anderson, 2003). In her (2013) study with 463 undergraduate online students, which showed the importance of interaction for learning, Ke advocates a balanced requirement of student-to-content, student-to-instructor, and student-tostudent interactions to promote reflective learning.

The creation of a faculty development program that would help faculty develop teaching strategies and methods that are student and community centered will bridge the gap between faculty intention and actual practice. This program would help to integrate instructional methods that are aligned with competencies. Faculty can be trained to design different types of interaction and use design aids such as visualizing tools, smart 
design advisors, tutorial examples, and create assessment rubrics and strategies that match the development of specific competencies. For example, concept maps that measure the relationship of concepts in a problem solving task, and interactive rubrics that assess collaborative learning and individual contributions to collaborative learning will assist faculty to develop more interactive and versatile learning environments online.

While we have determined from our results that an online course in a specific discipline will address similar competencies across countries, future research needs to explore in more detail the influence of context in such design, so we can determine how a course from one country can be adapted to another's local context. The main limitations of this study lie in the purposeful sample and the range of participants. A future study with more extensive participants across more disciplines and countries will enable us to have a better understanding of the correspondence between disciplinary competencies and the design of instructional interaction. 


\section{References}

Abedin, B., Daneshgar, F., \& D'Ambram, J . (2012). Pattern of non-task interactions in asynchronous computer-supported collaborative learning courses. Interactive Learning Environments. DOI:10.1080/ 10494820.2011.641676

Alden, J . (2011). Assessment of individual student performance in online team projects. J ournal of Asynchronous Learning Networks, 15(3), 5-20.

Anderson, T. (2003). Getting the mix right again: An updated and theoretical rationale for interaction. The International Review of Research in Open and Distance Learning, 4(2). Retrieved from http:// www.irrodl.org/index.php/irrodl/article/ view/ 149/230

Ball, A., Zaugg, H., Davies, R., Tateishi, I., Parkinson, A., J ensen, C., \& Magleby, S. (2012). Identification and validation of a set of global competencies for engineering students. International J ournal of Engineering Education, 28(1), 156-168.

Bernard, R. M., Abrami, P. C., Wade, A., Borokhovski, E., Tamim, R., Surkes, M., \& Bethel, E. C. (2009). A meta-analysis of three interaction treatments in distance education. Review of Educational Research, 79(3), 1243- 1289.

Bigatel, P. M., Raga, L. C., Kennan, S., May, J ., \& Redmond, B. F. (2012). The identification of competencies for online teaching success. J ournal of Asynchronous Learning Networks, 16(1), 59-77. Retrieved from http://sloanconsortium.org/jaln/v16n1/identification-competencies-onlineteaching-success

Biglan, A. (1973). The characteristics of subject matter in academic areas. J ournal of Applied Psychology, 57, 195-203.

Boon, J ., \&van der Klink, M. (2002, Feb.). Competencies: The triumph of a fuzzy concept. Proceedings of Academy of Human Resource Development Annual Conference, Honolulu, HA, 1, 327-334.

Cameron, L. (2008) Could pedagogical planners be a useful learning design tool for university lecturers? Readings in Education and Technology. Proceedings of ICICTE 2008 (pp. 496-507).

Davis, D., Beyerlein, S., \& Davis, I. (2005) Development and use of an engineer profile. Proceedings of the 2005 American Society for Engineering Education Annual Conference \& Exposition.

Erdogan, I., \& Campbell, T. (2008). Teacher questioning and interaction patterns in classrooms facilitated with differing levels of constructivist teaching practices. International J ournal of Science Education, 30(14), 1891-1914. 
Eraut, M. (1994). Developing professional knowledge and competence. London: Falmer Press.

Fulford, C.P., \& Sakaguchi, G. (2002). Validating a taxonomy of interaction strategies for two-way interactive distance education television. International J ournal of Instructional Media, 29(1), 79-92.

Gilbert, L., \& Moore, D. R. (1998). Building interactivity into web courses: Tools for social and instructional interaction. Educational Technology, 38(3), 29-35.

Gordon, S. G., Sorensen, C., Gump, A., Heindel, A., Caris, M., \& Martinez, C. (2011). Overcoming student resistance to group work: Online versus face-to-face. The Internet and Higher Education, 14(2), 121-128.

Gorsky, P., Caspi, A., Antonovsky, A., Blau, I., \& Mansur, A. (2010). The relationship between academic discipline and dialogic behavior in open university course forums. International Review of Research in Open and Distance Learning, 11(2), 49-72.

Guan, J ., Tregonning, S., \& Keenan, L. (2008). Social interaction and participation: Formative evaluation of online CME modules. J ournal of Continuing Education in the Health Professions, 28(3), 172-179.

Hong, S., \&J ung, I. (2012). The distance learner competencies: A three-phased empirical approach. Educational Technology Research and Development, 59(1), 21-42.

Hunter, J . (2008). Applying constructivism to nursing education in cultural competence. J ournal of Transcultural Nursing, 19(4), 354-362.

Hurumi, A. (2006). Analyzing and designing e-learning interaction. In C. J uwah (Ed.), Interactions in online education. Implications for theory \& practice (pp.46-72). New York: Routledge.

J anesick, V.J . (2003). The choreography of qualitative research design? Minuets, improvisations, and crystallization. In N. K. Denzin \&Y. S. Lincoln (Eds.), Strategies of qualitative inquiry (2nd ed., pp. 46-79). Thousand Oaks, CA: Sage.

J eris, L., \&J ohnson, K. (2004). Speaking of competence: Toward a cross-translation for human resource development (HRD) and continuing professional education (CPE). In T. Egan, M. Morris \& V. Inbakumar (Eds.), Proceedings of Academy of Human Resource Development, 2 (pp. 1103-1110). Austin, TX.

J uwah, C. (2006). Interactions in online education. Implications for theory \& practice. New York: Routledge.

Kale, U. (2008). Levels of interaction and proximity: Content analysis of video-based classroom cases. Internet and Higher Education, 11(2), 119-128. 
Ke, F. (2013). Online interaction arrangements on quality of online interactions performed by diverse learners across disciplines. Internet and Higher Education, 16, 14-22.

Keengwe, J ., \& Schnellert, G. (2012). Fostering interaction to enhance learning in online learning environments. International J ournal of Information and Communication Technology Education, 8(3), 28-35.

Kelly, G. J ., Luke, A., \& Green, J . (2008). Introduction. In G. J . Kelly, A. Luke \&J . Green (Eds.), Review of research in education Volume 32: What counts as knowledge in educational settings: Disciplinary knowledge, assessment, and curriculum (pp. vii-x). Thousand Oaks, CA: SAGE.

Loewen, S., \& Reissner, S. (2009). A comparison of incidental focus on form in the second language classroom and chatroom. Computer Assisted Language Learning, 22(2), 101-114.

Manca, S., Delfino, M., \& Mazzoni, E. (2009). Coding procedures to analyse interaction patterns in educational Web forums. J ournal of Computer Assisted Learning, 25(2), 189-200.

Masoumi, D., \&Lindström, B. (2012). Quality in e-learning: A framework for promoting and assuring quality in virtual institutions. J ournal of Computer Assisted Learning, 28(1), 27-41.

Monaghan, L., Goodman, J .E., \& Meta R. J . (Eds.). (2012). A cultural approach to interpersonal communication. Oxford: Wiley-Blackwell

Moore, M. G. (1989). Editorial: three types of interaction. The American J ournal of Distance Education, 3(2), 1-7.

Nandi, D., Hamilton, M., \& Harland, J . (2012). Evaluating the quality of interaction in asynchronous discussion forums in fully online courses. Distance education, 33(1), 5-30.

Nesi, H., \& Gardner, S. (2006). Variation in disciplinary culture: University tutors views on assessed writing tasks. In G. Clibbon, T. Kiely, P. Rea-Dickins, H. Woodfield (Eds.), British studies in applied linguistics, Volume 21: Language, culture and identity in applied linguistics (pp. 97-117). U.K.: Equinox Publishing.

Pfeffer, T. (2012). Competences for the effective use of educational technologies at universities. In T. Pfeffer (Ed.). Virtualization of universities. Innovation technology and knowledge management (pp.141-163). New York: Springer.

PISA Report. (n.d.). Retrieved from http:// www.oecd.org/pisa/35070367.pdf.

Quality Matters. (2011). Quality Matters rubric standards 2011 - 2013 edition with assigned point values. Retrieved from https:// www.qualitymatters.org/ rubric 
Roblyer, M. D., \&Wiencke, W. R. (2004). Exploring the interaction equation: Validating a rubric to assess and encourage interaction in distance courses. J ALN, 8(4), 25-37.

Rychen, D.S., \& Salganik, L.H., (Eds). (2001). The definition and selection of key competencies. DeSeCo Publications.

Silius, K., Tervakari, A.M., Kailanto, M., Huhtamäki, J ., Marttila, J ., Tebest, T., \& Miilumäki, T. (2012). Developing an online publication collaborating among students in different disciplines. Proceedings of the 20112 nd international congress on computer applications and computational science: Advances in Intelligent and Soft Computing, Volume 144.

Snášel, V., Abraham, A., Martinovič, J., Dráždilová, P., Slaninová, K., Daradoumis, T., Xhafa, F., \& Martínez-Monés, A. (2012). E-assessment of individual and group learning processes. J ournal of Computational and Theoretical Nanoscience, 9(2), 286-303.

Squires, G. (2005) Art, science and the professions. Studies in Higher Education, 30, 127- 36.

Stark, J . S. (2000). Planning introductory college courses: Content, context and form. Instructional Science, 28, 413-438.

Stark, J . S., Lowther, M. A., Bentley, R. J ., \& Martens, G. G. (1990). Disciplinary differences in course planning. Review of Higher Education, 13(2), 141-165.

Tsai, C., \& Lee, T. (2012). Developing an appropriate design for E-learning with Webmediated teaching methods to enhance low-achieving students' computing skills: Five studies in E-learning implementation. International J ournal of Distance Education Technologies, 10(1), 1-30.

Tseng, H. W., \&Yeh, H. T. (2013). Team members' perceptions of online teamwork learning experiences and building teamwork trust: A qualitative study. Computers and Education, 63, 1-9.

\section{Athabasca University $\mathbf{a}$}

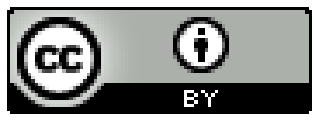




\section{An Elaborated Model of Student Support to Allow for Gender Considerations in Asian Distance Education}
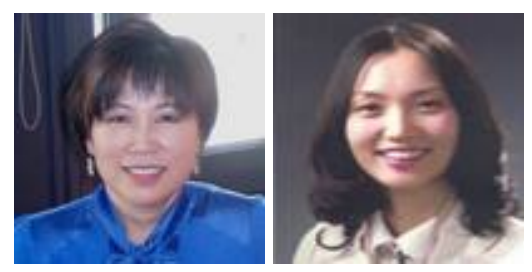

Insung Jung ${ }^{1}$ and Seongyoun Hong ${ }^{2}$

${ }^{1}$ International Christian University, Japan, ${ }^{2}$ Ajou University, Korea

\section{Abstract}

Research indicates that distance education (DE) students regard learner support systems as the key element in quality provision. This study sought to identify the key concerns of Asian DE students regarding support provision in different types of DE and dual-mode providers and formulate a student support model which took account of gender issues. An online survey was conducted with 1,113 distance learners in Japan, Korea, Hong Kong SAR China, Malaysia, India, Pakistan, Philippines, Singapore, and Thailand which required them to respond to open-ended questions regarding their main concerns over the quality of distance education. Their responses were analyzed with Nvivo 2.0 based on the framework of the Atkins (2008) ARCS model of distance learner support. It was found that in assessing the quality of DE the students valued 13 types of student support across five domains: affective, reflective, cognitive, systemic, and gender-considerate. It was also confirmed that there were gender differences in the students' perceptions of the need for student support. Building on these findings, an elaborated model for student support for Asian distance learners was developed from a systems perspective, and from this, a list of supporting strategies was proposed.

Keywords: Asian distance education; distance learner support; quality assurance; student support 


\section{Introduction}

Distance education (DE) students often judge the quality of DE courses by the academic and non-academic services provided by their institutions. The academic aspects include course design/ development, learner support, flexibility and interaction, and the nonacademic aspects include the costs and convenience of study and employability after graduation (Latchem \& J ung, 2009). Rumble (2000), Frydenberg (2002), J ung (2011), and Tang and Husin (2011) reveal the extent to which student support affects persistence and success in distance learners, stressing that this is one of the most critical factors in assuring quality in DE provision. Tait and Mills (2013) argue that given recent changes in DE such as inter-institutional and international competition, commercialism, the learner as consumer, and the larger enrollments and greater diversity in the learners' prior learning, abilities, cultural backgrounds and needs, the nature and quality of student support is of even greater significance.

While conventional universities may regard student support as ancillary because they assume that the on-campus students have regular face-to-face contact with their tutors and peers, when it comes to DE institutions, as Thorpe (2002, p. 106) points out, 'all aspects of an institution's provision . . . should be supportive in the sense of fostering high quality learning. A survey conducted with Asian distance learners by J ung (2012) supports this view by revealing that student support is the students' core concern in assessing quality in DE and that they expect clear and adequate study guidance; appropriate DE study skills training; continuous media/technology support; needsbased social, administrative, financial, and psychological support; flexibility and fairness in learning provision and evaluation; and frequent feedback.

Many studies have been carried out into various kinds of student support and their implications in a range of DE contexts (e.g., by Ludwig-Hardman \& Dunlap, 2003; Mandernach, 2009; Sewart, 1993), but few studies have offered a theoretical model to explain the key dimensions of student support from the learners' perspective. Mactague (2004) presents a model of academic learner support services for DE in higher education in which she outlines the specific methods of student support, assessment, remediation, tutoring, orientation, community building, mentoring, counseling, and professional development needed to help the students improve their research, writing, and time management skills, integrate practicum and coursework, and complete their dissertations on time. This model also specifies how to relate these support methods to students' academic needs. While Mactague's model focuses mainly on cognitive aspects of student support, Tait (2000) suggests that student support in DE should not only be cognitive (supporting and facilitating learning), but affective (supporting emotional/psychological aspects) and systemic (supporting students with rules and instructional systems) and again appropriate to the needs of diverse students. Atkins (2008, 2009) expands Tait's framework by adding reflective support (developing the capacity to reflect on action so as to engage in continuous learning). Atkins' model concerns student support in four domains (Affective, Reflective, Cognitive, and 
Systemic) and so is known as the ARCS model. It provides the basis for the UK Open University student support system (Stevens \& Kelly, 2012).

While four domains suggested in the Atkins' multidimensional ARCS model can be applied beyond the OU contexts, there might be other domains that are uniquely important in contexts where DE is regarded as a 'second rate' mode of education, where the students may be more accustomed to teacher-dependent schooling, where they may be more socially and economically disadvantaged, and where there is a more serious gender divide, as in Asia.

Regarding gender divide in the Asian DE contexts, Green and Trevor-Deutsch (2002) observe that female students in Asian DE tend to face more serious barriers than male students when the course content is not directly relevant to their livelihood; when access to the content is too costly; and when they do not feel able to use the technology competently. Taplin (2000) also reveals that personal or family problems and difficulties with getting course materials in time to complete assignments or examinations were the major problems for female students in Asian DE who were considering dropping out of their DE programs. Maybe that is why the Asian female students tend to receive more support socially, psychologically, and logistically than they do academically as found in Jung and Fukuda (2011).

While previous studies including those mentioned above have identified gender differences in the Asian DE contexts, few studies discuss gender mainstreaming that is a globally accepted strategy in tertiary education for promoting gender equality and needs to be reflected in the planning, implementation, and monitoring of all programs (Vimala, 2010). Jung (2007) has documented good practices in DE to ensure that learners, especially women, receive institutional support in order to successfully complete their studies. This involves a shift from a provider-centered to a learnercentered approach of student servicing and tutoring and close monitoring. The present study therefore aimed to elaborate the ARCS model by drawing upon Asian DE students' perceptions of quality support, identify any further dimensions that might be needed in regard to gender, and explore some gender mainstreaming strategies to meet different support needs of female and male DE students in Asia.

\section{Theoretical Framework}

Atkins's (2008) ARCS model was seen as the most appropriate model to take as a starting point because it is well tested, takes the distance learners' perspectives into account and includes both the academic and non-academic aspects of the support required for DE students, while other models such as Mactague's tend to reflect the DE provider's view, focus largely on the academic aspects, and ignore the learners' support needs for affective and reflective domains. The ARCS model categorizes student support services into four domains: affective, reflective, cognitive, and systemic. 
- The affective domain concerns such questions as How do I feel about studying? Am I confident and finding pleasure in it? It includes a variety of services that aim to help distance learners promote personal development at both self and social levels. Suggested services include strategies to help students develop identity, values and beliefs, interests, and potential as students of a particular subject, boost confidence and independence, sustain motivation and celebrate success, and develop selfmanagement skills.

- The reflective domain addresses such questions as Why am I doing this study? What are my motivations? It includes both assistive and developmental supports. Assistive supports are the provision of information, advice, and guidance regarding subject matter, finance and fees, disability and additional requirements, and admission and registration, whereas developmental supports focus on the provision of information, advice, and guidance to help the distance learners clarify their objectives and feelings about their studies and strengthen their motivation and ability to manage their emotions.

- The cognitive domain addresses such questions as What am I learning and developing? Does it make sense to me? It includes the means of helping distance learners gain the kinds of knowledge they need to satisfy their learning needs and apply these to real-life situations. Examples contain supports for formative assessment, feedback on assessment and on other activities, subject knowledge acquisition, navigation of learning media, and preparation for assessment including exams.

- The systemic domain covers such questions as Who and what is helping me with studying? Do these support me? It includes assistance in such areas as registration, progress through learning, assessment and accreditation, library access, technical support, and all affective, reflective, and cognitive support needed for successful learning.

The current study sought to answer the following questions:

1) Is the general framework of the ARCS model applicable to Asian DE contexts?

2) Would an elaborated model be needed in regard to Asian DE students' support needs? If so, what other domains and types of support should be added to the ARCS model?

3) Are there gender differences in Asian DE students' perceptions and how can these differences be reflected in the student support system? 


\section{Method}

\section{Participants}

The participants in this study were 1,113 distance learners enrolled in DE institutions or programs in Japan, Korea, Hong Kong SAR China, Malaysia, India, Pakistan, Philippines, Singapore, and Thailand. They were asked to respond to closed items for another study (Jung, 2012) and provide answers to three open questions for the purposes of this study which was undertaken between J une and October 2010.

Seventy percent (775) of those contacted, $67 \%$ of whom were male, completed the open questions as requested. Forty-nine percent were aged $21-30$ and $22 \%$ were aged 31-40. Around $46 \%$ of the students were enrolled in DE universities, 31\% were engaged in DE programs offered by conventional universities, and the remaining $23 \%$ were taking DE courses provided by overseas DE universities, for-profit providers, their own companies, or non-government organizations. Around $46 \%$ were studying mainly through print/correspondence and almost $20 \%$ were studying entirely online. The remainder was studying by mixed means.

\section{Instrument}

The online survey included three open questions. The first question asked the main concerns of male students regarding the quality of $\mathrm{DE}$, and the second one asked the main concerns of female students in relation to the quality of DE. The third question asked students to make additional comments or suggestions regarding the quality of service of DE considering their own gender-related needs.

\section{Procedure}

Following a general ethics code for research, the survey proposal was reviewed and approved by the Academic Affairs' Office at the first author's university. An invitation email was sent out to lecturers teaching DE courses at the different types of Asian institution including state-funded mega universities, small and large private institutions, dual-mode universities, for-profit e-learning companies, community centers, and NGOs. These faculty members distributed the survey link to their students in various major areas to respond online.

\section{Data Analysis}

The 1,540 responses to the three open questions from the 775 respondents were exported to Nvivo 2.0 for the purposes of classifying and organizing the nonnumerical data, examining relationships in the data, and combining analysis with modeling. Responses without particular meaning were eliminated, and 1,317 responses were then used for the initial coding. The code classification process was cyclic, 
following four stages: meaning-making, reduction, elaboration, and modeling. This process was repeated several times until there was total concurrence between the two authors.

At the meaning-making stage, the 1,317 responses were analyzed to identify significant chunks for coding. Where responses included more than one concern, each concern was recorded as a significant chunk. In total, 1,872 significant chunks were identified and categorized into 84 codes. Code names were created to highlight the representative meaning of significant chunks.

At the reduction stage, these chunks and code names were reviewed by the authors to see if each chunk was appropriately assigned to a code representing its most important meaning, and whether some chunks could be combined because they represented similar meanings. As a result of two rounds of this review process, 84 codes were decreased to 71 codes, and again to 47 codes.

At the elaboration stage, all 47 codes were once again reviewed and the code names were refined several times. Finally, 37 codes remained, each having a distinctive name highlighting the meaning of the included chunks.

At the modeling stage, these 37 codes were categorized using the four domains in the ARCS model. During this process, some codes were combined, a few code names were once more refined, and a new domain was created to include those codes which did not belong to the ARCS' four domains. Eventually 1,785 chunks (from the initial 1,872) and 33 codes (from the initial 84) were included in the final modeling process, and classified into five domains: affective, reflective, cognitive, systemic, and gender-considerate. A code was re-titled as 'focus of support' and similar sub-elements were grouped as a 'type of support'. In total, 13 types of support were created and 33 focuses of support, as presented in Table 1. Responses by male and female students were compared across the five domains and sub-categories.

\section{Results}

\section{Coding and Categorization}

The general framework of the ARCS model was found to be applicable to Asian DE contexts but the study confirmed the need to consider the gender dimensions. The open ended responses were therefore classified into five domains (affective, reflective, cognitive, systemic, and gender-considerate support domains) as shown in Table 1. During the four-stage analysis process, it was found that the affective domain required three types of support (social, practical, and emotional support); the reflective domain required two types of support (developmental and assistive guidance); the cognitive 
domain required three types of support (strategic learning, content, and tutorial and assessment support ); the systemic domain required two types of support (policy and customized support); and the gender-considerate domain required three types of support (life skills development, policy and learning environment, and confidence building). Examples in Table 1 show indicative types of responses from the Asian DE learners in each of the 33 focuses of support.

Table 1

Coding and Categorization of Support Services Perceived Important for Quality DE by Asian Distance Learners

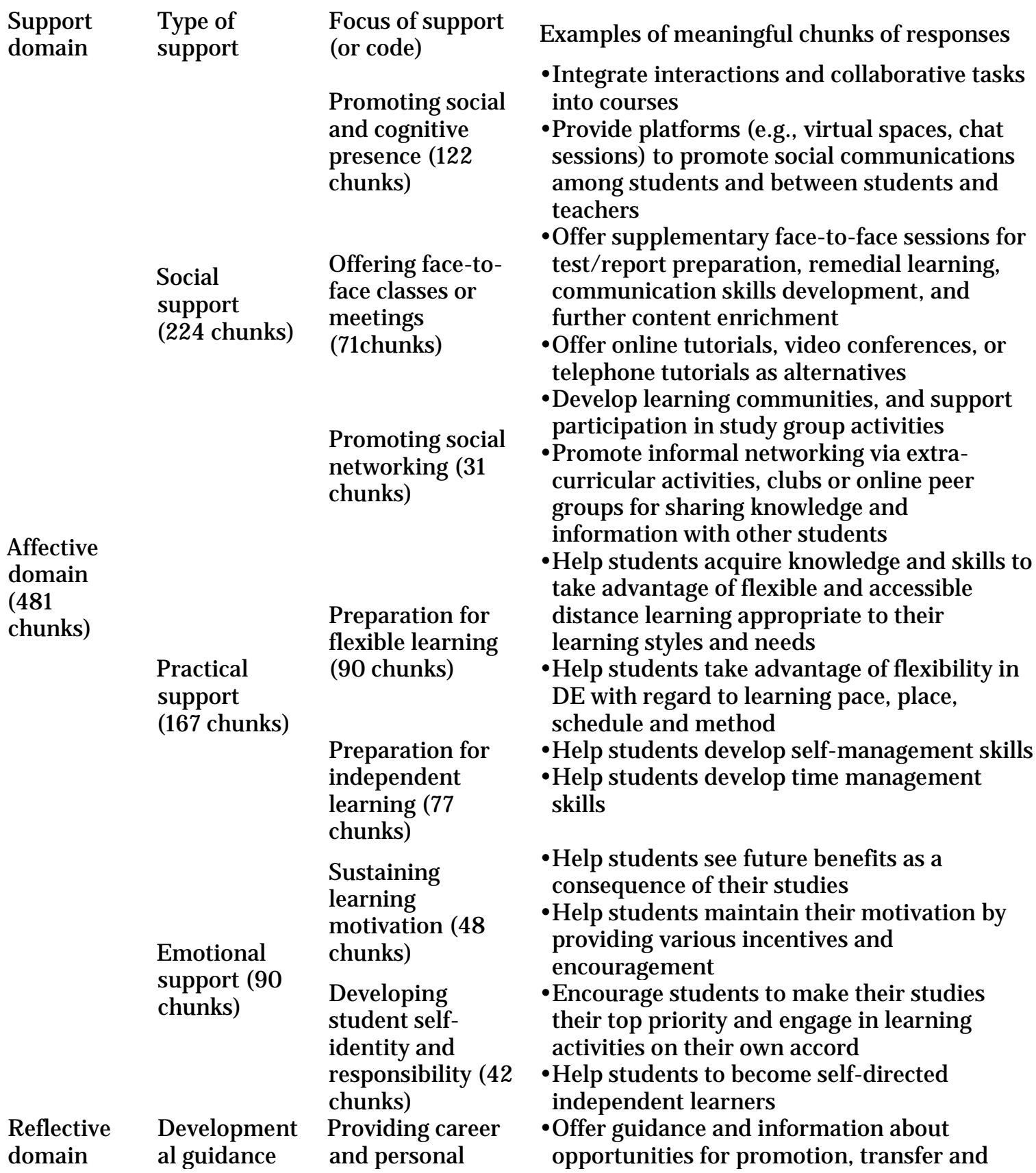


(199

chunks)
(119 chunks)

Assistive guidance (80 chunks)

Strategic learning support (188 chunks)

Cognitive domain (504 chunks) development opportunities (88 chunks) Preparing essential literacy (31 chunks)

Offering guidance and information on academic matters (49 chunks)

Obtaining support from family and workplace (16 chunks)

Offering financial support (15 chunks)

Developing effective distance learning strategies (110 chunks)

Facilitating knowledge acquisition (46 chunks)

Offering opportunities for further studies (32 chunks)

Providing relevant learning resources (67 chunks)

Content support (165 chunks)
Offering practical and applicable content (54 chunks) Offering up-todate content (44 chunks) new employment as a consequence of successful completion of the study

- Offer job-hunting or internship opportunities

- Offer training in basic computer skills and communication skills

- Assist students in effectively accessing using various resources for their studies

- Offer guidance and information on rules and processes of admission, transfer and graduation

- Provide detailed information on study methods, assignments and tests prior to registration and periodically via online, mobile phone or social media systems

- Promote the various benefits of DE to gain emotional support from students' family and workmates

- Organize appropriate learning schedules to suit students' family and work obligations

- Offer direct or indirect financial support to students in need

- Provide financial support or rental assistance for laptops and other technologies required for study

- Integrate DE strategies into courses and materials to acquaint students with effective distance learning strategies appropriate to their learning styles

- Help students improve their learning methods via periodic meetings, discussions, or technology-mediated methods

- Integrate appropriate design strategies to help students grasp the key concepts and ideas in courses and materials

- Provide teaching and learning materials which include concrete examples and explanations to help students master the content

- Offer further studies to advanced students (e.g., in the forms of additional or more demanding assignments, extra readings, classes etc.)

- Provide optional workshops, external activities and hands-on experience to meet the needs and interests of advanced students

- Provide detailed and comprehensive reading materials, lecture notes, video clips and related learning materials

- Offer multimedia resources including videos and animations to promote engaging and interactive learning

- Integrate practical and applicable knowledge and skills in courses and materials

- Offer materials which will be relevant to students after graduation

- Update content and curriculum as often as necessary

-Improve study materials in accord with 
Tutorial and assessment support (151 chunks)

Policy support (209 chunks)

Systemic domain (295 chunks)

Genderconsiderate Domain (306 chunks

Customized support (86 chunks)

Life skills development (166 chunks)
Offering timely tutorials (87 chunks)

\section{Offering quick} feedback on assignments and tests (46 chunks) Applying fair assessment criteria (18 chunks) Developing and implementing policies to create a supportive learning environment (119 chunks) Meeting external quality standards (90 chunks)
Implementing a flexible payment system (36 chunks) Locating study centers close to learners (29 chunks)

Integrating learners' opinions in institutional policy (21 chunks) Developing skills to balance life, work and learning (146 chunks) Developing skills to manage the innate nature of gender (20 chunks)
- Hire sufficient well qualified or experienced tutors and instructors for DE lecturing and tutoring

- Secure sufficient number of tutors and instructors who can answer students' queries by face-to-face or online means

- Offer prompt and accurate feedback on assignments, quizzes/tests, portfolios, etc.

- Reply promptly to the students' questions/concerns

- Develop policies to assure fair and equitable admissions and assessments, and prohibit cheating/ plagiarism, etc.

- Provide clear and detailed assessment criteria

- Offer inclusive, user-friendly learning environments which include easily accessible virtual learning systems, digital libraries, and 24-hour services

- Undertake frequent inspections of DE systems and technologies and students, perceptions of these

-Ensure a high reputation for DE institutions by meeting high quality standards for academic accreditation at national and international levels

- Improve public perceptions of DE degree study in comparison with conventional education

- Charge affordable tuition and other fees

-Allow students to pay tuition and other fees by installment

-Ensure easy access to study centers, libraries, etc.

- Organize science labs, seminar rooms, computer labs, etc. close to students' locations

- Conduct student surveys regularly and consult student representative(s)

- Use the results of students' opinions in improving policies and programs - Offer students training in balancing lifestyles, study and domestic and workplace demands

- Pay special attention to female students and their demands of work and family

- Help students appreciate gender differences in learning

- Overcome any innate gender-specific characteristics which impede learning (e.g., offering encouragement to shy female students who post messages, and assisting male students with low level of concentration to develop attention maintenance skills) 
Policy and learning environment (81 chunks)
Reducing gender discrimination (50 chunks)
-Implement policies and strategies to reduce gender discrimination or stereotyping in admissions, courses, courseware, learning support and assessment

- Provide a supportive learning environment for female students experiencing social and familial prejudices

- Be responsive to gender differences in learning in courses and services(e.g., by offering more structured, interactive or shortterm sessions for male students as they are found to be less likely to engage in online discussions)

- Offer gender-specific academic support (e.g., additional support for female students showing lower levels of technology competencies or mathematical skills)

Establishing a secure learning environment (10 chunks)

- Enforce rules and regulations to ensure safe learning environments that are free from violence (both physical and verbal) and sexual threat, especially for female students

- Reinforce security in study centers Improving overall $\cdot$ Blend distance or online learning modes with

Confidence building ( 59 chunks)

Improving confidence in distance learning (33 chunks)

face-to-face sessions to develop students' confidence in distance learning

- Allow female students to ask questions directly to tutors or instructors before publicly posting messages

- Offer both on-demand and continuous technology selfefficacy (26 chunks) technical training and support

-Adapt an easy-to-use learning management system (LMS) and offer step-by-step guidance in using it

\section{Gender Differences in Student Support}

Analyzing and comparing the concerns of the male and female respondents, several gender differences in students' perceptions became apparent.

1. The affective domain in general was regarded as more important by the male students (182 chunks) than the females (121 chunks), although more males indicated that Offering face-to-face classes or meetings and Feeling ready for independent learning were more important than did the females.

2. The reflective domain was also perceived to be more important by males ( 82 chunks) than females (48 chunks) and, in particular, the economic and developmental aspects such as Offering financial support and Providing career and personal development opportunities.

3. The cognitive domain was similarly perceived as more important by males (135 chunks) than the females (74 chunks), particularly in regard to Offering practical 
and applicable content. Both genders perceived Developing effective distance learning strategies and Offering timely tutorials as the most important type of support in this domain.

4. In regard to the systemic domain, Developing policies to create a supportive learning environment was regarded as the most important type of support by males and females alike, while Implementing a flexible payment policy and Integrating learners' opinions in institutional policy were seen as more important by the males.

5. The gender-considerate domain revealed types of support that were regarded as more important by females than males, for example, Develop skills to balance life, work and learning, Reduce gender discrimination, Improve technology selfefficacy and Overall confidence in distance learning. Only the female respondents (9 chunks) expressed concern for Establishing a secure learning environment.

\section{Discussion}

To address the complexities of student support, the design and implementation of student support services needs to be addressed holistically, employing a systems approach which is a process of understanding how elements of a system influence one another within a whole system and in relation to its external environment, and making decisions accordingly (Littlejohn, 1996). Tackling any one of the five domains in the student support model without considering the others or taking the external environment into account will inevitably fail to meet the learners' needs.

A conceptual model of systemic student support for Asian distance learners was therefore proposed as an elaborated, gender-considerate version of the ARCS model. Figure 1 shows the key components of the five domains in this model.

- Affective support helps the distance learners remain motivated and connected during the course of their studies and to become successful independent learners.

- Reflective support helps the distance learners become reflective in regard to academic and non-academic matters.

- Cognitive support promotes effective and efficient learning by providing appropriate content, resources, tutorials, and assessment.

- Systemic support is provided through institutional policies and systems for all students and customized support at the individual level.

- Gender-considerate support addresses the socio-economic, cultural, and educational barriers that can still seriously impede females' participation and success in higher education study. 


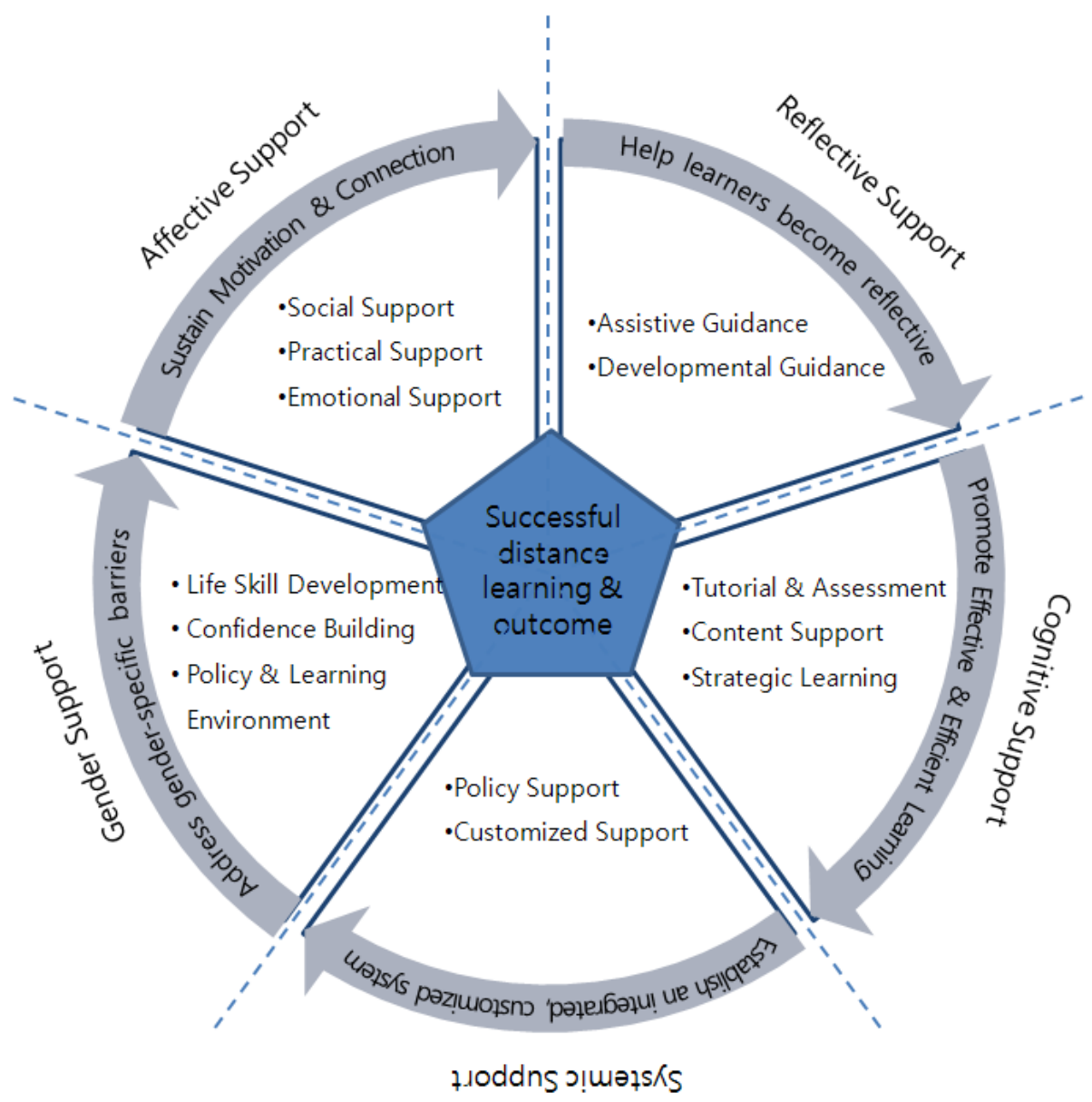

Figure 1. A model of systemic student support for Asian distance learners.

Support strategies that may be particularly useful for Asian distance learners in each of the five domains are suggested based on the survey results and other related studies.

In the affective domain, promoting social and cognitive presence is seen as the most important form of support required. Social presence, the learners' feeling of belonging to a learning community and having instructors and tutors who care for them, can be promoted by providing, for example, virtual spaces, chat sessions, uses of social media for welcoming messages, student profiles, audio/video introductions, sharing instructor's personal stories and opinions, using humor and emoticons and peer-to-peer learning and embedding these in the course design (Aragon, 2003). Cognitive presence, the extent to which learners are able to construct and confirm meaning through sustained reflection and discourse in a critical community of inquiry' (Garrison, Anderson, \& Archer, 2001, p. 9), can be promoted by engaging learners in critical inquiry, integrating interactions and collaborative tasks in DE courses, and scaffolding discussions by posting meaningful questions and leading the learners to find resolution 
and reach consensus, as suggested by Darabi, Arrastia, Nelson, Cornille, and Liang (2011).

In the reflective domain, the most valuable support for Asian distance learners would be guidance for career and personal development. As Abdullah (2004) observes, the majority of Asian distance learners are in low or middle level jobs and have poor academic backgrounds, so if $\mathrm{DE}$ is to help them climb the career ladder, DE institutions must offer clear and positive guidance and information on opportunities for promotion, job transfer, employment, and internships.

In the cognitive domain, the most important support would be helping the students to improve their self-learning strategies. This calls for appropriate orientation programs before the commencement of formal study and on-demand periodic meetings and discussions and/or technology-mediated training and advisory sessions throughout the course of study. These are needed to develop the cognitive skills necessary for the learners to develop the capacity to preview, organize, and review content for the purposes of independent or minimally supervised learning, apply elaboration strategies in order to develop ever deeper understanding of the content and ability to apply this learning in different contexts, and the meta-cognitive skills necessary to plan and regulate their learning progress and learning strategies in accord with their particular learning styles and circumstances (Hong \& J ung, 2011). Time management skills also need to be developed as these are important for distance learners who typically have to cope with multiple responsibilities (Levy, 2007).

In the systemic domain, DE institutions need to make the effort to provide supportive, inclusive, and user-friendly learning environments for all of their learners, regardless of their locations and circumstances. These should include easily accessible, user-friendly virtual learning spaces, communication channels, digital libraries, 24-hour on-call or online services, online payment systems, technical help desks, and social networking opportunities for peer support and sharing learning and experiences (Alias \& Rahman, 2005).

In the gender-considerate domain, caution is needed in regard to gender stereotyping and gender inequality, both for men and women. For example, while both genders may need financial support or flexible payment systems, in certain Asian contexts, this may be more important for males than females because it can be the men who have the prime financial responsibility, not only for their own families but also for their extended families.

However, female participants may need special support because their participation and success can be influenced by a number of factors:

- The nature and quality of the secondary education they received (in some countries, girls' high schools have different curricula from co-educational or boys' schools, do not teach science and mathematics at an advanced level and as a consequence, girls 
cannot enter certain university departments and if they do, may struggle with the content and methods)

- Their economic circumstances

- Their locations and the availability of study and support

- $\quad$ Class, caste, race, and occupation-related identity issues

- Cultural and religious norms governing gender relations

- Early marriage, child-raising, household responsibilities, and pressures to work leading to problems in balancing lifestyle, work and learning, assignment and examination. That is a common cause of dropout as confirmed in a study of Indian female distance learners by Taplin (2000).

- Mindsets and gender stereotyping which encourage women to pursue careers in child development, education, medicine (nursing), and service sector occupations (Vimala,2010).

Support to counter or compensate for these factors can be offered by means of formal and informal face-to-face or online sessions dealing with such matters as time management (Hong \& J ung, 2011) and providing flexible study schedules or classroom attendance requirements (J ung, 2012).

Assisting female distance learners with their confidence with and use of information and communications technology (ICT) and other DE tools and methods is also found to be important in the study. Several studies conducted in Asia report on male students' higher self-efficacy in ICT and DE, for example, Atan, Azli, Rahman, and Idrus (2002) in regard to Malaysian undergraduates, Tekinarslan (2009) in regard to Turkish undergraduates, and Zhang, Li, Duan, and $\mathrm{Wu}$ (2001) in regard to Chinese undergraduate and graduate students. All of these studies indicate need for scaffolding, personal tuition, and technical support, particularly for female distance learners.

Sadly, the last twenty years have seen a significant increase in media reporting on gender-based violence including sexual harassment in educational institutions. It can also be the case that overt and subtle forms of sexual harassment influence the ability of women to pursue higher education (Vimala, 2010). As indicated by several participants of this study, there is therefore need for safe and secure learning environments for female students in countries such as India and Pakistan where incidents of sexual harassment or violence toward females occur in and around study centers. 


\section{Conclusion}

Student support is critical to the success, status, and quality of DE. The present study confirmed the usefulness of the four support dimensions of the ARCS model in Asian DE contexts. But it also identified one gender-related dimension needed and proposed a systemic, conceptual model of student support based upon the views of Asian distance learners. This conceptual model provided the basis for suggested support strategies appropriate to Asian contexts and beyond.

It is acknowledged that this study has its limitations. It did not examine any differences between the conditions of learners in the various Asian countries so the results and recommendations may not apply in every country, economy, or social and learning culture. So caution is needed in interpreting the conceptual model and further studies are required to consider these diversities, the culture-specific gender issues, and need for gender-considerate support. Finally, these data were collected in 2010. Since that time, Asian countries' technological infrastructure has been improved, DE has been more widely accepted by the public, and the DE policies have changed. The impact of these changes also calls for further investigation.

\section{Acknowledgements}

This study was funded by the Openness and Quality in Asian Distance Education Project from the International Development Research Centre (IDRC) of Canada in 2010. 


\section{References}

Abdullah, S. (2004). Students in distance and open learning: The Asian experience. In H. Perraton \& H. Lentell (Eds.), Policy for open and distance learning: World review of distance education and open learning (pp. 66-75). New York: Routledge.

Alias, N. A., \& Rahman, N. S. N. A. (2005). The supportive distance learning environment: A study on the learning support needs of Malaysian online learners. European J ournal of Open and Distance Learning. Retrieved from http://www.eurodl.org/materials/contrib/2005/Alias Rahman.htm

Aragon, S. (2003). Creating social presence in online environments. New Directions for Adult and Continuing Education, 100, 57-68.

Atan, H., Azli, N., Rahman, Z., \& Idrus, R. (2002). Computers in distance education: Gender differences in self perceived computer competencies. J ournal of Educational Media, 27(3), 123-135.

Atkins, P. (2008). Transformation and integration through research and enquiry: A centre for excellence in teaching and learning perspective. In M. Weaver (Ed.), Transformative learning support models in higher education: Educating the whole student (pp. 181-196). London: Facet Publishing.

Atkins, P. (2009). ARCS-an integrating model of learning support for an integrated future? Retrieved from http:// www.open.ac.uk/ opencetl/files/opencetl/ file/ ecms/ web-content/ARCSPoster.pdf

Darabi, A., Arrastia, M. C., Nelson, D. W., Cornille, T., \&Liang, X. (2011). Cognitive presence in asynchronous online learning: A comparison of four discussion strategies. J ournal of Computer Assisted Learning, 27, 216-227.

Frydenberg, J . (2002). Quality standards in eLearning: A matrix of analysis. The International Review of Research in Open and Distance Learning, 3(2). Retrieved from http:/ / www.irrodl.org/ index.php/irrodl/ article/view/ 109/ 189

Garrison, D. R., Anderson, T., \&Archer,W. (2001). Critical thinking, cognitive presence and computer conferencing in distance education. The American J ournal of Distance Education, 15(1), 7- 23.

Green, L., \& Trevor-Deutsch, L. (2002). Women and ICTs for open and distance learning: Some experiences and strategies. Vancouver: Commonwealth of Learning. Retrieved from http:// www.col.org/SiteCollectionDocuments/ women\%20and\%20ICTs.pdf 
Hong, S., \&J ung, I.S. (2011). The distance learner competencies: A three-phased empirical approach. Educational Technology Research and Development, 59(1), 21-42.

J ung, I. (2007). Innovative practices of distance education (including e-learning) in Asia and the Pacific. International J ournal for Educational Media and Technology, $1(1), 48-60$.

J ung, I. (2011). The dimensions of e-learning quality: From the learner's perspective. Educational Technology Research and Development, 59(4), 445-464.

J ung, I. (2012). Asian learners' perception of quality in distance education and gender differences. The International Review of Research in Open and Distance Learning, 13(2), 1-25.

J ung, I.S., \& Fukuda, A. (2011, September 30). Gender differences in Asian learners' perception of the quality in distance education and e-learning: Implications for a gender-considerate support system. Paper presented at the 25th AAOU conference. Penang, Malaysia.

Latchem, C., \&J ung, I. S. (2009). Distance and blended learning in Asia. New York and London: Routledge.

Levy, Y. (2007). Comparing dropouts and persistence in e-learning courses. Computers and Education, 48(2), 185-204.

Littlejohn, S. W. (1996). System theory. In S. Littlejohn, Theories of human communication (pp. 42-63). Belmont, CA: Thomson Learning Global Rights Group.

Ludwig-Hardman, S., \& Dunlap, J . (2003). Learner support services for online students: Scaffolding for success. The International Review of Research in Open and Distance Learning, 4(1). Retrieved from http:// www.irrodl.org/index.php/irrodl/article/view/131/211

Mactague, N. J . (2004). Development of a model of academic learner support services for distance education programs for higher education. In U. Bernath \&A. Szucs (Eds.), Supporting the learner in distance education and e-learning (pp. 348355). Oldenburg, Germany: Bibliotheks- und Informationssystem der Universitaet Oldenburg.

Mandernach, B. (2009). Effect of instructor-personalized multimedia in the online classroom. The International Review of Research in Open and Distance Learning, 10(3). Retrieved from http:// www.irrodl.org/index.php/irrodl/article/view/606/ 1263 
Rumble, G. (2000). Student support in distance education in the 21st Century: Learning from service management. Distance Education, 21(2), 216-235.

Sewart, D. (1993). Student support systems in distance education. Open Learning, 8(3), 3-12.

Stevens, C., \& Kelly, P. (2012). Change and renewal: The role of a change team in improving student support. Open Learning: The Journal of Open, Distance and e-Learning, 27(2), 137-148.

Tait, A. (2000). Planning student support for open and distance learning. Open Learning, 15(3), 287-299.

Tait, A., \& Mills, R. (Eds.). (2013). Rethinking learner support in distance education: Change and continuity in an international context. New York: Routledge.

Tang, S. F., \&Hussin, S. (2011). Quality in higher education: A variety of stakeholder perspectives. International J ournal of Social Science and Humanities, 1(2), 126-131.

Taplin, M. (2000). Problems experienced by female distance education students of IGNOU: Why do some consider dropping out while others decide to stay? Indian J ournal of Open Learning, 9(2), 191-210.

Tekinarslan, E. (2009). Turkish university students' perceptions of the world wide web as a learning tool: An investigation based on gender, socio-economic background, and web experience. The International Review of Research in Open and Distance Learning, 10(2). Retrieved from http:// www.irrodl.org/index.php/irrodl/article/ view/ 598/ 1217

Thorpe, M. (2002). Rethinking learner support: The challenge of collaborative online learning. Open learning, 17(2), 105-119.

Vimala, R. (2010). Gender issues in higher education - Advocacy Brief. Bangkok: UNESCO Bangkok. Retrieved from http:// unesdoc.unesco.org/images/0018/001898/189825e.pdf

Zhang, J., Li, F., Duan, C., \&Wu, G. (2001). Research on self-efficacy of distance learning and its influence to learners' attainments. In C.H. Lee (Ed.), Proceedings of the International Conference on Computers in Education (ICCE)/ SchoolNet 2001 (pp. 1510-1517). Incheon, South Korea: Incheon National University of Education. 


\section{Athabasca University $\mathbf{A}$}

(c) (i) 


\section{Blending Online Asynchronous and Synchronous Learning}

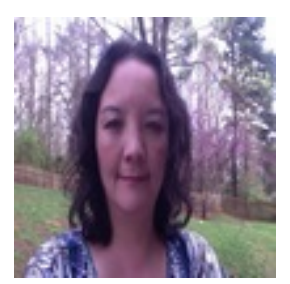

Lisa C. Yamagata-Lynch

University of Tennessee, USA

\section{Abstract}

In this article I will share a qualitative self-study about a 15-week blended $100 \%$ online graduate level course facilitated through synchronous meetings on Blackboard Collaborate and asynchronous discussions on Blackboard. I taught the course at the University of Tennessee (UT) during the spring 2012 semester and the course topic was online learning environments. The primary research question of this study was: How can the designer/instructor optimize learning experiences for students who are studying about online learning environments in a blended online course relying on both synchronous and asynchronous technologies? I relied on student reflections of course activities during the beginning, middle, and the end of the semester as the primary data source to obtain their insights regarding course experiences. Through the experiences involved in designing and teaching the course and engaging in this study I found that there is room in the instructional technology research community to address strategies for facilitating online synchronous learning that complement asynchronous learning. Synchronous online whole class meetings and well-structured small group meetings can help students feel a stronger sense of connection to their peers and instructor and stay engaged with course activities. In order to provide meaningful learning spaces in synchronous learning environments, the instructor/designer needs to balance the tension between embracing the flexibility that the online space affords to users and designing deliberate structures that will help them take advantage of the flexible space.

Keywords: Online learning environments; synchronous learning; asynchronous learning; student reflections 
The purpose of this study was to explore how synchronous online learning can complement asynchronous learning in higher education settings. I will engage in this discussion by introducing a study about a 15-week online graduate level course that I taught in spring 2012 at the University of Tennessee (UT). The discussion of the study will take place within a self-study context where I as the instructor, designer, and researcher engaged in the data collection, analysis, and reporting of the study. The course in which this study took place was about online learning environments.

As a self-study, this work is concerned with making private privileged teaching knowledge public through rigorous and systematic qualitative research methods (Loughran, 2007). In this type of study, the goal of the investigation is to uncover knowledge about practice while recognizing how the self can contribute to scholarly works about teaching and address personal beliefs while acting on them (Hamilton \& Pinnegar, 2000; Hamilton, Smith, \& Worthington, 2008; Loughran, 2005). While engaging in this investigation, I relied on observations shared by LaBoskey (2004) about the five elements of self-study methodologies that recommends that the study (a) is self-initiated and focused, (b) is improvement aimed, (c) is interactive, (d) relies on multiple primarily qualitative methods, and (e) uses exemplar-based validation.

Findings from this type of work generates moderatum generalizations that are moderate in scope and are open to change, but are testable for future confirmation or refutation when new evidence is uncovered (Payne \& Williams, 2005). As an instructional designer the moderatum generalizations that I am able to offer to the scholarly community are design lessons related to designing, developing, and implementing online courses and how those lessons apply to future course and program designs. With that being said, I approach design as an ill-defined problem solving activity in messy-real world situations (J onassen, 2011; Rowland, 1993). As a designer, I framed the reporting of this study following the traditions of design case studies where the goal is to build design knowledge based on precedents (Howard, Boling, Rowland, \& Smith, 2012). While this work is not a design case in itself, based on evidence from teaching experiences and student reflections much of the data analysis and reporting efforts were put into sharing design experiences from a reflective practitioner perspective (Schön, 1987).

I will begin this article with background information about myself as the designer/instructor and the course. While it may seem awkward to begin a research report with this type of autobiographical sketch, in a self-study it is important for the reader to have this information to fully understand the study context to see the privileged data through the perspective of the self. Following the background information, I will introduce literature on current trends in blended online learning and online synchronous and asynchronous learning. Finally, I will present findings and implications for future practice, research, and design of online synchronous learning. 


\section{Designer/ Instructor and Course Background}

I have been working in higher education institutions as a faculty of instructional technology since 2001. I began my career primarily teaching face-to-face courses, but gradually my teaching modality shifted from face-to-face to blended face-to-face/ online, and to fully online. Eventually, I made career choices where I became the program coordinator of a $100 \%$ online instructional technology master's program at UT. The course that I will be discussing in this article is one of the first courses I taught at UT.

Prior to my arrival to UT, faculty had made a curricular decision that the course I will discuss in this article was to be delivered $100 \%$ online. I also learned that within my department most online delivery was synchronous and not asynchronous. This was new to me because in the past all of my online courses relied on asynchronous communications using learning management systems such as Blackboard and Moodle.

I first made the decision regarding the course design to rely on university supported online instructional delivery technologies to ensure that students would have access to full time support from the university information technology services office. These tools were bundled as part of the learning management system and included discussion boards for asynchronous activities on Blackboard and a synchronous meeting platform on Blackboard Collaborate. I chose to design the class as a blended online course with 50\% asynchronous discussions and 50\% synchronous online meetings. During the 15 weeks of the course, weekly activities typically started with students reading assigned materials. Then they participated in asynchronous discussions about the readings and other related topics and/ or activities. When the course met synchronously they engaged in whole class and team synchronous activities related to the weekly topic.

\section{Research Goals}

This was the first time that I designed and implemented a 100\% online course equally relying on both synchronous and asynchronous technologies, and I was struck by a very simple question: How can the designer/instructor optimize learning experiences for students who are studying about online learning environments in a blended online course relying on both synchronous and asynchronous technologies? It is apparent that this question stemmed from a personal level and because of that this article is based on a self-study, but I have taken measures to present this study in a rigorous manner.

The availability of video and text exchanges on personal computers, smart phones, and social media in the United States has resulted in many American adults relying on online videos as an everyday source of information (Percell, 2013). In the business world virtual teams relying on document sharing and synchronous meeting technologies has risen (Anderson, McEwan, Bal, \& Carletta, 2007). Therefore, a discussion of pedagogically sound blended online course design that goes beyond the shortfalls of 
text-based chat and explores the advantages of video conferencing synchronous communications is a timely topic.

Many research studies in the field of education introduce asynchronous discussions as a tool to instill active student participation. As I prepared for developing my course, relying on ideas from authors such as Palloff and Pratt (2007), Gayol (2010), and Garrison and Cleveland-Innes (2005), it became clear that most research on online learning environments has focused on asynchronous communications. In contrast, synchronous chat communications are often introduced as an optional means to engage students in discussions. However, there is often a caveat that synchronous chats are likely to be ineffective due to the chaotic nature of rapid exchanges (Hrastinski, 2010; J ohnson, 2006; Petty \& Farinde, 2013).

\section{Relevant Discussions to Synchronous Online Learning}

In this section I will introduce several issues related to online synchronous and asynchronous learning. I will start by introducing the recent discussions that point to the newly heightened interest in blended learning within higher education for effectively and efficiently providing optimal learning experiences to students. Then I will introduce literature on synchronous online learning and asynchronous participatory online learning.

\section{Heightened Interest among Higher Education Administrators in Blended Learning}

Recently online education has become a topic of discussion in the mainstream news and research literature related to higher education. Many university presidents are showing interest in online learning as a viable mode of instruction (Young, 2011). Online education is now being touted as a method to make educational opportunities accessible to a wide range of audiences. It has been gaining attention as a vehicle for improving pedagogy, introducing flexibility in student access to instruction, and lowering costs associated with education (Graham, 2006; Taplin, Kerr, \& Brown; 2013). Interests in online education among higher education and corporate professionals have risen to the point that Carnegie Mellon University is now leading the creation of a consortium including other universities and corporate entities for developing standards to promote best practices for online learning (O'neil, 2013).

There are also efforts to better define blended learning; however, in many cases the answer to what is blended learning is "it depends." For example, Graham, Woodfield, and Harrison (2013) introduced a spectrum of course delivery modalities in higher education that situated blended learning within the context of traditional face-to-face delivery and completely online delivery with a caveat that institutions of higher education liberally label course delivery modes as blended as long as they are 
somewhere on the spectrum. Similarly, several authors have pointed out that institutions of higher education may refer to blended learning as a combination of online and face-to-face learning when it involves anywhere from $20 \%$ to $80 \%$ blending of online instruction with traditional face-to-face courses. In many cases, there is no agreed upon percentage of what constitutes a course as blended, and in many institutions there are idiosyncratic definitions of online, distance education, and blended instruction.

Graham (2006) defined blended learning not based on percentages of instructional delivery mode, but on what is being blended. Graham, referred to instructional modalities/ delivery media, methods, and the ratio of online and face-to-face instruction as elements that all take a role in defining blended learning. Blended learning has also been referred to as a catalyst of potential change in institutions of higher education because there is a little bit of old and new mixed together, but it needs a better articulated definition so that higher education institutions can align their strategic goals to be successful at facilitating blended learning (Moskal, Dzinban, Hartmen, 2013). Therefore, blended learning has been found to not only bring flexibility into student learning, but also to help institutions explore efficient use of space and faculty time (Dziuban, Hartman, J uge, Moskal, \& Sorg, 2006).

\section{Synchronous Online Learning}

Much of the current scholarly discussions related to designing online learning environments within instructional technology are focused primarily on asynchronous communications. While looking for books and articles that specifically discussed synchronous pedagogy I found Finkelstein (2006) in recent works, and older publications related to interactive video conferencing such as Knox (1997), Carville and Mitchell (2000), and Fetterman (1996). The older literature tended to discuss the effectiveness of video-conferencing compared to face-to-face meetings and the potential of video-conferencing to deliver education to geographically remote learners who do not have access to traditional educational facilities. In many cases, these articles established a discussion for how video-conferencing tools can be a legitimate media for instruction, but did not provide insights on how to engage students in active learning. One article that provided pedagogical insights for both synchronous and asynchronous learning was Bonk and Cummings (1998) where the authors discussed their experiences teaching online and aligned their ideas about teaching online to the American Psychological Association's Learner Centered Psychological Principles.

Within more recent literature related to synchronous communications Asterhan and Schwarz (2010) pointed out that there is little discussion regarding how to effectively support learners in synchronous online learning environments. Asterhan and Schwarz conducted a study regarding online synchronous group discussions and effective moderation that relied on a communication tool that enabled participants to communicate through text and diagramming. Their study included $9^{\text {th }}$ grade students and graduate students. Participants from both groups expected a good moderator to be 
active and keep the live discussions focused to help participants to stay on topic. Participants also reported that they did not necessarily desire the moderator to insert his or her expert opinion regarding the topic during the discussion. Asterhan and Schwarz concluded that the type of dialogue that the instructor facilitated and the degree to which students were engaged in synchronous collaborative discussion affected student-learning outcomes for both the $9^{\text {th }}$ grade students and graduate students. They also concluded that the nature of discussion in asynchronous and synchronous online discussions was qualitatively different. Other studies have found that while engaged in synchronous learning when compared to asynchronous learning participants (a) find a stable means of communication, (b) tend to stay on task, (c) feel a larger sense of participation, and $(\mathrm{d})$ tend to experience better task/course completion rates (Chen \& You, 2007; Mabrito, 2006; Hrastinski, 2010).

In terms of the use of video conferencing in university synchronous instruction Han (2013) examined the effects of instructor video casting on his/her students' sense of connection to the instructor. Han found that in courses that included instructor video casting, compared to courses that did not use video casting, students were able to overcome the sense of being at a distance from the instructor. The use of video casting helped Han's study participants to engage in meaningful interactions with the instructor and peers to minimize what Moore $(1993,2013)$ discussed as transactional distance. According to Moore (1993) transactional distance is a pedagogical concept that learners at a distance from their instructors and peers experience through their interactions with one another and defines the nature of their relationship. Participants may sense more or less transactional distance in an online course depending on the level of shared dialogue, the structures that the instructor puts in place, and the level of autonomy participants experience in a course (Moore, 2013).

\section{Asynchronous Online Participatory Learning}

Studies about asynchronous online learning suggest that students will experience meaningful learning when they are in participatory learning environments (Pratt \& Palloff, 2011). These environments are intentionally designed to help participants develop a sense of community to provide them with opportunities to engage in collaborative discussions. These interactions encourage participants to actively construct new meanings related to the course content (Conrad \& Donaldson, 2011; Lehman \& Conceição, 2011). Asynchronous online participatory learning involves a series of highly complex and ill-defined activities that requires participants to reflect and question their traditional learning practices while developing a new identity as a learner (Palloff \& Pratt, 2011).

The success of community development efforts in an asynchronous text-based learning environment is often associated to how much participants feel present within the shared space. Works such as Garrison, Anderson, and Archer's (2000) study related to the community of inquiry model played a considerable role in bringing attention to the value of presence in online asynchronous learning environments. These works 
heightened interest among researchers and practitioners in how social presence, teaching presence, and cognitive presence affect participants' level of engagement. Garrison and Cleveland-Innes (2005) also found through a multi-case comparison study of asynchronous courses that participant interaction alone does not instill a shared feeling of social presence or engagement in an online course. They found that participants of asynchronous online courses need structures placed by the instructor/designer or participants themselves to help them engage in meaningful learning activities. By understanding presence and its relation to participant engagement in a course from its physical, social, emotional, and psychological aspects designers of online learning environments are able to understand the inherently social nature involved in human learning that needs to be carefully addressed in asynchronous learning environments (Lehman \& Conceição, 2011).

For many adults who attend asynchronous online programs the developmental process involved in understanding and becoming a participatory learner is a completely new experience (Arbaugh, 2004). Most adults need to adjust their role as a learner and the way they understand the role of the instructor. This can be a unique individualized process, but in many cases prior to becoming an effective online participatory learner students need assistance learning how to (a) use technologies involved in managing their online course experiences, (b) navigate course materials, and (c) engage in appropriate communication with other participants (Motteram \& Forrester, 2005). Ultimately, to succeed in online programs, students need time to figure out how to make their online course related activities fit into their lives while managing other obligations for family and work (Muilenburg \& Berge, 2005).

\section{Study Methods}

I engaged in this self-study as the instructor/designer of a course by taking a development research approach (Brown, 1992; The Design-Based Research Collective, 2003). I acted as a participant observer (Glesne, 2011) and took a critical role in the course design and instruction. While engaging in the practice of designing and teaching the course during the fall 2011 and spring 2012 semesters research took a secondary place, and my primary goal was to develop and implement the course. This type of development research can be difficult, but has been identified as necessary when developing and investigating effective collaborative online degree programs (Reeves, Herrington, \& Oliver, 2004; Wang \& Hannafin, 2005).

\section{Completing a Worthwhile Self-Study}

First self-study research has to take place and be reported within a well-grounded context that provides reasons for why the reader ought to be engaged with the topic and trust the author's reflexive findings (Feldman, 2003). In a rigorous qualitative study the topic that is being studied has to be worthwhile (Tracy, 2010). To this end I have (a) 
shared my autographical background related to this self-study for the reader to develop his/her understanding of the investigator as the self, and (b) presented scholarly discussions relevant to this work in terms of online learning and methodological issues.

Second, a high quality self-study requires the researcher to sensitively balance the tension between reporting about him/herself and the research (Freeman, et al., 2007). Through this process the researcher has the opportunity to demonstrate his/her sincerity by addressing biases and self-reflexive findings. This enables the researcher to be transparent about methodological challenges (Tracy, 2010). I engaged in this balancing act throughout the writing of this report by strategically constructing the organization of the report to best represent this balance.

Third, I engaged in data triangulation (Denzin, 1989) by collecting data from multiple sources. For each participant I had access to both primary and secondary data sources. The primary data source for this study was the student reflection papers that were part of the course assignments (see Appendix). I collected these reflections at three different times during the semester. I tested the guiding framework for the reflection paper in a different study (Yamagata-Lynch, Click, \& Smaldino, 2013) where we relied on activity systems analysis (Engeström, 1987) as a tool for engaging students in reflection on activities in an online course that blended synchronous meetings on Second Life and asynchronous discussions on Blackboard. All students enrolled in the course completed this assignment, but for the purpose of this study I had voluntary permission from eight out of a total 13 students to review their reflection papers.

I had access to various secondary data sources such as student assignments, synchronous participation recordings, and asynchronous discussion board postings. I had access to an anonymous student initial course survey that I created asking students to identify past experiences as online learners. I also had access to the end of semester university student course evaluation comments. Finally, as part of my own tenure and promotion process I had a fellow faculty member observe and comment on one week's worth of asynchronous and synchronous course activities.

In terms of data analysis I started by reading and re-reading the student reflections to engage in a thematic analysis (Merriam, 2009). These reflections became the starting point for identifying emerging themes, which then guided me while constructing the narrative presented in the findings. As I prepared the narratives based on themes that emerged I relied on my reflections and secondary data sources to uncover contextual information. 


\section{Findings}

\section{Participant Characteristics}

Among the eight participants in this study, one student was male and the others were female. While none of the participants shared the same professional background, all participants were involved in jobs or areas of research related to adult learning. Most participants were working professionals except for two full time graduate students. The contexts in which participants worked or conducted research included corporate training, higher education, nursing, and teacher professional development.

Through the anonymous initial course survey regarding student online learning experiences most students indicated that my class was not their first online course. Several of them had experiences taking courses that were blended asynchronous and face-to-face, fully asynchronous, or fully synchronous, but they did not have experience in a blended synchronous and asynchronous format. Some students who were taking my course as an elective shared in their reflections that in courses they had taken in the past, synchronous meetings were plagued with technical difficulties and they were not looking forward to the once a week meetings set aside for my class. Others indicated in the anonymous survey that they had expected my class would be a "self-paced," "passive asynchronous course." These students were a little taken aback by the synchronous and participatory collaborative nature of my course after reading the syllabus and weekly course activities expectations.

Some students continued to share this initial apprehension regarding synchronous activities when they wrote their first reflection paper. For example, Tracy shared that she was "more comfortable with the old idea of isolation and online lectures than collaboration and engaged learning... This [course] makes me very anxious" (Reflection Paper 1, January 2012). Samantha echoed this sentiment in her first reflection, and indicated that all of her past experiences with online courses involved self-paced asynchronous activities, and she was initially expecting my course to follow that format.

When sharing reasons for why students chose to enroll in my class in the anonymous survey, most students indicated that in the future they were likely to be involved in designing online courses themselves and they were interested in learning how to best facilitate adult learning online. Even though they had experienced several online courses prior to my class this was the first time where the topic was about facilitating online learning. Therefore, many participants commented that they came into the course slightly anxious about the live weekly meetings, but they were willing to give their best try to become familiar with how to learn and facilitate learning through synchronous online communications. 


\section{Requirements for Successful Blended Synchronous and Asynchronous Online Learning}

\section{Students need to be familiar with synchronous meeting tools.}

The reason why students were apprehensive about the synchronous meetings stemmed from difficulties they had or they heard about from colleagues in other courses related to synchronous meeting technologies. For example, Samantha shared in her first reflection that in one of her past online courses where the content was delivered primarily asynchronously with three synchronous meetings even until the last course meeting there were students who never learned how to use the communication tools appropriately and inevitably during all three sessions there were students who were stuck in the "what I can't hear you" situation. She commented that without technical proficiency shared among all participants, the synchronous platform could become "just a clunky environment" that takes time away from student learning opportunities.

Greg shared in his first reflection paper when discussing how he became familiar with the synchronous learning tools that he realized for an online synchronous course the community extends beyond the instructor and participants. After registering in my class he decided to voluntarily attend a two-hour workshop hosted by the university technology support office on Blackboard Collaborate prior to the first week of class. By learning about the synchronous tools prior to the course meeting he became comfortable with the learning space and felt ready to use it as a classroom and not a place where he would become overwhelmed with the technical aspects.

Yumin also shared how she felt about being prepared for the synchronous meetings in her first reflection paper. She commented that on the first day of class she was initially nervous about the synchronous aspects of the course. However, after the class met for the first time she realized that other course participants were approximately at the same technological proficiency level as she was and this made her much more comfortable to take part in the class.

\section{Ground rules need to be enforced.}

Several students in their reflection papers indicated that through their experiences in my class they had a newfound appreciation for course ground rules. During the first week of class, following suggestions from assigned readings, I introduced to the class a draft of the course ground rules. Based on prior experience, and another week's worth of readings students engaged in asynchronous discussion and synchronous small group discussions to review the ground rules and suggest modifications. During the whole group synchronous discussion in the second week of the course we reached a consensus and finalized the ground rules, with the understanding that whenever necessary any member of the course can suggest modifications for all to review. At this point the ground rules included items in Table 1. For the rest of the semester, these ground rules helped to set both synchronous and asynchronous course participation expectations. 
While reflecting on the value of ground rules of an online course Betty shared in her third reflection paper that

I have developed a deeper respect for course ground rules. In an online learning environment, without the familiar constraints of classroom walls, ground rules are not as easily assumed...Having online ground rules explicitly stated and always available helps to ensure a healthy, safe, and respectable learning environment. (Reflection Paper 3, April 2012)

Table 1

Course Ground Rules

1. Be prepared for synchronous sessions by having access to and properly set up computer equipment and USB headphones/microphone for each session.

2. Be proactive about seeking help from the instructor regarding course issues and OIT for technical troubleshooting.

3. Be open-minded and share my own ideas as well as listen to ideas that others share about themselves and my work even when at times they may be difficult advice.

4. Be able to take the time to think before responding to others.

5. Be responsive and communicative to other participants through email, asynchronous discussion, and synchronous discussions.

6. Be open to comments from other participants, and do not assume that they are negative, instead assume that they are positive and supportive.

7. Be self-disciplined and take charge of managing my own learning by making the time to read, participate, and reflect on course activities.

8. Be honest, respectful, and open while interacting with other participants.

9. Remember that discussion posts for this course are due $7 \mathrm{pm}$ on the due date, and formal assignments are due 11:59pm of the due date.

10. Side discussions during synchronous sessions are welcomed in this course as long as they do not disrupt anyone's work. When participants of the side discussions determine that their conversation would benefit the entire class one of the participants need to raise their hand to make others aware of the side discussion content.

11. Focus Wiki articles to more recent work, preferably from the last 5 to 7 years unless the selected older work is cited frequently by more recent work.

The ground rules helped identify formal rules that students could then interpret as a guide to identify how to behave appropriately in course related activities in both the synchronous and asynchronous platforms. For example based on these ground rules, Kelly shared in her second reflection paper the efforts she put into presenting herself during synchronous meetings as a fully attentive, respectful, and participative student to others. Her efforts included:

...online etiquette rules (e.g., maintaining a presence by marking "checks" when appropriate, or indicating "applause" (or other) when applicable, not interrupting 
speakers, keeping side chats brief and non-distracting); tacit rules of general politesse and professionalism; communication with the instructor directly as concerns/questions arise (Reflection Paper 2, March 2012).

Once the ground rules were set, to a certain extent I as the instructor relied on students to responsibly enact them. However, Samantha pointed out in her reflection paper there could have been reinforcement of the ground rules every now and then during the semester. For example, during the entire semester we had issues with students not following the ground rules and course requirements in the syllabus related to participating in class with a USB headphone and a microphone. Some students chose for themselves that they did not have to follow this requirement. While I did not receive complaints directed to me during private synchronous meetings or through email, in the final reflection paper that was due at the end of the semester several students commented that when other students did not use a USB headphone and microphone during synchronous sessions it made it difficult to communicate with them and challenging to fully engage in group learning activities.

\section{Students need to know where the course is heading.}

Several students commented in their reflections that while participating in an online course it is important for them to gain a sense of structure and where the course is heading. For example, Betty shared in her first reflection: "Before I begin any online course work my initial goal is to ground myself in organization.. I create structure from calendar due dates, task lists, and management of course content" (Reflection Paper 1, January 2012). Students also commented that they needed to spend time at the beginning of the semester to learn how to organize their own course related efforts within the structure of the course provided by the instructor. Betty in her third reflection commented that when she is able to organize her time within the structure of the course she becomes able to fully participate with a sense of stability in both the synchronous and asynchronous platforms. She commented: "I believe the overall nature of stability ensured my participation and engagement with course activities and connections with fellow classmates remained high and fully engaged" (Reflection Paper 3, April 2012).

Kelly, Greg, and Tracy all commented that the sense of direction that they gained from the structure I provided for the course in the syllabus and the way they organized their work to accommodate the structure of the course provided them with reasons to exert their energy into the participation of both synchronous and asynchronous activities. For example, Kelly found the small group breakout synchronous meetings to be very difficult to participate in and Greg found the asynchronous discussions difficult to fit into his busy life juggling school and work. Both students pointed out in their reflection paper that as long as they knew the purpose of each activity in the bigger picture of the course and their personal goals for the course they were able to make themselves 
continue to be interested in activities they felt less comfortable and personally less interested in.

\section{Benefits from Synchronous Online Learning}

Students shared that being part of an online blended synchronous and asynchronous course gave them the opportunity to experience a higher level of participation in a flexible learning environment where they had no time to be a passive non-present student. For example, Greg commented that as a general trend when he is in online courses he often needs to find ways to stay engaged throughout a semester while juggling his busy work life. Through the blended format and seeing how the asynchronous activities built towards the synchronous meetings he was able to continue participating in the asynchronous activities. Additionally, he saw how some of the other students prefer asynchronous communications, unlike him, and while working to comprehensively participate in class Greg discovered that for him to get to know other course participants he needed to listen to them through both synchronous and asynchronous communications. In some cases, the blended online format of the course helped students gain a stronger sense of connection. Jane commented in her second reflection paper that

During the past nine weeks, I have had the opportunity to interact with all participants in online activities. I feel like I have gotten to know each of the class participants at least as well, and probably better, than I would have in a face-to-face class. (Reflection Paper 2, March 2012)

Some of the other flexible features of the course that students commented were beneficial to their learning included the variety of communication styles that the two technologies brought to the class. Through the synchronous communications they were able to engage in spontaneous discussions while through the asynchronous communications they were able to take the time to reflect and prepare a response for discussion topics that were designed for any given week. A final flexible feature that students enjoyed was that they could work in their own space, and did not have to rely on equipment that was not their own when participating in synchronous meetings. J ane commented in her first reflection paper that it was important to her that her learning space was her own and not in a classroom where she did not have the control to optimize the environment for herself.

\section{Areas of Future Development in Synchronous Online Learning}

In my class the area that students experienced the greatest difficulties with were in the synchronous breakout activities. Greg in his third reflection paper pointed out a simple problem where in breakout rooms someone had to speak up at first so the team did not waste time trying to figure out who would start the conversation. In other comments shared by students in the reflection papers it became clear that they needed more 
guidance structuring breakout sessions. As a response to this finding that I discovered during the course, I started to suggest roles for each participant to take during breakout activities and provided a framework for managing the allotted time for live activities.

Kelly commented in her second reflection paper a similar sentiment as Greg and added that she got frustrated when in small groups other participants were not willing to talk, and this was one reason she felt more comfortable and less frustrated with asynchronous discussions. Kelly kept reflecting on this issue in her subsequent reflections to explore how to make synchronous breakout activities less frustrating. In her third reflection paper she commented:

I think it might really help if participants always used the video feature when they talk. I consider myself a very visual person and I think I have trouble staying engaged (and not getting distracted) when the monitor that I am staring at doesn't change at all. ( Reflection Paper 3, spring 2012)

This was a suggestion I received in my peer teaching evaluation from my colleague as well. My teaching evaluator commented that I was losing the opportunity for participants to develop a stronger connection with each other and in the future I ought to require participants to turn their video on while speaking.

On another note about breakout activities, Tracy commented that she ended up with the same group members several times and it was difficult for each small group activity to stay interesting because the group started to lack varied viewpoints. This was my error from ignorance. As the moderator of the synchronous sessions I relied on a function within Blackboard Collaborate for assigning students randomly into breakout rooms when I created the rooms for each session. I did not realize until later in the semester while reading student reflections that this random assignment was not so random. Therefore, while it was late into the semester I started to create peer rotation groups and created a chart of assigned peer activity groups where students were randomly assigned to three different peer groups.

\section{Conclusions}

I started this article by sharing my experience as an instructor, designer, and researcher of online learning environments in higher education settings. I specifically addressed the potential benefits for integrating synchronous learning into asynchronous course activities because I wanted to see how they can be best matched to benefit student experiences (see LaBoskey, 2004-(a) is self-initiated and focused and (b) improvement aimed). I followed the development research approach where as the researcher, designer, instructor I engaged in iterative just-in-time and long-term modifications of 
the design by responding to evidence from course experiences and student data (see LaBoskey, 2004-(c) is interactive). Following the qualitative research traditions I used multiple methods for collecting course and student data to engage in a trustworthy data collection and analysis (see LaBoskey, 2004-(d) relies on multiple primarily qualitative methods, and (e) uses exemplar-based validation). In this section I will address both the implications related to teaching online courses where I introduce design lessons that I discovered as moderatum generalizations. Then I will introduce implications from those design lessons to the greater scholarly discussions about online learning environments.

\section{Implications for Designing Online Learning Environments}

\section{Online Learning Environments Design Lesson 1: Participants come to online courses with varied participatory learning experiences, and need time to find a new identity as an online learner.}

Many participants of this study had varied experiences in past online courses, and to many of them taking a participatory approach was a foreign concept. This necessitated an adjustment phase for taking on the expectations for becoming a participatory online learner much like observations made by Arbaugh (2004). Similar to findings shared by Motteram and Forrester (2005), participants of this study discussed in their reflection papers that following the course ground rules, overall course structure, and becoming proficient with course technologies helped them become effective course participants. They also shared in their papers that they had to juggle personal, work, and course obligations while participating in course related activities much like what was reported in Muilenburg and Berge (2005). Similar to findings shared by Palloff and Pratt (2011) by engaging in a series of complex course related activities and finding new ways to fit them into their personal learning space, study participants discovered a new identity as online participatory learners.

\section{Online Learning Environments Design Lesson 2: Synchronous delivery modes can provide a stronger sense of connection among participants, and a blended online synchronous and asynchronous course can strengthen social presence.}

Participant reflections specifically related to synchronous technologies indicated that they were in alignment with previous studies relying on text-based chat exchanges. For example, participants reported that they found the nature of synchronous and asynchronous communications to be different from one another similar to what Asterhan and Schwarz (2010) found. Participants sensed a stronger connection to other students while engaged in spontaneous conversations during synchronous meetings that they did not experience in the asynchronous discussions. Students also reported that with the synchronous and asynchronous blended online course format they felt they gained a sense of stability, stayed on task, and gained a stronger connection with other participants similar to what was reported by Chen and You (2007) and Hrastinski (2010). In other words, the synchronous meeting platform that enabled live online video and voice communications between the instructor and participants helped participants develop a stronger sense of social presence. While this work alone cannot speak to how 
the synchronous platform affected the physical, social, emotional, and psychological aspects of social presence that Lehman and Conceiçã (2001) identified, this work indicates that there is room for future investigations related to synchronous online learning and its impact on social presence.

\section{Online Learning Environments Design Lesson 3: Participant experiences are greatly affected by the designer/instructor's ability to bring a sense of cohesion and structure in the synchronous learning environments.}

When reflecting on the experiences I gained through designing and teaching the course and the research findings from this study I find that the instructor/ designer's ability to provide participants with appropriate structures within a flexible shared virtual space takes a critical role in the success of synchronous online learning. This is perhaps similar to what Garrison and Cleveland-Innes (2005) reported in their work regarding the need for structure within asynchronous online learning environments to ensure that participants engage in meaningful learning activities. In a synchronous online learning space the instructor/designer needs to carefully reflect and be deliberate about the structures $\mathrm{s} /$ he makes available to participants because in many cases if the same activity were to take place in a face-to-face setting it is not likely that participants would need the same amount of guidance.

\section{Implications for Studying Online Learning Environments}

At the course design level of scholarly discussion, as the number of online courses relying on synchronous technologies rises in the future, the nature of the tension between structure and flexibility may evolve. As a result, scholars need to purposefully engage in research that questions the transitions in this tension because it is likely to have effects on participant perception of transactional distance (Moore, 1993, 2013). This implies that what we know now from past and current research may no longer be the status quo and online learning environment scholars need to be willing to conceptually change their understanding related to synchronous online learning. As future online learners gain the experiences they need to become savvy synchronous learners they may identify the structures themselves that need to be in place. The continual question for the instructor/ designer/researcher then is to identify when and how much structure within a flexible system is appropriate for their participants based on who the participants are, the course schedule, the content, and the affordances of the synchronous communication technologies. For these continued design improvements to occur at the course level, online learning environment scholars need to move beyond solely examining the asynchronous participatory instructional delivery mode, and explore experiences related to synchronous online delivery beyond text-based chat interactions.

At the programmatic level, much of the current discussion related to online learning focuses on introducing blended learning into higher education as an opportunity for making college education accessible, pedagogically innovative, flexible, and economical 
(Graham, 2006; Taplin, Kerr, \& Brown, 2013). This has resulted in a need for defining what qualifies as blended learning, which has not yielded a consensus on the matter (Graham, Woodfield, \& Harrison, 2013). These discussions represent conversations related to how online learning environments can be assimilated into historical practices of brick and mortar higher education institutions. Unfortunately, using the sole perspective of a brick and mortar institution as the primary vantage point for addressing future developments in online learning limits the potential transformation that it can bring to instructor and student experiences within universities.

Based on the experiences I gained through this investigation and the design lessons I uncovered there are three questions that I propose online learning environment scholars need to address in the future. First, scholars need to address: How can higher education institutions provide meaningfully structured learning experiences within flexible online learning spaces, while not being burdened by their historical highly structured brick and mortar infrastructure? Works that address this question will add to the scholarly discussions related to social presence, transactional distance, and blended learning. The second question that scholars need to address is: How can faculty and university support staff work together to transform faculty into designers of online courses and share their experiences in a scholarly manner? Works that address this question will add to the discussions related to developmental research and self-study research. Finally, scholars who engage in investigations related to the above questions need to address: How can both course and program level design lessons that are discovered through developmental research and self-studies be shared as design knowledge based on precedents? Through these types of scholarly work the online research and practitioner community will be able to refer to moderatum generalizations (Payne \& Williams, 2005) about online learning environments while continuing to design, develop, and implement online learning courses, programs, and research. 


\section{References}

Anderson, A. H., McEwan, R., Bal, J ., \& Carletta, J . (2007). Virtual team meetings: An analysis of communication and context. Computers in Human Behavior, 23(5), 2558-2580. doi:10.1016/j.chb.2007.01.001

Arbaugh, J . (2004). Learning to learn online: A study of perceptual changes between multiple online course experiences. The Internet and Higher Education, 7(3), 169- 182. doi:10.1016/j.iheduc.2004.06.001

Asterhan, C. S. C., \& Schwarz, B. B. (2010). Online moderation of synchronous eargumentation. International J ournal of Computer-Supported Collaborative Learning, 5(3), 259-282. doi:10.1007/ s11412-010-9088-2

Brown, A. L. (1992). Design experiments: Theoretical and methodological challenges in creating complex interventions in classroom settings. The J ournal of The Learning Sciences, 2(2), 141-178. doi:10.1207/s15327809j1s0202_2

Carville, S., \& Mitchell, D. R. (2000). “It's a bit like Star Trek': The effectiveness of video conferencing. Innovations in Education \& Training International, 37(1), 4249. doi:10.1080/135580000362070

Chen, W., \&You, M. (2007). The differences between the influences of synchronous and asynchronous modes on collaborative learning project of industrial design. In D. Schuler (Ed.), Online communities and social computing (pp. 275-283). Berlin Heidelberg : Springer. Retrieved from http://link.springer.com/ chapter/ 10.1007/978-3-540-73257-0 31

Conrad, R.-M., \&Donaldson, J . A. (2011). Engaging the onlinelearner: Activities and resources for creative instruction (2nd ed.). San Francisco: J ossey-Bass.

Dziuban, C., Hartman, J ., J udge, F., Moskal, P., \& Steven, S. (2006). Blended learning enters mainstream. In C. J . Bonk \& C. R. Graham (Eds.), The handbook of blended learning: Global perspectives, local designs (pp. 195- 208). San Francisco: Pfeiffer.

Engeström, Y. (1987). Learning by expanding: An activity-theoretical approach to developmental research. Retrieved from http://lchc.ucsd.edu/MCA/Paper/ Engestrom/expanding/toc.htm

Feldman, A. (2003). Validity and quality in self-study. Educational Researcher, 32(3), 26- 28. doi:10.3102/0013189X032003026

Fetterman, D. M. (1996). Videoconferencing on-Line: Enhancing communication over the Internet. Educational Researcher, 25(4), 23- 27. doi:10.2307/ 1176777 
Finkelstein, J . E. (2006). Learning in real time: Synchronous teaching and learning online. J ossey-Bass.

Freeman, M., deMarrais, K., Preissle, J ., Roulston, K., \& Pierre, E. A. S. (2007). Standards of evidence in qualitative research: An incitement to discourse. Educational Researcher, 36(1), 25- 32. doi:10.3102/0013189X06298009

Garrison, D. R., Anderson, T., \&Archer, W. (2000). Critical inquiry in a text-based environment: Computer conferencing in higher education. The Internet and Higher Education, 2(2-3), 87- 105. doi:10.1016/ S1096-7516(00)00016-6

Garrison, D. R., \& Cleveland-Innes, M. (2005). Facilitating cognitive presence in online learning: Interaction Is not enough. American J ournal of Distance Education, 19, 133- 148. doi:10.1207/s15389286ajde1903_2

Glesne, C. (2011). Becoming qualitative researchers: An introduction (4th ed.). Prentice Hall.

Graham, C. R. (2006). Blended learning systems: Definition, current trends, and future directions. In C. J . Bonk \& C. R. Graham (Eds.), The handbook of blended learning: Global perspectives, local designs (pp. 3- 21). San Francisco: Pfeiffer.

Graham, C. R., Woodfield, W., \& Harrison, J . B. (2013). A framework for institutional adoption and implementation of blended learning in higher education. The Internet and Higher Education, 18, 4- 14. doi:10.1016/j.iheduc.2012.09.003

Hamilton, M. L., \& Pinnegar, S. (2000). On the threshold of a new century trustworthiness, integrity, and self-study in teacher education. J ournal of Teacher Education, 51(3), 234- 240. doi:10.1177/0022487100051003012

Hamilton, M. L., Smith, L., \&Worthington, K. (2008). Fitting the methodology with the research: An exploration of narrative, self-study and auto-ethnography. Studying Teacher Education, 4(1), 17-28. doi:10.1080/ 17425960801976321

Han, H. (2013). Do nonverbal emotional cues matter? Effects of video casting in synchronous virtual classrooms. American J ournal of Distance Education, 27(4), 253-264. doi:10.1080/08923647.2013.837718

Howard, C. D., Boling, E., Rowland, G., \&Smith, K. M. (2012). Instructional design cases and why we need them. Educational Technology, 52(3), 34- 39.

Hrastinski, S. (2010). How do e-learners participate in synchronous online discussions? Evolutionary and social psychological perspectives. In N. Kock (Ed.), Evolutionary psychology and information systems research (pp. 119- 147). US : Springer. Retrieved from http:/ / link.springer.com/ chapter/ 10.1007/978-1$\underline{4419-6139-6 \quad 6}$ 
J ohnson, G. M. (2006). Synchronous and asynchronous text-based CMC in educational contexts: A review of recent research. TechTrends, 50(4), 46- 53. doi:10.1007/s11528-006-0046-9

J onassen, D. H. (2011). Learning to solve problems: A handbook for designing problem-solving learning environments. New York: Routledge.

Knox, D. M. (1997). A review of the use of video-conferencing for actuarial education a three-year case study. Distance Education, 18(2), 225- 235. doi:10.1080/0158791970180204

LaBoskey, V. K. (2004). The methodology of self-study and its theoretical underpinnings. In J. J . Loughran, M. L. Hamilton, V. K. LaBoskey, \& T. Russell (Eds.), International handbook of self-study of teaching and teacher education practices (pp. 817- 869). Netherlands : Springer. Retrieved from http:// link.springer.com/ chapter/ 10.1007/978-1-4020-6545-3_21

Loughran, J . (2005). Researching teaching about teaching: Self-study of teacher education practices. Studying Teacher Education, 1(1), 5- 16. doi:10.1080/17425960500039777

Loughran, J . (2007). Researching teacher education practices responding to the challenges, demands, and expectations of self-study. J ournal of Teacher Education, 58(1), 12-20. doi:10.1177/ 0022487106296217

Lehman, R. M., \& Conceição, S. C. O. (2010). Creating a sense of presence in online teaching: How to "be there" for distance learners. San Francisco: J ossey-Bass.

Mabrito, M. (2006). A study of synchronous versus asynchronous collaboration in an online business writing class. American J ournal of Distance Education, 20(2), 93- 107. doi:10.1207/ s15389286ajde2002_4

Merriam, S. B. (2009). Qualitative research: A guide to design and implementation: Revised and expanded from qualitative research and case study applications in education (3rd ed.). San Francisco, California: J ossey-Bass.

Moore, M. G. (1993). Theory of transactional distance. In D. Keagan (Ed.), Theoretical principles of distance education (pp. 22- 29). New York: Routledge. Retrieved from http:// www.uni-oldenburg.de/ zef/cde/support/readings/moore93.pdf

Moore, R. (2003). Reexamining the field experiences of preservice teachers. J ournal of Teacher Education, 54(1), 31-42.

Moskal, P., Dziuban, C., \& Hartman, J . (2013). Blended learning: A dangerous idea? The Internet and Higher Education, 18, 15- 23. doi:10.1016/j.iheduc.2012.12.001 
Motteram, G., \& Forrester, G. (2005). Becoming an online distance learner: What can be learned from students' experiences of induction to distance programmes? Distance Education, 26, 281-298. doi:10.1080/01587910500291330

Muilenburg, L. Y., \& Berge, Z. L. (2005). Student barriers to online learning: A factor analytic study. Distance Education, 26, 29- 48.

doi:10.1080/01587910500081269

O'neil, M. (2013, November 11). New council to develop standards, best practices for online learning. Wired Campus. The Chronicle of Higher Education. Retrieved from http:// chronicle.com/blogs/ wiredcampus/ new-council-to-developstandards-best-practices-for-onlinelearning/48171?cid=wc\&utm source=wc\&utm medium =en

Palloff, R. M., \& Pratt, K. (2007). Building online learning communities: Effective strategies for the virtual classroom (2nd ed.). San Francisco: J ossey-Bass.

Payne, G., \&Williams, M. (2005). Generalization in qualitative research. Sociology, 39(2), 295- 314. doi:10.1177/ 0038038505050540

Percell, K. (2013). Online video | Pew Research Center's Internet \&American Life Project (p. 23). Washington, D.C.: Pew Research Center. Retrieved from http:// www.pewinternet.org/ Reports/2007/Online-Video.aspx

Petty, T., \& Farinde, A. C. (2013). Investigating student engagement in an online mathematics course through windows into teaching and learning. J ournal of Online Learning and Teaching, 9(2), 261-270.

Reeves, T. C., Herrington, J ., \& Oliver, R. (2004). A development research agenda for online collaborative learning. Educational Technology Research and Development, 52(4), 53-65. doi:10.1007/BF02504718

Rowland, G. (1993). Designing and instructional design. Educational Technology Research and Development, 41(1), 79- 91. doi:10.1007/ BF02297094

Schön, D. A. (1987). Educating the reflective practitioner: Toward a new design for teaching and learning in the professions. San Francisco: J ossey-Bass.

Taplin, R. H., Kerr, R., \& Brown, A. M. (2013). Who pays for blended learning? A costbenefit analysis. The Internet and Higher Education, 18, 61- 68. doi:10.1016/j.iheduc.2012.09.002

The Design-Based Research Collective. (2003). Design-based research: An emerging paradigm for educational inquiry. Educational Researcher, 32(1), 5-8. doi:10.3102/0013189X032001005 
Tracy, S. J . (2010). Qualitative quality: Eight "big-tent" criteria for excellent qualitative research. Qualitative Inquiry, 16(10), 837-851. doi:10.1177/ 1077800410383121

Wang, F., \& Hannafin, M. (2005). Design-based research and technology-enhanced learning environments. Educational Technology Research and Development, 53(4), 5- 23. doi:10.1007/BF02504682

Yamagata-Lynch, L. C., Click, A., \& Smaldino, S. E. (2013). Activity systems as a framework for scaffolding participant reflections about distance education in an online instructional technology course. Reflective Practice, 14(4), 536- 555. doi:10.1080/ 14623943.2013.809336

Young, J . R. (2011, August 28). College presidents are bullish on online education but face a skeptical public. The Chronicle of Higher Education. Retrieved from http:// chronicle.com/article/ College-Presidents-Are-Bullish/ 128814/ 


\section{Appendix}

\section{Online Learner Self Reflection Guide}

\section{Last Updated J anuary 11, 2012}

You will keep a reflective log of your own process of becoming an online learner. You need to complete 3 assigned reflections at the beginning, middle, and end of this course. Follow the Reflection Template guided by activity systems analysis when completing this assignment. Use the form, with the triangle imbedded within it, for completing each of your reflections. There are additional open-ended statements related to your personal learning and the course structure to be completed as well.

This reflection focuses on your course related activities and how you see yourself as an online learner. Please use the following graphical model to clarify what to include in your reflections addressing Subject, Tool, Object, Rules, and Community, Division of Labor. Please indicate any specific conflicts between areas of the model when appropriate in your reflections.

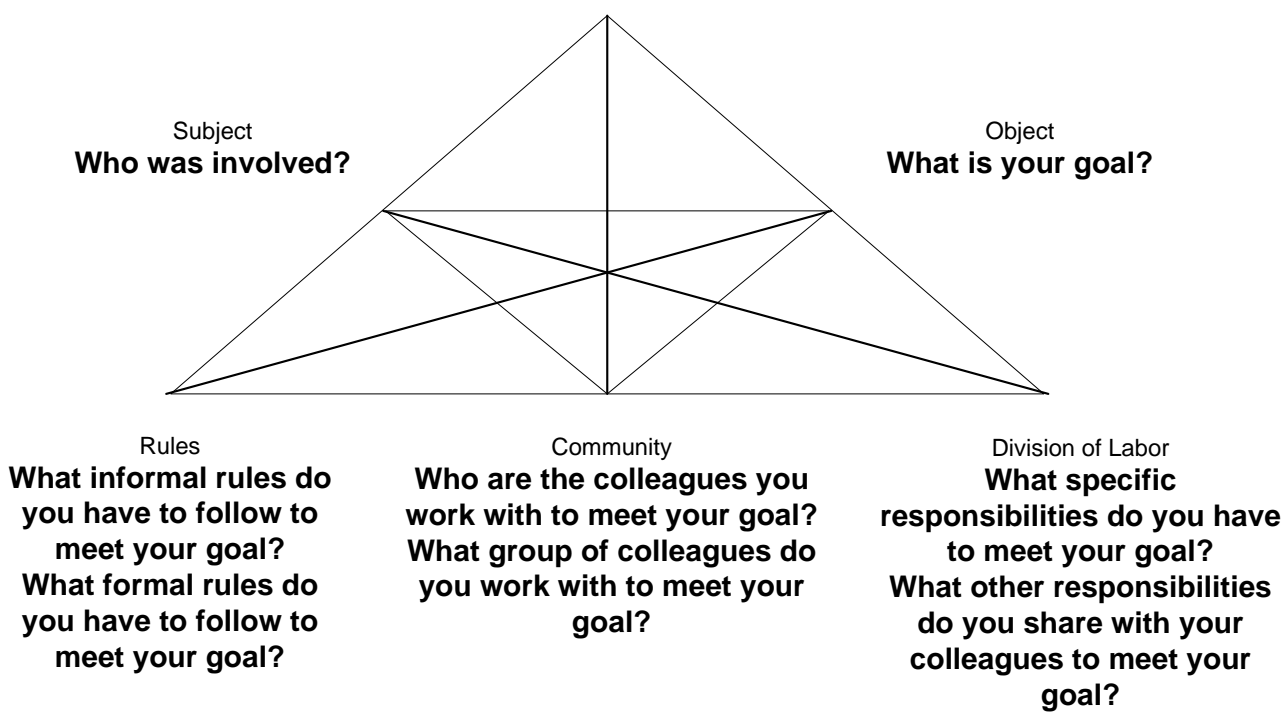

\section{Reflections on Personal Course Activities}

Subject: Participants involved in my recent activities in this course included... 
Tool: Resources related to my course activities were...

Object: My personal goals related to course activities were....

Rules: Formal and informal rules that influenced my course activities were....

Community: Other participants who took a role in my activities were....

Distribution of Labor: The responsibilities that I shared with other participants in these activities were...

The conflicts I found while engaging in course activities were...

The structure of this course helps or impedes my participation in course activities because...

\section{Reflections on How You See Yourself as an Online Learner}

If I were to describe myself as an online learner based on past and current online learning experiences I am...

What I know about myself as an online learner will influence how I design future online courses/ program by...

\section{Athabasca University $\mathbf{1}$}

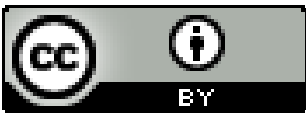




\section{Is Blended e-Learning as Measured by an Achievement Test and Self-Assessment Better than Traditional Classroom Learning for Vocational High School Students?}
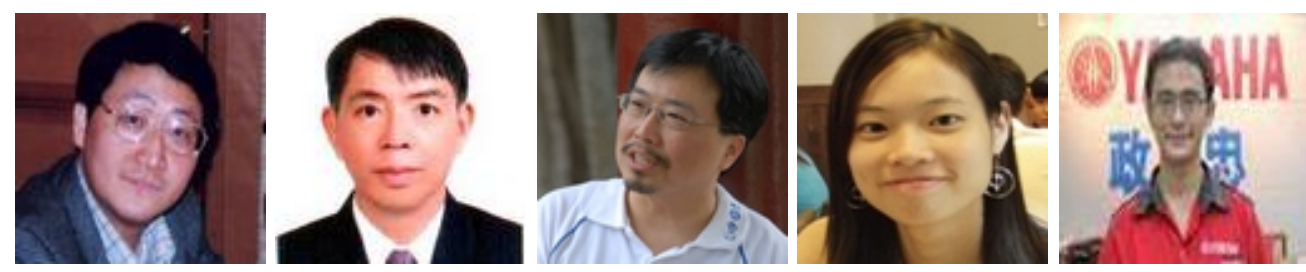

Chi-Cheng Chang ${ }^{1}$, Kuen-Ming Shu' ${ }^{2}$, Chaoyun Liang ${ }^{3}$, Ju-Shih Tseng ${ }^{1}$, and Yu-Sheng Hsu ${ }^{1}$ ${ }^{1}$ National Taiwan Normal University, Taiwan, ${ }^{2}$ National Formosa University, Taiwan, ${ }^{3}$ National Taiwan University, Taiwan

\section{Abstract}

The purpose of this study is to examine the effects of blended e-learning on electrical machinery performance (achievement test and self-assessment). Participants were two classes of 11th graders majoring in electrical engineering and taking the electrical machinery class at a vocational high school in Taiwan. The participants were randomly selected and assigned to either the experimental group $(n=33)$ which studied through blended e-learning or the control group ( $\mathrm{n}=32$ ) which studied through traditional classroom learning. The experiment lasted for five weeks. The results showed that (a) there were no significant differences in achievement test scores between blended elearning and traditional learning; (b) students in the experimental group obtained significantly higher scores on self-assessment than students in the control group; (c) students' scores on self-assessment were significantly higher after studying through blended e-learning than before. Overall, blended e-learning did not significantly affect students' achievement test scores, but significantly affected their self-assessment scores.

Keywords: Blended e-learning; self-assessment; electrical machinery; learning performance 


\section{Introduction}

As information technology has developed over the past years, e-learning technology has shaped education. However, e-learning is not always appropriate to be implemented in all curricula. Some curricula are appropriate to be learned by traditional learning, but some curricula are appropriate to be learned by e-learning, depending on the purposes of each curriculum (Bolliger \& Martindale, 2004). Blended e-learning keeps the advantages of both traditional learning (instructor-oriented) and e-learning (learneroriented) (Bersin, 2004). The drawbacks of e-learning including reduced real interactions and high drop-out rates due to frustration can be covered by the advantages of traditional learning, so students' learning quality and performance can be enhanced (Cottrell \& Robison, 2003; Singh, 2003). Hence, blended e-learning has become a trend in education (Bonk, 2006) and is appropriate to most learners who have different learning styles (Wakefield, Carlisle, Hall, \&Attree, 2008).

In recent years, an increased number of researchers have been involved in studies about blended e-learning. Some of the study results revealed that blended e-learning enhanced students' learning performance (Gülbahar \& Madran, 2009; Usta \& Ozdemir, 2007; Vaughan \& Garrison, 2005). However, different aspects of learning performance that were enhanced by blended e-learning were not further examined. Some studies (Bersin, 2004; Hofmann, 2008; López-Pérez, Pérez-López, \& Rodríguez-Ariza, 2011) stated that blended e-learning had more positive effects than traditional learning, but they mostly focused on higher education or employment training, not on primary and secondary schools. Some studies examined the effects of individual differences or gender on learning performance, such as learning achievement, attitudes, and satisfaction, but they did not compare the results with a control group (Alshwiah, 2009; Lee et al., 2007; Méndez \& González, 2010). Although some study results showed that blended e-learning facilitated students' attitudes toward the course with three aspects, cognition, skill, and attitude (CSA) (Chen \& Lin, 2002), there was a lack of comparison among the effects on the three aspects.

The Employment e-Training Platform in the Project of Multi-Employment e-Training, proposed by the Council of Labor Affairs in Taiwan, focuses on the subjects of electricity, electronics, and food and beverage service, and so on. The learning unit, transformer, may be served as a complement of the electrical machinery course in vocational high schools. Electrical machinery plays an important role in electrical engineering; therefore it is a graduation requirement. The key feature for vocational high schools is practical training programs. Most practical training programs are learning-by-doing. Problems faced by instructors in practical training programs include large size classes and insufficient facilities. Such problems make teachers unable to cater to individual differences and students unable to reach learning goals (Roblyer, 2006). These problems can be overcome when practical training programs are delivered by blended elearning, in which learning activities are extended outside the classroom (Garrison \& Vaughan, 2008). Blended e-learning also promotes greater depth and breadth of learning. Furthermore, practical training programs that are delivered 
through both traditional learning and e-learning will allow students to absorb knowledge and build skills due to repetitive reading and practice (Bersin, 2004). This will enrich and facilitate their learning experiences.

Based on the study background above, the purpose of the present study was to compare the effects of blended e-learning and traditional learning on electrical machinery performance (achievement test and self-assessment). Thus, the statistics were applied in the present study to analyze the differences in learning performance (achievement test and self-assessment) between blended e-learning and traditional learning. The learning material in the present study was the learning unit, transformer, from the Employment e-Training Platform (http://el.evta.gov.tw/). The learning intentions for the learning unit included: cognition, skill, and attitude. Blended e-learning that covers the advantages of both e-learning and traditional learning enables students to learn at their own pace and to practice repeatedly, so it is beneficial to utilize blended e-learning on electrical machinery. The research questions are as follows:

1. Are there any significant differences in electrical machinery achievement test scores between blended e-learning and traditional learning?

2. Are there any significant differences in self-assessment scores with three aspects including cognition, skill, and attitude between blended e-learning and traditional learning?

3. Are there any significant differences in self-assessment scores with three aspects including cognition, skill, and attitude before and after studying through blended e-learning?

\section{Research Method}

\section{Participants}

Participants were two classes of $11^{\text {th }}$ graders, with a total of 65 students, majoring in electrical engineering and taking the electrical machinery class at a vocational high school in Taiwan. The participants were randomly selected and assigned to either the experimental group $(n=33)$ or the control group $(n=32)$. The two groups were taught by the same teacher who had more than 10 years teaching experience and two years experience with blended e-learning.

\section{Experimental Design}

The pretest-posttest nonequivalent-group quasi-experimental design was employed in the present study. The experimental design is shown in Table 1. 
Table 1

Experimental Design

\begin{tabular}{|c|c|c|c|c|}
\hline Group & $\mathrm{N}$ & Pretest & Treatment & Posttest \\
\hline Experimental & 33 & \multirow{2}{*}{$\begin{array}{l}\text { Average score of last } \\
\text { two midterms } \\
\text { Self-assessment }\end{array}$} & $\begin{array}{l}\text { Blended e- } \\
\text { learning }\end{array}$ & \multirow{2}{*}{$\begin{array}{l}\text { Achievement test } \\
\text { Self-assessment }\end{array}$} \\
\hline Control & 32 & & $\begin{array}{l}\text { Traditional } \\
\text { learning }\end{array}$ & \\
\hline
\end{tabular}

\section{Experimental Procedure}

\section{Preparation.}

The teaching schedule and method in the experiment were discussed with the teacher. Before the experiment, an orientation on e-learning and learning guidance was provided to students, so students were ready to take the course through the Internet.

\section{Pretest.}

Students' scores on the last two midterms were collected for examining the homogeneity of both groups. The pretest on self-assessment was administered to students for understanding the assessment on their own performance.

\section{Learning activity.}

The experiment lasted for five weeks, as shown in Table 2, and at three hours per week; so there was a total of fifteen hours. The learning unit was transformer, including its principles, structures, characteristics, connections, tests, and maintenance.

Table 2

Experimental Procedure

\begin{tabular}{|c|c|c|c|c|}
\hline Week & $\begin{array}{l}\text { Learning } \\
\text { method }\end{array}$ & $\begin{array}{l}\text { Number } \\
\text { of class }\end{array}$ & Topic & Learning objectives \\
\hline \multirow[t]{2}{*}{1} & $\begin{array}{l}\text { Traditional } \\
\text { learning }\end{array}$ & 2 & \multirow[t]{2}{*}{$\begin{array}{l}\text { Principles of } \\
\text { transformer }\end{array}$} & \multirow{2}{*}{$\begin{array}{l}\text { Understanding its principle, } \\
\text { equivalent circuit and per- } \\
\text { unit value }\end{array}$} \\
\hline & e-Learning & 1 & & \\
\hline \multirow[t]{2}{*}{2} & $\begin{array}{l}\text { Traditional } \\
\text { learning }\end{array}$ & 2 & \multirow{2}{*}{$\begin{array}{l}\text { Structure and } \\
\text { characteristics of } \\
\text { transformer }\end{array}$} & \multirow{2}{*}{$\begin{array}{l}\text { Understanding its structure, } \\
\text { characteristics and various } \\
\text { computing methods }\end{array}$} \\
\hline & e-Learning & 1 & & \\
\hline \multirow[t]{2}{*}{3} & $\begin{array}{l}\text { Traditional } \\
\text { learning }\end{array}$ & 2 & \multirow[t]{2}{*}{$\begin{array}{l}\text { Connections of } \\
\text { transformer }\end{array}$} & \multirow{2}{*}{$\begin{array}{l}\text { Understanding its polarity } \\
\text { test, three-phase connection } \\
\text { and parallel operation }\end{array}$} \\
\hline & e-Learning & 1 & & \\
\hline \multirow[t]{2}{*}{4} & $\begin{array}{l}\text { Traditional } \\
\text { learning }\end{array}$ & 2 & \multirow{2}{*}{$\begin{array}{l}\text { Tests and } \\
\text { maintenance of } \\
\text { transformer }\end{array}$} & \multirow{2}{*}{$\begin{array}{l}\text { Being familiar with its } \\
\text { measurements of winding } \\
\text { resistance and insulation } \\
\text { resistance, temperature, }\end{array}$} \\
\hline & e-Learning & 1 & & \\
\hline
\end{tabular}




\begin{tabular}{|c|c|c|c|c|}
\hline & & & & $\begin{array}{l}\text { breaking down and impulse } \\
\text { voltage tests, and } \\
\text { maintenance }\end{array}$ \\
\hline \multirow[t]{2}{*}{5} & $\begin{array}{l}\text { Traditional } \\
\text { learning }\end{array}$ & 2 & $\begin{array}{l}\text { Comprehensive } \\
\text { review \& } \\
\text { supplementary } \\
\text { explanation }\end{array}$ & $\begin{array}{l}\text { Being familiar with each } \\
\text { chapter }\end{array}$ \\
\hline & e-Learning & 1 & $\begin{array}{l}\text { Review based on } \\
\text { students' needs }\end{array}$ & \\
\hline
\end{tabular}

The differences between the learning methods of both groups were as follows: a) the control group received face-to-face lectures, paper-based handouts, and teaching materials, with three in-class hours per week; b) the experimental group received two in-class hours per week and one class hour in the computer classroom per week. Students who spent one class hour in the computer classroom logged into the website, Employment e-Training Platform, for access to the learning unit, transformer. The experimental group was supported by review and repeated practices using the website. The activity for blended e-learning was based on the eight learning phases proposed by Baldwin-Evans (2006) and Bielawski and Metcalf (2005), as shown in Table 3. The differences between both groups are shown in Table 4 .

Table 3

Learning Activity for Blended e-Learning

\begin{tabular}{|c|c|c|c|}
\hline Activity & Topic & Description & $\begin{array}{l}\text { Learning } \\
\text { Phase }\end{array}$ \\
\hline \multirow[t]{2}{*}{ Preparation } & Syllabus & $\begin{array}{l}\text { A syllabus was emailed to } \\
\text { students for them to get to know } \\
\text { about the course. }\end{array}$ & Prepare me \\
\hline & $\begin{array}{l}\text { Orientation of } \\
\text { blended e-learning }\end{array}$ & $\begin{array}{l}\text { An introduction of blended e- } \\
\text { learning was delivered for guiding } \\
\text { students how to learn by } \\
\text { providing learning guidance and } \\
\text { supporting students to acquire } \\
\text { learning mechanism and user } \\
\text { guide. }\end{array}$ & $\begin{array}{l}\text { Prepare me } \\
\text { Tell me }\end{array}$ \\
\hline \multirow{2}{*}{$\begin{array}{l}\text { Traditional } \\
\text { learning } \\
\text { (two class } \\
\text { hours ) }\end{array}$} & In-class course & $\begin{array}{l}\text { Lecture on textbook material and } \\
\text { opportunities for students to } \\
\text { practice were provided }\end{array}$ & $\begin{array}{l}\text { Tell me } \\
\text { Show me } \\
\text { Let me }\end{array}$ \\
\hline & Paper-based test & $\begin{array}{l}\text { Understanding students' learning } \\
\text { progress }\end{array}$ & Check me \\
\hline \multirow[t]{2}{*}{$\begin{array}{l}\text { e-Learning } \\
\text { (one class } \\
\text { hour) }\end{array}$} & Online course & $\begin{array}{l}\text { The course content was similar to } \\
\text { the textbook material in } \\
\text { traditional learning, which } \\
\text { provided teacher-led instructions } \\
\text { and assisted students to review. }\end{array}$ & $\begin{array}{l}\text { Tell me } \\
\text { Show me } \\
\text { Let me }\end{array}$ \\
\hline & $\begin{array}{l}\text { Online practice } \\
\text { and test }\end{array}$ & $\begin{array}{l}\text { Online practice and test were } \\
\text { available for each unit, which } \\
\text { enabled students to practice }\end{array}$ & Check me \\
\hline
\end{tabular}




\begin{tabular}{llll}
\hline & & $\begin{array}{l}\text { repeatedly, collect information } \\
\text { and receive feedback for getting } \\
\text { to know their learning progress. }\end{array}$ & \\
\hline $\begin{array}{l}\text { After-class } \\
\text { tutoring }\end{array}$ & $\begin{array}{l}\text { Discussion board } \\
\text { and email support }\end{array}$ & $\begin{array}{l}\text { An opportunity for students to } \\
\text { ask questions via discussion } \\
\text { board or email after the class. }\end{array}$ & $\begin{array}{l}\text { Support me } \\
\text { Coach me } \\
\text { Connect me }\end{array}$ \\
\hline
\end{tabular}

Table 4

Differences Between Both Groups

\begin{tabular}{|c|c|}
\hline $\begin{array}{l}\text { Learning } \\
\text { method }\end{array}$ & Learning activity \\
\hline $\begin{array}{l}\text { Traditional } \\
\text { learning }\end{array}$ & $\begin{array}{l}\text { Lecture (three in-class hours per week) with paper-based handouts, } \\
\text { teaching materials and teaching aids. }\end{array}$ \\
\hline $\begin{array}{l}\text { Blended e- } \\
\text { learning }\end{array}$ & $\begin{array}{l}\text { Lecture (two in-class hours per week) with paper-based handouts, } \\
\text { teaching materials and teaching aids. } \\
\text { The Employment e-Training Platform (one in-class hour per week) } \\
\text { Students could review the course material flexibly through the } \\
\text { learning platform based on their schedule and proficiency. } \\
\text { Students could understand the transformer more through online } \\
\text { practices (Figure 1). } \\
\text { Online test was given after each chapter for students to assess their } \\
\text { own learning condition and discuss with peers and the teacher. }\end{array}$ \\
\hline
\end{tabular}

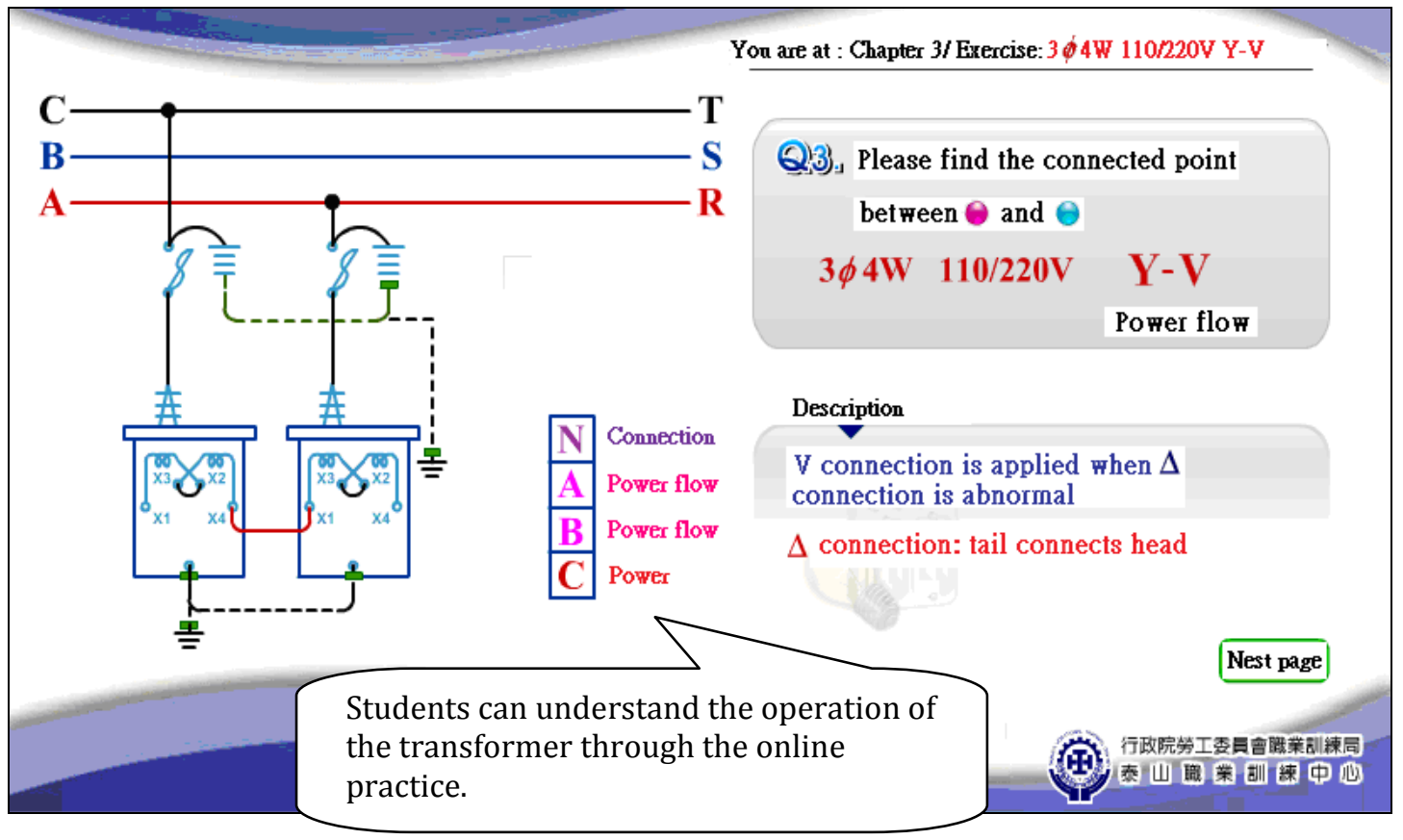

Figure 1. The Employment e-Training Platform Website. 


\section{Posttest.}

The experiment lasted five weeks. After the experiment was over, students in both groups were required to take the posttest, including both achievement test and selfassessment.

\section{Validity and Reliability of Instruments}

\section{1) Achievement test}

The achievement test was designed by the teacher based on the course material. The teacher had ten years of teaching experience on electrical machinery in the vocational high school. The achievement test was used for many years and modified based on the changes to the course materials and students' learning conditions. Therefore, the achievement test applied in the present study contained face validity.

There were 25 multiple-choice questions in the achievement test. The 25 questions were related to the transformer and were categorized into four dimensions, including its principles, structures and characteristics, connections, and tests and maintenance. Item analysis was performed for examining the reliability of the achievement test. The top $27 \%$ of the total scores was assigned to the high score group, whereas the bottom $27 \%$ was assigned to the low score group (Kelley, 1939). A t-test was conducted to examine the differences in the score of each question between the high score group and the low score group. The results showed that there were two insignificant questions, which should be deleted. Pearson's correlation was then performed to examine the relationships between the score of each question and the overall score of the test. The result showed that there was only one insignificant question, which should be deleted.

The difficulty index refers to the percentage of students who answered the item correctly, whereas the discrimination index refers to how well the item discriminates between low and high score groups (Ebel \& Frisbie, 1991). The calculating formula for the difficulty index $(\mathrm{P})$ is $\left(\mathrm{P}_{\mathrm{h}}+\mathrm{P}_{1}\right) / 2$ and the discrimination index (D) is $\mathrm{P}_{\mathrm{h}}-\mathrm{P}_{1}$.

If the difficulty index of an item is close to .5, the item has a moderate level of difficulty; if it is less than .25, the item is difficult; and if it is greater than .75 , the item is easy (Ebel \& Frisbie, 1991). The difficulty index for items in the achievement test ranged from .17 to .64 . The overall difficulty index for the achievement test was .36, meaning that the difficulty level of the test was between moderate and difficult.

On the other hand, if the discrimination index of an item is greater than .4, the item is excellent; if it is greater than .3 and less than .4, the item is good; and the minimum standard for the discrimination index is .25 (Ebel \& Frisbie, 1991). The discrimination indices for items in the achievement test were greater than .25, with three items greater than .3 and five items greater than .4. The overall discrimination index for the achievement test was .43 , meaning that the discrimination level of the test was excellent. 


\section{2) Self-assessment}

According to the literature review, a self-assessment questionnaire about blended elearning developed by the study contained three aspects: cognition ( 5 items), skill (5 items), and attitude (6 items) (see Appendix). In total, there were 16 items in the questionnaire. The self-assessment questionnaire was revised several times by the researcher and the teacher, so it possessed content validity.

a) Item analysis

The top $27 \%$ of the total scores was assigned to the high score group, whereas the bottom $27 \%$ was assigned to the low score group (Kelley, 1939). Independent samples ttest was conducted to examine the differences in the score of each item between both groups. The results revealed that $t$ values of all items were significant, indicating that the questionnaire possessed a good discrimination level. Pearson's correlation was then performed to examine the relationships between the score of each question and the overall score of the test. The result was consistent, so no item was deleted.

b) Factor analysis

The Kaiser-Meyer-Olkin (KMO) index was greater than .5 and the Bartlett test of sphericity was significant (see Table 5), indicating that factor analysis could be performed (Gravetter \& Wallnau, 2008; Kaiser, 1974). Principal component analysis (PCA) with an orthogonal rotation was conducted to examine the construct validity. The result showed that factor loading for each item was greater than .5, indicating that there was no need to delete items (Hair, Black, Babin, \& Anderson, 2010). Factors with eigenvalues greater than 1 were extracted, including cognition, skill, and attitude. The explained variances of the three aspects were all greater than $50 \%$, revealing that the questionnaire possessed good construct validity (Hair et al., 2010), as shown in Table 5.

c) Reliability

Cronbach's $\alpha$ for each aspect in the questionnaire was greater than .7, indicating that the questionnaire had a good reliability (Bryman \& Cramer, 2011). 
Table 5

Validity of Self-Assessment Questionnaire

\begin{tabular}{llllll}
\hline \multirow{2}{*}{ Item } & \multirow{2}{*}{ KMO } & \multirow{2}{*}{ Explained variance } & \multicolumn{2}{l}{ Bartlett test of sphericity } & \\
\cline { 4 - 5 } & & & \multirow{2}{*}{ Chi-square } & \multirow{2}{*}{ Sig. } & \multirow{2}{*}{ Cronbach's $\alpha$} \\
& & & 115.460 & $.000^{* * *}$ & .779 \\
\hline Cognition & .681 & $54.267 \%$ & 125.995 & $.000^{* * *}$ & .821 \\
\hline Skill & .738 & $58.676 \%$ & 98.776 & $.000^{* * *}$ & .700 \\
\hline Attitude & .538 & $63.149 \%$ & & & \\
\hline
\end{tabular}
$* * * p<.001$

Results

\section{The Differences on the Achievement Test Scores Between Blended e-Learning and Traditional Learning (Research Question 1)}

The average score of the last two midterms on electrical machinery was applied as the covariance for preventing the interruptions of prior knowledge. ANCOVA was performed to examine the differences on achievement test scores between blended elearning and traditional learning. Levene's test of equality of covariance was insignificant ( $p=.858)$, meaning that the variance of pretest score was equal across groups and the homogeneity assumption was sustained, as shown in Table 6. Furthermore, regression slope appeared insignificant, suggesting that the relationship between the covariance and the dependent variable (posttest score) would not be affected by the independent variables, and the homogeneity assumption was sustained.

Table 6

Test of Homogeneity for Achievement Test Scores of Both Groups

\begin{tabular}{llll}
\hline Levene's test & \multicolumn{3}{c}{ Regression slope } \\
\hline F & Sig. & F & Sig. \\
\hline .032 & .858 & .151 & .699 \\
\hline
\end{tabular}

The average score on the achievement test for the experimental group was slightly higher than that for the control group, but ANCOVA showed an insignificant result ( $p=$ .825), as shown in Table 7 and 8. This result revealed that the difference between both 
groups was not significant, indicating that blended e-learning did not significantly affect achievement test scores.

Table 7

Descriptive Statistics for Achievement Test Scores of Both Groups

\begin{tabular}{llllllll}
\hline $\begin{array}{l}\text { Experimental } \\
\text { group }\end{array}$ & \multicolumn{2}{l}{ Control group } & \multicolumn{2}{l}{ Experimental group } & \multicolumn{2}{l}{ Control group } \\
\hline $\mathrm{M}$ & $\mathrm{SD}$ & $\mathrm{M}$ & $\mathrm{SD}$ & $\begin{array}{l}\text { Adjusted } \\
\mathrm{M}\end{array}$ & $\begin{array}{l}\text { Adjusted } \\
\text { SD }\end{array}$ & $\begin{array}{l}\text { Adjusted } \\
\mathrm{M}\end{array}$ & $\begin{array}{l}\text { Adjusted } \\
\text { SD }\end{array}$ \\
\hline $\begin{array}{l}35.394 \\
220.990\end{array}$ & $\begin{array}{l}33.75 \\
0\end{array}$ & 19.141 & 35.092 & 3.252 & 34.061 & 3.302 \\
\hline
\end{tabular}

Table 8

ANCOVA Summary on Achievement Test Scores of Both Groups

\begin{tabular}{lrlllll}
\hline Source & $\begin{array}{l}\text { Sum of } \\
\text { squares }\end{array}$ & df & $\begin{array}{l}\text { Mean } \\
\text { square }\end{array}$ & F & Sig. & Effect size \\
\hline $\begin{array}{l}\text { Covariance } \\
\text { (average score of } \\
\text { the last two } \\
\text { midterms) }\end{array}$ & 3823.814 & 1 & 3823.814 & 10.967 & $.002^{* *}$ & .150 \\
\hline $\begin{array}{l}\text { Between-group } \\
\text { (learning mode) }\end{array}$ & 17.250 & 1 & 17.250 & .049 & .825 & .001 \\
\hline $\begin{array}{l}\text { Within-group } \\
\text { (error) }\end{array}$ & 21618.065 & 62 & 348.678 & & & \\
\hline Total & 25485.785 & 64 & & & & \\
\hline
\end{tabular}

\section{The Differences on the Self-Assessment Between Blended e- Learning and Traditional Learning (Research Question 2)}

The MANCOVA with the pretest score of self-assessment as the covariance was performed to examine the differences on self-assessment scores between blended elearning and traditional learning. As shown in Table 9, Box's test of equality of covariance matrices and Levene's test of equality of covariance were insignificant, meaning that the variance of cognition, skill, and attitude was equal across groups and the homogeneity assumption was sustained. Furthermore, Wilk's $\Lambda(p=.250)$ and regression slope appeared insignificant, suggesting that the homogeneity assumption was sustained and the covariance had the same degree of impact to the participants. 
Table 9

Test of Homogeneity for Posttests on Self-Assessment of Both Groups

\begin{tabular}{|c|c|c|c|c|c|c|}
\hline \multirow{2}{*}{$\begin{array}{l}\text { Dependent } \\
\text { variables }\end{array}$} & \multirow{2}{*}{$\begin{array}{l}\text { Box's } \\
\text { M } \\
\text { (Sig.) }\end{array}$} & \multicolumn{2}{|c|}{ Levene's test } & \multirow{2}{*}{$\begin{array}{l}\text { Wilk's } \Lambda \\
\text { (Sig.) }\end{array}$} & \multicolumn{2}{|c|}{ Regression slope } \\
\hline & & $\mathrm{F}$ & Sig. & & $\mathrm{F}$ & Sig. \\
\hline Cognition & \multirow{4}{*}{$\begin{array}{l}6.614 \\
(.802)\end{array}$} & .606 & .439 & \multirow{4}{*}{$\begin{array}{l}.913 \\
(.250)\end{array}$} & 1.714 & .195 \\
\hline Skill & & .621 & .434 & & 2.951 & .091 \\
\hline Attitude & & .045 & .833 & & 1.115 & .295 \\
\hline Overall & & .285 & .596 & & 2.495 & .119 \\
\hline
\end{tabular}

As shown in Table 10 , Wilk's $\Lambda$ ( $\mathrm{p}<.01)$ showed a significant result, indicating that students in both groups had significant differences in at least one dependent variable (cognition, skill, and attitude). The result revealed that there were significant differences in cognition ( $F=13.309 ; \mathrm{p}<.01)$ and skill $(\mathrm{F}=6.246$; $\mathrm{p}<.05)$ between the two groups, but there was no significant difference in attitude $(F=3.455 ; \mathrm{p}=.068)$. The experimental group had significantly higher adjusted means on cognition, skill, and overall self-assessment than the control group, as shown in Table 11, indicating that blended e-learning students were significantly better than traditional learning students in cognition and skill.

Table 10

MANCOVA Summary on Self-Assessment Scores of Both Groups

\begin{tabular}{|c|c|c|c|c|c|c|c|c|}
\hline $\begin{array}{l}\text { Wilk's } \Lambda \\
\text { (Sig.) }\end{array}$ & Source & $\begin{array}{l}\text { Dependent } \\
\text { variables }\end{array}$ & $\begin{array}{l}\text { Sum of } \\
\text { squares }\end{array}$ & $\mathrm{df}$ & $\begin{array}{l}\text { Mean } \\
\text { square }\end{array}$ & $\mathrm{F}$ & Sig. & $\begin{array}{l}\text { Effect } \\
\text { size }\end{array}$ \\
\hline \multirow{16}{*}{$\begin{array}{l}.791 \\
\left(.007^{* *}\right)\end{array}$} & \multirow[t]{4}{*}{ Covariance } & Cognition & 3.860 & 1 & 3.860 & 13.593 & $.000 * * *$ & .180 \\
\hline & & Skill & 5.671 & 1 & 5.671 & 15.238 & $.000 * * *$ & .197 \\
\hline & & Attitude & 5.387 & 1 & 5.387 & 16.621 & $.000 * * *$ & .211 \\
\hline & & Overall & 4.964 & 1 & 4.964 & 20.770 & $.000 * * *$ & .251 \\
\hline & \multirow{4}{*}{$\begin{array}{l}\text { Between- } \\
\text { group }\end{array}$} & Cognition & 3.779 & 1 & 3.779 & 13.309 & $.001^{* *}$ & .177 \\
\hline & & Skill & 2.325 & 1 & 2.325 & 6.246 & $.015^{*}$ & .092 \\
\hline & & Attitude & 1.120 & 1 & 1.120 & 3.455 & .068 & .053 \\
\hline & & Overall & 2.196 & 1 & 2.196 & 9.186 & $.004^{* *}$ & .129 \\
\hline & \multirow{4}{*}{$\begin{array}{l}\text { Within- } \\
\text { group }\end{array}$} & Cognition & 17.605 & 62 & .284 & & & \\
\hline & & Skill & 23.074 & 62 & .372 & & & \\
\hline & & Attitude & 20.094 & 62 & .324 & & & \\
\hline & & Overall & 14.818 & 62 & .239 & & & \\
\hline & \multirow[t]{4}{*}{ Overall } & Cognition & 24.138 & 64 & & & & \\
\hline & & Skill & 30.041 & 64 & & & & \\
\hline & & Attitude & 25.938 & 64 & & & & \\
\hline & & Overall & 21.038 & 64 & & & & \\
\hline
\end{tabular}

$* \mathrm{p}<.05, * * \mathrm{p}<01, * * * \mathrm{p}<001$ 
Table 11

Descriptive Statistics for Self-Assessment of Both Groups

\begin{tabular}{lllllllll}
\hline \multirow{2}{*}{ Aspects } & \multicolumn{2}{l}{$\begin{array}{l}\text { Experimental } \\
\text { group }\end{array}$} & \multicolumn{2}{c}{ Control group } & \multicolumn{2}{l}{$\begin{array}{l}\text { Experimental } \\
\text { group }\end{array}$} & \multicolumn{3}{l}{$\begin{array}{l}\text { Experimental } \\
\text { group }\end{array}$} \\
\cline { 2 - 9 } & $\mathrm{M}$ & $\mathrm{SD}$ & $\mathrm{M}$ & $\mathrm{SD}$ & $\mathrm{M}$ & $\mathrm{SD}$ & $\mathrm{M}$ & $\mathrm{SD}$ \\
\hline Cognition & 3.62 & .52 & 3.21 & .64 & 3.66 & .09 & 3.17 & .10 \\
\hline Skill & 3.36 & .65 & 3.08 & .70 & 3.41 & .11 & 3.03 & .11 \\
\hline Attitude & 3.45 & .58 & 3.28 & .69 & 3.50 & .10 & 3.23 & .10 \\
\hline Overall & 3.48 & .50 & 3.20 & .57 & 3.52 & .09 & 3.15 & .09 \\
\hline
\end{tabular}

The criteria for determining the effect size of MANCOVA are: $\eta^{2}$ of .010 is a small effect, $\eta^{2}$ of .059 is a medium effect, and $\eta^{2}$ of .138 or above is a large effect (Cohen, 1988). Among the effect sizes for the three aspects of self-assessment, cognition had the largest effect $\left(\eta^{2}=.177\right)$, indicating a high correlation, and skill had a medium correlation $\left(\eta^{2}=\right.$ .092). In other words, blended e-learning had a high effect on students' cognition and a medium effect on students' skill. After the five-week experiment, there were significant differences on cognition and skill between both groups, but there was no significant difference on attitude.

For the overall self-assessment, there was a significant difference between both groups. The effect size $\left(\eta^{2}\right)$ of the overall self-assessment was .129, indicating a medium correlation between blended e-learning and students' overall self-assessment score.

\section{The Differences on the Self-Assessment Before and After the Blended e-Learning (Research Question 3)}

Paired-samples t-test was conducted to examine the differences before and after the blended e-learning. As shown in Table 12, there were significant differences on the overall self-assessment, including three aspects, cognition, skill, and attitude, before and after blended e-learning. This result implied that blended e-learning had a significant impact on students' self-assessment, which confirmed the study done by Chen and Lin (2002).

The effect size of the t-test on each aspect of self-assessment is shown in Table 12 . Cohen (1988) proposed an effect size coefficient, called Cohen's d, for examining the difference in outcome before and after the treatment. The formula for Cohen's $d$ was the mean score of the pretest $\left(\mu_{1}\right)$ subtracted from the mean score of the posttest $\left(\mu_{2}\right)$, and then divided by the standard deviation $\left(\sigma_{1}\right)$ of the pretest, as shown in the following:

$$
\text { Cohen's } \mathrm{d}=\left(\mu_{2}-\mu_{1}\right) / \sigma_{1}
$$


The criteria for determining the effect size of t-test are: $\eta^{2}$ of .2 or below is a small effect, $\eta^{2}$ between .5 and .8 is a medium to large effect, and $\eta^{2}$ of .8 or above is a large effect (Cohen, 1988). The effect sizes for the three aspects of self-assessment and the overall self-assessment were medium to large, revealing that blended e-learning enhanced students' self-assessment scores on electrical machinery (cognition, skill, attitude, and overall).

Table 12

Paired-Samples t-Test on Self-Assessment Scores for the Experimental Group

\begin{tabular}{llllllll}
\hline \multirow{2}{*}{ Aspects } & Pretest & \multicolumn{3}{c}{ Posttest } & \multirow{3}{*}{$\begin{array}{c}\text { Effect } \\
\text { size }\end{array}$} & Sig. \\
\cline { 2 - 5 } & $\mathrm{M}$ & $\mathrm{SD}$ & $\mathrm{M}$ & $\mathrm{SD}$ & & .52 & \\
\hline Cognition & 3.24 & .58 & 3.62 & .52 & 2.801 & .66 & $.009^{* *}$ \\
\hline Skill & 2.88 & .60 & 3.36 & .65 & 3.294 & .81 & $.002^{* *}$ \\
\hline Attitude & 2.76 & .49 & 3.45 & .58 & 5.766 & 1.40 & $.000^{* * *}$ \\
\hline Overall & 2.95 & .38 & 3.48 & .50 & 5.742 & 1.40 & $.000^{* * *}$ \\
\hline
\end{tabular}

$* * \mathrm{p}<.01, * * * \mathrm{p}<.001$

\section{Discussion}

For research questions 1 and 2, there were no significant differences on achievement test scores between both groups, but there were significant differences on selfassessment scores. The experimental group had significantly higher self-assessment scores than the control group, indicating that the experimental group had more positive perceptions of blended e-learning but did not significantly outperform the control group in the achievement test. A possible explanation is that it was the first time for the experimental group to experience blended e-learning which led to significantly higher scores on the self-assessment than the control group. However, the course implemented in the study lasted only five weeks which was not enough time for students to get used to blended e-learning, so there was no significant difference in achievement test scores between both groups. The effect of blended e-learning on achievement test scores should be examined in the long run, so that students have enough time to get used to blended e-learning which can be a complement to traditional learning. The differences on achievement test scores between both groups can be further understood when the course lasts two or more months.

For research questions 2 and 3, there were significant differences on self-assessment scores between both groups; and there was also a significant difference on selfassessment scores for the experimental group before and after the blended e-learning. This result confirmed that blended e-learning can enhance students' self-assessed 
learning performance (Chen \& Lin, 2002; Garrison \& Vaughan, 2008; Kim, Bonk, \& Teng, 2009; Usta \& Ozdemir, 2007; Vaughan \& Garrison, 2005).

By comparing with traditional learning, students who learned through blended elearning had more positive perceptions of cognition and skill because blended elearning can make up for the drawbacks of traditional learning. The explanation for it is that blended e-learning provides both a traditional learning and an e-learning environment at the same time, which enables students to review the material repeatedly and discuss with peers online. However, there was no significant difference on attitude between both groups because the development of attitude was slower, which confirmed the viewpoint proposed by Linn and Miller (2005).

Conclusion and Implication

\section{Implication for Practice}

For blended e-learning, teachers need to put more efforts into and spend more time on interactions with students (including classroom and the Internet) than teachers in traditional learning (Rovai \&J ordan, 2004). Students in the experimental group did not have prior experience of blended e-learning. Peer discussions and interactions were less frequent on the Internet because students did not get used to an e-learning environment. Therefore, teachers are not only required to encourage students to discuss issues with peers, but they are also required to engage in students' discussions for enhancing peer interactions (Hiltz \& Goldman, 2005).

The purpose of the Employment e-Training Platform was to fulfill students' workplace needs and remove employment barriers. Hence, the platform was revised each year by interacting with industry. In order to help vocational high school students meet requirements in the workplace, it is recommended that the Bureau of Employment and Vocational Training in Taiwan communicates and cooperates with industries and academics. By doing so, teaching materials from both vocational high schools and employment training organizations can be shared with each other, and vocational high school teachers can employ the learning materials in the Employment e-Training Platform for blended e-learning and hence enhance students' knowledge and skills.

The study results revealed that blended e-learning had significantly positive effects on self-assessed cognition and skill. It is recommended that the Employment e-Training Platform adds more course content and materials with animated simulation. It was found that blended e-learning had no significant impact on students' achievement test scores, but significantly affected self-assessment scores. Therefore, it is suggested that teachers who engage in blended e-learning should not only assess students' learning 
performance by achievement tests, but also by self-assessment, so students' learning performance can be assessed both objectively and subjectively.

\section{Limitation and Future Work}

The sequence of the learning activities in the present study was traditional learning followed by e-learning, because e-learning was considered as a supporting learning tool that was provided after class. However, the role of e-learning can be considered differently, such as a learning tool for the course preview. It is suggested that the sequence of the learning activities in future studies can be that e-learning comes before traditional learning. Finally, the study results from both learning sequences (traditional learning comes before e-learning vs. e-learning comes before traditional learning) can be compared and examined in a future study. 


\section{References}

Alshwiah, A. (2009). The effects of a blended learning strategy in teaching vocabulary on premedical students' achievement, satisfaction and attitude toward English language (Unpublished master thesis). Arabian Gulf University, Bahrain.

Baldwin-Evans, K. (2006). Key steps to implementing a successful blended learning strategy. Industrial and Commercial Training, 38(3), 156-163.

Bersin, J . (2004). The blended learning book: Best practices, proven methodologies, and lessons learned. San Francisco, CA: Pfeiffer.

Bielawski, L., \& Metcalf, D. (2005). Blended eLearning: Integrating knowledge, performance support, and online learning ( $2^{\text {nd }}$ ed.). Amherst, MA: HRD Press.

Bolliger, D. U., \& Martindale, T. (2004). Keys factors for determining student satisfaction in online courses. International J ournal of E-Learning, 3(1), 61-67.

Bonk, C. J . (2006). The future of online teaching and learning in higher education. Educause Quarterly, 11(4), 22-30.

Bryman, A., \& Cramer, D. (2011). Quantitative data analysis with IBM SPSS 17, 18 \& 19: A guide for social scientists. London, UK: Psychology Press.

Chen, N. S., \& Lin, K. M. (2002). Analysis of learning behavior and learning performance in WBI. J ournal of Information Management, 8(2), 121-133.

Cohen, J . (1988). Statistical power analysis for the behavioral science ( $2^{\text {nd }}$ ed.). Hillsdale, NJ : Lawrence Erlbaum Associates.

Cottrell, D. M., \& Robison, R. A. (2003). Blended learning in an accounting course. The Quarterly Review of Distance Education, 4(3), 261-269.

Ebel, R. L., \& Frisbie, D. A. (1991). Essentials of educational measurement. Englewood, NJ : Prentice Hall.

Garrison, D. M., \&Vaughan, N. D. (2008). Blended learning in higher education: Framework, principles, and guidelines. San Francisco, CA: J ossey-Bass.

Gravetter, F. J ., \&Wallnau, L. B. (2008). Statistics for behavioral science (7th ed.). Belmont, CA: Thomson.

Gülbahar, Y., \& Madran, R. (2009). Communication and collaboration, satisfaction, equity, and autonomy in blended learning environments: A case from Turkey. International Review of Research in Open and Distance Learning, 10(2), 117138. 
Hair, J . F., Black, W. C., Babin, B. J ., \&Anderson, R. E. (2010). Multivariate data analysis: A global perspective. NewJ ersey, USA: Pearson Education.

Hiltz, S. R., \& Goldman, R. (2005). Learning together online: Research on asynchronous learning networks. Mahwah, NJ : Lawrence Erlbaum Associates.

Hofmann, A. (2008). Development in blended learning. Economics and organization of enterprise, 1(1), 55-62.

Kaiser, H. F. (1974). Little J iffy, Mark IV. Educational and Psychological Measurement, 34, 111-117.

Kelley, T. L. (1939). The selection of upper and lower groups for the validation of test items. J ournal of Educational Psychology, 30(1), 17-24.

Kim, K. J ., Bonk, C. J ., \& Teng, Y. T. (2009). The present state and future trends of blended learning in workplace learning settings across five countries. Asia Pacific Education Review, 10(3), 299-308.

Lee, C., Yeh, D., Kung, R., \&Hsu, C. (2007). The influences of learning portfolios and attitudes on learning effects in blended e-learning for Mathematics. J ournal of Educational Computing Research, 37(4), 331-350.

Linn, R. L., \& Miller, M, D. (2005). Measurement and assessment in teaching (9th ed.). Englewood Cliffs, NJ : Prentice-Hall.

López-Pérez, M. V., Pérez-López, M. C., \& Rodríguez-Ariza, L. (2011). Blended learning in higher education: Students' perceptions and their relation to outcomes. Computers \&Education, 56(3), 818-826.

Méndez, J . A., \& González, E. J . (2010). A reactive blended learning proposal for an introductory control engineering course. Computers \& Education, 54(4), 856865.

Roblyer, M. D. (2006). Integrating educational technology into teaching ( $4^{\text {th }}$ ed.). Upper Saddle River, NJ : Pearson/ Merrill Prentice Hall.

Rovai, A. P., \&J ordan, H. M. (2004). Blended learning and sense of community: A comparative analysis with traditional and fully online graduate courses. International Review of Research in Open and Distance Learning, 5(2), 1-13.

Singh, H. (2003). Building effective blended learning programs. Education and Technology, 43(6), 51-54.

Usta, E., \& Ozdemir, S. M. (2007). An analysis of students' opinions about blended learning environment. Paper presented at the International Educational Technology (IETC) Conference, Nicosia, Turkey. 
Vaughan, N., \& Garrison, D. R. (2005). Creating cognitive presence in a blended faculty development community. Internet and Higher Education, 8(1), 1-12.

Wakefield, A. B., Carlisle, C., Hall, A. G., \&Attree M. J . (2008). The expectations and experiences of blended learning approaches to patient safety education. Nurse Education in Practice, 8(1), 54-61. 


\section{Appendix}

\section{Questionnaire for Self-Assessment on Electrical Machinery Course}

\begin{tabular}{|l|l|}
\hline & Extremely
\end{tabular}

Disagree /

Disagree /

Neutral /

Agree /

Extremely Agree

1. Cognition

1. I think this course is helpful to me in improving knowledge about electrical machinery.

2. I think this course is helpful to me in retaining knowledge about electrical machinery

3. I think this course is helpful to me in understanding the structure of electrical machinery

4. I think this course is helpful to me in understanding the characteristic of electrical machinery

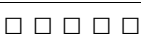

प्र००

무

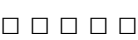

무

5. I think this course is helpful to me in understanding the principle of electrical machinery

2. Skill

6. I think this course is helpful to me in improving my skill of electrical machinery.

7. I think this course is helpful to me in keeping retaining my skill of electrical machinery.

8. I think this course is helpful to me in operating electrical machinery.

9. I think this course is helpful to my data collection ability.

10. I think this course is helpful to me in doing electrical machinery assignments.

3. Attitude

11. I think this course is helpful to me in enhancing my interest in electrical machinery

12. I think this course is helpful to me in enhancing my learning efficiency for electrical machinery

13. I think this course is helpful to me in facilitating my thinking about electrical machinery.

14. I think this course is helpful to me in discussing the homework for electrical machinery.

15. I think this course is helpful in interacting with peers.

16. I think this course is helpful in interacting with teachers.

प्व००

무

प्व००

ด्व०

प्व००

प्र००

\section{Athabasca University $\mathbf{I}$}

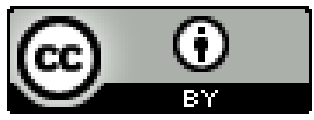




\section{Neither the Frying Pan nor the Fire: In Search of a Balanced Authentic e-Learning Design through an Educational Design Research Process}
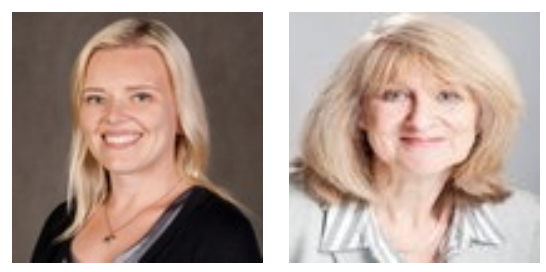

Hanna Teräs ${ }^{1}$ and Jan Herrington ${ }^{2}$

${ }^{1}$ Curtin University, Australia, ${ }^{2}$ Murdoch University, Australia

\section{Abstract}

Teaching in higher education in the 21st century can be a demanding and complex role and academic educators around the globe are dealing with questions related to change. This paper describes a new type of a professional development program for teaching faculty, using a pedagogical model based on the principles of authentic e-learning. The program was developed with the help of an iterative educational design research process and rapid prototyping based on on-going research and redesign. This paper describes how the findings of the evaluations guided the design process and how the impact of the measures taken was in turn researched, in order to eventually identify and refine design principles for an authentic e-learning program for international teaching faculty professional development.

Keywords: Authentic learning; e-learning; educational design research; professional development 


\section{Introduction}

Being a teacher in higher education in the 21st century is, in many ways, a demanding and complex place to be. Academic educators everywhere are dealing with questions related to change: the pressure of integrating technology in education, changing curriculum, quality standards and measures, and increasingly multicultural and diverse groups of learners. For many teachers, the mysterious "net generation" learners that populate universities provide further pressure to be "innovative" to meet their different learning needs. Very often, however, little or no adequate training is provided, and opportunities for informed discussion and critical evaluation of the ever-changing world outside the university gates are scarce. Innovation also tends to be translated quite literally as "technology", whereas pedagogy-either online or offline-seldom receives equal attention.

These realities motivated Tampere University of Applied Sciences (TAMK) to design 21st Century Educators, an international, fully online postgraduate certificate program that was designed for teachers in higher education to enhance their theoretical understanding as well as practical application of teaching, learning, assessment, and education technology in the global knowledge economy context. The learning design of the program was based on the principles of authentic e-learning as described by Herrington, Reeves, and Oliver (2010), and it was developed and implemented using an iterative educational design research process (e.g., Reeves, McKenney, \& Herrington, 2011; Reeves, 2011; McKenney \& Reeves, 2012).

Typically for educational design research, the goal of the research process is twofold. One of the goals is practice-driven: to design an intervention (in this case, a postgraduate certificate program) as a useful solution to a complex educational problem (lack of support and professional development resources for higher education teachers in an increasingly complex, global working environment). The other goal is theoryoriented: to produce knowledge about whether and why a certain type of intervention (a fully online program based on authentic e-learning principles) works effectively in a given context (multicultural cohort studying alongside teaching work) and, based on this knowledge, produce design principles that may assist designers in other projects to develop effective and workable interventions (Plomp, 2007).

This paper discusses the stages of formative evaluation and the resulting redesign in the research process. We will describe how the findings of the evaluations guided the design process and how the impact of the measures taken was in turn evaluated, in order to eventually tighten the net and identify design principles for an authentic e-learning program for international teaching faculty. 


\section{Why Educational Design Research?}

Educational design research was chosen to guide this particular research context primarily because there was a complex educational problem that had to be addressed in a way that would have potential for high-level practical impact and relevance (Plomp, 2007; Anderson \& Shattuck, 2012). Unfortunately, as much as the latter might expect to be the default in any research, this is not always the case. Reeves, McKenney, and Herrington (2011) ask a very fundamental question: Why is it that while the number of educational research publications has increased dramatically, at the same time educational attainment is either declining or remaining stagnant? Reeves (2011) suggests that one of the reasons for this is that most studies concentrate on the wrong variables: Instead of meaningful pedagogical dimensions, such as design factors, feedback, or aligning learning outcomes and assessment, the focus tends to be on comparing instructional delivery methods, such as traditional versus online instruction, face-to-face versus video lectures, or computer-based versus pencil and paper assessment. As Reeves observes, these types of studies almost without exception render results of "no significant differences" (Reeves, 2011), and thus they do not have the potential to significantly improve educational practice either. Indeed, Reeves labelled

such research "pseudoscience" and claimed it was so flawed that it has little relevance "for anyone other than the people who conduct and publish it" (Reeves, 1995, p. 9).

\section{Characteristics of Educational Design Research}

Although there are subtle variations, design research is also known as design-based research (Kelly, 2003), development research (van den Akker, 1999), and design experiments (Brown, 1992). As such, it is a research approach that has the capacity to address complex and relevant educational problems for which there are no clear guidelines or solutions available (Anderson \& Shattuck, 2012). The approach is very different from the comparative research approach criticized by Reeves: Instead of attempting to compare whether method $\mathrm{A}$ is better in a given context than method $\mathrm{B}$, the aim is to develop an optimal, research-based solution for the problem, perhaps best described by Reeves (1999) as seeking “to improve, not to prove” (p. 18).

Although educational design research has one foot firmly in practice, the other one is just as firmly in theory. In the words of Cobb, Confrey, diSessa, Lehrer, and Shauble (2003), 'the theory must do real work' (p. 10). According to McKenney and Reeves (2012), the unusual characteristic of the theoretical orientation in educational design research is that scientific understanding is not only used to frame the research, but also to shape the design of the intervention. The hypotheses embodied in the design are validated, refined, or refuted through empirical testing, evolving through multiple cycles of development, testing, and refinement. Figure 1 illustrates these iterative phases of the approach, as depicted by Reeves (2006). 


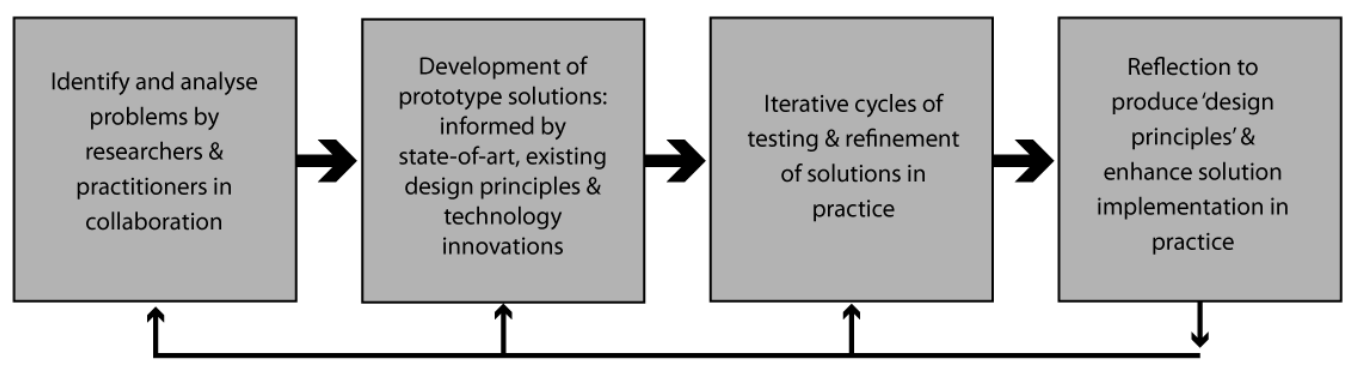

Figure 1. Stages of educational design research (Reeves, 2006, p. 59).

The role of evaluation in design research is paramount: A design is continuously improved based on information gained through evaluation. In the next section, we describe the critical role of evaluation in educational design research.

\section{Evaluation in an Educational Design Research Process}

Evaluation - either formal or informal-is always a part of developing almost any kind of educational intervention. In design research, evaluation is systematic, and it aims at concurrently producing theoretical knowledge and developing the intervention. Evaluation is accompanied with reflection upon findings and observations to refine theoretical understanding and inform decisions for a redesign (Reeves \& Hedberg, 2003). Anyone who has been involved in designing an educational intervention of any sort will know that there can be a major gap between the intention and the actual outcomes. Van den Akker (2003) makes a distinction between three representations of a curriculum: the intended, the implemented, and the attained. The same distinction is useful also from the educational design research point of view. Table 1 below illustrates this.

Table 1

Three Forms of an Intervention (adapted from van den Akker, 2003, p. 3)

Intended intervention Ideal, written

Implemented intervention Perceived, operational

Attained intervention Experiential, learned
What the intervention sets out to do

How the intervention is used in practice

What the outcomes of the intervention are

In an educational design research process, interventions are carried out in actual settings instead of a controlled test environment. This can be seen as a limitation, but, 
on the other hand, the strength of educational design research is that it is authentic and provides information of how designs work in real life, not only in ideal, controlled settings that have little to do with the complexity of an actual classroom (Collins, J oseph, \& Bielaczyc, 2004; Reeves, 2006). In the current study, this was seen as especially important for adult learners who were taking the program alongside very demanding and hectic work schedules, had family responsibilities, and whose learning was thus affected by the whole spectrum of real life events. Therefore, the implemented and attained forms of the intervention (see Table 1) are directly influenced by the complexity of the real life context within which it was implemented.

In the following sections, the aforementioned factors will be considered in more detail, specifically by introducing the educational problem that necessitated the design research process as well as the real life context where the intervention would take place; by describing the intended intervention and introducing the design principles that were used, explaining why they were chosen, and describing what the intervention was intended to achieve; and finally by presenting an analysis of the implemented and attained intervention.

\section{Identifying the Need}

An educational design research process begins with identifying and analysing the problem or need (see Figure 1). In this case, TAMK was to develop and deliver a fully online postgraduate certificate for teaching in higher education for a cohort of international higher education practitioners in the United Arab Emirates.

For the past decade, TAMK had been developing more engaging and authentic ways of conducting online pedagogical qualification studies for in-service teachers, which had yielded very promising results with regard to using social media tools and authentic learning approaches (Teräs \& Myllylä, 2011). At the same time, Higher Colleges of Technology (HCT) in the United Arab Emirates (UAE), a major provider of higher education in the Middle East, was looking for ways of supporting the professional development of its teaching faculty in the areas of teaching and learning, assessment, and innovative use of new pedagogies and technologies. All the teachers worked oncampus, but the role of technology in classroom and blended approaches to teaching and learning was constantly increasing.

The model that had worked well for in-service teachers of vocational subjects in Finland (Teräs \& Myllylä, 2011) was used as a starting-point for development. However, the context in the UAE was in many ways very different, and the original Finnish teacher education program would need to be developed further to meet the needs of the diverse group of learners. Therefore, the first step of the educational design research process was to identify these needs. This stage involved negotiations with HCT representatives, as well as a web conference where all the interested faculty members were invited to 
share their views and express their expectations regarding the program. These discussions were combined with a curriculum analysis of the original program to help customize the content adequately.

An important driver for the need of professional development for teaching faculty was the ongoing paradigm shift towards a networked knowledge society (e.g., Castells, 2007; Siemens, 2005) and its implications for education. The education-related discussion in the past years has been dominated by this construct; however, the focus has often been on individual phenomena rather than attempting to develop a holistic understanding of the underlying paradigm. This discussion can be very challenging for the educators, especially as it is often underpinned with an undefined but insistent demand to change in order not to fall behind. Therefore, one of the aims in developing the program was to demystify this discourse and offer a forum for critical and informed discussion. Also futures studies and trends were examined, such as the Horizon Report (J ohnson, Smith, Willis, Levine, \& Haywood, 2011), which regularly predicts a set of key trends_based on a yearly analysis of current articles, interviews, papers, and new research-considered to be the major drivers of educational technology adoptions during the next five years. To avoid a superficial showcase of trends and technologies, the aim was to combine theoretical knowledge of teaching, learning, and assessment with key trends in education, and bring both down to practice.

\section{Authentic E-Learning Design: Creating the Prototype}

The next step was to develop a prototype solution, informed by existing theoretical knowledge, design principles, and technological solutions.

The principles of authentic e-learning as defined by Herrington, Reeves, and Oliver (2010) were chosen as the framework for the design. Firstly, it was clear that the approach of a program that aims to transform teaching practice could not follow a traditional, top-down, one-to-many content delivery model that characterized the industrial age paradigm of learning (Castells, 2007). Secondly, it was crucial to ensure that the learning design would not fall into the pit that is extremely common in online learning: simply adapting new technology to traditional systems, practices, and methods (Herrington et al., 2010), rather than using authentic learning principles that complement the affordances and characteristics of online learning.

The designers were cautious to avoid the pitfalls often identified with regard to teacher professional development. Very often, the professional development is implemented rather poorly, typically in the form of isolated workshops that concentrate on developing teachers' technical skills with specific technologies (Dabner, Davis, \& Daka, 2012). Many teacher professional development programs remain superficial and fail to provide ongoing support for teachers when they attempt to apply the new curricula or pedagogies (Dede, Ketelhut, Whitehouse, Breit, \& McCloskey, 2009). The information is 
fragmented and does not fit with the professional contexts of the participants (Dede et al., 2009; Dabner et al., 2012). There are often limited opportunities for participants to interact with each other (Cho \& Rathburn, 2013). Therefore, impactful professional development opportunities that lead not only to increased knowledge, but also to improved teaching practice is very much needed (Dede et al., 2009, Ostashewski, Moisey, \& Reid, 2011). The principles of authentic e-learning were seen as a useful design framework in order to meet these requirements.

Table 2 illustrates the characteristics of nine principles of authentic e-learning and how each was instantiated in the learning design of the program.

Table 2

The Elements of Authentic e-Learning (Herrington et al., 2010) and their Application in the $21^{\text {st }}$ Century Educators Program

Element of authentic e-learning

Authentic context:

- The learning environment represents the kind of setting where the knowledge will ultimately be used.

- A non-linear learning design preserves the complexity of the reallife setting.

- The pathway through the learning environment is flexible.
Authentic tasks:

- Activities that have strong real life relevance.

- Ill-defined, overarching complex problems instead of multiple small tasks.

- A sustained period of time for investigation

- The opportunity for the students to evaluate the relevance of sources and make decisions.
How it was implemented in the design

- $\quad$ Studying alongside work and using one's classroom as a part of the learning environment allows for immediate application of the skills and knowledge in an authentic context.

- A non-linear learning environment was created using blogs, Google tools and online tools of one's own choice instead of only using a traditional LMS.

- Participants can choose to concentrate on phenomena relevant for their work instead of forcing exactly the same topics for everyone.

- $\quad$ Each module includes a long term project (6 months) that involves applying new theoretical knowledge in one's teaching

- Authentic product: a digital presentation that draws together all stages of the project (in many cases this also turned to be a real life conference presentation).

- The participants find sources for their projects themselves instead of being given a list of required reading. 
Element of authentic e-learning

Access to expert performances:

- Access to expert thinking and modelling of processes.

- Access to other learners with various levels of expertise.

- Opportunity to share narratives and stories about professional practice.

Multiple perspectives:

- Opportunity to explore issues from different points of view.

- Multiple pathways through the learning resources and materials.

- Various sources of information instead of for example a single textbook.

Collaborative construction of knowledge:

- Tasks are completed in pairs and groups rather than individually.

- The nature of the tasks direct towards group collaboration instead of simple cooperation.

- The group effort is assessed, not only the individual performance.

Reflection:

- Students are required to make decisions about how to complete the tasks.

- Students work in groups that enable discussion and social reflection.

- Nonlinear organization of materials to allow students to return to resources and act upon reflection.

- Students can compare their thoughts and ideas to experts, teachers and other learners.

Articulation:

- The tasks require students to discuss and articulate their growing understanding.

- There are groups to enable articulation.

- Students are required to publicly present and defend arguments.
How it was implemented in the design

- Plenty of collegial sharing and learning from expert colleagues through blogs, discussions and team projects.

- Networking with international experts through social media tools.

- Working in multidisciplinary, international teams, blogging and online discussions invite to explore phenomena from various perspectives.

- $\quad$ No textbook. Instead, multiple voices represented in the form of research papers, blogs, news articles, TED talks and other resources. Students were also encouraged to find resources themselves and share them with each other.

- $\quad$ Projects required team work.

- Blogging and online discussions promote collaboration - not automatically though, but they must be well designed and aligned with learning goals.

- Constant reflection on readings, phenomena discussed and the projects in blogs.

- Blog commenting and discussions related to readings and projects allow for collaborative discussion and comparing one's ideas to others.

- Blogs and discussions used for articulating one's growing knowledge

- Genuine collaboration and working towards a common project requires and encourages articulation

- Blogging and the digital online presentations require presenting and defending arguments publicly. 
Element of authentic e-learning

Scaffolding and coaching:

- There is collaborative learning where learners are able to assist with coaching.

- Coaching and scaffolding are available when needed.

Authentic assessment:

- Assessment is seamlessly integrated with the activity.

- There are multiple indicators of learning.

- Significant student time and effort in collaboration with others.
How it was implemented in the design

- Locally trained facilitators to coach the learning teams

- Feedback from program coordinator

- Scaffolding especially through learning design

- Discussion forums for learners to share good practices and help each other.

- Blogs used as e-portfolios, where different phases and aspects of the learning process are documented in a reflective manner, assessment integrated into learning tasks

- Learning process assessed instead of separate assessment tasks at the end

- All tasks and readings build up to the project

- Evaluating group efforts

Once the intended intervention or the prototype of the solution was designed, it was evaluated and tested internally at TAMK. The design team guided a review team through the program, documented their recommendations, and implemented the final changes before the program went live in September 2011.

\section{The First Iteration and Way Forward}

Divided into three modules, the program was designed to run through three semesters. After each module, a survey was conducted to evaluate the appropriateness and effectiveness of the intervention. This section discusses the first iteration and evaluation and how it was used to inform the redesign.

\section{Data Collection and Analysis}

The first formative evaluation of the program was conducted in January 2012. The method chosen was an online survey that was designed within an online survey tool (SurveyMonkey). The survey included both multiple choice and open-ended questions, out of which quantitative data was used to obtain an overview of the trends, and then the qualitative data were analysed in more detail. Out of the 30 participants who completed the module and the nine facilitators involved, 27 people completed the survey. 
A thematic analysis was conducted of the data received through the open-ended questions. A framework for the analysis was constructed using the elements of authentic e-learning for the categorization of the data. The respondents' comments were first arranged into the nine categories, according to the element of authentic e-learning to which they best belonged. In the second phase of the analysis, the categorized comments were sorted into challenges and opportunities regarding each given element. Once all the responses were categorized, recurring themes were sought and they were arranged thematically. The findings of the first evaluation have been reported earlier (Teräs, Teräs, \& Herrington, 2012; Teräs, 2013), allowing this paper to concentrate on the most significant challenges that were identified, and explain how they informed the iterative design research process.

\section{Translating Findings into Design Action Points}

The analysis of the data revealed that especially four elements had caused challenges to the participants: authentic tasks, collaborative construction of knowledge, scaffolding and coaching, as well as authentic assessment. The open-ended quality of authentic tasks was new and challenging for many, and often it had been unclear for the participants what was expected of them. The same problem was reflected in the uncertainty with regard to authentic assessment: The communication of the intertwined nature of the authentic tasks and assessment had been ambiguous and the idea of assessing the learning process instead of clearly defined assessment tasks remained unclear. Moreover, collaboration and working in teams had been difficult. Team members not adhering to schedules, communication difficulties, and different expectations caused friction. Scaffolding at the metacognitive level was also often seen as insufficient when more active facilitator directions and feedback were expected (Teräs, Teräs, \& Herrington, 2012).

The first evaluation stage was followed by translating the gathered information into a refined redesign. As McKenney and Reeves (2012) point out, the challenge in educational design research is to redesign in a way that remains true to the original intervention goals. This requires careful reflection instead of hastily jumping to conclusions with regard to the usefulness of the intervention. For example, although in this study there appeared to be uncertainty and dubiety regarding authentic tasks, this should not automatically lead to the conclusion that traditional assignments are "better" than authentic tasks. Indeed, a closer examination of the nature of the challenges suggested room for improvement in the implementation of the authentic e-learning principles in the learning design.

The analysis of the data emphasised the crucial role of scaffolding and coaching in the success of an authentic e-learning design. Three areas (site design, facilitator's role, and learning task design) were identified where a balance needs to be sought, in order to avoid a jump from the frying pan into the fire-in other words, trying to change an unwanted situation by going to the other extreme that is equally dangerous, or that 
sacrifices the principles upon which the approach was based. Each of the pitfalls is illustrated in Table 3 by a metaphor: As for site design, the extremes are "rail shooter" (the term refers to a type of video game where the player has no control over the path of her or his avatar but is taken from beginning to end as if tied to rails) and a "lost without a map" scenario. The facilitator should avoid "force feeding" as well as "negligence", and the task design should resemble neither "assembly line" nor "needle in a haystack".

Table 3

Balanced Authentic E-Learning Design

\begin{tabular}{|c|c|c|}
\hline & Frying pan & Fire \\
\hline $\begin{array}{l}\text { Site } \\
\text { design }\end{array}$ & $\begin{array}{l}\text { "Rail shooter": } \\
\text { Very structured and } \\
\text { linear design, } \\
\text { information in chunks. } \\
\text { Teacher / designer is } \\
\text { responsible for the } \\
\text { cognitive process, } \\
\text { students are walked } \\
\text { through a single path } \\
\text { to a defined } \\
\text { destination. }\end{array}$ & $\begin{array}{l}\text { "Lost without a map": } \\
\text { Very messy and } \\
\text { chaotic, information } \\
\text { hard to find, } \\
\text { instructions not readily } \\
\text { available (even when } \\
\text { asked). Students' } \\
\text { cognitive load is } \\
\text { overwhelming and it } \\
\text { feels stressful. No one } \\
\text { ends up in their goal. }\end{array}$ \\
\hline
\end{tabular}

Balanced design

Inclusive, accessible and user-friendly design, clear and consistent goals and navigation, used together with the open-ended, userdriven and unpredictable characteristics of social media. Allow students to make their own decisions of working methods and tools.

Facilitator "Force feeding": Teacher-centered, rich with instructions, to the point where students don't need to make any decisions or look for anything themselves.
"Negligence". Invisible facilitator, students are left alone without help. They feel abandoned and get the feeling that nobody cares for their learning.
Timely and constructive feedback, active communications, allow students room and time to think for themselves, don't give answers (or give hints of answers), instead scaffold the thinking process with well placed, genuine questions and comments. Help students deal with complexity instead of cleaning it out. Be reachable, not omnipresent. 


\begin{tabular}{|c|c|c|c|}
\hline & Frying pan & Fire & Balanced design \\
\hline $\begin{array}{l}\text { Task } \\
\text { design }\end{array}$ & $\begin{array}{l}\text { "Assembly line" } \\
\text { Very detailed } \\
\text { instructions on } \\
\text { assignments, defined } \\
\text { steps to a well-defined } \\
\text { (by someone else) } \\
\text { problem. Outcomes are } \\
\text { uniform: there is an } \\
\text { "ideal performance", } \\
\text { usually in the head of } \\
\text { the teacher, the one } \\
\text { who produces the } \\
\text { closest equivalent } \\
\text { scores best. }\end{array}$ & $\begin{array}{l}\text { "Needle in a haystack": } \\
\text { Very ill-defined } \\
\text { problems, to the point } \\
\text { that no one has any } \\
\text { idea as for what to do } \\
\text { (including the } \\
\text { facilitator). Students } \\
\text { don't know what they } \\
\text { should be looking for, } \\
\text { not to mention where } \\
\text { they could start } \\
\text { looking for it. }\end{array}$ & $\begin{array}{l}\text { Authentic tasks that } \\
\text { are relevant for the } \\
\text { students and that } \\
\text { they can feel } \\
\text { ownership to. } \\
\text { Consider the } \\
\text { possibility of allowing } \\
\text { students choose their } \\
\text { own tasks, or at least } \\
\text { their own perspective } \\
\text { to the task. Scaffold } \\
\text { the combining of } \\
\text { theoretical and } \\
\text { practical, high level } \\
\text { of applied science. } \\
\text { Include ongoing } \\
\text { reflection of both the } \\
\text { meaning of } \\
\text { theoretical } \\
\text { knowledge to the } \\
\text { individual and of the } \\
\text { application to } \\
\text { practice. }\end{array}$ \\
\hline
\end{tabular}

The redesign of the learning environment involved practical adjustments that are described in more detail in the following section.

\section{The Practical Redesign Steps Taken}

One of the biggest individual challenges regarding the redesign was the learning management system (LMS) used. The LMS that had been in use during Module 1 did not seem to lend itself easily to the constructivist, authentic e-learning design. Being rather content-driven it allowed for little flexibility in the way the site could be presented, and the embedded tools, such as the synchronous meeting tool, were extremely teacher-centric. Relying fully on social media was not an option, due to privacy and legal issues related to assessment and student information. Therefore, a bold decision of changing the learning management system in the middle of the program was made and a new learning design was implemented in the Moodle LMS. The aim of the LMS transition was to improve communication and reduce the confusion with the learning tasks and assessment with the help of a clearer design, as well as to provide more user-centric forums for discussion. Moreover, a fortnightly email newsletter was introduced. The newsletter was visually appealing and informal in tone, with the twofold purpose of improving communication between the program leaders, facilitators, and participants, and promoting a sense of community by introducing brief participant and facilitator biographies, news, and examples of participants' work. 
In order to better support online collaboration, the teams were restructured. They were reduced in size and each small team was allocated a designated facilitator. Moodle discussion forums were established to allow for spontaneous discussion related to the topic at hand. In addition to these measures that aimed to better support collaboration, the team project of Module 2 was redesigned to be less dependent on individual team members' performance.

To clarify the authentic assessment process, three scaffolding measures were employed. A clearer assessment rubric specifically adapted for blog writing and online collaboration was introduced. Moreover, the instructions for the project and blog writing tasks were rewritten in a way that illustrated more clearly how they formed a reflective part of the assessment. Finally, a Google spreadsheet for project milestone tracking was linked into Moodle. The spreadsheet allowed for the participants to mark completed milestones themselves, thus also making their progress visible for other team members. They could also share information about the scope and goals of their project through the spreadsheet, as well as share addresses to their blogs. The challenges related to facilitation were addressed in two ways. Facilitators' tasks were reorganized to reduce the workload and to clarify responsibilities, and the team facilitators were offered more systematic support from TAMK.

Figure 2 illustrates the way the identified challenges were translated into redesign.

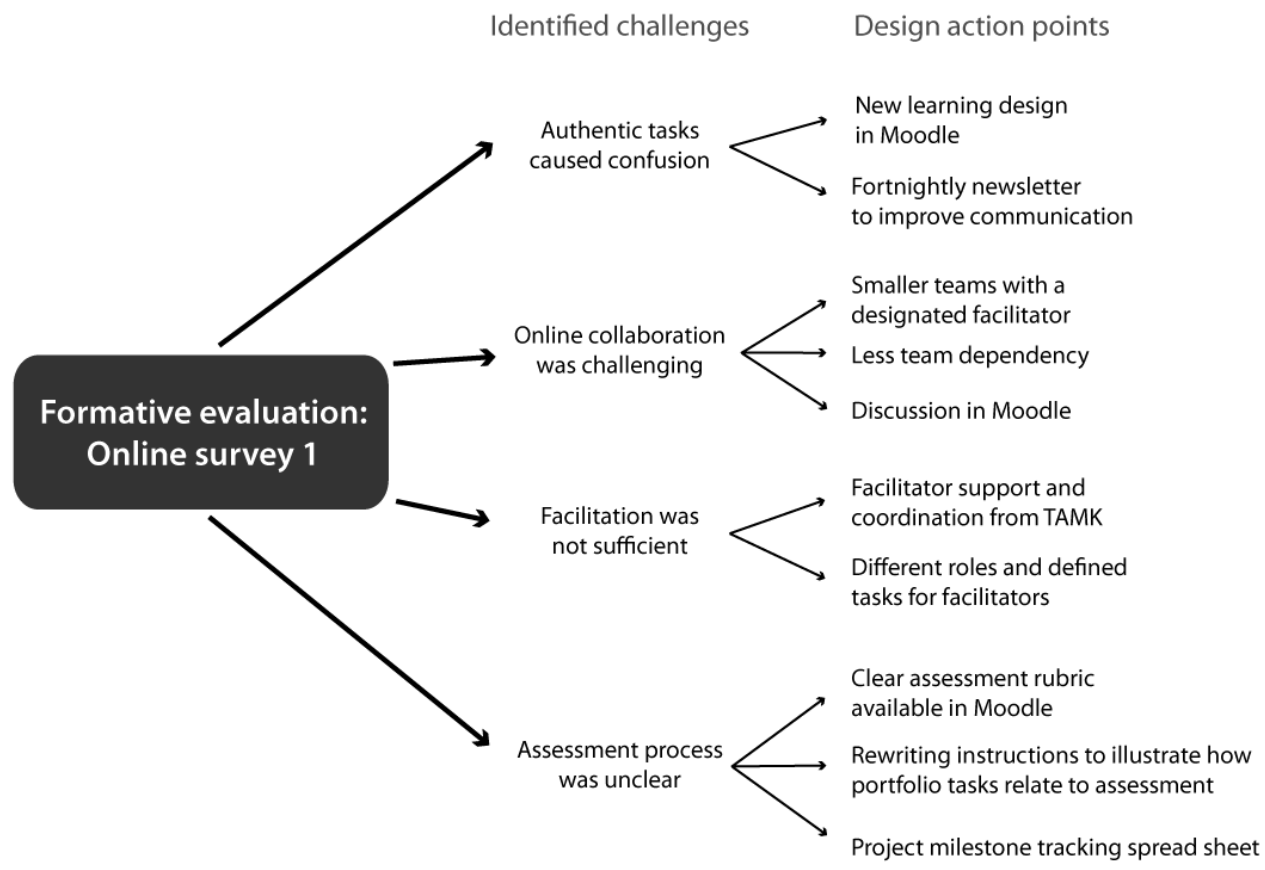

Figure 2. Translation of evaluation results into design action points. 


\section{Evaluating the Adequacy of the Redesign}

A new survey was conducted at the end of Module 2, in order to evaluate the adequacy of the redesign measures, and identify new challenges and successes. The methods of gathering, thematising, and analysing data were similar to the first survey. This time, 10 participants out of the 19 that completed the module responded to the survey. Responding to both surveys was optional, so the significant decrease in the response rate is noteworthy. It might indicate that people had fewer pressing concerns after the second module and did not therefore feel the need to respond to voice their concerns. It could, of course, also suggest decreased interest, perhaps due to disappointment regarding how impactful the earlier feedback was. However, judging by the positive trend identified in the responses, this would seem less probable.

In the following section, the question of the adequacy of the redesign is addressed first, then a discussion of the new challenges and successes revealed by the data.

\section{Authentic Tasks}

Authentic tasks was an area that was addressed through several changes in the learning design. This proved to be successful: Nine out of 10 respondents found the requirements of the tasks clearer compared to the first module. The majority felt that the newsletter had brought added value. All respondents found Moodle a more suitable and more intuitive learning management system for the purposes of the program. Two respondents would still have hoped for clearer instructions, whereas some had found it difficult to implement the authentic task in practice.

However, this time the successful areas outweighed the challenges. Almost all the respondents reported that working on the project had been a highly rewarding learning experience. Learning to integrate relevant technology in one's own teaching, improving one's teaching skills with new ideas and methods, as well as positive impact on student experience were mentioned in the comments. This also became evident in the blogs where the participants continuously reflected upon the different stages of the project, in relation to theoretical knowledge and experiences from implementing and evaluating it. It is noteworthy that not all projects ended up being successes-sometimes they simply did not work out as planned. However, this also constituted a useful and rewarding learning experience - one of the respondents mentioned that the best part of the module had been "reflecting what went wrong with my project".

\section{Collaborative Construction of Knowledge}

Collaborative construction of knowledge also improved, but remained one of the most challenging areas. Half of the respondents found that collaboration had improved, whereas the other half found no difference. Six out of 10 found that the discussion forums in Moodle supported collaboration, mainly by allowing informal discussion and interaction between people from different teams. Sharing experiences and realizing that 
others struggled with similar questions had been very important for some of the respondents. However, others felt the discussions had not added value.

As for remaining challenges, two themes could be identified. There appeared to be a tendency of perceiving some other participants as hindrances to collaboration, either due to lack of knowledge, interest, experience, commitment, or engagement. As one of the respondents put it: "Too many participants think all they need to do is make a post. They don't seem to try to engage in the discussion or respond to what others say."

Respondents reported that peers had not provided feedback, or that they did not offer in-depth contributions or engage in discussion. Some participants hoped there would have been a way to find colleagues with similar working methods as themselves and form teams with them. One respondent even doubted that collaboration could ever be successful between people with such different levels of experience.

The few suggestions for better supporting collaboration all involved increasing the number of synchronous meetings, for example, through Google Hangouts. This had indeed been the intention in the redesign, however, the way these meetings were realized in the end varied greatly. Some facilitators made a much more systematic use of it than others. Some teams had found it hard to find common timeslots. This would probably always be the case in a program that is taken alongside work and other life commitments. A development consideration for the future might be to include more regular, pre-scheduled synchronous meetings, with the recommendation to attend a certain number of them.

Some participants felt that collaboration had greatly improved, predominantly due to the introduction of new collaboration channels. It could also be seen in the data that the tasks being less heavily dependent on collaboration made the process easier. However, the design team felt this as a slight compromise in the authentic e-learning design: Collaboration should not be an optional and additional extra, but a built-in requirement for the successful completion of the authentic task (Herrington, Reeves, \&Oliver, 2010). Therefore, reducing the dependency on the team was "the easy way out". Collaborative learning is in many ways more demanding than traditional individual ways, even more so in online environments, so it is very easy for the learning designers and teachers to simply revert to traditional practices. We feel, though, that a closer examination of the element of scaffolding and coaching and development of appropriate design principles is a more promising way forward in order to ensure that students can benefit from the strengths of collaborative endeavor.

\section{Scaffolding and Coaching}

The redesign regarding scaffolding and coaching turned out to be partly very successful, partly less so. Overall it could be said that the redesign of scaffolding-the aspects that could be improved with learning design-resulted in desired outcomes, whereas 
coaching — the aspect that required changes in the facilitators' work-was more difficult to improve. It was quite obvious that the new learning design was successful in reducing the anxiety and confusion that some participants had experienced during Module 1. The balance that was sought between the "rail shooter" and the "lost without a map" scenarios (see Table 3) seemed to be well achieved. However, the same balance was not found with regard to facilitation. The comments concerning facilitation displayed considerable variation. Some would not stop praising their team facilitator, whereas others felt that the team had been mostly working on their own.

The two main themes observed in the data were: 1) a need for more timely and betterfocussed feedback to support the learning process, and 2) a need for more active involvement of the facilitators to improve the sense of community. The respondents suggested that the facilitators' workload would have to be adjusted more adequately ("they are doing a great job considering the little time that they have"), or that they should receive more training. Although the workload issue was beyond the influence of the design team, the important observation was that the role of the facilitator is central for the successful authentic e-learning process, and it should be ensured that facilitators have sufficient resources, relevant knowledge and experience, and sound understanding of the authentic e-learning model to be able to avoid the extremes of "force-feeding" and "negligence" as described in Table 1.

\section{Authentic Assessment}

The authentic assessment in Module 2 consisted of a development project where the teachers were requested to choose a technology that they would study, integrate in their teaching, and evaluate. They were to search for literature and earlier research regarding the technology, write an implementation plan of how and why they would be using it, reflect upon the different stages of the project in their blog, and, in the end, design and share an interactive electronic presentation about the project. During the course of the module, theoretical background regarding online pedagogies was also introduced and the participants reflected upon the theory and its applicability in their project in their blogs. The process was explained in detail, and the milestone tracking tool was used to facilitate keeping up to date and to offer a support structure to the process. Compared to Module 1, there was significantly more scaffolding in place; however, the project still fulfilled the requisites for an authentic assessment task: The interactive presentation was a polished, refined product; students participated in the activity for an extended period of time (6 months), and the students were assessed on the product of an in-depth investigation.

\section{Other Elements of Authentic E-Learning}

The second evaluation indicated that all the areas that were redesigned had improved, and no new major challenges were identified. With regard to the five other elements of authentic e-learning, the most important observations were related to reflection and 
articulation. The ways in which the personal blogs were used in the program seemed to support these areas very well. For many, writing the blog was the most rewarding learning experience as it supported ongoing reflection in a systematic way. The way the blog and other activities contributed to the project and supported reflection was also appreciated:

I enjoyed keeping track of the project and now have the possibility to look back. For me, that is a new experience and one that I appreciate, i.e. to have written down a teaching process and having shared it publicly.

The idea of public articulation of one's growing understanding was at first new and challenging to some participants, but it soon proved to be beneficial. In the words of one of the respondents:

Writing my blog was not always easy as my learning process was now public. However, I have appreciated the challenge and regard it as one the best learning opportunities of this course. It has made me reflect a lot on teaching practices.

Thus a fruitful connection could also be found between articulation and reflective practice: Being encouraged to continuously make the learning process public supported the formation of a practice of reflection. Considering Schön's definitions of reflectionin-action, the type of reflection that takes place while we work, and reflection-on-action, where we look back and evaluate our own performance (1983), the process of articulation could also be seen as a way of making the reflection-in-action visible and public. Traditionally, students are usually required to publish polished, well-structured arguments that are evaluated and assessed. Therefore learners may at first feel quite uncomfortable with publishing unfinished thoughts, initial ideas, and works in progress, just as the above quote suggests. However, it seems that this type of pedagogical use of blogs and discussion forums might be more effective in supporting the systematic development of reflective skills, which in turn seems to have a positive impact on professional development. When asked what the most rewarding experience during the program was, one of the respondents said the following: "Writing my blog, because it gave me the opportunity to reflect. I appreciate that as in my day to day I don't have much time for reflection and it is an essential part of learning and personal/professional development."

As for access to expert performances and multiple perspectives, some participants found the discussion forums very useful. The forums provided an informal channel for collegial sharing and support. Some of the participants made an extensive use of the forums, whereas others did not find them that useful and chose not to take part in them. The discussions were not a formal requirement, but the opportunity was provided on a 
regular basis. Keeping in mind that the participants were busy educators studying alongside work, it is noteworthy that so many took the opportunity to engage. This suggests that the need for an informal way of interacting and sharing with colleagues is very genuine and should be taken into account in the learning design.

\section{Conclusion}

This paper has described the use of an educational design research process in finding the right balance in an authentic e-learning design of a fully online postgraduate certificate program. Educational design research has proved to be a very fruitful approach for designing, implementing, and improving an educational intervention in a complex setting. It allows for rapid prototyping and very agile, targeted redesign through iterative cycles in order to gain a deeper understanding of the learner experience during the process. The iterative cycles of implementation and revision enables the learning design to be user-centered and significantly improved where required, and the strengths of the program can be identified at an early stage in order to further enhance the successful elements.

When implementing a fully online authentic e-learning program, it is helpful to identify the challenges and potential pitfalls. It is worthwhile to recognize and be aware of the extremes - the frying pans and the fires-and resist the temptation of hasty corrective measures. Authentic e-learning differs in many ways from some traditional educational approaches to which the students may be accustomed. Therefore, especially at the beginning of the learning process, the students may experience difficulties with some of the elements of authentic e-learning. These challenges are best addressed with adequate scaffolding and coaching measures. We close by suggesting four strategies for planning and implementing effective scaffolding and coaching to enhance the authentic elearning experience.

1. Scaffolding by learning design. Much of the scaffolding can be built in the learning design, which frees resources for coaching. A clear and user-friendly site design, clearly communicated goals and schedules, as well as easy navigation to resources and tools are paramount.

2. Scaffolded authentic tasks. Building scaffolding measures, such as project milestones, into an authentic task helps learners to pace their work, to reflect both in-action and on-action, and to collaborate with each other. It is crucial, however, to resist the temptation of breaking the task into small, pre-digested chunks. Instead, all resources, discussions, and activities can be used as scaffolding measures, integrated in a way that builds towards a polished product. 
3. Encourage and enable peer support. Peer support allows for shared expertise, community building, and the development of a reflective practice by continuous articulation. Moreover, it is another way of freeing facilitator time for coaching activities.

4. Coaching for collaboration. When scaffolding and peer support are successfully built into the learning design, the valuable teaching resources can be directed towards coaching and facilitating team effort and collaborative knowledge construction. Collaboration and forming of a learning community is a crucial but also the most challenging aspect of an authentic e-learning program and it can only succeed when properly facilitated.

Authentic e-learning was found to be very useful as a framework for both design and evaluation. The authentic approach allowed for a better transfer of learning and impact on teaching practice: Instead of merely gaining knowledge of pedagogy or learning technologies, or even learning how to use new teaching methods and technologies in practice, the participants had the chance to fully incorporate these into their teaching on a deeper level and thus transform their practice. 


\section{References}

Anderson, T., \& Shattuck, J . (2012). Design-based research: A decade of progress in education research? Educational Researcher, 41(1), 16-25.

Brown, A. L. (1992). Design experiments: Theoretical and methodological challenges in creating complex interventions. J ournal of the Learning Sciences, 2(2), 141-178.

Castells, M. (2007). Communication, power and counter-power in the network society. International J ournal of Communication, 1(1), 238-266.

Cho, M., \& Rathbun, G. (2013). Implementing teacher-centred online teacher professional development (oTPD) programme in higher education: A case study. Innovations in Education and Teaching International, 50(2), 144-156.

Cobb, P., Confrey, J ., diSessa, A., Lehrer, R., \& Schauble, L. (2003). Design experiments in educational research. Educational Researcher, 32(1), 9-13.

Collins, A., J oseph, D., \& Bielaczyc, K. (2004). Design research: Theoretical and methodological issues. The J ournal of the Learning Sciences, 13(1), 15- 42.

Dabner, N., Davis, N., \&Zaka, P. (2012). Authentic project-based design of professional development for teachers studying online and blended teaching. Contemporary Issues in Technology and Teacher Education, 12(1), 71-114.

Dede, C., Ketelhut, D. J., Whitehouse, P., Breit, L., \& MoCloskey, E. M. (2009). A research agenda for online teacher professional development. J ournal of Teacher Education, 60, 8-19.

Herrington, J ., Reeves, T., \& Oliver, R. (2010). A guide to authentic e-learning. London: Routledge.

J ohnson, L., Smith, R., Willis, H., Levine, A., \&Haywood, K. (2011). The 2011 horizon report. Austin, Texas: NMC. Retrieved from http:// www.nmc.org/ publications/2011-horizon-report

Kelly, A. E. (2003). Research as design. Educational Researcher, 32(1), 3-4.

McKenney, S., \& Reeves, T. C. (2012). Conducting educational design research. New York: Routledge.

Ostashewski, N., Moisey, S., \& Reid, D. (2011). Applying constructionist principles to online teacher professional development. The International Review of Research in Open and Distance Learning, 12(6), 143-155. 
Plomp, T. (2007). Educational design research: An introduction. In T. Plomp \&N. Nieveen (Eds.), An introduction to educational design research. SLO: NICD.

Reeves, T. C. (1995). Questioning the questions of instructional technology research. Invited Peter Dean Lecture, National Convention of the Association for Educational Communications and Technology. Anaheim, CA. Abbreviated version retrieved from http://itforum.coe.uga.edu/paper5/ paper5a.html

Reeves, T. C. (1999). A research agenda for interactive learning in the new millennium. In P. Kommers \& G. Richards (Eds.), Proceedings of EdMedia 1999 (pp. 15-20). Norfolk, VA: AACE.

Reeves, T. C. (2006). Design research from a technology perspective. In J . van den Akker, K. Gravemeijer, S. McKenney \&N. Nieveen (Eds.), Educational design research (pp. 52-66). London: Routledge.

Reeves, T. C. (2011). Can educational research be both rigorous and relevant? Educational Designer, 1(4).

Reeves, T. C., \& Hedberg, J .G. (2003). Interactive learning systems evaluation. Englewood Cliffs, N.J .: Educational Technology.

Reeves, T., McKenney, S., \& Herrington, J . (2011). Publishing and perishing: The critical importance of educational design research. Australasian J ournal of Educational Technology, 27(1), 55-65.

Schön, D. A. (1983). The reflective practitioner: How professionals think in action. London: Temple Smith.

Siemens, G. (2005). Connectivism: A learning theory for the digital age. International J ournal of Instructional Technology and Distance Learning, 2(1), 3-10.

Teräs, H. (2013). Dealing with "learning culture shock" in multicultural authentic elearning. In T. Bastiaens \& G. Marks (Eds.), Proceedings of World Conference on E-Learning in Corporate, Government, Healthcare, and Higher Education 2013 (pp. 442-472). Chesapeake, VA: AACE.

Teräs, H., \& Myllylä, M. (2011). Educating teachers for the knowledge society: Social media, authentic learning and communities of practice. In S. Barton et al. (Eds.), Proceedings of Global Learn 2011 (pp. 1012-1020). AACE.

Teräs, H., Teräs, M., \& Herrington, J. (2012). A reality check: Taking authentic elearning from design to implementation. In T. Amiel \&B. Wilson (Eds.), Proceedings of World Conference on Educational Multimedia, Hypermedia and Telecommunications 2012 (pp. 2219-2228). Chesapeake, VA: AACE. 
van den Akker, J . (1999). Principles and methods of development research. In J . van den Akker, N. Nieveen, R. M. Branch, K. L. Gustafson \& T. Plomp (Eds.), Design methodology and developmental research in education and training (pp. 1-14). The Netherlands: Kluwer.

van den Akker, J . (2003). Curriculum perspectives: An introduction. In J . van den Akker, W. Kuiper \&U. Hameyer (Eds.), Curriculum landscapes and trends (pp. 1-11). The Netherlands: Kluwer.

\section{Athabasca University $\mathbf{I}$}

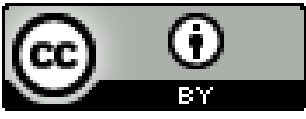




\section{Mobile Cloud Learning for Higher Education: A Case Study of Moodle in the Cloud}
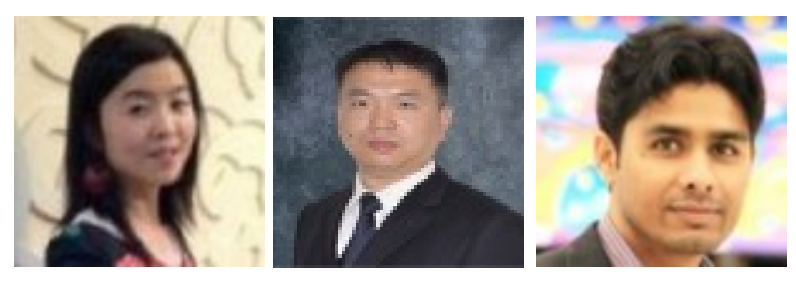

Minjuan Wang ${ }^{1}$, Yong Chen ${ }^{2}$, and Muhammad Jahanzaib Khan ${ }^{3}$ ${ }^{1}$ San Diego State University, USA and Shanghai International Studies University (Oriental Scholar), ${ }^{2}$ Old Dominion University, USA, 3Higher College of Technology, UAE

\section{Abstract}

Mobile cloud learning, a combination of mobile learning and cloud computing, is a relatively new concept that holds considerable promise for future development and delivery in the education sectors. Cloud computing helps mobile learning overcome obstacles related to mobile computing. The main focus of this paper is to explore how cloud computing changes traditional mobile learning. A case study of the usage of Moodle in the cloud via mobile learning in Khalifa University was conducted.

Keywords: Cloud computing; mobile learning; mobile cloud learning; Moodle; higher education 


\section{Introduction}

The rapid progress of mobile technology becomes a powerful trend in the development of mobile learning (Bai, Shen, Chen, \& Zhuo, 2011). However, due to the high costs of mobile devices, networks, low network transmission rate, and limited education resources, mobile learning is not widely deployed ( $\mathrm{Li}, 2010)$. With the continuous rapid development and widespread applications of new information technologies, cloud computing is bringing major changes and new breakthroughs in teaching and learning. It is becoming the dominant method in which mobile, online, and other types of applications operate (Rao, Sasidhar, \& Kumar, 2010).

Cloud computing is "a model for enabling ubiquitous, convenient on-demand network access to a shared pool of configurable computing resources (e.g., networks, servers, storage, applications, and services) that can be rapidly provisioned and released with minimal management effort or service provider interaction" (Mell \& Grance, 2009). It has two inherent characteristics: elasticity (resource scaling up) and resource pooling (running various independent services) (Hirsch \& Ng, 2011). Cloud computing makes up the inadequacies of mobile learning and leads to a revolution in mobile learning. Cloud computing can store a huge amount of educational resources and provide infrastructure, platform, and application services for users instead of letting users save them in their devices ( $\mathrm{Li}, 2010)$. It can also provide unlimited computing power for the completion of various types of application (Chen, Liu, Han, \& Xu, 2010).

Mobile cloud learning is an amalgamation between cloud computing and mobile learning (Hirsch \& $\mathrm{Ng}, 2011$ ). It integrates the cloud computing into the mobile environment and overcomes obstacles related to mobile computing (Dinh, Lee, Niyato, \& Wang, 2011). In this paper, we examine mobile cloud learning and explore how it can be used in higher education. We achieve this through a brief case study of the implementation of Mobile Moodle in Khalifa University, Abu Dhabi, UAE.

\section{Background}

\section{Definition of Mobile Cloud Learning}

Mobile cloud learning (Figure 1), a novel unification of cloud computing and mobile learning, is a relatively new concept that holds great promise for future development of education (Hirsch \&Ng, 2011). 


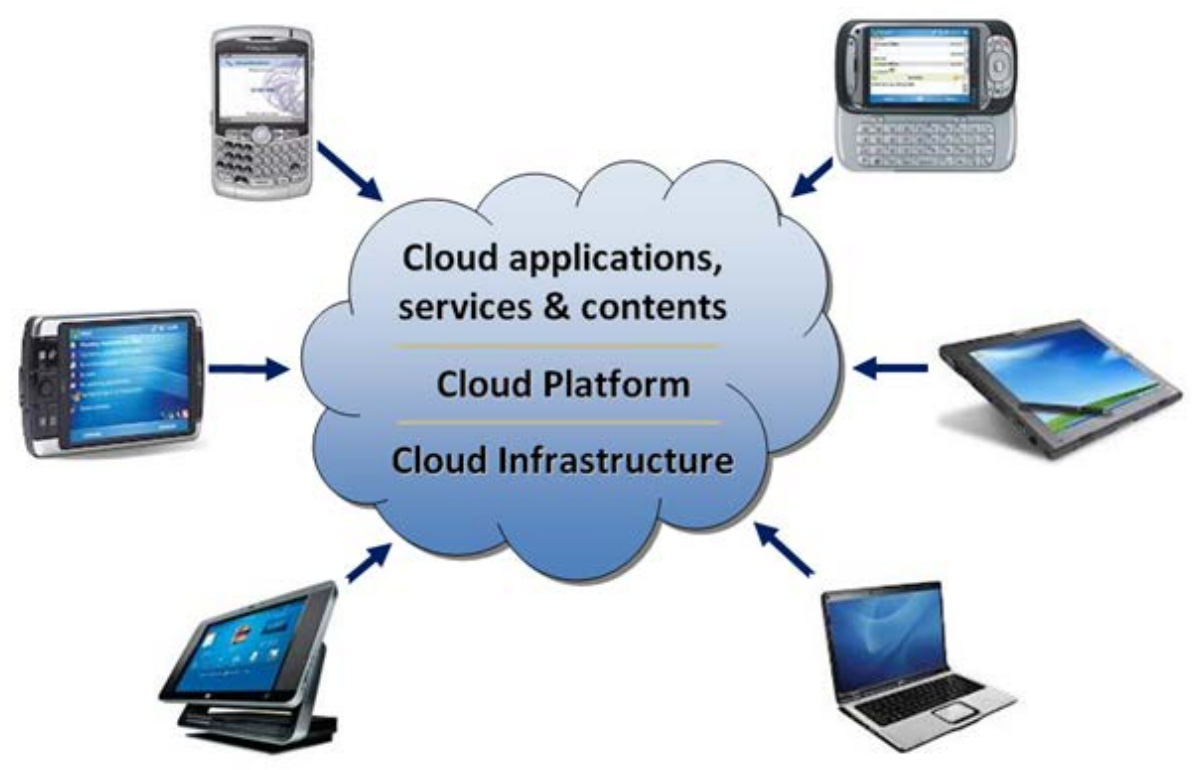

Figure 1. The concept of mobile cloud learning (Hirsch \& Ng, 2011).

Mobile learning has been evolving, from the early definitions of "learning with mobile devices" (Harris, 2011; Kossen, 2001) to the current terminology that emphasizes learner mobility, resulting from the use of mobile devices. The shift of the mobile learning definition changes the focus from mobile devices to mobile learners, and requires designers not to design instructions for a new class of mobile technologies, but to broaden their perspectives of what mobility for the learner entails in relation to learning. Only after recognizing this focus shift in design can designers identify a dichotomy of guidelines with one set focusing on the technology and one set focusing on the learner. In addition, mobile learning research from mobile learners' perspectives require the study of "... how the mobility of learners augmented by personal and public technology can contribute to the process of gaining new knowledge, skills, and experience" (Sharples, Arnedillo-Sánchez, Milrad, \& Vavoula, 2009). This multidimensional view of mobility greatly enriches the discourse in mobile learning and also poses new directions for research and development in this field.

Mobile learning enables learners to acquire learning content anytime anywhere via portable devices. But low processing power and memory constraints of mobile devices, expensive network connection fees, slow network transmission, and limited educational resources fundamentally limit the development of mobile learning ( $\mathrm{Li}, 2010)$. Mobile cloud learning integrates cloud computing into mobile learning. The advantages of cloud computing, such as massive data storage, high-performance computing, and easy access overcome obstacles related to mobile learning (Dinh, Lee, Niyato, \&Wang, 2011). Figure 2 shows the architecture of mobile cloud learning. In mobile cloud learning, learners can access content, such as text-based documents, audio, and video files, over 
the Cloud via their mobile devices connected with the Internet (such as GPRS, UMTS, HSPA, WiFi, WiMAX, or LTE) (Rao, Sasidhar, \& Kumar, 2010; Kitanov \& Davcev, 2012).

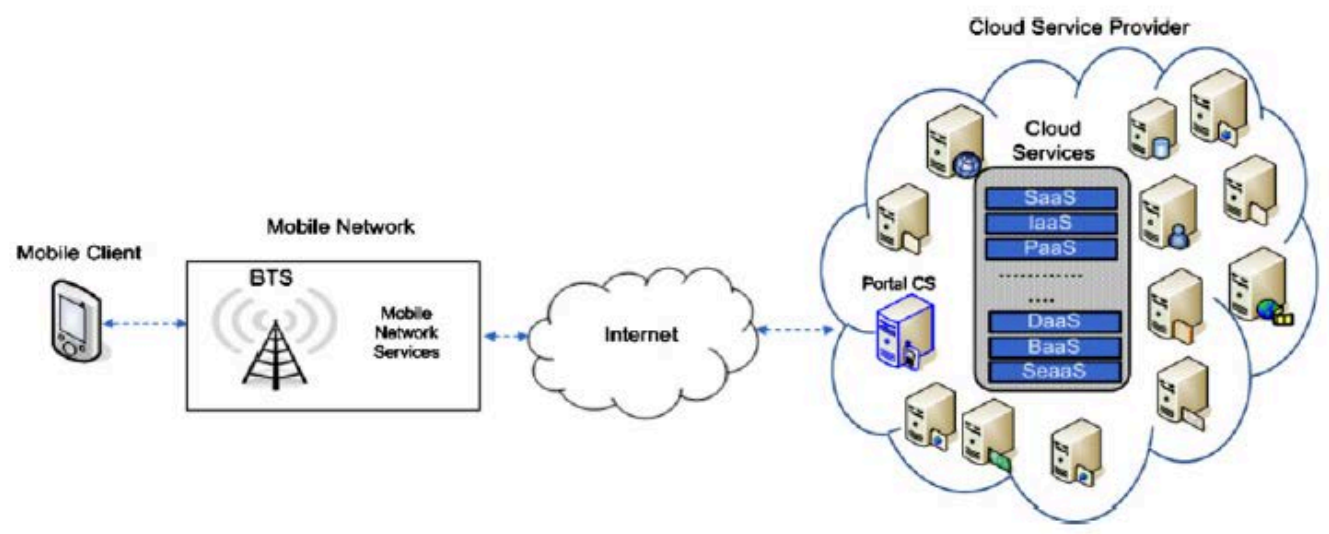

Figure 2. Mobile cloud learning architecture (Khan, Kiah, Khan, \& Madani, 2012).

\section{Benefits of mobile cloud learning.}

Traditional mobile learning must deal with the following drawbacks-high device and network costs, low network transmission rates, and limited education resources available. Combining the advantages of mobile learning and cloud computing, mobile cloud learning is introduced to solve these limitations (Kitanov \& Davcev, 2012). Weber (2011) argues "greater connectivity between centralized server-side applications and low cost/low processor capacity mobile devices could provide better access, more control, and greater freedom for e-learners" (p. 565).

Mobile cloud learning has a number of benefits to both the content providers and the learners. First and foremost, it costs less. For content providers, it saves the large initial cost, spending on hardware and software incurred when installing all kinds of systems (Freeman, 2000). By paying regular monthly fees, even small schools and universities, which cannot justify the return-on-investment for the high initial setup costs can provide mobile cloud learning services without spending large set-up costs for infrastructure (Hirsch $\& \mathrm{Ng}$, 2011). In addition, they do not need to instantly maintain and upgrade hardware or software. Meanwhile, because all computing, storage, and updates are completed on the cloud side, mobile devices serve for display only (Mohamudally, 2011). As a result, users can utilize web-based applications on their mobile devices with small memory spaces because there is no need for software loading and document saving (Rao, Sasidhar, \& Kumar, 2010). They can use variable mobile devices to access learning content without purchasing, installing, or updating any software. 
Second, mobile cloud learning can also be easily accessed as long as a mobile network is available. Palmer and Dodson (2011) point out that rural students, who do not have access to high-speed broadband Internet connections, can access curriculum content easily via 3G mobile technologies. They can use services from the cloud data center for learning selected topics over their mobile phones even when they are in a small village or remote area (Rao, Sasidhar, \& Kumar, 2010). Although one may need a subscription, mobile cloud learning is open access to everybody. The fact that people might access such a program through their mobile devices makes it convenient for them in any part of the world to access learning resources (Woodill, 2010).

Third, because learning resources stored in clouds are shared across different schools and universities, more educational resources are available for mobile cloud learning users. In addition, novel applications and services, which improve collaboration, can be implemented, such as collaboration tools between students of different institutions, social communities, and more (Hirsch \& Ng, 2011).

Finally, mobile cloud learning is also flexible and allows for adjustments, depending upon learners' needs. Since it is accessed through subscription, the user does not need to know where the learning sources are (Rittinghouse \& Ransome, 2009).

\section{Characteristics of mobile cloud learning.}

Mobile cloud learning has the following characteristics.

1) Storage and sharing: Learning outcomes and resources can be stored in the "Cloud," which provides almost unlimited store and computation capacities. Documents can be commonly edited and shared in the "Cloud," such as services provided by GoogleDocs, Live Skydrive, and Office Live.

2) Universal accessibility: Learners can study as long as they have access to the network. Mobile cloud learning also makes a low-cost access terminal possible, because software, applications, and data are all operated in the cloud servers. This improved accessibility can greatly benefit developing regions.

3) Collaborative interactions: Learners can cooperate anywhere in the "Cloud." From social learning perspectives, they can collaboratively build common knowledge through frequent and convenient interactions.

4) Learner centered: Mobile cloud learning is heavily people-oriented, which meets the individual needs of learners. Learners in the "Cloud" select suitable resources and can track their learning progress and outcomes.

Given the above characteristics, mobile cloud learning is mostly utilized to enable communication between educators and students, manage the teaching and learning processes, and add knowledge to interested and willing users, utilized among learners, and so on. (Chang, Bacigalupo, Wills, \&De Roure, 2010). 
The responses of learners to using this learning method are excellent. Most studies share the finding that currently young people natively communicate through the language of mobile phones, the Internet, and social networks. Today's learners have more readily embraced learning and educational technologies compared to other traditional learning methods, as these new learning methods allow them to share their knowledge and experiences through online sites. Learners have also been identified as exhibiting better learning behaviors, while using these learning technologies, since they are a flexible, 'fun' way to learn, and manageable (Sharif, 2010).

In a recent survey of students in a UAE university, a large percentage of learners (about $80 \%$ use laptops, mobile phones, or both regularly for their learning purposes. Kennington, Olinick, and Rajan (2010) found most learners revealed that gadgets, such as laptops and mobile phones, are must haves and that Internet access is absolutely necessary. Additionally, learners want learning environments to be freer and more comfortable than classrooms. They prefer informal places rather than formal ones. Mobile cloud learning provides such an opportunity, allowing learners to check their timetables, obtain tutor's notes/assignments, complete research, and even learn an entire course using the same process (Kennington, Olinick, \& Rajan, 2010).

\section{The Use of Mobile Cloud Learning in Middle Eastern Regions}

Although cloud computing has been introduced almost all over the world, developed countries use it more than their developing counterparts. Among the countries in the Middle East, some are highly developed, while others are still underdeveloped. These countries are in a Muslim region and have quite different life styles and perceptions of issues compared with non-Islamic countries. However, Islamic and non-Islamic countries share the same needs for advanced technologies, including the education sector (Eze \& Onyegegbu, 2006). More and more people, including girls and women, are becoming educated today than a number of years ago in these Islamic countries.

Even though many countries in the Middle East are Islamic countries, each is unique. Big challenges come from the heterogeneous nature of their economies, geography, politics, and cultures. The region has diverse languages, cultures, and religions, although the widely practiced religion is Islam. Consequently, special options must be considered in the process of designing and developing advanced technology applications, such as mobile cloud learning. For example, the economies of the countries in this region are not at the same level. Some countries are very wealthy due to the oil industry, while others are poor due to their locations in an arid to semi-arid area (J aatun, Zhao, \& Rong, 2010). Therefore, a special blend of policies about technology upgrades must be made to ensure the underdeveloped countries can afford the costs. In addition, the technology levels of the countries in this region are not the same. Some countries, such as UAE, are more advanced than other countries, which are still trying to adopt the ever-changing technology (Al-Zoube, El-Seoud, \&Wyne, 2010). 
According to Weber (2011), there is a widespread shortage of qualified information and communication technology (ICT) professionals, training programs, and trained elearning educational staff in the Middle East and North African region. Some Middle Eastern countries, such as Saudi Arabia, Bahrain, and Yemen, are experiencing the rumblings of dissent related to recent political upheavals in several North African countries. The society and educational initiatives in Middle East countries are undoubtedly disrupted. Therefore, renting computer platforms and scalable power becomes a reasonable option for educational institutions in this region to deal with the threat of potential destruction of hardware. Mobile cloud learning can be designed appropriately for a specific group of people or a specific region. Without using extra facilities, the information technology (IT) specialists may design the learning process to meet the requirements of people in remote areas or those who are not prosperous. For example, instead of having a one-time subscription, they may introduce a learning process where one can access the cloud through bundles. For Islam countries, the process may be designed for some of the Middle Eastern languages among others. This technology is also referred to as a borderless learning method, which means literacy can reach individual people in deeply remote areas where there are no libraries, tutors, and/ or schools (Xu, Wang, \& Li, 2011).

\section{Moodle in the Cloud}

Moodle is a widely adopted open source learning management system (LMS), also known as a course management system (CMS) or a virtual learning environment (VLE) (Bamiah, Brohi, \& Chuprat, 2012), which supports both small and large deployments (with several sites well beyond millions of users) and includes course management tools, various Web 2.0 technologies, online assessments, integration with plagiarism detection tools, integration with repositories and electronic portfolio software, and other features common to learning management systems. As Xhafa, Caballé, Rustarazo, and Barolli (2010) argue, " Moodle distinguishes for easy configuration and maintenance as well as content course creation. A great advantage of using Moodle is the easiness of content creation, including forum, questionnaires, tasks, wikis, chats, etc." (p. 207). According to Moodle Statistics, Moodle is present in 223 countries, at 70,736 sites, hosting 6,790,797 courses, and 63,218,611 users and 1,290,273 instructors. The top 10 countries using Moodle by registrations are shown in Table 1. 
Table 1

Top 10 Countries Using Moodle by Registrations

\begin{tabular}{lr} 
Country & Registrations \\
\hline United States & 12,087 \\
\hline Spain & 6,143 \\
\hline Brazil & 5,088 \\
\hline United Kingdom & 3,949 \\
\hline Germany & 2,962 \\
\hline Mexico & 2,897 \\
\hline Portugal & 2,163 \\
\hline Colombia & 1,940 \\
Australia & 1,720 \\
Italy & 1,692
\end{tabular}

The normal way of setting up Moodle is to install it on a Windows or a Linux server in a data center, and manage it as part of an IT system. The setting up requires large investments in hardware and software. If Moodle is hosted in the Cloud, no big investments are needed.

Take Azure of Microsoft as an example of a platform in the cloud. First, the original Moodle must be converted to operate on Azure. Moodle on Azure, an open source tool, can achieve the conversion automatically, while making minimal alterations to the original Moodle. It is used to migrate locally hosted Moodle to the cloud/Azure environment. The current version of Moodle on Azure, open for public download, is capable of converting original Moodle 2.2. It is composed of patches and support extensions that make Moodle run well on Azure, either as a new installation or as a reinstallation.

Then, the operation of Moodle on Azure will generate a package ready for uploading to Azure for deployment. The download and upload processes are necessary because this is the method to ensure that customized Moodle works on Azure. However, the uploaded package can be installed only on one virtual server on the cloud (Morgado \& Schmidt, 2012).

Now Moodle running in the cloud is ready for learners to access. Mobile learning learners can visit learning resources inside the Moodle stored in the cloud. In this way, education institutions do not need to purchase expensive web servers to host their learning management systems. They do not need to hire an information technology team to maintain and update these systems. For learners, they do not need to buy mobile devices that have huge storage space and strong computation ability. In this case, Moodle is running in the cloud and data are stored in the cloud too. All they need to do is access the learning materials with their mobile devices via the Internet. 


\section{Implementation of Mobile Moodle in the Cloud at Khalifa} University

The biggest benefits for Khalifa University to move Moodle to the cloud are that investments and resources to operate its own servers are saved. As a result, Khalifa Universtiy can focus on supporting learners and teachers/professors as needed. Another benefit to moving Moodle to the Cloud is off-campus users can access it via mobile devices, such as smart mobile phones and iPad.

Khalifa University currently runs Moodle Version 1.9. To implement Moodle on the cloud, Moodle was upgraded to Version 2.0 because newer versions are able to support smart phones correctly. The applications introduced by Moodle 2.0 are the predominant paradigm for mobile development. Some Moodle 2.0 applications are attractive, such as myMobile and mBot. Based on Moodle 2.0+ and JqueryMobile, myMobile is customized and optimized for supporting smart phone devices and tablets. As an Android application for Moodle, mBot remembers credentials, logs and pages users visit and lists assignments. It can also open Microsoft Office documents and even add users' classmates to their Google contacts. Moodle Apps 1.0, which can be customized as well, has several options to meet users' needs and requirements.

In addition, Banner, a student information system, is integrated with Moodle in Khalifa University. Although they both operate on the local/in-house Active Directory Server, their authentication mechanisms are different. In other words, even with the same username and password, users must logon to the two systems differently or ONE BY ONE. They cannot access the two systems with a single login. Unfortunately, moving Moodle to the cloud does not fix this issue. As Hirsch and Ng (2011) assert, integration is still one of the challenges for mobile cloud learning.

Technology integration in Khalifa University is based upon sound pedagogical foundations. Following social constructivism, the integration of Moodle and Banner aims to facilitate a student-centered learning environment. Another objective of the integration is to facilitate communications among students, between students and teachers, as well as between students and resources. 


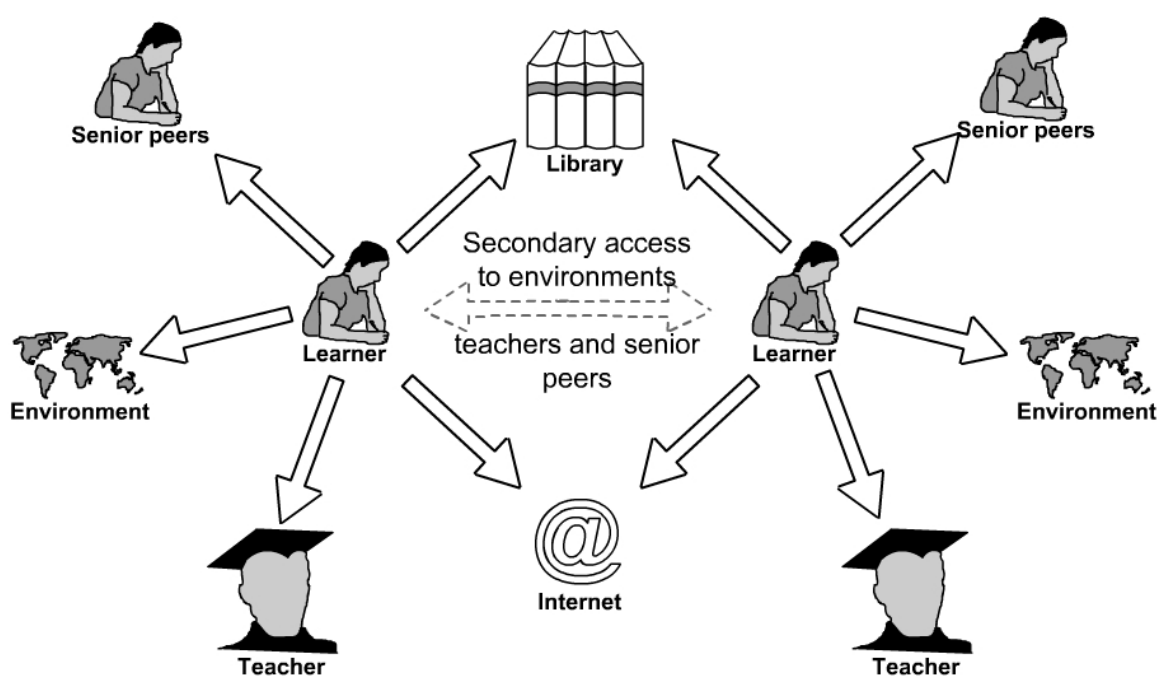

Figure 3. The learner centered collaborative environment.

Moodle in the cloud facilitates collaboration as well. Learning through social interactions is an important part of social constructivism. Learner-centered learning interactions provided by Moodle in the cloud not only improves learner engagement, but also develops personal intellect and understanding of the content. Learners have access to a wider range of resources, due to the collaboration between Khalifa University and nation-wide and international education sectors. For professors and teachers, collaborating with other researchers becomes convenient. Furthermore, the contact between instructors and learners expands off campus.

\section{Discussion}

Although Moodle is widely used in the education sector around the world, some instructors and students are unwilling to accept this technology. Even though Moodle is moved to the cloud, the problem of acceptance still exists. Ambraziene, Miseviciene, and Budnikas (2011) argue that the learning curve for mastering Moodle is high for instructors and students. Therefore, they do not use it very often-only for educational purposes. Students are unwilling to use Moodle because it does not have features to support their active communications and collaborations. Since social communication is an important aspect for learning (Mason, 2008) combining some social networking tools for education with Moodle may be helpful to facilitate learning and teaching.

Both Google and Microsoft offer free cloud email and collaboration services to educational institutions. Microsoft Live@edu, a cloud-based email system that contains communication tools, such as instant messaging along with contact management and calendar software, has a free plug-in for Moodle. Teachers and students can use Live@edu e-mail service, as well as other services, such as cloud storage of 25GB, data 
synchronization, instant messaging, and Microsoft Office applications in the browser (Ambraziene, Miseviciene, \&Budnikas, 2011).

Khalifa University can integrate Moodle with Live@edu email system by using a plug-in from Education Labs. In this way, Moodle can serve as the main portal of learning resources for students, whether they are on-campus or off-campus. Furthermore, the integration of Moodle and Live@edu provides students with a single sign-on to their email accounts, cloud storage space, and Moodle. Because Moodle turns into a part of students' active communications and collaborations, it is much easier to be accepted by users.

Meanwhile, the challenges in mobile cloud learning should not be overlooked.

1. Mobile network condition. Mobile cloud learning depends on learners' wireless connection. The quality of the mobile networks might not be adequate for delivering satisfactory user experience via the collaboration between mobile devices and cloud services (Hung, Shih, Shieh, Lee, \& Huang, 2012).

2. Control of applications. Learning materials are stored on the cloud and computations are performed on the cloud; learners are no longer in full control of applications (Hung, Shih, Shieh, Lee, \&Huang, 2012).

3. Security and privacy. Learners' sensitive information and their privacy can be easily violated when cloud providers utilize user data for claimed purposes (Dinh, Lee, Niyato, \&Wang, 2011; Hung, Shih, Shieh, Lee, \&Huang, 2012).

\section{Conclusion}

Mobile cloud learning positively influences the learning process, as seen from both educators and learners. Although it may be more cumbersome for some to access the program than others, it makes it easier for more people to obtain knowledge through their mobile devices without worrying much about other hardware. In other words, mobile cloud learning brings the classroom to the student unlike other traditional methods. It is of benefit not only to the learners but also to the educators in their classroom management. Meanwhile, learners must run the risks, such as losing control of applications and damage to personal information security and privacy, to take advantage of mobile cloud learning. 


\section{References}

Al-Zoube, M., Abou El-Seoud, S., \&Wyne, M. F. (2010). Cloud computing based elearning system. International J ournal of Distance Education Technologies (IJ DET), 8(2), 58-71.

Ambraziene, D., Miseviciene, R., \& Budnikas, G. (2011). Application of cloud computing at KTU: MS Live@ Edu Case. Informatics in Education-An International J ournal, 10(2), 259.

Bai, Y., Shen, S., Chen, L., \&Zhuo, Y. (2011, July). Cloud learning: A new learning style. In 2011 IEEE International Conference on Multimedia Technology (ICMT), 3460-3463.

Bamiah, M. A., Brohi, S. N., \& Chuprat, S. (2012). Using virtual machine monitors to overcome the challenges of monitoring and managing virtualized cloud infrastructures. In Fourth International Conference on Machine Vision (ICMV 11) (pp. 83491M-83491M). International Society for Optics and Photonics.

Chang, V., Bacigalupo, D., Wills, G., \&De Roure, D. (2010, May). A categorisation of cloud computing business models. In Proceedings of the 2010 10th IEEE/ ACM International Conference on Cluster, Cloud and Grid Computing (pp. 509-512). IEEE Computer Society.

Chen, X., Liu, J ., Han, J ., \&Xu, H. (2010). Primary exploration of mobile learning mode under a cloud computing environment. In E-Health Networking, Digital Ecosystems and Technologies (EDT), 2010 International Conference on (Vol. 2, pp. 484-487). IEEE.

Dinh, H. T., Lee, C., Niyato, D., \&Wang, P. (2011). A survey of mobile cloud computing: Architecture, applications, and approaches. Wireless Communications and Mobile Computing, 1587-1611.

Eze, D. N., \& Onyegegbu, N. (Eds.) (2006). Information communication technology (ICT) in the service of education (pp. 293-297). Enugu: Timex.

Freeman, H. (2000). The virtual university: The Internet and resource-based learning. Routledge.

Harris, P. (2001, J uly). Goin' mobile. Learning Circuits, ASTD Online Magazine.

Hirsch, B., \&Ng, J . W. (2011). Education beyond the cloud: Anytime-anywhere learning in a smart campus environment. In Internet Technology and Secured Transactions (ICITST), 2011 International Conference (pp. 718-723). IEEE.

Hung, S. H., Shih, C. S., Shieh, J . P., Lee, C. P., \&Huang, Y. H. (2012). Executing mobile applications on the cloud: framework and issues. Computers \& Mathematics with Applications, 63(2), 573-587. 
J aatun, M. G., Zhao, G., \& Rong, C. (Eds.). (2010, Dec.). Cloud computing. First International Conference, CloudCom 2009, Beijing, China, 2009, Proceedings (Vol. 5931). Springer.

Kennington, J ., Olinick, E., \& Rajan, D. (Eds.). (2010). Wireless network design: Optimization models and solution procedures. Springer.

Khan, A. N., Mat Kiah, M. L., Khan, S. U., \& Madani, S. A. (2012). Towards secure mobile cloud computing: A survey. Future Generation Computer Systems, 29, 1278- 1299.

Kitanov, S., \& Davcev, D. (2012). Mobile cloud computing environment as a support for mobile learning.In Cloud Computing 2012, The Third International Conference on cloud computing, GRIDs, and Virtualization (pp. 99-105).

Kossen, J . S. (2001). When e-learning becomes m-learning. Palmpower Magazine. Retrieved from http:/ / zatz.com/ computingunplugged/article/ when-e-learningbecomes-m-learning/

Li, J . (2010). Study on the development of mobile learning promoted by cloud computing. In IEEE 2010 2nd International Conference on Information Engineering and Computer Science (ICIECS), 1-4.

Mason, R. (2008). E-learning and social networking handbook: Resources for higher education. Routledge.

Mell, P., \&Grance, T. (2009). The NIST definition of cloud computing . Retrieved from http:// csrc.nist.gov/ publications/nistpubs/800-145/ SP800-145.pdf

Mohamudally, N. (2011). The technological challenges in mobile networks and communications in view of unleashing the full potential of m-learning. Formatex 2011. Retrieved from http:// www.formatex.info/ict/book/ 548555.pdf

Moodle. (2012). Statistics. Retrieved from http:// moodle.org/ stats

Morgado, E. M., \& Schmidt, R. (2012, J une). Increasing Moodle resources through cloud computing. In Information Systems and Technologies (CISTI), 2012 7th Iberian Conference (pp. 1-4). IEEE.

Palmer, R., \& Dodson, L. (2011). Distance learning in the cloud: Using $3 \mathrm{G}$ enabled mobile computing to support rural medical education. J ournal of the Research Center for Educational Technology, 7(1), 106-116.

Rao, N. M., Sasidhar, C., \& Kumar, V. S. (2010). Cloud computing through mobilelearning. Computing, 1(6). 
Rittinghouse, J . W., \& Ransome, J . F. (2009). Cloud security challenges. Cloud Computing: Implementation, Management, and Security, 158-161.

Sharif, A. M. (2010). It's written in the cloud: The hype and promise of cloud computing. J ournal of Enterprise Information Management, 23(2), 131-134.

Sharples, M., Arnedillo-Sánchez, I.A., Milrad, M., \& Vavoula, G. (2009). Mobile learning: Small devices, big issues. In S. L. Montandon, N. Balacheff, S. Ludvigsen, T. de J ong \&A. Lazonder (Eds.), Technology-enhanced learning: Principles and products (pp. 233- 251). Berlin: Springer-Verlag.

Weber, A. S. (2011). Cloud computing in education in the Middle East and North Africa (MENA) Region: Can barriers be overcome? In Conference proceedings of eLearning and Software for Education (No. 01, p. 565).

Woodill, G. (2010). The mobile learning edge: Tools and technologies for developing your teams. McGraw-Hill.

Xhafa, F., Caballé, S., Rustarazo, I., \& Barolli, L. (2010). Implementing a mobile campus Using MLE Moodle. In P2P, Parallel, Grid, Cloud and Internet Computing (3PGCIC), 2010 International Conference on (pp. 207-214). IEEE.

Xu, B., Wang, N., \& Li, C. (2011). A cloud computing infrastructure on heterogeneous computing resources. J ournal of Computers, 6(8), 1789-1796.

\section{Athabasca University $\mathbf{a}$}

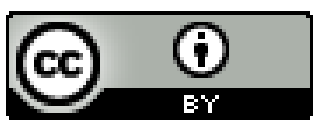




\section{Massive Online Obsessive Compulsion: What are They Saying Out There about the Latest Phenomenon in Higher Education?}

Vera L B Dolan

University of Toronto, Canada

\section{Abstract}

This article is a review of ideas, comments, and inquiries about massive open online courses (MOOCs) gathered from a wide variety of online journal and magazine articles, and web blogs. As a seasoned "traditional" online educator, as well as a student participant in several MOOCs, I also take the opportunity to share my personal insight from my own learning experiences, with the goal of illustrating some of the concerns unearthed in my research. One serious issue regarding MOOCs is that some learners can feel isolated and/or neglected, particularly when they perceive that other course participants and/or the professor are ignoring their contributions. Our era has witnessed "the McDonaldization of Education" (Lane \& Kinser, 2012), in which one size fits all and information is delivered to student "customers" via systematically managed "factories" whose overseers frown upon any supposed waste of valuable resources or human effort. In the mass-appeal environment of a MOOC, it is quite possible that a student will receive no customized feedback from nominal experts in the field. Lack of meaningful interaction is likely a key factor driving high attrition numbers in the online education environment - numbers that are apparently even higher in the case of MOOCs.

The ideas presented herein also formed part of a webinar that I created for Pennsylvania State University in March 2013.

Keywords: MOOCs; online education; open universities; peer grading; attrition; course credit; McDonaldization 


\section{In the Beginning...}

Not long ago I had the opportunity to present a webinar for Pennsylvania State University discussing what we know so far about massive open online courses (MOOCs). Although only a few months have passed since my presentation, it would be more accurate to say "what we knew about MOOCs", because every day we seem to get another update on how this most recent mode of delivering higher education has further evolved.

We seem to be compulsively obsessed with MOOCs. We wake up every morning realizing that someone somewhere, myself included, is writing an article, an essay, a blog, you name it, in an effort to dissect what these courses represent and their impact on global higher education. We have even reached the state where MOOCs are coined with lowercase prefixes: cMOOCs, connecting people and relying on person-to-person exchanges; xMOOCs, predominantly computer graded with low human interaction; and now oMOOCs, where the "o" stands for original (Bell, 2013). It seems that, with so many current variations in how these courses are used by educational institutions, original refers back to what Canadian educators Stephen Downes and George Siemens had in mind when they launched the first MOOC in 2008 - which was also the first of a series of MOOCs I have participated in as a student. Entitled Connectivism and Collective Knowledge (CCK08), it was meant to provide access to the masses and to "people who cannot afford to pay the cost to travel to and attend [...] small in-person events" (Bell, 2013, ๆ 2). Moreover, "original MOOCs (oMOOCs) were free, or at least extremely affordable, fully online, well-crafted, and contained a lot of interesting pedagogy and institutional design. The target demographic was the underserved, both nationally and internationally" ( $(\mathbf{5}$ ). Indeed, my impression was that the CCK08 course had participants from all corners of the planet, with an enormous variety of social, cultural, and professional backgrounds.

\section{Rapid Paradigmatic Changes}

Now that a few years have passed since CCK08, we see a wide range of deviations from the initial intent, based on what the constantly growing MOOC-related literature has brought to light so far. As is the case with any innovation, making sense of MOOCs has become a never-ending quest for many of us - an attempt to nail down how they affect, both positively and negatively, the lives of all stakeholders. This is why so much has been written about the subject and why the controversy surrounding MOOCs only seems to grow.

There is no shortage of supporters for this new paradigm in higher education, despite the fact that students in MOOCs must embrace what seems to be a chaotic learning environment in which the apparent virtues of openness and connectedness also bring a high degree of complexity and the need for greater self-organization (deWaard, Abajian, 
Gallaher, Hogue, Keskin, Koutropoulos, \& Rodriguez, 2011). As Vaidhyanathan (2012) puts it,

The strangest thing about this MOOC obsession is the idea that something that very wealthy private institutions offer for free, at a loss, as a service to humanity, must somehow represent the magic numbers in the higher-education lottery. It's new, it's "innovative," and it's big, the thinking goes. So it must be the answer ( $₫ 5)$.

\section{The Pros and Cons}

Thomas Friedman, a columnist from The New York Times, is enthusiastic about MOOCs and has raised eyebrows - including mine - for painting what some critics perceive as a naïve and one-dimensional picture of their wonders. From his perspective, all MOOCs seem to have an "o" prefix because they offer the potential to revolutionize higher education, finally allowing the global population to gain free access to top-quality education and escape poverty (Friedman, 2013). André Dua (2013), a McKinsey \& Company director, asserts that MOOCs, if delivered properly, "[promise] students faster, more consistent engagement with high-quality content, as well as measurable results" ( $₫ 1$ ). Although both writers find supporters among leaders of prestigious institutions - for instance, H. K. Bottomly, president of Wellesley College (Letter to the editor, The New York Times, 2013) - there are numerous dissenting opinions. DePaul University's Beth Rubin notes that Friedman does not mention some key limitations of MOOCs, and cites low completion rates as just one example. Rubin goes on to say:

There is limited formative feedback to help students develop critical thinking and writing skills; assessment is typically either computer-graded or "crowd sourced." [...] Most students do not get known as individuals, so there is little sense of social presence. [...] Generally only the driven, self-motivated and organized students who already have strong basic skills are likely to succeed (Letter to the editor, The New York Times, ๆ 5).

In her short note, Rubin summarizes the critical issues that have been debated ad nauseam: attrition rates; lack of meaningful interaction between faculty and course participants; and the pitfalls of peer grading. And then there is an even more crucial issue: Should students be given credit for these courses and, if so, under what circumstances? The fact is that, "over the last year, massive open online courses, or MOOCs, have quickly traversed the cultural cycle of hype, saturation, backlash, and 
backlash-to-the-backlash" (Carey, 2012, I 6). The opinions just keep coming, but verdicts seem to be moving further out of reach.

For the longest time I was purely a MOOC detractor, and, although I have finally caught a glimpse of the positive aspects of this type of course, I could not help but respond to Friedman's column with a high dose of cynicism. In fact, in one of my infrequent blog posts, I commented:

The hype surrounding [MOOCs] these days seems to be growing by the minute; apparently, anyone can create a MOOC, anyone can teach a MOOC, anyone can learn from a MOOC. Even better, anyone can learn from a MOOC, even if there are $500,1,000$ or 100,000 people providing their input, alternating themselves in the role of educators. Welcome to the deMOOCracy era! Now everyone can have a shot at teaching, everyone can learn, everyone can collaborate. And for my fellow dinosaurs who remember the 1973 film Lost Horizon, let's all take a MOOC while singing "Living Together, Growing Together" (2012, ๆ 6).

\section{Learning - A Matter of Semantics?}

This notion that MOOCs can elevate humanity to a new reality in which everyone benefits - learning from the best post-secondary educators and gaining a chance at a more fulfilling life - is seductive. However, it originates in a utopian desire and is unlikely ever to happen. For starters, we must define "learning". If by learning we mean having the opportunity to view a recorded lecture by a renowned professor from a topranked university, and to be referred to additional materials related to the topic presented, then yes, one could say that everyone with an Internet connection anywhere in the world can learn. But the fact is that this is the kind of learning that can only happen in Shangri-La, to return to my Lost Horizon reference - and those who remember the film will also recall that once you left the valley, things did not go well.

The problem with the MOOC learning experience is that the mere exposure to information does not lead to the assimilation of knowledge and personal growth. In my own experience as both student and teacher - mentored as a novice, incidentally, by the aforementioned Beth Rubin of DePaul University - I find that learning requires regular back-and-forth exchanges, with validation and constructive criticism of one's ideas. My years of teaching have led me to fully appreciate what Rubin stressed when she first guided me in delivering courses online: If I do not have opportunities to bounce some of my ideas off others in the class and gain the feedback I am hoping to receive, the odds are high that I'll realize that the information is not etched in my brain - it does not 
come as second nature when put to the test in the real world. Indeed, all I have really learned after having taken several MOOCs is that I become extremely frustrated when I seem to be talking to the virtual walls that contain them. I become deflated and I want to leave the environment in a hurry, because it does not inspire positive associations. In other words, lack of meaningful interaction has been detrimental to my desire to continue participating in a MOOC. My case definitely illustrates some of the research findings about MOOCs, in which feelings of social and intellectual disconnection negatively influence learners' motivation to carry on to the end of class.

As noted by Rubin (2013) - and also in The New York Times (2013) - student attrition rates have reached the $90 \%$ mark, even in small-scale online courses. Vaidhyanathan (2012) observes that these high attrition numbers seem to have been swept away by all the fanfare surrounding these courses and the congratulatory enthusiasm around enrolment numbers that reach into the thousands. However, the truth is that many course participants seem to lose momentum once they realize that there are no incentives for course participation (Chambelin \& Parish, 2011). When it is practically impossible for a professor to interact with thousands of students - even $1 \%$ of a MOOC student population could represent as many as 1,000 people (Mittell, 2013) - and when many learners still rely on teacher-student interaction to stay motivated and on track, it is not surprising that huge numbers of them give up, often in the first week of the course. No matter how sophisticated the technology used in a MOOC, for professors such as Timothy Burke of Swarthmore College, the essence of education still lies in the subtle interplay between students and teachers, which cannot be simulated by machines, regardless of refinements in programming (Carr, 2012). Nevertheless, Coursera co-founder Daphne Koller sees the need to clarify one point: No direct correlation can be established between lack of course completion and failure of the MOOC idea. In Koller's view, it all depends on each student's intent when enrolling in a course. Many only want to explore, perhaps exchange ideas with others and move on to something else without taking quizzes or completing assignments (Kolowich, 2013). But even when students intend to complete a course and participate in every activity, the use of peer grading - a practice adopted by Coursera professors who have to rely on course participants to assess each other's work - may become a source of discouragement and a strong reason to drop out. In this regard Lewin (2012) raises an important question: How can one be sure whether any MOOC participant is capable of matching the professor's grading standards?

\section{The Credit Controversy}

An even more troubling matter is the question of credit. Many colleges are likely to start accepting MOOC certificates as transfer credits - particularly when they see this concession as a significant tool for marketing, and consequentially higher enrolment numbers (Carey, 2012). But according to a survey conducted by the journal Chronicle of 
Higher Education, 72\% of faculty members who have taught MOOCs still don't think credits should be granted (Ferenstein, 2013). Nevertheless, the American Council on Education's College Credit Recommendation Service (ACE CREDIT) has already given its stamp of approval to five Coursera courses. ACE President Molly Corbett Broad believes in the endorsed validity of some courses, as long as professors thoroughly evaluate course content, pedagogy employed, and evidence of student engagement, among other elements, and conclude that these are on a par with equivalent courses taught by an accredited university (Young, 2012).

Aside from whether MOOCs are worthy of any credits, there is also the issue surrounding what accreditation might mean to traditional faculty members, particularly those who are not tenured. Parry (2013), in paraphrasing Richard Grusin, an English professor at UW-Milwaukee, suggests,

When colleges start to award credit for MOOCs serving thousands of students, the result could be a reduction in the need for faculty members to teach those courses. [...] Much of that reduction [...] would hit teaching assistants. Rather than teaching their own sections or classes, they may find themselves managing online discussions" ( $($ 8).

\section{The Implications}

Scepticism surrounding the benefits of MOOCs is far from negligible. Indeed, those who oppose the concept do so loudly. Gary W. Matkin, Dean of Continuing and Distance Education at the University of California, Irvine, warns that "everyone should be afraid of MOOCs, although there are some that should be more afraid than others" (Wallis, 2013, I 10). For many detractors, MOOCs epitomize "the McDonaldization of education" - they make it easy to obtain, inexpensive and insubstantial (Schmidt, 2013). And to extend the analogy: Fast food may taste good to many if not most of us, but no one could expect to live a long and healthy life relying solely on its poor nutritional value. Sooner or later, we'd need a radical and substantial change in our eating habits or otherwise we'd perish.

The University of California faculty union laments that professors "irrevocably grant the university the absolute right and permission to use their course content, name, image and likeness" (Rivard, 2013, ๆ 4), which has the potential to weaken faculty intellectual property rights and collective bargaining agreements. Furthermore, MOOCs, according to Gerry Canavan, assistant professor at Marquette University in Milwaukee, WI, boost the trend toward hiring adjuncts and devalue labour in the university environment. Canavan asserts that MOOCs embody a "labour model in search of a pedagogy" (Beware of MOOCs, ASQ Higher Education Brief, 2013, ๆ 7). 


\section{Where Are Faculty in All of This?}

When so much seems to be at stake for faculty, their views are of fundamental importance, although some claim that their voices have not been heard when it comes to the decision to embrace MOOCs (Azevedo, 2012). For Peter Struck, professor of classical studies at the University of Pennsylvania (Chronicle of Higher Education interview, 2012), the biggest concern is whether a faculty member can cultivate the engagement and dedication that students must put into their studies in order to gain value from the educational experience. Otherwise MOOCs can simply become a means to transfer data, which is not transformative and hence not a noteworthy form of education. As a veteran online instructor, I cannot fathom leading a class in which I do not have customized contact with each and every one of my students. And, as a student, I crave tailored feedback that will help me grow and fulfill my need for self-actualization. Therefore, it is in my nature to try to give my students what I believe they are looking for in order to have a positive course experience. So far no one has told me to stop providing customized treatment.

Some faculty, while not totally averse to the MOOC concept, remain cautious. However, the March 2013 Chronicle of Higher Education survey reveals that for half of respondents MOOCs, despite being time and energy consuming, can be as successful and as academically rigorous as the traditional versions of their courses. Additionally, many professors seem to feel that MOOCs should be incorporated "into the traditional system of credit and degrees" ( ( 9). I agree, provided that these courses are used as support tools in the traditional delivery of education. MOOCs can be strong allies in educating people who have a concurrent opportunity to experience meaningful and customized interactions with peers and faculty.

Faculty members who have embraced the MOOC reality, at least at first glance, have a variety of reasons for doing so. However, they seem to have two main sources of motivation: One, altruistic in nature, is the ability to reach a student population that otherwise might never have the opportunity to learn from the very best scholars. On the other hand, a great many faculty members seem to be teaching MOOCs for egocentric reasons: They do not want to be left behind by their peers; they hope to increase their visibility and perhaps gain tenure more quickly; they hope to sell more of their textbooks; they like the idea of reaching a larger audience (Kolowich, 2013); and some enjoy the celebrity status they've gained even among students abroad (Friedman, 2013).

\section{Are MOOCs Really Worth the Cost of Delivery?}

Despite the diversity of opinion, MOOC providers and their university partners seem to believe that they will ultimately see a payoff for the time and financial resources invested in the preparation and delivery of these courses. Given the undeniable high figures of enrolment in MOOCs, their proponents feel impelled to carry on, striving to 
find ways to begin making money. In fact, Coursera seems to have begun making some return on its investment - or rather, the investment of venture capital firms such as Kleiner Perkins Caufield \& Byers and New Enterprise Associates (Levy, 2012). Under Coursera's "Signature Track", for US\$50 students can pay to write proctored exams and receive a verified completion certificate (Rivard, 2013). This idea put US $\$ 220,000$ into the company's coffers in the first quarter of 2013. Coursera also receives a percentage of Amazon.com's sales when its course participants purchase textbooks suggested by a professor. Nevertheless, meaningful revenues have yet to be realized by MOOC providers, who have been working incessantly on ideas that might finally allow them to monetize the MOOC experience.

The opinion that MOOCs help build a university's brand is not unusual among some professors and administrators (Anderson, 2012). For the University of Virginia, for example, offering MOOCs might bring two kinds of return on investment. The first is more noble: the general public's opportunity to gain knowledge from a reputable university. The second form of return is more self-interested (Vaidhyanathan, 2012): the strengthening of the university's name, which should attract more students. Friedman (2013) presents an example of this kind of "branding" at work: A 15-year-old Mongolian student who took a MOOC with the Massachusetts Institute of Technology and the University of California, Berkeley was encouraged to apply to both institutions after receiving a perfect score on his final exam.

\section{Some Final, Fundamental Questions}

The good news is that with the advent of open education, universities and colleges are revisiting their missions and focusing significantly more attention on providing better quality of teaching (Daniel, 2012). As Chamberlin and Parish (2011) have suggested, the sense of connectedness in the online experience encourages learners to expand their knowledge base and elaborate on their interpretations. At the very least, MOOCs can definitely be complementary to what colleges do (Wallis, 2013). But what is even more certain is that there is still a myriad of unanswered questions, at least for the time being. Udacity's founder, Sebastian Thrun, wonders whether MOOC classes have the power to reach current university students and take away business from traditional institutions or if they in fact reach new students and add to the overall education market (Wallis, 2013). Other important questions to consider include:

- What is the value added by university campuses "when demand can be aggregated either by bringing students to campus or, much less expensively, by reaching and teaching students online virtually anywhere in the world" (Guile, 2013, ๆ 8).

- "Emerging technologies may allow us to educate the world more efficiently, [but...] can we educate people more effectively" (Head, 2013, ๆ 1)? 
- And finally, perhaps the most critical question of all: What are MOOCs for (Rivard, 2013)?

I'll end this paper with my own question: Why are we so compulsively obsessed with comparing apples to oranges? If we are so concerned with which medium delivers higher quality of education - MOOCs or traditional classes - then we must first look for ways to enhance all educational environments, regardless of their nature, and let students choose the route that best satisfies their personal needs. Why should the two environments be mutually exclusive? Let both traditional and massive online courses earn that "o" prefix, indicating that the intent that shaped them reflects the original plan - encouraging people to become decent and ethical citizens of the world, striving for a better and less unhappy society. 


\section{References}

Anderson, N. (2012, November 3). Elite education for the masses. The Washington Post. Retrieved from http:// articles.washingtonpost.com/2012-1103/local/35506250 1_coursera-free-online-courses-higher-education

Azevedo, A. (2012, September 26). In colleges' rush to try MOOC's, faculty are not always in the conversation. The Chronicle of Higher Education. Retrieved from http://chronicle.com/article/In-Colleges-Rush-to-Try/ 134692/

Bell, K. (2103, May 6). The hijacking of MOOCs. Inside Higher Ed. Retrieved from http:// www.insidehighered.com/views/2013/ 05/ 06/ essay-suggests-moocsare-losing-their-original-worthy-goals

Beware of MOOCs. (2013). ASQ Higher Education Brief, 6(2). Retrieved from http:// asq.org/ edu/2013/03/innovation/ beware-ofmoocs.pdf?WT.dcsvid=ODk0Mzg1MTAyNAS2\&WT.me id=EM119905

Bottomly, H. K. (2013, J anuary 28). Online courses and pitfalls. [Letter to the editor.] The New York Times. Retrieved from http:// www.nytimes.com/2013/01/29/opinion/online-courses-possibilitiesand-pitfalls.html

Carey, K. (2012, September 3). Into the future with MOOC's. The Chronicle of Higher Education. Retrieved from http:// chronicle.com/article/Into-the-Future-WithMOOCs/ 134080

Carr, N. (2012, September 27). The crisis in higher education. MIT Technology Review. Retrieved from http:// www.technologyreview.com/featuredstory/429376/thecrisis-in-higher-education/

Chamberlin, L., \& Parish, T. (2011, August). MOOCs: Massive open online courses or massive and often obtuse bourses? eLearn Magazine. Retrieved from http:// elearnmag.acm.org/ featured.cfm?aid=2016017

Daniel, J . (2012, September 25). [Web log message]. Making sense of MOOCs: Musings in a maze of myth, paradox and possibility. Retrieved from http://sirjohn.ca/ wordpress/wpcontent/ uploads/ 2012/ 08/ 120925MOOCspaper2.pdf

deWaard, I., Abajian, S., Gallagher, M. S., Hogue, R., Keskin, N., Koutropoulos, A., \& Rodriguez, O. C. (2011). Using mLearning and MOOCs to understand chaos, emergence, and complexity in education. International Review of Research in Open \& Distance Learning, 12(7), 94-115. 
Dua, A. (2013, may). College for all. Retrieved from http://www.mckinsey.com/insights/social sector/college for all

Ferenstein, G. (2013, March 22). Cited as Fereinstein ; please ensure correct spelling $72 \%$ of professors who teach online courses don't think their students deserve credit. Retrieved from http:// techcrunch.com/2013/03/22/72-of-professorswho-teach-online-courses-dont-think-their-students-deserve-credit/

Friedman, T. L. (2013, J anuary 26). Revolution hits the universities. The New York Times. Retrieved from http://www.nytimes.com/2013/01/27/opinion/sunday/friedman-revolutionhits-the-universities.html

Friedman, T. L. (2013, March 5). The professor's big stage. The New York Times. Retrieved from http:// www.nytimes.com/2013/03/06/opinion/friedman-theprofessors-big-stage.html? $\mathrm{r}=0$

Guile, B. (2013, March 12). The real winners of the coming revolution in higher education. Forbes. Retrieved from http:// www.forbes.com/ sites/forbesleadershipforum/2013/03/12/the-realwinners-of-the-coming-revolution-in-higher-education/

Head, K. (2013, J anuary 24). Here a MOOC, there a MOOC: But will it work for freshman composition? The Chronicle of Higher Education. Retrieved from http:// chronicle.com/blogs/ wiredcampus/ here-a-mooc-there-a-mooc-but-willit-work-for-freshman-composition/41883

Kolowich, S. (2013, J anuary 23). Universities try MOOCs in bid to lure successful students to online programs. The Chronicle of Higher Education. Retrieved from http:// chronicle.com/blogs/ wiredcampus/ universities-try-mooc2degreecourses-to-lure-successful-students-to-online-programs/41829

Kolowich, S. (2013, February 4). Georgia Tech and Coursera try to recover from MOOC stumble. The Chronicle of Higher Education. Retrieved from http://chronicle.com/blogs/ wiredcampus/ georgia-tech-and-coursera-try-torecover-from-mooc-stumble/ 42167

Kolowich, S. (2013, February 7). American Council on Education recommends 5 MOOCs for credit. The Chronicle of Higher Education. Retrieved from http:// chronicle.com/article/article-content/ 137155/

Kolowich, S. (2013, February 18). Professor leaves a MOOC in mid-course in dispute over teaching. The Chronicle of Higher Education. Retrieved from http:// chronicle.com/blogs/ wiredcampus/ professor-leaves-a-mooc-in-midcourse-in-dispute-over-teaching/ 42381 
Kolowich, S. (2013, February 21). How EdX plans to earn, and share, revenue from its free online courses. The Chronicle of Higher Education. Retrieved from http:// chronicle.com/article/How-EdX-Plans-to-Earn-and/ 137433/

Kolowich, S. (2013, February 21). Competing MOOC providers expand into new territory -and each other's. The Chronicle of Higher Education. Retrieved from http:// chronicle.com/blogs/ wiredcampus/competing-mooc-providers-expandinto-new-territory-and-each-others/42463

Kolowich, S. (2013, March 4). Online education may make top colleges more elite, speakers say. The Chronicle of Higher Education. Retrieved from http://chronicle.com/article/Online-Education-May-Make-Top/137687/

Kolowich, S. (2013, March 18). The minds behind the MOOCs. The Chronicle of Higher Education. Retrieved from http:// chronicle.com/article/The-ProfessorsBehind-the-MOOC/ 137905/\#id=overview

Kolowich, S. (2013, March 20). SUNY signals major push toward MOOCs and other educational models. The Chronicle of Higher Education. Retrieved from http://chronicle.com/blogs/ wiredcampus/suny-signals-major-push-towardmoocs-and-other-new-educational-models/43079

Lane, J ., \& Kinser, K. (2012, September 28). MOOC's and the McDonaldization of global higher education [blog]. Retrieved from http:// chronicle.com/blogs/ worldwise/ moocs-mass-education-and-themcdonaldization-of-higher-education/30536

Levy, A. (2012, April 18). Education startup Coursera raises \$16 million From Kleiner, NEA. Retrieved from http:// www.businessweek.com/news/2012-04$\underline{\text { 18/ education-startup-coursera-raises-16-million-from-kleiner-nea }}$

Lewin, T. (2012, J uly 17). Universities reshaping education on the Web. The Chronicle of Higher Education. Retrieved from http:/ / www.nytimes.com/ 2012/ 07/ 17/ education/ consortium-of-collegestakes-online-education-to-new-level.html?pagewanted=all

Mittell, J . (2013, March 4). Cited as Mittel ; please ensure correct spellingThe real digital change agent. The Chronicle of Higher Education. Retrieved from http:// chronicle.com/article/The-Real-Digital-Change-Agent/ 137589/

Parry, M. (2013, May 8). Scholars sound the alert from the "dark side" of tech innovation. The Chronicle of Higher Education. Retrieved from https:// chronicle.com/article/ Scholars-Sound-the-Alert-From/139103/ 
Rivard, R. (2013, February 21). Twice as many MOOCs. Inside Higher Ed. Retrieved from http:// www.insidehighered.com/news/2013/02/21/ coursera-and-edxadd-universities-and-hope-expand-global-reach

Rivard, R. (2013, February 27). Rate my MOOCs. Inside Higher Ed. Retrieved from http:// www.insidehighered.com/news/2013/02/27/ users-grade-free-onlinecourses

Rivard, R. (2013, February 28). The MOOC-averse technology U. Inside Higher Ed. Retrieved from http:/ / www.insidehighered.com/news/ 2013/02/28/carnegiemellons-online-efforts-include-spinoffs-and-subsidiaries-not-moocs

Rivard, R. (2013, March 8). Measuring the MOOC dropout rate. Inside Higher Ed. Retrieved from http:// www.insidehighered.com/news/2013/03/08/ researchers-explore-whotaking-moocs-and-why-so-many-drop-out

Rivard, R. (2013, March 19). Who owns a MOOC. Inside Higher Ed. Retrieved from http:// www.insidehighered.com/news/2013/03/ 19/u-california-faculty-unionsays-moocs-undermine-professors-intellectual-property

Rivard, R. (2013, March 22). Coursera commits to admitting only elite universities. Inside Higher Ed. Retrieved from http:// www.insidehighered.com/ news/2013/03/22/ coursera-commitsadmitting-only-elite-universities

Rubin, B. (2013, J anuary 28). Online courses: Possibilities and pitfalls. [Letter to the editor.] The New York Times. Retrieved from http:// www.nytimes.com/2013/01/29/opinion/online-courses-possibilitiesand-pitfalls.html

Schmidt, M. (2013). MOOCs: Massive opportunity or mucky mess? ASQ Higher Education Brief, 6(2). Retrieved from http:// asq.org/ edu/2013/03/innovation/ moocs-massive-opportunity-ormucky-mess.pdf?WT.dcsvid=ODk0Mzg1MTAyNAS2\&WT.mc id=EM119905

The Chronicle of Higher Education. (2013, J une 10). What you need to know about MOOCs. Retrieved from http:// chronicle.com/ article/ What-You-Need-toKnow-About/133475/

Vaidhyanathan, S. (2012, J uly 6). What's the matter with MOOCs? The Chronicle of Higher Education. Retrieved from http:// chronicle.com/blogs/innovations/ whats-the-matter-with-moocs/ 33289 
Vaidhyanathan, S. (2012, J uly 18). Going public the UVa way. The Chronicle of Higher Education. Retrieved from http:// chronicle.com/blogs/innovations/goingpublic-the-uva-way/ 33623

Young, J . R. (2012, J uly 19). Inside the Coursera contract: How an upstart company might profit from free courses. The Chronicle of Higher Education. Retrieved from http:/ / chronicle.com/article/ How-an-Upstart-Company-Might/ 133065/

Young, J . R. (2012, September 25). When professors print their own diplomas, who needs universities? The Chronicle of Higher Education. Retrieved from http://chronicle.com/article/When-Professors-Print-Their/ 1185

Young, J . R. (2012, November 13). American Council on Education may recommend some Coursera offerings for college credit. The Chronicle of Higher Education. Retrieved from http:// chronicle.com/article/American-Council-onEducation/135750/

Young, J . R. (2013, April 3). Stanford U. and edX will jointly build open-source software to deliver MOOCs. The Chronicle of Higher Education. Retrieved from http://chronicle.com/blogs/ wiredcampus/stanford-u-and-edx-will-jointlybuild-open-source-software-to-deliver-moocs/43301

Wallis, D. (2013, March 18). Colleges assess cost of free online-only courses. The New York Times. Retrieved from http:// www.nytimes.com/2013/03/19/ education/ colleges-assess-cost-of-freeonline-only-courses.html?ref=nationalspecial $2 \& \_r=0$

\section{Athabasca University $\mathbf{a}$}

(2) $\stackrel{0}{\mathrm{IV}}$ 


\section{Book Review - The Architecture of Productive Learning Networks}

The Architecture of Productive Learning Networks (2014), ISBN: 978-0-415-81656-4

Authors: Lucila Carvalho and Peter Goodyear

Reviewer: Terry Anderson, Athabasca University, Canada

As I grow older, I come to realize that I shouldn't let principles always stand in the way of good ideas. Thus, though I've made a commitment to no longer contribute to closed scholarly works, I can't help but at least contribute a review of The Architecture of Productive Learning Networks by Lucila Carvalho and Peter Goodyear. A personal disclosure is that I count Goodyear as a friend and I was present when the book was being planned after the Networking Learning Conference in Maastricht in 2012.

Carvallo and Goodyear have been involved for some years in the interesting intersection between architecture and learning, positing that both the physical and networked spaces that we create have very important (but often unrecognized) effects on teaching and learning or as Winston Churchill aptly put it, "We shape our buildings; thereafter they shape us". I was initially attracted to their earlier work on patterns and pattern languages modelled in part on the architectural pattern work of Christopher Alexander, and have thereafter been trying to discern and better utilize both the created and emergent social patterns of effective formal and informal learning.

In this volume the authors set forth an initial set of architectural entities that describe and define a network of individuals associated together in order to collectively achieve some goal. As the title implies, these associations are focused on learning but in a very broad sense that includes formal education, informal and professional learning, and social action. The structures that we devise and sustain to support this learning are referred to as networks - aggregations based upon connections of people and resources, that in this context are focused on learning - and of course doing so productively. Networks imply a more defined aggregation than the nebulous "community" and a less structured form than a group where "everyone knows everyone". A network is emergent, bursty and defined more by connections and activities than by rules, memberships, or authority. 
The book is structured around Goodyear and Carvalho's theoretical and architectural framing of an analysis structure by which subsequent chapters describe real life (and judged effective by the editors) learning networks. The architecture they proscribe is focused on "what it is that people are actually doing and the tools, and resources and interactions that become bound up in that activity". The analysis begins by identifying the structures and epistemic elements of each network. I had to look this one up as they define epistemic elements "as those most closely associated with learning tasks, and those that seem to reflect epistemic structuring" (p. 61), which is far too tautological a definition for me. In any case I understand epistemic as the structure and the activities of the network specifically designed to create and support productive learning. They then ask the authors of the case studies to describe the place and the set structure of the network - how the connections and resources are linked, stored, organized, and made available for use and the processes for creation and support of new connections, unlike the way that Jon Dron and I use the term set, as a non group and non network aggregation of learners. The authors attempt to extract the important lessons, patterns, and structures that they find most compelling from the case.

The bulk of the 294 page text is made up of these 14 case studies. The cases range from formal learning activities (both higher and elementary education), professional development (teachers leading curriculum change), social action (One Laptop per Child), school enrichment (iSpot sharing nature) to my favorite - a network focused on artistic creation (the Virtual Choir). The final case study chapter is not really a case study following the model of the others but is an interesting contribution as it describes an open source tool set that can be used for network analysis by researchers and more importantly by network participants to visualize and gain a meta overview of their own emergent networks.

In architectural parallel with the case studies, Carvalho and Goodyear end the book with a synthesis chapter of their own. They begin by reflecting on the relationships amongst the elements in their analytic design of effective networks. Pragmatically, they first instruct us to look to the users' perceptions of value and efficacy and ease of use as the most important measurements of effectiveness. The editors then dive into principles of knowledge construction using legitimation code theory which (fortunately) soon leads to discussion of six practical design principles - which I found to be (as likely designed) the more generalizable contribution of the text.

Despite the cost (US \$44.95 in paper, \$155.00 in hardback from Routledge), I found much of value in this text. I hope that at least parts of the work become available openly, as there is much for us to learn as educators, social activists, and human connectors from this timely tome! 
Athabasca University $\mathbf{A}$

(c) 